Rainer Volk

Vergleich der

Vergünstigungseffekte der verschiedenen

investitionsfördernden

Maßnahmen 
Rainer Volk

\section{Vergleich der Vergünstigungseffekte der verschiedenen investitionsfördernden Maßnahmen}

In den letzten Jahrzehnten wurden zahlreiche Instrumente zur Förderung von Investitionen entwickelt. Mit diesen Förderinstrumenten sind für die Investoren unterschiedlich hohe Vorteile (Vergünstigungseffekte) verbunden. Die Höhe der Begünstigung hängt von der individuellen Situation des Investors ab. Es wird gezeigt, wie sich verschiedene Besteuerungssituationen und Nutzungszeiträume der Investitionsobjekte auswirken. Dabei werden die finanziellen Vorteile sowohl in der Investitionsperiode als auch über den gesamten Nutzungszeitraum betrachtet. Außerdem wird ein Vergleich dieser Vergünstigungseffekte vorgenommen, wobei dem Vergleich eine gleiche fiskalische Belastung der staatlichen Haushalte durch die einzelnen Fördermaßnahmen zugrunde gelegt wird.

Rainer Volk studierte von 1984 bis 1989 Volkswirtschaftslehre an der AlbertLudwigs-Universität Freiburg. Von 1990 bis 1993 war er Doktorand am Institut für Finanzwissenschaft in Freiburg. Er promovierte 1993 bei Prof. Dr. Oberhauser. 
Vergleich der Vergünstigungseffekte der verschiedenen investitionsfördernden $\mathrm{Maßnahmen}$ 


\section{FINANZWISSENSCHAFTLICHE SCHRIFTEN}

Herausgegeben von den Professoren

Albers, Krause-Junk, Littmann, Oberhauser, Pohmer, Schmidt

Band 62

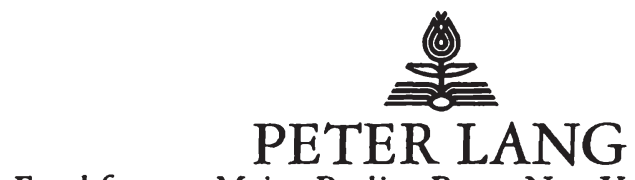

Frankfurt am Main · Berlin - Bern · New York · Paris - Wien 


\section{Rainer Volk}

\section{Vergleich der Vergünstigungseffekte der verschiedenen investitionsfördernden Maßnahmen}

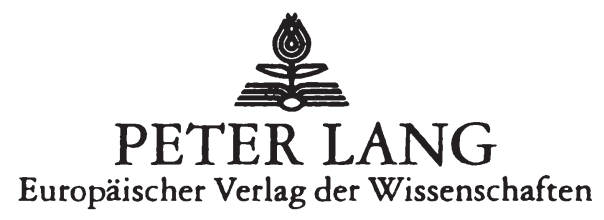


Die Deutsche Bibliothek - CIP-Einheitsaufnahme

Volk, Rainer:

Vergleich der Vergünstigungseffekte der verschiedenen investitionsfördernden Maßnahmen / Rainer Volk. - Frankfurt am Main ; Berlin ; Bern ; New York ; Paris ; Wien : Lang, 1994

(Finanzwissenschaftliche Schriften ; Bd. 62)

Zugl.: Freiburg (Breisgau), Univ., Diss., 1993

ISBN 3-631-46862-8

NE: GT

Open Access: The online version of this publication is published on www.peterlang.com and www.econstor.eu under the international Creative Commons License CC-BY 4.0. Learn more on how you can use and share this work: http://creativecommons.org/licenses/ by/4.0.

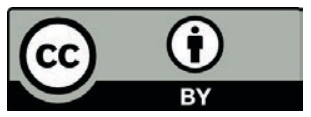

This book is available Open Access thanks to the kind support of ZBW - Leibniz-Informationszentrum Wirtschaft.

\author{
D 25 \\ ISSN 0170-8252 \\ ISBN 3-631-46862-8 \\ ISBN 978-3-631-75243-2 (eBook) \\ (C) Peter Lang GmbH \\ Europäischer Verlag der Wissenschaften \\ Frankfurt am Main 1994 \\ Alle Rechte vorbehalten.
}

Das Werk einschließlich aller seiner Teile ist urheberrechtlich geschützt. Jede Verwertung außerhalb der engen Grenzen des Urheberrechtsgesetzes ist ohne Zustimmung des Verlages unzulässig und strafbar. Das gilt insbesondere für

Vervielfältigungen, Übersetzungen, Mikroverfilmungen und die Einspeicherung und Verarbeitung in elektronischen Systemen.

Printed in Germany 123467 


\section{INHALTSÜBERSICHT}

Seite

A. PROBLEMSTELLUNG UND AUFBAU DER UNTERSU-

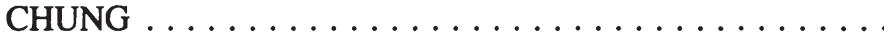

B. BEGRIFFSABGRENZUNGEN $\ldots \ldots \ldots \ldots \ldots \ldots$

I. Zur Abgrenzung des Begriffs Vergünstigungseffekt ...

1. Vergünstigungseffekte investitionsfördernder Maßnahmen

2. Mikroökonomische Förderungsüberwälzung . . . .

3. Makroökonomische Einkommensverteilungswirkungen ...............

4. Zusammenfassung .............

II. Zur Abgrenzung staatlicher Investitionsfördermaßnahmen . . . . . . . . . . . . . . . .

1. Inhalt des Begriffs investitionsfördemde Maßnahmen . . . . .................

2. Einsatzbereiche investitionsfördernder Maßnahmen

C. ZUR FRAGE DER QUANTITATIVEN ERFASSUNG VON VERGÜNSTIGUNGSWIRKUNGEN . . . . . . . . . . . .

I. Zum Problem der Quantifizierung von Vergünstigungseffekten investitionsfördernder Maßnahmen ........

II. Prämissen einer quantitativen Erfassung von Vergünstigungswirkungen $\ldots \ldots \ldots \ldots \ldots \ldots \ldots$ 
1. Die wesentlichen Tatbestände der Unternehmens-

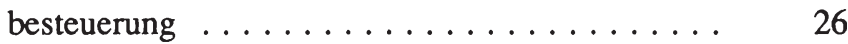

2. Der Kalkulationszinsfuß im Barwertmodell .... 32

III. Zusammenfassung $\ldots \ldots \ldots \ldots \ldots \ldots \ldots \ldots$

D. ANALYSE DER VERGÜNSTIGUNGSWIRKUNGEN EINZELNER INVESTITIONSFÖRDERNDER MASSNAHMEN

I. Zur Ausgestaltung der Parameter für die Modellrechnun-

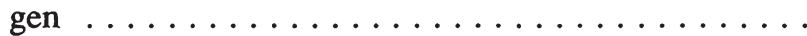

1. Modellannahmen $\ldots \ldots \ldots \ldots \ldots \ldots$

2. Der Umfang der Subventionsbeträge der Investitionsfördermaßnahmen ..............

a. Zum Problem des Vergleichsmaßstabs ... 40

b. Subventionsbeträge ausgewählter Fördermaßnahmen ................

II. Abschreibungsvergünstigungen $\ldots \ldots \ldots \ldots \ldots \ldots$

1. Beschleunigte Abschreibungen ......... 48

a. Erscheinungsformen beschleunigter $\mathrm{Ab}$ schreibungen $\ldots \ldots \ldots \ldots \ldots \ldots$

b. Vergünstigungswirkungen beschleunigter Abschreibungen .............

2. Abschreibung über die Anschaffungs- oder Herstellungskosten hinaus $\ldots \ldots \ldots \ldots \ldots \ldots$

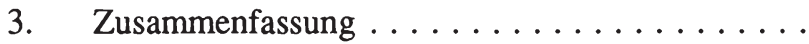

III. Übertragung stiller Reserven . . . . . . . . . . . . . 67 
1. Die Entstehung stiller Rücklagen, deren Aufdekkung und Übertragung . . . . . . . . . . . . .

2. Vergünstigungseffekte der Übertragung stiller Reserven ...................

3. Zusammenfassung .............. 74

IV. Investitionsfreibeträge $\ldots \ldots \ldots \ldots \ldots \ldots \ldots$

1. Grundzüge und Ausgestaltungselemente von Investitionsfreibeträgen $\ldots \ldots \ldots \ldots \ldots$

2. Vergünstigungseffekte der Investitionsfreibeträge

3. Zusammenfassung $\ldots \ldots \ldots \ldots \ldots \ldots$

V. Investitionsrücklagen $\ldots \ldots \ldots \ldots \ldots \ldots$

1. Charakterisierung der Investitionsrücklagen ....

2. Ungebundene Investitionsrücklage $\ldots \ldots \ldots$

a. Vergünstigungseffekte bei der Bildung einer ungebundenen steuerfreien Rücklage .....

b. Vergünstigungswirkungen bei der Auflösung der ungebundenen steuerfreien Rücklage . .

aa. Steuerfreie Rücklage ..........

bb. Auflösung einer steuerfreien Rücklage bei gleichzeitiger Gewährung eines Investitionsfreibetrages $\ldots \ldots \ldots \ldots$

cc. Auflösung einer steuerfreien Rücklage bei gleichzeitiger Gewährung einer Sonderabschreibung $\ldots \ldots \ldots \ldots$

3. Die antizyklisch ausgerichtete Investitionsrücklage und deren Vergünstigungseffekte $\ldots \ldots \ldots \ldots$. 
4. Zusammenfassung $\ldots \ldots \ldots \ldots \ldots \ldots$

VI. Vergünstigungswirkungen steuerlicher Investitionsfördermaßnahmen unter Berücksichtigung eines intertemporalen Verlustausgleichs $\ldots \ldots \ldots \ldots \ldots \ldots$

1. Begriff und Begründung eines intertemporalen Verlustausgleichs $\ldots \ldots \ldots \ldots \ldots \ldots \ldots$

2. Der Einfluß des interperiodischen Verlustausgleichs auf die Vergünstigungswirkungen steuerlicher Investitionsfördermaßnahmen . . . . . .

a. Vergünstigungseffekte investitionsfördernder Maßnahmen unter Zurhilfenahme eines Verlustrücktrags $\ldots \ldots \ldots \ldots \ldots \ldots$

b. Vergünstigungswirkungen investitionsfördernder Maßnahmen unter Berücksichtigung eines Verlustvortrags .............

c. Der Einfluß des Verlustausgleichs auf die Nachversteuerungswirkungen von Fördermaßnahmen ................

d. Berechnungen zum Einfluß eines intertemporalen Verlustausgleichs auf die Nettoeinkommenswirkungen von Investitionsfördermaßnahmen ..................

3. Zusammenfassung . . . . . . . . . . . . . . . 109

VII. Investitionsprämien $\ldots \ldots \ldots \ldots \ldots \ldots \ldots \ldots \ldots$

1. Konzeption der Investitionsprämien . . . . . . . 111

2. Vergünstigungswirkungen der Investitionsprämien 114

3. Zusammenfassung .............. 120

VIII. Investitionszuschüsse . . . . . . . . . . . . . 122 
1. Varianten der Investitionszuschüsse . . . . . . .

2. Vergünstigungseffekte von Investitionszuschüssen

3. Zusammenfassung . . . . . . . . . 128

IX. Zinszuschüsse . . . . . . . . . . . . . . 129

1. Abgrenzung von Finanzierungshilfen . . . . . . 129

2. Erscheinungsformen und Ausgestaltungselemente der Zinszuschüsse . . . . . . . . . . . .

3. Vergünstigungswirkungen der Zinszuschüsse ...

4. Zusammenfassung . . . . . . . . . . 138

X. Investitionszulagen $\ldots \ldots \ldots \ldots \ldots \ldots \ldots$

1. Einsatzbereich, Ausgestaltung und Vergünstigungswirkungen der Investitionszulagen . . . . . .

2. Zusammenfassung $\ldots \ldots \ldots \ldots \ldots \ldots$

XI. Zusammenfassender Überblick . . . . . . . . . . . . .

E. VERGLEICH DER VERGÜNSTIGUNGSEFFEKTE INVESTITIONSFÖRDERNDER MASSNAHMEN . . . . . . .

I. Systematischer Vergleich der Vergünstigungswirkungen über den gesamten Nutzungszeitraum eines geförderten Investitionsobjektes . . . . . . . . . . . . . . 144

1. Gegenüberstellung der Nettobarwerte investitionsfördernder Maßnahmen . . . . . . . . . . . .

2. Vergleichende Betrachtung der Vergünstigungswirkungen von Investitionsfördermaßnahmen für Unternehmen mit verschieden hohen Grenzsteuersätzen 
3. Vergleich der Vergünstigungseffekte von Investitionsfördermaßnahmen für kurz- und langlebige Wirtschaftsgüter ...............

4. Vergleichende Analyse der Vergünstigungswirkungen bei Grenzsteuersatzänderungen im Zeitablauf

II. Vergleich der Liquiditätsvorteile im Jahr der Investitionsvornahme ................. 160

F. SCHLUSSBETRACHTUNG $\ldots \ldots \ldots \ldots \ldots \ldots \ldots$

ANHANG

Abbildungsverzeichnis . . . . . . . . . . . . . 171

Tabellenverzeichnis .................. 172

Symbolverzeichnis . . . . . . . . . . . . . . . 176

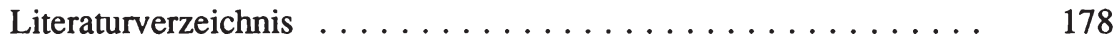




\section{A. PROBLEMSTELLUNG UND AUFBAU DER UNTERSUCHUNG}

In allen Industrienationen werden seit Jahrzehnten erhebliche Beträge zur Förderung der privaten Investitionstätigkeit aufgewandt. Unabhängig davon, welche wirtschaftspolitische Absicht der Gesetzgeber mit einer Förderung verfolgt, jede Förderung von Investitionen, mit der eine Ausgabe oder ein Einnahmeverzicht des Staates verbunden ist, wirkt unmittelbar auf das Einkommen des Geförderten. Diese Arbeit will zeigen, zu welchen unmittelbaren Einkommenswirkungen die Förderungsmaßnahmen führen, die hauptsächlich in der Praxis angewandt und wissenschaftlich diskutiert werden. Nicht jeder Investor wird durch eine Investitionsfördermaßnahme gleich begünstigt. Diese Verteilungswirkungen spielen sowohl in der praktischen Wirtschaftspolitik als auch in der wirtschaftswissenschaftlichen Forschung - verglichen mit der Effizienzfrage der Investitionsförderung - kaum eine Rolle; sie sind wenig beachtete Nebenwirkungen. ${ }^{1}$

Die Arbeit beschäftigt sich nur mit den unmittelbaren Einkommenswirkungen. Die über die Ebene des geförderten Investors hinausgehenden Verteilungswirkungen werden nicht untersucht. Eine Abgrenzung verschiedener Verteilungswirkungen erfolgt im Kapitel B. Außerdem wird in diesem Kapitel konkretisiert, welche Maßnahmen als investitionsfördernde Maßnahmen betrachtet werden.

Die unmittelbaren Einkommenseffekte erstrecken sich bei zahlreichen Fördermaßnahmen über einen mehr oder weniger langen Zeitraum. Zur Ermittlung dieser Einkommenseffekte kommen vor allem die Bar- und Zeitwertmethode in Betracht. Im Kapitel C wird auf die Möglichkeiten und Grenzen beider Verfahren näher eingegangen.

Investitionsfördermaßnahmen führen nicht nur zu Vergünstigungseffekten der Geförderten, sondern belasten zugleich die öffentlichen Haushalte. Die Vergün-

${ }^{1} \mathrm{Vgl}$. Bohling, W., Wirtschaftspolitische und wirtschaftsverfassungsrechtliche Probleme staatlicher und kommunaler Subventionen. Zum Verhältnis von Staat und Wirtschaft, Frankfurt am Main, Bern, New York, Paris 1989, S. 5. 
stigungseffekte einer investitionsfördernden Maßnahme können deshalb nur vor dem Hintergrund ihrer fiskalischen Belastung beurteilt werden. Für die Quantifizierung der Vergünstigungseffekte werden im Kapitel D und zu deren Vergleich im Kapitel E die Subventionsbeträge der einzelnen Fördermaßnahmen so dosiert, $\mathrm{da} ß$ sie in einer bestimmten Basissituation für den Staat gleich hohe fiskalische Belastungen zur Folge haben. Bei der Quantifizierung der unmittelbaren Einkommenswirkungen werden unterschiedliche Datenkonstellationen, beispielsweise eine unterschiedliche Nutzungsdauer oder Besteuerungssituation, unterstellt. Die Fördermaßnahmen unterscheiden sich dann in ihren Einkommenswirkungen, so daß in diesen Unterschieden die Sensitivität der einzelnen Förderinstrumente bei Datenänderungen zum Ausdruck kommt. 


\section{B. BEGRIFFSABGRENZUNGEN}

Im folgenden ist zunächst herauszuarbeiten, welche Sachverhalte unter den Ausdrücken Vergünstigungseffekt und investitionsfördernde Maßnahme verstanden werden.

\section{Zur Abgrenzung des Begriffs Vergünstigungseffekt \\ 1. Vergünstigungseffekte investitionsfördernder Maßnahmen}

In der Einführung wurden die Vergünstigungseffekte investitionsfördernder Maßnahmen als unmittelbare Einkommenswirkungen umschrieben. Diese Umschreibung soll nun näher konkretisiert werden. Investitionsförderinstrumente verändern die Einnahmen und Ausgaben der geförderten Unternehmen. Sofern diese Einnahmen und Ausgaben die Höhe des zu versteuernden Periodenüberschusses berühren ${ }^{1}$, führen sie bei den Geförderten zu unterschiedlich hohen Nettoeinkommenswirkungen. Nicht alle Fördermaßnahmen beeinflussen das zu versteuernde Einkommen und letztlich das Nettoeinkommen. ${ }^{2}$ Die nicht einkommensteuerpflichtigen Einnahmen aus einer Förderung erhöhen unmittelbar das verfügbare Einkommen des Investors. Das verfügbare Einkommen setzt sich aus dem Nettoeinkommen und den nicht einkommensteuerpflichtigen Einnahmen zusammen und ist somit die Maßgröße für die Verteilungswirkungen. Die Betrachtung beschränkt sich auf die erste Wirkungsrunde, was auch als Primärinzidenz oder direkte Inzidenz bezeichnet wird. ${ }^{3}$

Die Vergünstigungseffekte umfassen nur einen Teilbereich der gesamten Einkommensverteilungseffekte, die von der Gewährung investitionsfördernder

${ }^{1}$ Beispielsweise bewirkt eine Sonderabschreibung eine Kürzung der Steuerbemessungsgrundlage und somit eine Erhöhung des Nettoeinkommens in der Förderperiode.

2 Beispielsweise ist eine Investitionszulage steuerfrei.

$3 \mathrm{Vgl}$. Kops, M., Der Inzidenzbegriff in der Finanzwissenschaft, in: Wirtschaftswissenschaftliches Studium 1987, S. 61. 
Maßnahmen ausgehen können. Bevor mit einer konkreten Analyse der Vergünstigungseffekte begonnen wird, soll auf weitere Einkommensverteilungswirkungen eingegangen werden.

\section{Mikroökonomische Förderungsüberwälzung}

Investitionsfördermaßnahmen führen für den Investor zu einem finanziellen Vorteil. Dieser Vorteil muß nicht im geförderten Unternehmen bleiben; er kann unter Umständen auf der mikroökonomischen Ebene überwälzt werden. Es bestehen also über den oben dargelegten direkten Verteilungszusammenhang hinaus weitere Verteilungsrunden. Hierbei sind die mikroökonomischen Marktprozesse, die Macht- und Konkurrenzsituationen von Bedeutung. ${ }^{1}$ In den Wirtschaftswissenschaften werden diese Überwälzungen mit Hilfe der mikroökonomischen Verteilungstheorie, insbesondere der Grenzproduktivitätstheorie erforscht. Es werden für einzelne Marktkonstellationen die Preis- und Mengenwirkungen einer Investitionsfördermaßnahme ermittelt. ${ }^{2}$ Insofern konzentriert sich die Betrachtung auf eine Verteilungsanalyse für isolierte Einzelmärkte. Die Abbildung B.1 zeigt die Vielfalt von Überwälzungsmöglichkeiten.

${ }^{1} \mathrm{Vgl}$. Andel, $N$., Subventionen als Instrument des finanzwirtschaftlichen Interventionismus, Tübingen 1970, S 25f.

2 Vgl. Berthold, U., Zur Theorie der Subventionen. Ein Beitrag zur mikroökonomischen Analyse der Subventionswirkungen und ihrer wirtschaftspolitischen Beurteilung, Bern, Stuttgart 1967, S. 49ff; Folkers, C., Wer wird durch Steuervergünstigungen eigentlich begünstigt? Zu einem Problem der materiellen Inzidenz, in: Finanzarchiv 1988, S. $217 \mathrm{ff}$. 
Abbildung B.1: Die möglichen Begünstigten einer Weitergabe der Investitionsförderung

Beschaf fungsseite

Beginet Igte :

Arbeltnehmer

Lleferanten

Kreditgeber

Elgner des

Elgenkap1tals

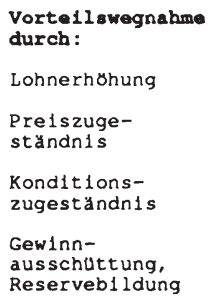

Absatzse1te

Beginet 1gte:

Vortellswegnahme durch:

Preis-

senkung

Ausweitung der

Kaufer

empfangendes

Unternehmen

Qualitatserhohung

Quelle: Zimmermann, H.IHenke, K.-D., Finanzwissenschaft. Eine Einführung in die Lehre von der öffentlichen Finanzwissenschaft, 5. Auflage, München 1987, S. 237.

Die Überwälzungen von Einkommensvorteilen aus investitionsfördernden Maßnahmen sind sehr schwer zu erfassen. Eine wichtige Frage ist dabei, über wieviele Stufen - also Wirkungsrunden - sollen und können die Verteilungswirkungen verfolgt werden. ${ }^{1}$ Es dürfte jedoch kaum möglich sein, den "final resting place" $^{2}$ der Vergünstigungseffekte einer Investitionsfördermaßnahme zu ermitteln. Noch größere Schwierigkeiten ergeben sich bei der Quantifizierung der überwälzten Vorteile. ${ }^{3}$

${ }^{1}$ Vgl. Zimmermann, H., Subventionen und Verteilung. Zur empirischen Erfaßbarkeit von Subventionswirkungen auf die personale Einkommensverteilung, in: Dreißig, W. (Hrsg.), Öffentliche Finanzwirtschaft und Verteilung IV, Berlin 1976, S. 11.

2 Schmölders, G./Hansmeyer, K.-H., Allgemeine Steuerlehre, 5. Auflage, Berlin 1980, S. 145.

${ }^{3}$ Das Meßbarkeitsproblem haftet nicht nur der mikroökonomischen Überwälzung von Staatsausgaben an, sondern auch der von Steuern. Vgl. Schneider, D., Steuerbelastung und Steuerüberwälzung der Unternehmung in der Inflation, in: Mertens, P. (Hrsg.), Die Unternehmung in ihrer gesellschaftlichen Umwelt, Wiesbaden 1975, S. 325. 
Bevor die Überwälzung untersucht werden kann, sind die Wirkungen einer Fördermaßnahme auf das verfügbare Einkommen des Investors - d.h. die Vergünstigungseffekte - zu ermitteln.

\section{Makroökonomische Einkommensverteilungswirkungen}

Investitionsfördernde Maßnahmen beeinflussen nicht nur die mikroökonomische Einkommensverteilung, sondern verändern darüber hinaus auch die Verteilung auf der makroökonomischen Ebene. Durch die Aggregation der Ergebnisse mikroökonomischer Verteilungsansätze ist es nicht möglich, gesamtwirtschaftliche Distributionsfragen zu beantworten. Hierzu bedarf es eines anderen Ansatzes.

Im Rahmen der makroökonomischen Einkommensverteilungstheorie ist die Kreislauftheorie der Verteilung ein wichtiger Erklärungsansatz. Sie bedient sich nicht nur anderer Methoden, sondern beschäftigt sich auch mit anderen distributiven Problemstellungen.

Einen wesentlichen Grundstein zur Entwicklung der Kreislauftheorie der Verteilung schuf J. M. Keynes. Keynes gewann aus Umformungen von Kreislaufidentitäten die sogenannte 2. Keynessche Gleichung, die aufgrund des tautologischen Charakters der Identitäten eine uneingeschränkte Gültigkeit erreicht ${ }^{1}$. Interpretiert man die 2. Keynessche Gleichung unter der ceteris-paribus-Bedingung, so ist die wesentliche Aussage, daß die Ausgaben der Unternehmer wieder an diese Gruppe zurückfließen, vermindert um die Ersparnis der Arbeitnehmer. Die Ausgaben des Staates erhöhen das Unternehmereinkommen zusätzlich. ${ }^{2}$ Die Nachfrage nach Gütern wird also zum Bestimmungsfaktor des aggregierten Unternehmereinkommens, worauf sich die Zuordnung der Keynesschen Vertei-

1 Vgl. Hauser, H.-J., Verteilungswirkungen der Staatsverschuldung. Eine kreislauftheoretische Inzidenzbetrachtung, Frankfurt am Main 1979, S. 26.

2 Dies gilt nur unter der Voraussetzung, daß die Ausgaben des Staates kreditfinanziert sind und kein crowding-out zustande kommt. 
lungsüberlegungen zu den nachfragetheoretischen Verteilungsansätzen begründet. ${ }^{1}$ In diese Kreislaufzusammenhänge der 2. Keynesschen Gleichung arbeitete N. Kaldor Verhaltensannahmen ein und entwickelte damit eine Kreislauftheorie der Verteilung, die "als die postkeynesianische Verteilungstheorie schlechthin verstanden wird" 2 . Welche Bedeutung kommt der Kreislauftheorie der Verteilung für die Distributionswirkungen von Investitionsfördermaßnahmen zu? Mit Hilfe der Kreislauftheorie der Verteilung lassen sich die Verteilungswirkungen der Aufbringung von Finanzmitteln für die Investitionsfördermaßnahmen als auch deren Verausgabung ableiten. Hierbei kann die Kreislauftheorie der Verteilung nur über die Verteilungseffekte zwischen den volkswirtschaftlichen Aggregaten Auskunft geben, woraus nicht auf die Einkommenswirkungen bei den einzelnen Wirtschaftssubjekten geschlossen werden kann. Abweichend von der in dieser Arbeit unterstellten Verteilungsbetrachtung sind die Verteilungssubjekte Unternehmer und Arbeitnehmer. Die entscheidende Fragestellung ist, wie verändert sich die Gewinn- und Lohnquote.

Mit der Kreislauftheorie der Verteilung können Erkenntnisse zur volkswirtschaftlichen Aggregatverteilung gewonnen werden. Jedoch ist es mit Hilfe der Kreislauftheorie der Verteilung nicht möglich, Aussagen über die Einkommenswirkungen bei einzelnen Wirtschaftssubjekten abzuleiten.

\section{Zusammenfassung}

Die Verteilungstheorie schlechthin gibt es nicht, weil grundlegende Abweichungen in der Fragestellung und Methode eine Synthese von mikro- und makroökonomischer Verteilungsanalyse verhindern. ${ }^{3}$ Keine Verteilungstheorie

\footnotetext{
${ }^{1}$ Vgl. Külp, B., Verteilungstheorie, 2. Auflage, Stuttgart, New York 1981, S. $7 \mathrm{ff}$. 160.

2 Blümle, G., Theorie der Einkommensverteilung, Berlin, Heidelberg, New York 1975, S.

${ }^{3}$ Vgl. Littmann, K., Problemstellung und Methoden der heutigen Finanzwissenschaft, in: Neumark, F. (Hrsg.), Handbuch der Finanzwissenschaft, Bd. 1, 3. Auflage, Tübingen 1977, S. 110.
} 
vermag, alle relevanten Determinanten vollständig zu berücksichtigen. Die Eignung des jeweiligen Ansatzes ist folglich vom Untersuchungsziel abhängig. In dieser Arbeit stehen die Wirkungen investitionsfördernder Maßnahmen auf das verfügbare Einkommen des Geförderten im Mittelpunkt.

\section{Zur Abgrenzung staatlicher Investitionsfördermaßnahmen}

Dem Ausdruck investitionsfördernde Maßnahmen, wie auch einer Reihe ähnlicher Bezeichnungen - z.B. Subventionen, Finanzhilfen, Investitionsanreize, Wirtschaftsförderung -, die zum Teil als Synonyme, zum Teil als unter- oder übergeordnete Begriffe für investitionsfördernde Maßnahmen dienen, ordnet man in der Literatur verschiedene Inhalte zu. Die Liste der Definitionen ist lang, ${ }^{1}$ sie soll nicht verlängert werden, zumal man $\mathrm{Andel}^{2}$ sicherlich beipflichten kann, daß der Grenzertrag der zahlreichen Definitionsversuche gegen Null geht, nicht selten sogar negativ ist. Dennoch ist es notwendig, den Begriff Investitionsfördermaßnahmen soweit zu operationalisieren, daß er als Grundlage zur Bearbeitung der vorgenommen Aufgabe dienen kann.

${ }^{1}$ Die Verschiedenheit der Inhalte, die alleine dem Begriff Subventionen in der wirtschaftswissenschaftlichen Literatur, in der Subventionsberichterstattung, in den Veröffentlichungen der Forschungsinstitute und jenen des Statistischen Bundesamtes zugemessen werden, machen das Definitionsproblem deutlich, vgl. Albrecht, D./Thormählen, T., Subventionen. Politik und Problematik, Frankfurt a. M., Bern, New York 1985, S. 18ff; von Bargen, R.-D., Subventionen und Subventionspolitik - Eine theoretische und empirische Analyse, Diss. Bremen 1987, S. 14-30; Böckenkamp, E., Besteuerung der Subventionen. Wirtschaftliche Wirkungen von öffentlichen Finanzhilfen ausgehenden Einflüsse auf die steuerlichen Bemessungsgrundlagen, Diss. Köln 1966, S. 10-15; Bös, D., Gedanken zum Subventionsbegriff in den Wirtschaftswissenschaften, in: Wenger, K.: Förderungsverwaltung, Wien, New York 1973, S. 43ff; Bundesministerium für Finanzen, Bericht der Bundesregierung über die Entwicklung der Finanzhilfen des Bundes und der Steuervergünstigungen für die Jahre 1987 bis 1990 (12. Subventionsbericht), Bonn 1989, S. 9ff.

2 Vgl. Andel, $N$., Subventionen als Instrument des finanzwirtschaftlichen Interventionismus, a. a. O., S 4. 


\section{Inhalt des Begriffs investitionsfördernde Maßnahmen}

Investitionsfördemde Maßnahmen umfassen "in weitestem Sinne alle Verbesserungen der Bedingungen für unternehmerisches Handeln"1. Jedoch können die Vergünstigungswirkungen eines großen Teils dieser Maßnahmen nicht quantifiziert werden. Mit den Instrumenten, die lediglich die Rahmenbedingungen für das Investieren verbessern, sind für den Investor nicht unmittelbar finanzielle Vorteile verbunden. $\mathrm{Zu}$ diesen allgemeinen Maßnahmen zählen beispielsweise ordnungspolitische Instrumente, Infrastrukturmaßnahmen oder eine allgemeine nachfrageorientierte Fiskalpolitik. Insofern wird hier nur ein Ausschnitt aus dem Spektrum des Investitionsförderinstrumentariums betrachtet.

In der Regel werden investitionsfördernde Maßnahmen als finanzielle Vorteile definiert, die der Staat den Unternehmen ohne wirtschaftliche Gegenleistungen gewährt. ${ }^{2}$ Mit Hilfe finanzieller Anreize sollen die betrieblichen Entscheidungen beeinflußt werden, vermehrt Investitionen vorzunehmen oder bestimmte Investitionsalternativen besonders zu berücksichtigen. Die Entscheidungskompetenz über Faktoreinsatz und Produktion verbleibt in der Unternehmung. Die investitionsfördernden Maßnahmen zielen lediglich auf eine Beeinflussung, nicht aber auf eine Bestimmung oder Erzwingung eines konkreten Entscheidungsergebnisses ab. ${ }^{3}$ Hierin liegt auch der Unterschied zur direkten Marktlenkung. ${ }^{4}$

1 Supper, M., Wirtschaftsförderung in marktwirtschaftlicher Sicht, in: Gantner, M./ Rinderer (Hrsg.), Staatliche Wirtschaftsförderung. Ökonomische Effizienz und politische Rationalität, Frankfurt a. M., Bern, New York, Paris 1988, S. 35.

$2 \mathrm{Vgl}$. Andel, $N$., Subventionen als Instrument des finanzwirtschaftlichen Interventionismus, a. a. O., S 5 f. Die Definitionen von Alewell, $K$., Subventionen als betriebswirtschaftliche Frage, Köln, Opladen 1965, S. 103ff, Hansmeyer, $K .-H$., Transferzahlungen an Unternehmen (Subventionen), in: Neumark, F. (Hrsg.), Handbuch der Finanzwissenschaft, Bd. 1, Tübingen 1977, S.963 und Meinhold, W., Subventionen, in: Handwörterbuch der Sozialwissenschaften, Bd. X, Stuttgart, Tübingen, Göttingen 1959, S. $237 \mathrm{f}$ umfassen zusätzlich auch geldwerte Leistungen des Staates.

${ }^{3}$ Vgl. Hansmeyer, K.-H., Transferzahlungen an Unternehmen (Subventionen), in: Neumark, F. (Hrsg.), Handbuch der Finanzwissenschaft, Bd. 1, a. a. O., S. 961.

${ }^{4}$ Vgl. Steger, U., Alternative Konzepte der Investitionsplanung - Ansatzpunkt, Probleme, Effizienzausgleich -, in: Sarrazin, T. (Hrsg.), Investitionslenkung, Bonn-Bad Godesberg 1976, 
Es ist nicht leicht zu bestimmen, welche finanziellen Vorteile die Investitionsentscheidung beeinflussen und somit als investitionsfördernde Maßnahmen gelten können, zumal nahezu jedes staatliche Handeln Auswirkungen auf die Investitionsentscheidungen haben kann. Der Kausalzusammenhang zwischen einzelnen Maßnahmen und ihrer investitionsfördernden Wirkung ist in der wirtschaftswissenschaftlichen Diskussion zum Teil sehr umstritten. ${ }^{1}$ Infolgedessen sollen nur Maßnahmen untersucht werden, die an einer Investition anknüpfen. Der Anlaß für die Förderung muß folglich die Vornahme einer Investition sein. $\mathrm{Ob}$ durch eine solche Fördermaßnahme zusätzliche Investitionen angeregt werden oder nur Mitnahmeeffekte stattfinden, muß dahingestellt bleiben.

Wenn man die oben genannten Abgrenzungskriterien berücksichtigt, läßt sich eine Übersicht mit den investitionsfördernden Maßnahmen aufstellen, die in der wirtschaftswissenschaftlichen Literatur diskutiert werden oder bereits zum Einsatz kamen. In der Systematik fehlt die Senkung der Unternehmensteuern. Die Vergünstigungseffekte dieser Maßnahme sind zwar quantifizierbar, jedoch muß ein Unternehmen nicht investieren, um in den Genuß dieser finanziellen Vorteile zu kommen; es besteht keine Verbindung zu einem konkreten Investitionsvorhaben. Die nachfolgende Systematik investitionsfördernder Maßnahmen kann aufgrund der Vielzahl von Fördermaßnahmen keinen Anspruch auf Vollständigkeit erheben.

\section{S. $52 \mathrm{ff}$.}

${ }^{1}$ Vgl. Geiger, K., Probleme steuerlicher Wirtschaftsförderung, in: Deutsches Steuerrecht 1977, S. 301. 
Abbildung B.2: Systematisierung investitionsfördernder Maßnahmen

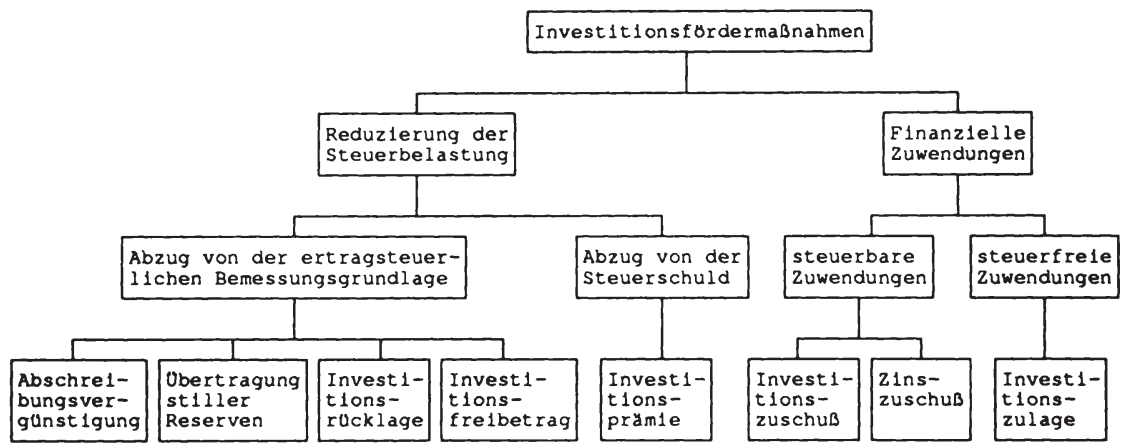

Die investitionsfördernden Maßnahmen können prinzipiell danach unterschieden werden, ob sie der geförderten Unternehmung als Einnahme zufließen, also eine finanzielle Zuwendung darstellen, oder ihre Steuerzahlungen verringern. Eine geringere Steuerbelastung kann entweder durch eine Kürzung der steuerlichen Bemessungsgrundlage oder der Steuerschuld herbeigeführt werden. ${ }^{1}$ Eine finanzielle Zuwendung kann in einer steuerfreien Form gewährt werden, sie kann aber auch beim geförderten Unternehmen der Besteuerung unterliegen.

Die in der Abbildung B.2 angeführten Investitionsfördermaßnahmen in der untersten Zeile werden im Kapitel D auf ihre Vergünstigungswirkungen untersucht und dort auch näher beschrieben.

1 Eine Senkung der Einkommen- und Körperschaftsteuersätze kann ebenfalls zu einer Senkung der Steuerbelastung führen. Nach der hier gewählten Definition ist dies jedoch keine direkte investitionsfördernde Maßnahme. 


\section{Einsatzbereiche investitionsfördernder Maßnahmen}

Grundsätzlich werden Investitionsfördermaßnahmen überall dort eingesetzt, wo das Ziel einer quantitativen Zunahme oder einer bestimmten qualitativen Ausprägung der Investitionen verfolgt wird. Zur Erfüllung dieser Aufgaben zielen die Förderinstrumente auf eine Verbesserung der Finanzierungsmöglichkeiten und eine Zunahme der Investitionsneigung ab. Eine alleinige Ausweitung des Finanzierungsspielraums reicht im Regelfall nicht aus, um die Investitionstätigkeit anzuregen. Daneben muß auch die Bereitschaft zur Investition verstärkt werden, die letztlich von den Erwartungen über die zukünftige Ertragsentwicklung bestimmt wird.

Im einzelnen werden Investitionsfördermaßnahmen vor allem in der Struktur-, Konjunktur- und Wachstumspolitik eingesetzt. Grundsätzlich bedient man sich in allen Bereichen der Wirtschaftspolitik sowohl ordnungspolitischer als auch ablaufpolitischer Instrumente, wobei investitionsfördernde Maßnahmen ausschließlich der letztgenannten Gruppe zugeordnet werden.

Mit der Strukturpolitik will der Gesetzgeber unmittelbar "das Verhältnis wesentlicher Teilbereiche einer Wirtschaft untereinander oder zu ihrer Gesamtheit"1 beeinflussen. Es wird damit versucht, die Zusammensetzung des Produktionspotentials zu verändern. ${ }^{2}$ Zum Aufgabenbereich der Strukturpolitik gehören die Mittelstandsförderung, die sektorale und regionale Wirtschaftspolitik. Einige Autoren sehen in der Förderung von Forschung und Entwicklung und der des Umweltschutzes eine gesonderte Aufgabe der Strukturpolitik. ${ }^{3}$ Wie man die

${ }^{1}$ Vgl. Schlecht, O., Strukturpolitik in der Marktwirtschaft, Köln, Berlin, Bonn, München 1968, S. 14f. S. 16.

${ }^{2}$ Vgl. Meißner, W.IFassing, W., Wirtschaftsstruktur und Strukturpolitik, München 1989,

${ }^{3}$ Vgl. Bohling, W., Wirtschaftspolitische und wirtschaftsverfassungsrechtliche Probleme staatlicher und kommunaler Subventionen, a. a. O., S. 125ff; Leibfritz, W., Staatliche Investitionsförderung in der Bundesrepublik. Ein Vergleich mit dem österreichischen Modell, in: IfoSchnelldienst, Heft 16, 1979, S. 31 f. 
Strukturpolitik aufspaltet und welche Abgrenzungen man trifft, ist eine Frage der Zweckmäßigkeit.

- Sektorale Strukturpolitik zielt auf die Erhaltung oder Anpassung von Strukturen und die Unterstützung von zukunftsträchtigen oder gesellschaftlich erwünschten Produktionszweigen und Produkten. ${ }^{1}$

- Die regionale Strukturpolitik dient der Förderung einzelner schwach strukturierter Wirtschaftsräume. Dabei wird versucht, die betrieblichen Standortentscheidungen zu beeinflussen, regionale Nachteile zu kompensieren und Hilfen zur Angleichung von Lebensbedingungen zu gewähren.

- Mit der Mittelstandsförderung, zu der auch die Existenzgründungsförderung gehört, will der Gesetzgeber den Wettbewerb erhalten und fördern. ${ }^{2}$ Man geht davon aus, daß sich mittelständische Unternehmen schneller an veränderte Bedingungen anpassen können.

Im Unterschied zur Strukturpolitik zielt die Konjunktur- und Wachstumspolitik, soweit sie an den Investitionen ansetzt, auf eine gesamtwirtschaftliche Niveausteigerung der Investitionen.

- Aus konjunktureller Sicht stellen die Investitionen einen wesentlichen Teil der gesamtwirtschaftlichen Nachfrage dar, deren starke Schwankungen im Konjunkturablauf durch Interventionen unterbunden werden sollen. Die Instrumente, die aus der Abbildung B.2 hervorgehen, sind lediglich zur Bekämpfung einer Rezession geeignet. Zur Vermeidung einer konjunkturellen Überhitzung müssen diese Förderinstrumente ausgesetzt werden. Zusätzlich können spezielle Maßnahmen zur Verhinderung einer konjunkturellen Überhitzung angewandt werden, beispielsweise eine Investitionssteuer oder ein Konjunkturzuschlag zur Einkommen- und Körperschaftsteuer.

1 Vgl. Hamm, W., Sektorale Wirtschaftspolitik, in: Handwörterbuch der Wirtschaftswissenschaft, Stuttgart, New York, Tübingen, Göttingen, Zürich 1977, S. 480.

2 Vgl. Becker, W., Die Eigenkapitalbasis nichtemissionsfähiger Unternehmen als Ansatzpunkt einer unternehmensgrößenbezogenen Strukturpolitik unter besonderer Berücksichtigung neuerer Entwicklungen in der Bundesrepublik Deutschland, Diss. Mainz 1979, S. 30; Hunsdiek, D.IMay-Strobl, E., Gründungsfinanzierung durch den Staat. - Fakten, Erfolg und Wirkung -, Stuttgart 1987, S. 1-9. 
- Das Verhindern starker Schwankungen des Sozialprodukts ist eine Voraussetzung für ein anhaltendes, positives Wachstum. Insofern ist die Konjunkturpolitik ein Stück weit auch Wachstumspolitik. Darüber hinaus tragen neue Investitionen den technischen Fortschritt in sich und stützen auf diese Weise den Wachstumsprozeß. Hier zeigt sich eine Verbindung zur sektoralen Strukturpolitik, speziell zur Förderung von Forschung und Entwicklung.

Im Gegensatz zur Konjunkturpolitik, die einen eher kurz- bis allenfalls mittelfristigen Zeithorizont besitzt, ist die Struktur- und Wachstumspolitik langfristig ausgerichtet. Trotz dieses und einiger anderer Unterschiede sind alle Aufgabenbereiche interdependent. Insbesondere kann man die Instrumente zur Erreichung der Förderziele nicht strikt trennen. Um die angesprochenen Ziele zu erreichen, bedient sich der Gesetzgeber im wesentlichen der in Abbildung B.2 dargestellten Investitionsförderinstrumente. 


\section{ZUR FRAGE DER QUANTITATIVEN ERFASSUNG VON VER- GÜNSTIGUNGSWIRKUNGEN}

\section{Zum Problem der Quantifizierung von Vergünstigungseffekten investi- tionsfördernder Maßnahmen}

Investitionsfördernde Maßnahmen beeinflussen die Höhe des verfügbaren Einkommens des Investors und können in den betreffenden Perioden sowohl zu einer Liquiditätsbe- als auch zu einer -entlastung führen. ${ }^{1}$ Verändert eine Maßnahme das verfügbare Einkommen in mehreren Perioden, bedarf es über die Liquiditätsbetrachtung hinaus einer Gesamtbetrachtung der Einkommenswirkungen über den förderungsrelevanten Zeitraum. Zu diesem Zweck kann man zwei Darstellungsformen wählen, die des Zeitwertes und die des Barwertes einer Fördermaßnahme.

Der Zeitwert bringt die nominelle Veränderung des verfügbaren Einkommens über den förderungsrelevanten Zeitraum zum Ausdruck. Die zeitliche Komponente - die zu unterschiedlichen Zeitpunkten anfallenden Einnahmen bzw. Ausgaben - wird im Zeitwert nicht berücksichtigt. Das ist für die Vergleichbarkeit der Vergünstigungseffekte von Investitionsfördermaßnahmen ein gravierender Nachteil.

Der Barwert geht über die einfache Addition der jährlichen Wirkungen einer Förderung auf das verfügbare Einkommen - wie sie im Zeitwert zum Ausdruck kommt - hinaus. Die Zeitkomponente wird einbezogen, indem alle Einnahmen und Ausgaben, die mit der Förderung in einem ursächlichen Zusammenhang stehen, mit einem Kalkulationszinssatz auf die Gegenwart abdiskontiert werden.

${ }^{1}$ An dieser Stelle ist darauf zu verweisen, daß der in dieser Arbeit verwandte Liquiditätsbegriff nicht unproblematisch ist. Eine Unternehmung muß zu jedem Zeitpunkt in der Lage sein, fällige Verbindlichkeiten durch liquide Mittel abzudecken. Das bedeutet, daß der Liquiditätsbegriff strikt zeitpunktbezogen gesehen werden muß. Hier wird der Saldo der Zahlungsströme einer Periode als Liquiditätseffekt definiert. 
Die Ergebnisse der Berechnungen von Vergünstigungswirkungen werden wesentlich von den zugrunde gelegten Annahmen beeinflußt. Im folgenden werden die unterstellten Prämissen für die in dieser Arbeit vorgenommenen Berechnungen erläutert. Zunächst wird im Abschnitt II.1 auf die Unternehmensbesteuerung eingegangen, die sowohl für die Zeit- als auch Barwerte von Bedeutung ist. Im Abschnitt II.2 werden einige Annahmen zum Abdiskontierungsfaktor erläutert, die nur für die Barwerte erheblich sind.

\section{Prämissen einer quantitativen Erfassung von Vergünstigungswirkun- gen}

1. Die wesentlichen Tatbestände der Unternehmensbesteuerung

Eine Reihe investitionsfördernder Maßnahmen knüpfen direkt oder indirekt an den Steuerzahlungen an. Die Beurteilung der Nettoeinkommenswirkungen dieser Fördermaßnahmen kann demnach nur vor dem Hintergrund eines Steuersystems geschehen. Die Komplexität konkreter steuerlicher Regelwerke kann insbesondere in den Zeit- und Barwerten schwerlich abgebildet werden. Zur Reduktion dieser Komplexität muß von bestimmten Teilen eines Steuersystems abstrahiert werden. Im folgenden sind die elementaren steuerlichen Tatbestände der Unternehmensbesteuerung zu erläutern und aufzuzeigen, auf welche Weise sich diese in den Zeit- und Barwerten niederschlagen.

Die erste Frage, die in diesem Zusammenhang auftaucht, bezieht sich auf die Steuerarten, die in die Überlegungen einbezogen werden sollen. In der Literatur wurden bereits verschiedene Wege aufgezeigt, wie sich unterschiedliche Ertragund Substanzsteuern vor allem in das Barwertmodell integrieren lassen. ${ }^{1}$ Hier

1 Vgl. Baan, W., Substanz- und Ertragsteuern in der Kapitalwertmethode, Der Betrieb 1980, S. $700 \mathrm{ff}$ und 746ff; Breuker, P., Besitzsteuerliche Korrekturen im Rahmen des investitionsrechnerischen Kapitalwert-Modelles, in: Steuer und Wirtschaft 1972, S. 241ff; Mellwig, W., Sensitivitätsanalyse des Steuereinflusses in der Investitionsplanung - Überlegungen zur praktischen Relevanz einer Berücksichtigung der Steuern bei der Investitionsentscheidung -, in: Zeitschrift für betriebswirtschaftliche Forschung 1980, S. $26 \mathrm{f}$. 
kann es genügen, sich auf die Steuern zu konzentrieren, die das Ausmaß der Vergünstigungswirkungen von Förderinstrumenten wesentlich beeinflussen. Von besonderem Gewicht sind in diesem Zusammenhang die Ertragsteuern. Zu den quantitativ bedeutendsten Ertragsteuern zählen die Einkommen- und die Körperschaftsteuer. Neben diesen in erster Linie zentralstaatlichen Steuern bestehen in vielen Industrienationen auch ertragsabhängige Steuem der nachgeordneten $\mathrm{Ge}$ bietskörperschaften. In der Bundesrepublik Deutschland ist es die Gewerbeertragsteuer, die der Gemeindefinanzierung dient. ${ }^{1}$ Der Einfluß der ertragsabhängigen Steuern auf die Vergünstigungswirkungen investitionsfördernder Maßnahmen läßt sich am einfachsten durch Unterstellung eines Ertragsteuersatzes aufzeigen, in dem die Einkommen- bzw. Körperschaftsteuer und die Gewerbesteuer enthalten ist. Die zahlreichen Detailregelungen des Steuerrechts können bei dieser Vorgehensweise nicht erfaßt werden.

Zur Bestimmung eines Ertragsteuersatzes ist zunächst auf die wesentlichen Unterschiede in der steuerlichen Behandlung von Einzelunternehmen und Personengesellschaften auf der einen Seite und Kapitalgesellschaften auf der anderen Seite einzugehen. ${ }^{2}$ Personenunternehmen müssen auf der Unternehmensebene Gewerbeertragsteuem entrichten. Der Gewerbeertragsteuersatz bemißt sich nach dem Hebesatz und der Steuermeßzahl. ${ }^{3}$ Der Unternehmensgewinn wird bei den

${ }^{1}$ Beispielsweise besteht auf der regionalen Ebene in Schweden eine kommunale Körperschaftsteuer, in den USA eine Körperschaftsteuer der Einzelstaaten, in Japan eine Unternehmensteuer und in Österreich eine Gewerbeertragsteuer, die zur Finanzierung von Kommunen und Ländern dient. Alle diese Steuern sind von der Bemessungsgrundlage der Körperschaftsteuer abzugsfähig. Vgl. Leibfritz, W./Meurer, C., Steuerliche Investitionsförderung im internationalen Vergleich, Berlin, München 1985, S. 78ff.

2 Es werden nur die Grundzüge der Unternehmensbesteuerung beschrieben. Die Ausführungen orientieren sich an den grundlegenden Elementen des deutschen Steuersystems.

3 Der Gewerbeertragsteuersatz ist von der Steuermeßzahl $\left(s_{m}\right)$ und dem Hebesatz $\left(s_{h}\right)$ abhängig:

$$
g_{\text {gew }}=\frac{s_{m} * s_{h}}{1+s_{h} * s_{m}}
$$

$\mathrm{g}_{\text {gew: }}$ marginaler Gewerbeertragsteuersatz 
Kapitaleignern unabhängig vom Ausschüttungsumfang besteuert. Die Einkommensteuer hat einen progressiven Tarif. Der Steuersatz steigt mit wachsendem Einkommen bis zu einem Spitzensteuersatz. Die Bemessungsgrundlage für die Einkommensbesteuerung des Kapitaleigners ist das Einkommen nach Abzug der Gewerbesteuer. Es gilt hier der Zusammenhang der Formel C. $2^{1}$.

$$
g=g_{e}+\left(1-g_{e}\right) * g_{g e w}
$$

Die Gewinne der Kapitalgesellschaften sind körperschaftsteuerpflichtig. Mit wenigen Ausnahmen, beispielsweise den USA und der Schweiz, werden die Unternehmensgewinne nach Maßgabe ihrer Verwendung steuerlich unterschiedlich behandelt. Thesaurierte Gewinne werden in der Bundesrepublik mit einem einheitlichen Körperschaftsteuersatz besteuert, der von der Gewinnhöhe unabhängig ist. Für die steuerliche Behandlung der ausgeschütteten Gewinne kommt es entscheidend auf das Anrechnungsverfahren auf die Einkommensteuerschuld des Kapitaleigners an. In der Bundesrepublik existiert eine Vollanrechnung, wobei für die ausgeschütteten Gewinne - im Vergleich zu den thesaurierten - ein niedrigerer Körperschaftsteuersatz gilt. Zusätzlich werden die ausgeschütteten Gewinne mit der Kapitalertragsteuer belastet. Auch die Kapitalgesellschaften müssen auf der Unternehmensebene Gewerbeertragsteuern entrichten. Die Gewerbeertragsteuerzahlungen sind ebenfalls als Betriebsausgaben gemäß der Formel C.2 abzugsfähig.

Auf der Ebene der Kapitaleigner werden die Körperschaftsteuerzahlungen und die Kapitalertragsteuern auf die Einkommensteuerschuld angerechnet. Wenn der

$\mathrm{s}_{\mathrm{b}}: \quad$ Gewerbesteuerhebesatz

$\mathrm{s}_{\mathrm{m}}$ : Gewerbesteuermeßzahl

${ }^{1}$ In der Formel C.2 finden folgende Symbole Verwendung:

g: Grenzsteuersatz

ge: marginaler Einkommen- bzw. Körperschaftsteuersatz

$\mathbf{g}_{\text {gew }}$ : marginaler Gewerbeertragsteuersatz 
individuelle Grenzsteuersatz des Kapitaleigners den Steuersat ${ }^{1}$ für ausgeschüttete Gewinne übersteigt, erfolgt abhängig von der Differenz eine Steuernachzahlung. Im umgekehrten Fall kommt es zu einer Steuererstattung. Damit gilt faktisch für die ausgeschütteten Gewinne analog zu den Personenunternehmen eine Einkommensteuerbelastung, die durch den individuellen Grenzsteuersatz des Kapitaleigners bestimmt wird. Die ausgeschütteten Gewinne können zur Eigenkapitalbildung genutzt werden, wenn ein Schütt-aus-hol-zurück-Verfahren ${ }^{2}$ angewandt wird. Durch dieses Verfahren werden die ausgeschütteten Gewinne mit dem individuellen Steuersatz des Kapitaleigners besteuert und der Unternehmung durch eine gleichzeitige Kapitalerhöhung wieder zugeführt. Auf diese Weise werden auch die Gewinne, die der Eigenkapitalbildung dienen, progressiv besteuert.

Als Ergebnis kann festgehalten werden, daß aufgrund des Vollanrechnungsverfahrens sowohl die Erträge von Kapitalgesellschaften als auch von Personenunternehmen progressiv besteuert werden. Wenn es zu Steuerbelastungsunterschieden zwischen Personenunternehmen und Kapitalgesellschaften kommt, ist dies im wesentlichen auf das Ausschüttungsverhalten der Kapitalgesellschaften zurückzuführen.

Als nächstes ist zu klären, welche Steuersätze aus den Tarifen der angesprochenen Ertragsteuern relevant sind. Im Rahmen der Investitionsentscheidungstheorie kann man diese Frage einfach beantworten. "Maßgebend für Investitionsentscheidungen ist der Steuersatz, mit dem die letzte Einheit Gewinn besteuert wird." ${ }^{3}$ Es ist der marginale Ertragsteuersatz (Grenzertragsteuersatz) anzuset-

1 Dieser Steuersatz errechnet sich aus dem Körperschaftsteuersatz für ausgeschüttete Gewinne und dem Kapitalertragsteuersatz.

2 Die Gewinnausschüttung ist für Kapitalgesellschaften dann von Vorteil, wenn der Gewinn im Falle einer Thesaurierung stärker besteuert wird als im Fall der Ausschüttung. Damit wird in einer solchen Situation für Kapitalgesellschaften ein Anreiz geschaffen, Gewinne auszuschütten und gleichzeitig eine Kapitalerhöhung durchzuführen, was man auch als Schütt-aus-hol-zurück-Politik bezeichnet.

${ }^{3}$ Albach, $H$., Steuersystem und unternehmerische Investitionspolitik, Wiesbaden 1970, S. 62. 
zen. Die Entscheidungstheorie geht der Frage nach, ob eine Investition rentabel oder ob sie gegenüber einer anderen vorteilhafter ist. In dieser Arbeit ist die Problemstellung eine andere. Es sind die unmittelbaren Verteilungswirkungen zu untersuchen. Investitionsfördermaßnahmen können zu erheblichen Einkommensänderungen führen, die einen breiten Bereich innerhalb der Progressionszone des Tarifs berühren. Insofern ist nicht ausschließlich ein Grenzsteuersatz relevant, vielmehr ist aus den Steuersätzen dieses Tarifabschnitts ein Durchschnittswert zu finden. Dieser Durchschnittssteuersatz, der für einen bestimmten Einkommensbereich gilt, geht als Steuersatz in die oben bereits dargelegte Formel C.2 ein. Der hier verwandte Ertragsteuersatz ist folglich aus Durchschnittssteuersätzen des Einkommen- bzw. des Körperschaftsteuertarifs und des Gewerbeertragsteuertarifs zusammengesetzt. ${ }^{1}$ Der Einfachheit halber wird jedoch in der Untersuchung vom Grenzsteuersatz oder vom marginalen Ertragsteuersatz gesprochen.

Der Umfang der ertragsabhängigen Besteuerung einer Unternehmung bemißt sich nach der Höhe des Ertragsteuersatzes und der zugrunde gelegten Steuerbemessungsgrundlage. Auf letztere wird im folgenden näher eingegangen. Die Steuerbemessungsgrundlage für die ertragsabhängigen Steuern, die hier mit dem Gewinn vor Steuern gleichgesetzt werden kann, soll vereinfachend aus dem jeweiligen Periodenüberschuß abzüglich der Normalabschreibung und der Fremdkapitalzinszahlungen gebildet werden. ${ }^{2}$ Zugleich sollen die betriebswirtschaftli-

1 Von einem Problem, das bei dieser Vorgehensweise auftritt, wird in den Berechnungen aus Vereinfachungsgründen abstrahiert. Bei einer Förderung durch eine steuerbare Finanzzuwendung erhöht sich die ertragsteuerliche Bemessungsgrundlage. Dagegen wirken steuerbare Zuwendungen senkend auf die ertragsteuerliche Bemessungsgrundlage. Daraus folgt, daß durch die Gewährung einer Zuwendung und einer Kürzung der Steuerbemessungsgrundlage entgegengerichtete Bereiche des Steuertarifs berührt werden. Deshalb müßte man bei der Berechnung der Vergünstigungswirkungen, auch wenn eine gleiche steuerliche Ausgangssituation vorliegt, abhängig von der unterstellten Form der Förderung mit unterschiedlichen Durchschnittsertragsteuersätzen rechnen.

2 Im deutschen Steuerrecht bestehen Unterschiede in den Bemessungsgrundlagen der Gewerbeertragsteuer und der Einkommen- und Körperschaftsteuer. Ein wesentlicher Unterschied betrifft die Hinzurechnung der Zinsen von Dauerschulden zur Steuerbemessungsgrundlage der Gewerbeertragsteuer. Von diesem und weiteren Unterschieden wird im weiteren Verlauf der Untersuchung abstrahiert (siehe auch Abschnitt C.II.2). Es wird also von einer 
chen Begriffe Auszahlungen, Ausgaben und Aufwendungen auf der einen Seite und Einzahlungen, Einnahmen und Erträge auf der anderen Seite als Synonyme angesehen werden.

Als Normalabschreibung wird die lineare Abschreibung des Investitionsobjektes über die gesamte wirtschaftliche Nutzungsdauer unterstellt. Dies dürfte betriebswirtschaftlich nicht unumstritten sein, da aus betriebswirtschaftlicher Sicht die Normalabschreibung den tatsächlich erfolgten periodischen Werteverzehr widerspiegeln sollte. Eine allgemeingültige Bestimmung des tatsächlichen Verlaufs des Werteverzehrs über die Nutzungsdauer ist jedoch kaum durchführbar, so daß es nicht überrascht, wenn die Meinungen um diesen Verlauf in der wissenschaftlichen Diskussion weit auseinandergehen. ${ }^{1}$ In der Formel C. $3^{2}$ werden die hier als wesentlich erachteten Komponenten der ertragsteuerlichen Bemessungsgrundlage dargestellt.

$$
S B_{t}=\left(E_{t}-A_{t}-D_{t}-F K_{t}\right)
$$

einheitlichen Steuerbemessungsgrundlage der verschiedenen ertragsabhängigen Steuern ausgegangen.

${ }^{1} \mathrm{Vgl}$. Albach, H., Die degressive Abschreibung. Ist die degressive Abschreibung eine nach betriebswirtschaftlichen Grundsätzen notwendige Abschreibung? Wiesbaden 1967, S. 45ff; Dietz, H., Die Normierung der Abschreibung in Handels- und Steuerbilanz, Opladen 1971, S. 154ff; $\mathrm{Hax}, K$., Was ist betriebswirtschaftlich notwendige Abschreibung? in: Angehrn, O./Künzi H. P. (Hrsg.), Beiträge zur Lehre von der Unternehmung, Stuttgart 1968, S. $151 \mathrm{ff}$.

2 In der Formel C.3 finden folgende Symbole Verwendung:

A: $\quad$ Ausgaben in Periode $\mathrm{t}$

$D_{i}$ : Normalabschreibungen in Periode $t$

$\mathrm{E}_{\mathrm{r}}$ : Einnahmen in Periode $\mathrm{t}$

$\mathrm{FK}_{\imath}$ : Fremdkapitalzinszahlungen

$\mathrm{SB}_{\imath}$ : Ertragsteuerbemessungsgrundlage in Periode $\mathrm{t}$ 


\section{Der Kalkulationszinsfuß im Barwertmodell}

Die Ein- und Auszahlungen, die durch die Investitionsfördermaßnahmen verursacht bzw. in ihrem Ausmaß verändert werden, fallen nicht in einem Zeitpunkt an. "Der zeitlich differente Anfall von Einzahlungen und Auszahlungen bedingt aber, daß wir zur Gewinnung einer einheitlichen Vergleichsbasis alle relevanten Daten auf einen Zeitpunkt ab- oder aufzuzinsen haben"1. Das heißt, daß früher erzielte Einnahmenüberschüsse höher bewertet werden als später anfallende. Der Wahl des Kalkulationszinsfußes ist deshalb eine erhebliche Bedeutung beizumessen.

Bei der Festlegung des Abdiskontierungssatzes geht es um die Frage, zu welchem Zinssatz auf der einen Seite Auszahlungsüberschüsse oder später anfallende Einzahlungen finanziert ${ }^{2}$ bzw. vorfinanziert und auf der anderen Seite die gegenwärtigen Einzahlungsüberschüsse angelegt werden können. Damit kommt im Zins ein Doppelphänomen zum Ausdruck. Er ist sogleich Aufwands- als auch Ertragsgröße. ${ }^{3}$ In der Realität muß man von verschiedenen Anlage- und Schuldzinsen ausgehen. Im Barwertmodell kann allerdings nur ein Zinssatz angewandt werden. Unter dieser modelltheoretischen Vereinfachung muß der zugrunde gelegte Zinssatz dem Marktzinssatz entsprechen. ${ }^{4}$

${ }^{1}$ Priewasser, E., Betriebliche Investitionsentscheidungen, Berlin, New York 1972, S. 26.

2 Hierbei spielt es keine Rolle, ob zur Finanzierung Fremd- oder Eigenkapital eingesetzt wird. Die Bindung von Eigenkapital in einem Investitionsobjekt bedeutet den Verzicht auf eine alternative Anlage (opportunity costs). Es gilt unabhängig der Finanzierung ein einheitlicher Zinssatz. Vgl. Keifer, R., Der Kalkulationszinsfuß und investitionstheoretische Entscheidungsmodelle, Diss. Mannheim 1970, S. 60.

3 Vgl. Schaub, G., Die Bestimmung des Kalkulationszinsfußes bei Investitionsentscheidungen auf Grund der Kapitalbeschaffungsmöglichkeiten der Unternehmer, Diss. Köln 1968, S. $15 f$.

4 Vgl. Rudolph, B., Klassische Kapitalkostenkonzepte zur Bestimmung des Kalkulationszinsfußes für die Investitionsrechnung, in: Zeitschrift für betriebswirtschaftliche Forschung 1986, S. 612. 
Neben dem Abdiskontierungssatz bedarf es der Bestimmung des Abzinsungszeitpunktes. In der Realität besteht in einer Rechnungslegungsperiode ein kontinuierlicher Ein- und Auszahlungsstrom. Vereinfachend werden alle Steuerzahlungen und finanziellen Zuwendungen innerhalb einer Periode so dargestellt, als wären sie am Periodenende erfolgt. ${ }^{1}$ Diese Zahlungsströme sind auf einen Zeitpunkt abzudiskontieren. Wenn man unterstellt, daß die Förderung oder zumindest ein Teil davon dem Investor im Verlauf der ersten Periode zukommt, dann erscheint es sinnvoll, die Zahlungsströme auf das Ende der ersten Periode zu beziehen.

Investitionsfördernde Maßnahmen können die Höhe der Steuerzahlungen und der Einnahmen beeinflussen. Diese Veränderungen der Steuerzahlungen und Einnahmen können ihrerseits zu Zinserträgen, Zinszahlungen bzw. entgangenen Zinserträgen führen. Zinsgewinne entstehen aus der Anlage von Steuerersparnissen und Einnahmen. Für die Vorfinanzierung einer nach dem Investitionszeitpunkt gewährten Förderung sind Zinsen auf das Fremdkapital zu zahlen. Erfolgt die Vorfinanzierung einer Förderung durch Eigenkapital, entgehen dem Investor Erträge. Diese Opportunitätskosten und -erträge berühren ebenfalls die Steuerbemessungsgrundlage. Deshalb ist der Abdiskontierungssatz nach Steuern bei der Barwertberechnung anzusetzen. ${ }^{2}$ Würden diese Opportunitätskosten und -erträge im Barwert steuerlich nicht berücksichtigt, wären die Zinszahlungen für Kredite nicht steuerlich abzugsfähig, die Erträge des eingesetzten Eigenkapitals und der Zinsgewinn aus einer Förderung steuerfrei. Der Barwert - dem der Kalkulationszinssatz nach Steuem zugrunde liegt - soll in dieser Arbeit als

1 Diese Vereinfachung berücksichtigt nicht, daß die Maßnahmen zu unterschiedlichen Zeitpunkten die Liquidität entlasten können. Der Zeitpunkt der Liquiditätsentlastung hängt bei einer Steuervergünstigungen von den Steuerterminen und der einer Zuwendung von der Antrags- und Genehmigungsdauer ab, vgl. Gröbner, B. F., Subventionen. Eine kritische Analyse, Göttingen 1983, S. 167.

${ }^{2}$ Vgl. Haberstock, L., Vergleichende Analyse steuerlicher Maßnahmen zur Beeinflussung der konjunkturellen Entwicklung, in: Reber, G.(Hrsg.), Personal- und Sozialorientierung der BWL, Bd. 2, Stuttgart 1977, S. 71; Krauskopf, K., Steuerliche Aspekte der Investitionspolitik, Diss. Bern 1972, S. 26. 
Nettobarwert bezeichnet werden. ${ }^{1}$ Der Bruttobarwert ist der Barwert, bei dem die Opportunitätskosten und -erträge steuerlich nicht berücksichtigt werden.

Die steuerliche Berücksichtigung der Opportunitätskosten und -erträge wirft auch Probleme auf. Es wird beim Nettobarwert vorausgesetzt, daß die Zinsgewinne und -zahlungen die Steuerbemessungsgrundlage in vollem Umfang erhöhen bzw. senken. Das ist im Rahmen der Einkommen- und Körperschaftsteuer zutreffend, aber nicht bei der Gewerbeertragsteuer. Dort müssen die Dauerschuldzinsen teilweise der Bemessungsgrundlage der Gewerbeertragsteuer hinzugerechnet werden. Weil eine entsprechende Behandlung der Hinzurechnungen in den Barwerten nicht möglich ist, ${ }^{2}$ muß folglich von der Hinzurechnung der Dauerschuldzinsen bei der Gewerbeertragsteuer abstrahiert werden.

Variieren die Grenzsteuersätze im Zeitablauf, ändert sich auch der Zinssatz nach Steuern und damit der Abdiskontierungsfaktor. Das heißt, daß in dieser Situation der jeweilige Zahlungsstrom mit periodenspezifischen Diskontierungssätzen abgezinst werden muß. ${ }^{3}$

${ }^{1}$ Eine Berücksichtigung der Besteuerung im Abdiskontierungsfaktor führt zu folgendem formalen Ansatz:

$$
i_{8}=(1-g) * i
$$

g: Grenzsteuersatz

i: unversteuerter Kalkulationszinssatz

$\mathrm{i}_{\mathbf{g}}$ : versteuerter Kalkulationszinssatz

2 Vgl. Schreiber, U., Rechtsformabhängige Unternehmensbesteuerung. Eine Kritik des Verhältnisses von Einkommen- und Körperschaftsteuer auf der Grundlage eines Modells für mehrperiodige Steuerbelastungsvergleiche, Köln 1987, S. 28.

${ }^{3}$ Wenn sich die Grenzsteuersätze im förderungsrelevanten Zeitraum ändern, müssen auch die Abdiskontierungsfaktoren der Nettobarwerte modifiziert werden. Der Ausdruck C.5 gilt nur für im Zeitablauf konstante Grenzsteuersätze

(C.5) $\quad \frac{1}{\left(1-i_{8}\right)^{t}}$ 
Im Diskontierungsfaktor könnte man zusätzlich eine weitere Einflußgröße, die Inflationsrate, berücksichtigen. Hierdurch würde der Aussagewert der ermittelten Vergünstigungswirkungen kaum, jedoch die Komplexität der Berechnungen und Wirkungszusammenhänge erheblich zunehmen. Zwar haben Preisniveauveränderungen mit einer zunehmenden zeitlichen Länge des Beobachtungszeitraums einen verstärkten Einfluß auf die Vergünstigungseffekte, jedoch ist zu berücksichtigen, daß die meisten Investitionen in das Anlagevermögen einen nicht sehr langen Zeithorizont haben. Folglich soll bei der vergleichenden Betrachtung von Investitionsförderinstrumenten von der Inflation abstrahiert werden. ${ }^{1}$

\section{Zusammenfassung}

Die vergleichende Untersuchung der Vergünstigungswirkungen verschiedener Investitionsfördermaßnahmen soll mit Hilfe des Barwert- und des Zeitwertansatzes durchgeführt werden. Hierbei wird insbesondere dem Nettobarwert beim Vergleich verschiedener Fördermaßnahmen stärkere Bedeutung beigemessen. Der Zeitwert soll die nominellen Änderungen des verfügbaren Einkommens im förderungsrelevanten Zeitraum zum Ausdruck bringen. Der Vorteil dieser Darstellungsform gegenüber dem Barwert beruht darin, daß die periodisch anfallenden Zahlungsströme durch den Kalkulationszinsfuß nicht "verzerrt" werden. In der Differenz zwischen Bruttobarwert und Zeitwert zeigt sich der unversteuerte Zinsertrag bzw. die steuerlich noch nicht berücksichtigten Zinszahlungen. Ent-

und muß bei variierenden Grenzsteuersätzen durch den folgenden Term C. 6 ersetzt werden:

$$
\prod_{j=1}^{t} \frac{1}{\left(1-i_{g}\right)^{t}}
$$

$i_{8}: \quad$ versteuerter Kalkulationszinssatz

$i_{\mathrm{gj}}$ : versteuerter Kalkulationszinssatz der Periode $\mathrm{j}$

${ }^{1}$ Zur Berücksichtigung der Inflation im Barwertmodell, vgl. Niemann, J., Die Beurteilung der Vorteilhaftigkeit einer Investition anhand ihres Kapitalwertes unter Berücksichtigung von Preis- und Geldwertschwankungen, Diss. Mainz 1970, S. 100ff; Schneider, D., Investitionen, Finanzierung und Besteuerung, 6. Auflage, Wiesbaden 1989, S. $308 \mathrm{ff}$. 
sprechend werden in der Abweichung von Nettobarwert und Zeitwert die versteuerten Zinserträge bzw. die steuerlich geltend gemachten Zinszahlungen sichtbar. Sowohl der Bar- als auch Zeitwertansatz zeigen eine Gesamtbetrachtung der Vergünstigungswirkungen über einen Zeitraum.

Neben dieser Gesamtbetrachtung können die Zahlungsströme einzelner Perioden, die eine Liquiditätsent- oder -belastung sind, ebenfalls eine große Bedeutung haben. Vom Unternehmer aus gesehen ist eine Subvention vielfach nur eine zusätzliche Liquidität. Dieser Liquiditätsvorteil erleichtert die Finanzierung einer Investition. Infolgedessen wird in der nachfolgenden Untersuchung nicht nur eine Gesamtbetrachtung der Wirkung auf das verfügbare Einkommen mit Hilfe des Bar- und Zeitwertes angestellt, sondern darüber hinaus werden auch die Liquiditätseffekte in den einzelnen Perioden betrachtet. 


\section{ANALYSE DER VERGÜNSTIGUNGSWIRKUNGEN EINZELNER INVESTITIONSFÖRDERNDER MASSNAHMEN}

Im Kapitel B wurden einige Investitionsfördermaßnahmen genannt, die in der Wissenschaft diskutiert werden oder bereits eingesetzt wurden. Hierzu zählen:

- die Abschreibungsvergünstigungen,

- die Übertragungen stiller Reserven,

- die Investitionsrücklagen,

- die Investitionsfreibeträge,

- die Investitionsprämien,

- die Investitionszuschüsse,

- die Zinskostenzuschüsse und

- die Investitionszulagen.

Die Aufgabe in diesem Kapitel ist es, diese investitionsfördernden Maßnahmen kurz zu beschreiben und die von ihnen ausgehenden Wirkungen auf das verfügbare Einkommen des Investors zu untersuchen. Die Vergünstigungseffekte sollen allgemein und mit Hilfe von Modellrechnungen analysiert werden. Die Ergebnisse bilden zugleich die Grundlage für den quantitativen Vergleich der Vergünstigungswirkungen im Kapitel E. Zunächst werden im Abschnitt I die den Modellrechnungen zugrunde gelegten Parameter konkretisiert.

\section{Zur Ausgestaltung der Parameter für die Modellrechnungen \\ 1. Modellannahmen}

Die Analyse und der Vergleich von Vergünstigungseffekten investitionsfördernder Maßnahmen mit Hilfe von Modellrechnungen kann nur vor dem Hintergrund eines Steuersystems geschehen. Hierbei soll von einem Steuersystem ausgegangen werden, das in den wichtigsten steuerrechtlichen Regelungen dem der Bundesrepublik Deutschland entspricht. 
Ein Steuersystem wird durch die in ihm enthaltenen Einzelsteuern und deren Gestaltung bestimmt. Im Kapitel $\mathrm{C}$ wurde dargelegt, daß in dieser Untersuchung lediglich die Einkommen-, Körperschaft- und Gewerbeertragsteuer berücksichtigt werden. In den Berechnungen werden zwei unterschiedliche Grenzsteuersatzentwicklungen im Zeitablauf unterstellt:

1. Die Grenzsteuersätze sollen im relevanten Zeitraum gleich bleiben. Es wird zwischen Grenzsteuersätzen von 0, 20, 40 und 60 Prozent unterschieden.

2. Die Grenzsteuersätze können sich im Zeitablauf ändern. Hierbei wird von zwei unterschiedlichen Grenzsteuersatzkombinationen ausgegangen. Die Grenzsteuersätze sollen erstens über einen Zeitraum von fünf Jahren in Zehnprozentschritten von 20 bis auf 60 Prozent steigen und zweitens von einem Grenzsteuersatz von 60 bis auf 20 Prozent sinken. Ausgangspunkt für die Variation der Grenzsteuersätze bildet die erste Periode. Ab demsechsten Jahr werden konstante Grenzsteuersätze angenommen.

Von Bedeutung für die Höhe der Grenzbesteuerung ist auch die Unternehmensrechtsform. Im Kapitel $\mathrm{C}$ wurde darauf hingewiesen, daß für die Erträge von Personenunternehmen und Kapitalgesellschaften unterschiedliche Steuertarife gelten:

- Es soll angenommen werden, daß die Gewinne von Einzelunternehmen und Personengesellschaften einem 0-, 20-, 40- oder 60-prozentigen Grenzsteuersatz unterliegen. Der 60-prozentige Steuersatz soll die Steuerbelastung in der oberen Proportionalzone ${ }^{1}$ und die Grenzsteuersätze von 20 und 40 Prozent diejenigen in der Progressionszone repräsentieren.

- Für die thesaurierten Gewinne der Kapitalgesellschaften soll ein Grenzsteuersatz in Höhe von 60 Prozent gelten. Bei einer vollständigen Gewinnausschüttung ist die Gewinnbesteuerung infolge der Anrechnung progressiv; sie gleicht damit der von Personenunternehmen.

${ }^{1}$ Eine Steuerbelastung in Höhe von ungefähr 60 Prozent kommt in der Bundesrepublik zustande, wenn man die Körperschaftsteuer bzw. die Einkommensteuer mit dem Spitzensteuersatz und die Gewerbeertragsteuer berücksichtigt. 
Ein interperiodischer Verlustausgleich wird zunächst nicht in die Berechnungen einbezogen. Dafür wird im Abschnitt D.VI der Frage nachgegangen, welche Vergünstigungseffekte durch Investitionsförderinstrumente in Verbindung mit einem Verlustvor- und -rücktrag zustande kommen können.

Außerdem werden in den Berechnungen folgende Annahmen unterstellt:

- Das geförderte Investitionsvolumen beträgt DM 100.000,-.

- Die geförderte Investition wird in der ersten Periode getätigt ${ }^{1}$. Die Einnahmen und Ausgaben werden auf das Ende dieser Periode bezogen.

- Zur Berechnung der Barwerte werden die Einnahmen und Ausgaben mit einem Zinssatz von acht Prozent abdiskontiert.

- Das Investitionsobjekt wird über einen Zeitraum von 5, 10, 15 bzw. 20 Jahre wirtschaftlich genutzt. ${ }^{2}$

Die Ausgestaltungselemente für die Modellrechnungen werden in der Tabelle D.1 zusammengefaßt.

${ }^{1}$ Davon abweichend wird in den Berechnungen zur Investitionsrücklage unterstellt, daß im Verlauf der ersten Periode die Investitionsrücklage gebildet wird. Die Investition erfolgt in diesem Fall erst im Zeitpunkt der Rücklagenauflösung.

2 Der größte Teil der Investitionen in Maschinen und Betriebseinrichtungen zu Produktionszwecken, in Büro- und Geschäftseinrichtungen und in Kraftfahrzeuge hat eine betriebsgewöhnliche Nutzungsdauer von durchschnittlich fünf bis zehn Jahren. Bauinvestitionen haben dagegen einen längeren Nutzungszeitraum. Vgl. Leibfritz, W./Meurer, C., Steuerliche Investitionsförderung im internationalen Vergleich, a. a. O., S. 209, Tabelle A 5. 
Tabelle D.1: Zusammenstellung der Ausgestaltungselemente der Modellrechnungen

\begin{tabular}{|c|c|}
\hline Determinante & Wert \\
\hline Investitionssumme: & DM $100.000,-$ \\
\hline Zinssatz: & $8 \%$ \\
\hline Investitionsdauer: & 5, 10, 15 bzw. 20 Jahre \\
\hline $\begin{array}{l}\text { Grenzsteuersätze } \\
\text { im Zeitablauf: } \\
\text { (1) konstant: } \\
\text { (2) varilerend: } \\
\text { Periode: } \\
\text { (a) aufsteigend: } \\
\text { (b) abfallend: }\end{array}$ & 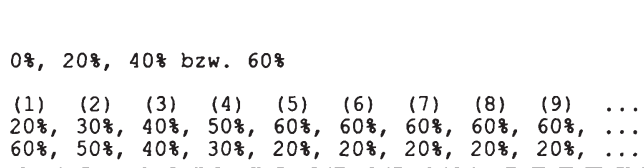 \\
\hline
\end{tabular}

\section{Der Umfang der Subventionsbeträge der Investitionsfördermaßnah- men}

\section{a. Zum Problem des Vergleichsmaßstabs}

Der quantitative Vergleich der unterschiedlichen Maßnahmen erfordert einen gemeinsamen Maßstab. In den Modellrechnungen sollen die Investitionsfördermaßnahmen so dosiert werden, daß sie in einer Basissituation einen gleich hohen Vergünstigungseffekt - gemessen durch den Nettobarwert - hervorrufen. Wählt man eine von dieser Basissituation abweichende Datenkonstellation, beispielsweise eine andere Nutzungsdauer oder Besteuerungssituation, kommt in den veränderten Vergünstigungswirkungen die unterschiedliche Sensitivität der einzelnen Förderinstrumente für Datenänderungen zum Ausdruck.

Die Basissituation ist wie folgt gekennzeichnet:

- Die Erträge des Investors unterliegen einer 40-prozentigen Grenzbesteuerung. Eine derartige Besteuerungssituation dürfte vor allem für kleine und mittlere Einzelunternehmen oder Personengesellschaften typisch sein. Eine solche Steuerbelastung ergibt sich auch für Kapitalgesellschaften, wenn die Gewinne ausgeschüttet werden und sich die Kapitaleigner in der Progressionszone des 
Einkommensteuertarifs befinden. Eine solche Datenkonstellation kann folglich als durchschnittlich für eine durch mittelständische Unternehmen geprägte Volkswirtschaft angesehen werden.

- Das Investitionsobjekt wird fünf Jahre genutzt.

- Die einzelnen Maßnahmen werden so dosiert, daß sich der Nettobarwert der durch die jeweilige Förderung verursachten Einnahmeüberschüsse auf jeweils DM 1.000,- beläuft.

Der Vorteil dieser Vorgehensweise besteht darin, daß der Nettobarwert zugleich die Nettobelastung des Staates über den förderungsrelevanten Zeitraum wiedergibt, was für die Beurteilung von Investitionsförderinstrumenten nicht unerheblich ist. Die Vergünstigungseffekte eines Investors sind nichts anderes als die unmittelbaren Budgetbelastungen des Staates; es sind zwei Seiten derselben Medaille. Der Nettobarwert eignet sich aus mehreren Gründen zur Darstellung der budgetären Konsequenzen der Investitionsförderung. Einmal zeigt der Nettobarwert die Nettobelastung des Staates und berücksichtigt damit, daß die fiskalische Belastung eben nicht immer nur durch die Höhe des Fördersatzes oder Förderbetrages bestimmt wird. Bei einigen Förderinstrumenten tritt infolge einer Versteuerung oder Nachholung der Förderung kein endgültiger Steuerausfall ein. Außerdem kommt im Nettobarwert die Belastung über den gesamten förderungsrelevanten Zeitraum zum Ausdruck. Damit werden auch alle Wirkungen - insbesondere die Nachholeffekte - erfaßt, die sich über die Förderperiode hinaus ergeben. Wenn man jedoch eine zeitraumbezogene Betrachtung durchführt, bedeutet das aber auch, daß damit die zeitpunktbezogene Budgetbelastung nicht berücksichtigt wird. So verteilen sich selbst in der Basissituation die fiskalischen Belastungen der einzelnen Fördermaßnahmen unterschiedlich über den förderungsrelevanten Zeitraum. Die Budgetbelastungen in jeder einzelnen Haushaltsperiode werden aufgrund der Ambivalenz der Förderung - als Haushaltsbelastung des Staates auf der einen Seite und Vergünstigungswirkung des Investors auf der anderen Seite - im Liquiditätseffekt deutlich. Eine zeitraumbezogene Nettobelastung könnte man zwar auch durch die Zeitwerte zum Ausdruck bringen. Der Staat hat jedoch durch die Förderung Ausgaben in Form von Zinszah- 
lungen, wenn er das staatliche Förderbudget kreditfinanziert. Das setzt jedoch voraus, daß sich der Staat zum selben Zinssatz verschuldet, zu dem der Investor Geld anlegen und ausleihen kann. Zusammenfassend kann man festhalten, daß der Nettobarwert eine geeignete Größe ist, um die Nettobelastung des Staates zu erfassen.

Die Überlegungen zu den fiskalischen Belastungen durch Investitionsfördermaßnahmen beschränken sich auf die unmittelbaren Effekte. Sie berücksichtigen nur den Zusammenhang zwischen der Förderung eines Investors und der dadurch entstehenden Budgetbelastung. Über diese direkten Kosten der Förderung eines Investitionsvorhabens hinaus entstehen in der Regel indirekte Kosten, z.B. Verwaltungskosten. Außerdem muß man auch die Rückwirkungen über den Markt auf die öffentlichen Haushalte berücksichtigen. Wenn der Staat durch eine Fördermaßnahme das Ziel - beispielsweise die Abschwächung einer Rezession - erreicht, können sich multiplikative und akzelerative Nachfrageerhöhung ergeben, so daß die Zunahme des Sozialprodukts zu Haushaltsentlastungen in Form von Steuermehreinnahmen führt, die sogar die ursprünglichen Belastungen übertreffen können. ${ }^{1}$ Dieser Gesichtspunkt ist zwar erheblich, kann jedoch nicht in das Vergleichskonzept aufgenommen werden.

\section{b. Subventionsbeträge ausgewählter Fördermaßnahmen}

Wie oben bereits dargelegt wurde, werden die Fördermaßnahmen so bemessen, daß sie in einer Basissituation eine einheitliche Vergünstigungswirkung oder aus der Sicht des Staates eine identische, zeitraumbezogene Nettobelastung hervor-

${ }^{1}$ Wenn der Staat in der Rezession eine kreditfinanzierte, antizyklische Ausgabenpolitik betreibt und der Staat über Einkommens- und Beschäftigungseffekte entsprechende Mehreinnahmen hat, spricht man in diesem Zusammenhang von einem "Schuldenparadox". Vgl. Oberhauser, A., Das Schuldenparadox, in: Jahrbuch für Nationalökonomie und Statistik, Stuttgart 1985, S. 333. 
rufen. Folglich bedarf es unterschiedlich hoher Subventionsbeträge ${ }^{1}$ für die einzelnen Förderinstrumente. Diese Subventionsbeträge, die den folgenden $\mathrm{Be}$ rechnungen zugrunde gelegt werden, zeigt die Tabelle D.2. Hierbei wird der jeweilige Subventionsbetrag durch den Fördersatz mit der entsprechenden Subventionsbemessungsgrundlage oder dem Förderbetrag angegeben.

Tabelle D.2: Förderbeträge und -sätze ausgewählter Förderinstrumente für die Modellrechnungen ${ }^{2}$

\begin{tabular}{|c|c|}
\hline Investitionsfördermaßnahme & Förderbetrag oder -satz \\
\hline Sonderabschreibung & 22,86 der AHK \\
\hline degressive Abschreibung & $37,21 \%$ des $\mathrm{BW}$ \\
\hline $\begin{array}{l}\text { Abschreibung über die Anschaffungs- oder Her- } \\
\text { stellungskosten hinaus }\end{array}$ & 2,74 \& der AHK \\
\hline Auflösungsbetrag einer stillen Reserve & DM $28.571,-$ \\
\hline Rücklagenbetrag einer Investitionsrücklage & DM $8.987,-$ \\
\hline Investitionsfreibetrag & 2,5 \& der AHK \\
\hline $\begin{array}{l}\text { Investitionsprämie, die nicht mit dem Buchwert } \\
\text { verrechnet wird }\end{array}$ & $1 \%$ der AHK \\
\hline $\begin{array}{l}\text { Investitionsprämie, die mit dem Buchwert } \\
\text { verrechnet wird }\end{array}$ & 1,58 \& der AHK \\
\hline erfolgswirksamer Investitionszuschuß & 1,67 \& der AHK \\
\hline erfolgsneutraler Investitionszuschuß & 1,58 \& der AHK \\
\hline Zinsverbilligung & 0,59 Prozentpunkte \\
\hline Investitionszulage & 1 o der AHK \\
\hline \multicolumn{2}{|c|}{$\begin{array}{ll}\text { Basissituation: } & \\
\text { - Investitionssumme: } & \text { DM } 100.000,- \\
\text { - Zinssatz: } & 8 \% \\
\text { - Investitionsdauer: } & 5 \text { Jahre } \\
\text { - Grenzsteuersatz: } & 40 \% \text { (konstant über die Nutzungsdauer) } \\
\text { - Vergunstigungswirkung: } & \text { DM } 1.000,- \text { (Nettobarwert) } \\
\text { AHK = Anschaffungs- oder Hersteliungskosten } \\
\text { BW = Buchwert }\end{array}$} \\
\hline
\end{tabular}

1 Der Subventionsbetrag ist deckungsgleich mit dem absoluten Förderbetrag, oder er errechnet sich aus dem Produkt von Förderungsbemessungsgrundlage und Fördersatz. Bei einer mehrperiodigen Förderung wird er aus der Summe der jährlichen Subventionsbeträge gebildet. Er ist also der Prozentsatz oder Betrag, mit dem eine Investition im gesamten Förderzeitraum gefördert wird. Beispielsweise errechnet er sich bei einer mehrperiodigen Abschreibungsvergünstigung aus der Summe der Mehrabschreibungen.

2 Die Fördersätze bzw. -beträge sind zum Teil gerundet. 
Die Tabelle D.2 zeigt sehr unterschiedliche Subventionsbeträge. Die Fördermaßnahmen müssen mit Subventionsbeträgen zwischen DM 1.000,- und DM 28.571,- ausgestattet werden. Angesichts der Verschiedenheit der Subventionsbeträge bedarf es einiger Erläuterungen.

Die unterschiedlich hohen Subventionsbeträge sind einmal auf die Datenkonstellation in der Basissituation zurückzuführen. Anhand einer Sonderabschreibung soll gezeigt werden, wie sich die Subventionsbeträge verändern, wenn die Daten in der Basissituation variiert werden. Würde man in der Basissituation eine zehnjährige Nutzungsdauer unterstellen, wäre der Fördersatz 12,31 Prozent. Bei einer Nutzungsdauer von fünfzehn Jahren würde man einen Fördersatz von 8,81 Prozent benötigen. Ein entscheidendes Gewicht kommt auch der Frage zu, welche Steuerpflichtigen die Investitionsfördermaßnahmen in Anspruch nehmen. Bei der Berechnung der Subventionsbeträge wurde ein Grenzsteuersatz von 40 Prozent unterstellt. Geht man davon aus, daß der Grenzsteuersatz des durchschnittlichen Subventionsempfängers höher oder niedriger anzusetzen ist als in der oben definierten Basissituation, muß es aufgrund der unterschiedlichen Wirkungen der Steuersätze zu einer Verschiebung der Subventionsbeträge kommen. Diese wenigen Beispiele machen deutlich, welchen Einfluß die zugrunde gelegten Annahmen haben. Die Förderbeträge und -sätze der Tabelle D.2 werden im folgenden nicht variiert. Sie gelten für alle nachfolgenden Berechnungen.

Während die Datenkonstellation in der Basissituation die absolute Höhe der Subventionsbeträge beeinflußt, ist es letztlich auf die Verschiedenheit der Fördermaßnahmen zurückzuführen, daß die Subventionsbeträge unterschiedlich hoch bemessen werden müssen. Betrachtet man die Subventionsbeträge der Tabelle D.2, so zeigen sich entsprechend den Ansatzpunkten der Förderinstrumente erhebliche Unterschiede. Eine Maßnahme, die als Abzug von der ertragsteuerlichen Bemessungsgrundlage konzipiert ist, muß mit den vergleichsweise höchsten Subventionsbeträgen ausgestattet werden. Erheblich weniger hoch müssen die anderen Maßnahmen bemessen werden. Die steuerfreien Zuwendungen, d.h. die Investitionszulagen, bedürfen der geringsten Subventionsbeträge. Obwohl die 
unterschiedlichen Subventionsbeträge in der Basissituation zu einer einheitlichen Vergünstigungswirkung und Nettobelastung des Staates führen, besitzt die Höhe der Subventionsbeträge eine psychologische Bedeutung und darf insoferm in der Praxis nicht unterschätzt werden. Der Investor, der die Vergünstigungseffekte einer Fördermaßnahme nicht genau kennt, fühlt sich durch einen hohen Subventionsbetrag subjektiv stärker gefördert. Er unterliegt einer "Subventionsillusion", die über die Effizienz der Förderung mitbestimmt. Auf der anderen Seite kann dieser Effekt auch beim Gesetzgeber auftreten. Ein hoher Subventionsbetrag kann den Gesetzgeber möglicherweise von der Entscheidung für eine bestimmte Maßnahme abhalten, insbesondere wenn er die exakte Nettobelastung nicht quantifizieren kann. Dies trifft besonders auf Maßnahmen zu, die zu Nachversteuerungen und damit zu zukünftige Mehreinnahmen für die öffentlichen Kassen führen können. Der Umfang dieses Rückflusses kann kleiner, aber auch höher als der Subventionsbetrag sein. 


\section{Abschreibungsvergünstigungen}

In den Unternehmen werden Wirtschaftsgüter zur Leistungserstellung eingesetzt. Diese Wirtschaftsgüter können in einer oder mehreren Perioden verbraucht werden. Erstreckt sich der Verbrauch über mehrere Perioden, so ist jeder einzelnen Periode der wirtschaftlichen Nutzungsdauer der in ihr entstandene Werteverzehr zuzurechnen und als Aufwand vom steuerpflichtigen Periodenerfolg abzusetzen. Darf ein Investor den betriebswirtschaftlich gerechtfertigten Abschreibungsbetrag in einer Periode überschreiten, so wird diese Mehrabschreibung im Rahmen dieser Untersuchung als investitionsfördernde Maßnahme betrachtet. ${ }^{1}$

An früherer Stelle wurde bereits auf die Schwierigkeiten, die bei der Ermittlung der betriebswirtschaftlich notwendigen Abschreibungen entstehen, hingewiesen. $^{2}$ Hier wird davon ausgegangen, daß die lineare Abschreibung über die gesamte wirtschaftliche Nutzungsdauer zugleich die betriebswirtschaftlich richtige Abschreibung ist.

Die Unterschiede zwischen den einzelnen Abschreibungsvarianten können insbesondere auf eine abweichende Ausgestaltung der folgenden drei Elemente zurückgeführt werden: ${ }^{3}$

- die Abschreibungsmethode,

- die steuerliche Nutzungsdauer und

- den der Abschreibung zugrunde liegende Wert.

Bevor die Vergünstigungswirkungen einzelner Abschreibungsmethoden erläutert werden können, ist eine begriffliche Klärung notwendig. Es muß zwischen den

${ }^{1}$ Hierbei ist allerdings nur dann von einer investitionsfördernden Abschreibung auszugehen, wenn die Mehrabschreibung - verglichen mit den linearen Abschreibungsbeträgen einer eventuellen Minderabschreibung vorgelagert ist. Deshalb kann beispielsweise eine progressive Abschreibung nicht als investitionsfördernd angesehen werden.

2 Vgl. Abschnitt C.II.1.

${ }^{3}$ Vgl. Jatzek, H.-G./Leibfritz, W., Der Einfluß der Steuern auf die Investitionstätigkeit der Unternehmen, Berlin, München 1982, S. 61. 
Begriffen technische, wirtschaftliche und steuerliche Nutzungsdauer differenziert werden. Die technische Nutzungsdauer eines Anlagegutes umfaßt den Zeitraum, in dem ein Wirtschaftsgut zweckorientiert betrieblich genutzt werden kann. Der Einsatz eines Wirtschaftsgutes über die gesamte technische Nutzungsdauer muß für den Betrieb jedoch nicht gleichzeitig wirtschaftlich effizient sein. Insbesondere erfordert der technische Fortschritt zur Erhaltung der wirtschaftlichen Effizienz den Ersatz von Wirtschaftsgütern vor Ablauf der technischen Nutzungsdauer. Die wirtschaftliche Nutzungsdauer entspricht infolgedessen dem Zeitraum, in dem eine wirtschaftlich effiziente Nutzung eines Anlagegutes möglich ist. Die Länge der ökonomisch sinnvollen Nutzung eines Wirtschaftsgutes ist lediglich im Einzelfall bestimmbar. Das Steuerrecht kann aber nur in begrenztem Maße auf eine Einzelfallregelung eingehen. Es wird ein Ersatzmaßstab konstruiert, die betriebsgewöhnliche Nutzungsdauer, die wiederum den sogenannten AfA-Tabellen ${ }^{1}$ zugrunde liegt. Die steuerliche und die wirtschaftliche Nutzungsdauer können demzufolge voneinander abweichen. Außer diesen systembedingten Abweichungen zwischen der steuerlichen und der wirtschaftlichen Nutzungsdauer können gezielte Kürzungen der steuerlichen Nutzungsdauer vorgesehen werden. Diese Kürzungen sind in erster Linie wirtschaftspolitisch motiviert. Auf diese gezielten Kürzungen der steuerlichen Nutzungsdauer wird in dieser Arbeit noch einzugehen sein.

Abschreibungsvergünstigungen kann man zwei Gruppen zuordnen. Zur ersten Gruppe zählen die Abschreibungen, deren kumulierte Abschreibungsbeträge die Anschaffungs- oder Herstellungskosten nicht überschreiten. Im Rahmen der investitionsfördernden Abschreibungen sind dies die sogenannten beschleunigten Abschreibungen. In der zweiten Gruppe sind die Abschreibungen, die von einer höheren Abschreibungsbasis als den Anschaffungs- oder Herstellungskosten abgesetzt werden.

1 Die AfA-Tabellen werden in der Bundesrepublik Deutschland zur Bestimmung der durchschnittlichen Nutzungszeiträume von Anlagegütem in den einzelnen Branchen herangezogen. 
Abbildung D.1: Übersicht über die Abschreibungsvergünstigungen

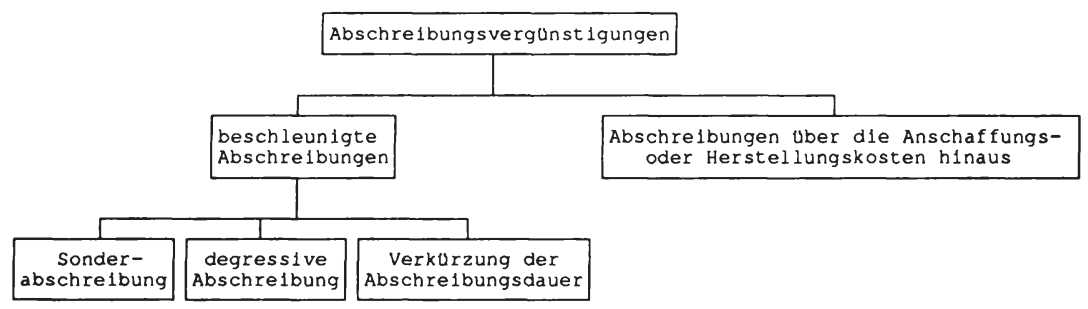

\section{Beschleunigte Abschreibungen}

Eine beschleunigte Abschreibung bedeutet - bezogen auf die lineare Abschreibung - eine zeitliche Vorwegnahme von Abschreibungen. ${ }^{1}$ Obwohl die Abschreibungsbeträge in der ersten Periode bzw. den ersten Perioden die der linearen Abschreibung übersteigen, entspricht die Abschreibungssumme über den Nutzungszeitraum den Anschaffungs- oder Herstellungskosten.

\section{a. Erscheinungsformen beschleunigter Abschreibungen}

Eine beschleunigte Abschreibung eines Investitionsobjektes läßt sich mit Hilfe von drei Abschreibungsvarianten erreichen:

- der Sonderabschreibung,

- der degressiven Abschreibung,

- und der Verkürzung der steuerlichen Abschreibungsdauer.

1 Vgl. Weichsel, L., Beschleunigte Abschreibungen, Wachstum und Konjunktur, Köln, Opladen 1964, S. 15. Eine weitgreifendere Abgrenzung beschleunigter Abschreibungen nehmen Huiskamp, J. C. L./Wisselink, M. A./Siedenberg, A., Steuerpolitik und private Investitionstätigkeit in der EG, in: Steuer und Wirtschaft 1977, S. 90, vor, die auch Abschreibungen vom Wiederbeschaffungswert den beschleunigten Abschreibungen zurechnen. 
Sonderabschreibungen sind Absetzungen vom Buchwert, die neben der Regelabschreibung vom Investor vorgenommen werden dürfen. Diese Fördermaßnahme wird unter anderem zur Konjunkturbelebung, zur Regionalförderung und zur Förderung bestimmter Wirtschaftsgüter eingesetzt. ${ }^{1}$ Derzeit benutzt man in der Bundesrepublik Deutschland dieses Instrument auch zur Förderung der wirtschaftlichen Entwicklung in den fünf neuen Bundesländern. ${ }^{2}$

Die Vornahme einer Sonderabschreibung kann dem Investor für eine oder für mehrere Perioden der Nutzungsdauer eingeräumt werden. Außerdem kann dem Investor die Wahl des Vornahmezeitpunktes einer Sonderabschreibung innerhalb eines Begünstigungszeitraumes freigestellt werden. ${ }^{3}$

Die degressiven Abschreibungen unterscheiden sich von den Sonderabschreibungen dadurch, daß sie an die Stelle der linearen Abschreibungen treten. Allen degressiven Abschreibungsmethoden ist gemeinsam, daß die Anschaffungs- oder Herstellungskosten mit jährlich sinkenden Abschreibungsbeträgen über die Nutzungsdauer abgesetzt werden. Der degressiven Abschreibung wird von einigen Autoren die investitionsfördernde Wirkung abgesprochen. Diese Autoren gehen davon aus, daß der tatsächliche Werteverzehr über den Nutzungszeitraum einen degressiven Verlauf aufweist. ${ }^{4}$ Andererseits zählt die degressive Abschreibung

1 Vgl. Gaugler, E., Sonderabschreibungen als Konjunkturmaßnahme, in: Zeitschrift für betriebswirtschaftliche Forschung 1968, S. 518ff; Kupsch-Werner, T., Betriebswirtschaftliche Wirkungsanalyse steuerlicher Investitionshilfen, dargestellt am Beispiel von Bewertungsfreiheit, Mehrfach-AfA und Investitionszulage, Diss. Regensburg 1977, S. 83 und S. $91 \mathrm{ff}$; Röthlingshöfer, K. Ch./Sprenger, R.-U., Effizienz der indirekten steuerlichen Forschungsförderung, Berlin, München 1977, S. 38ff und $43 \mathrm{ff}$.

2 Vgl. Scheffler, W., Betriebswirtschaftliche Analyse der Steuerbegünstigungen für Investitionen in den neuen Bundesländern, in: Deutsches Steuerrecht 1991, S. 527f.

3 Die Wahlmöglichkeiten können so weit ausgedehnt werden, daß sogar die Sonderabschreibung vor den Investitionszeitpunkt vorgezogen werden kann. Diese Möglichkeit besteht beispielsweise im deutschen Steuerrecht ( $\$ 7$ a Absatz $2 \mathrm{EStG}$ ) für den Fall, wenn bereits eine Anzahlung auf die Anschaffungskosten getätigt wurde oder eine Teilherstellung des Investitionsobjektes erfolgte.

4 Auf die Diskussion der "richtigen" Normalabschreibung wurde bereits im Abschnitt C.II.1 eingegangen. 
zu den Fördermaßnahmen im Konjunktur- und Wachstumsgesetz. ${ }^{1}$ Die degressive Abschreibung dürfte mit zunehmender Intensität der Degression den Charakter einer investitionsfördernden Maßnahme haben. ${ }^{2}$

In der Literatur finden sich mehrere Varianten, die zum Teil auch in die Steuergesetze Eingang fanden. Insbesondere sind die Degression mittels fallender Staffelsätze ${ }^{3}$, die geometrisch-degressive und die arithmetisch-degressive Abschreibung zu nennen. Außerdem kann eine Übergangsmöglichkeit von einer geometrisch-degressiven zur linearen Abschreibungsmethode eingeräumt werden, wodurch das Problem der zum Teil sehr beachtlichen Abschreibungsrestwerte ("Schrottwerte") gelöst wird. Der degressive Abschreibungsverlauf der diversen Verfahren resultiert aus dem jährlichen Abnehmen des zugrunde gelegten Wertes oder des Abschreibungssatzes.

Tabelle D.3: Systematik der degressiven Abschreibungsmethoden

\begin{tabular}{|l|l|l|}
\hline Abschreibungsmethode & $\begin{array}{l}\text { Abschreibungsbe- } \\
\text { messungsgrundlage }\end{array}$ & Abschreibungssatz \\
\hline \hline $\begin{array}{l}\text { geometrisch-degressive } \\
\text { Abschreibung }\end{array}$ & $\begin{array}{l}\text { variiert } \\
\text { (Buchwert) }\end{array}$ & $\begin{array}{l}\text { konstant } \\
\text { (Degressionssatz) }\end{array}$ \\
\hline $\begin{array}{l}\text { arithmetisch-degressive } \\
\text { Abschreibung }\end{array}$ & $\begin{array}{l}\text { konstant } \\
\text { (Anschaffungswert) }\end{array}$ & $\begin{array}{l}\text { variiert nach einer } \\
\text { arithmetischen Reihe }\end{array}$ \\
\hline $\begin{array}{l}\text { degressive Abschreibung } \\
\text { mit fallenden Staffelsätzen }\end{array}$ & $\begin{array}{l}\text { konstant } \\
\text { (Anschaffungswert) }\end{array}$ & $\begin{array}{l}\text { variiert nach einer } \\
\text { bestimmten Vorgabe }\end{array}$ \\
\hline
\end{tabular}

${ }^{1}$ Im Konjunktur- und Wachstumsgesetz ist die Möglichkeit der Variation der degressiven Abschreibungssätze zur Konjunkturstabilisierung vorgesehen (§ 51 Abs. 2 EStG).

2 Wittmann, F., Die Erhöhung der degressiven AfA-Sätze - Ein geeignetes Mittel zur Investitionsbelebung? in: Die Betriebswirtschaft 1978, S. 395ff.

${ }^{3}$ Bei dieser Abschreibungsform werden für jede Periode die Abschreibungssätze vorgegeben. Die Abschreibungssätze sind über den Abschreibungszeitraum degressiv gestaffelt. 
Die Vergünstigungswirkungen einer geometrisch-degressiven Abschreibung werden im Abschnitt D.II.2 berechnet. Deshalb soll diese Variante kurz beschrieben werden. Die jährlichen Abschreibungsbeträge (AD) errechnen sich durch einen konstanten Prozentsatz (d) am Buchwert (BW). Der konstante Prozentsatz wird als Degressionssatz bezeichnet.

(D.I)

$A D=d * B W$

Die Verkürzung der Abschreibungsdauer tritt als wirtschaftspolitische Maßnahme vor allem in Verbindung mit der sogenannten Abschreibungsfreiheit auf. Danach soll es dem Investor freigestellt werden, wie er die Abschreibungsbeträge über die Nutzungsdauer verteilt. Ein Spezialfall der Verkürzung der Abschreibungsdauer ist die Sofortabschreibung. ${ }^{1}$ Die Sofortabschreibung erlaubt dem Investor die Absetzung der Investitionskosten in einem Betrag im Jahr der Anschaffung oder Herstellung, ${ }^{2}$ was faktisch eine Gleichbehandlung der Anschaffungs- oder Herstellungskosten mit einer Betriebsausgabe bedeutet. Im Gegensatz zu den anderen beschleunigten Abschreibungen stimmt durch die Verkürzung der Abschreibungsdauer die steuerliche und wirtschaftliche Nutzungsdauer nicht mehr überein. Maßgebend für die Abschreibungen ist die steuerliche Nutzungsdauer.

\section{b. Vergünstigungswirkungen beschleunigter Abschreibungen}

Die Vergünstigungswirkungen aller beschleunigten Abschreibungen gleichen sich, weil sie in den Anfangsperioden durch Mehrabschreibungen zu Steuereinsparungen und in den Folgeperioden zu Steuernachholungen führen.

${ }^{1}$ Vgl. Schuler, D. W., Der Einfluß von Sonderabschreibungen auf Zahlungsströme, Diss. Berlin 1975, S. 46.

2 In Schweden waren Sofortabschreibungen im Rahmen der Abschreibungsfreiheit bis in das Jahr 1951 gestattet, vgl. Pfaffenberger, W., Investitionssteuerung mit Hilfe steuerfreier Rücklagen, Neue konjunkturpolitische Instrumente in Schweden und in der Schweiz, Berlin 1969 , S. $12 \mathrm{f}$. 
Tabelle D.4: Vergünstigungseffekte einer Sonderabschreibung in Höhe von DM 22.856,-

\begin{tabular}{|c|c|c|c|c|c|c|c|c|c|c|c|c|c|c|c|c|c|c|c|c|c|}
\hline \multirow{4}{*}{$\begin{array}{l}\begin{array}{l}\mathrm{Pe}- \\
\text { rio- } \\
\text { de }\end{array} \\
\text { (1) }\end{array}$} & \multirow{4}{*}{$\begin{array}{l}\text { Ab- } \\
\text { schrei- } \\
\text { bungs- } \\
\text { bet räge } \\
\text { in DM } \\
\quad(2)\end{array}$} & \multirow{4}{*}{$\begin{array}{l}\text { Rest- } \\
\text { buch- } \\
\text { wert } \\
\text { in DM } \\
\\
\text { (3) }\end{array}$} & \multirow{4}{*}{$\begin{array}{l}\text { För- } \\
\text { der- } \\
\text { be- } \\
\text { trag } \\
\text { in DM } \\
\text { (4) }\end{array}$} & \multicolumn{18}{|c|}{ Vergünstigungswirkungen bei alternativen Grenzsteuersätzen in DM } \\
\hline & & & & \multicolumn{12}{|c|}{ konstante Grenzsteversätze } & \multicolumn{6}{|c|}{ variierende Grenzsteuersätze } \\
\hline & & & & \multicolumn{3}{|c|}{$0 \%$} & \multicolumn{3}{|c|}{208} & \multicolumn{3}{|c|}{408} & \multicolumn{3}{|c|}{$60 \%$} & \multicolumn{3}{|c|}{ steigend } & \multicolumn{3}{|c|}{ fallend } \\
\hline & & & & ZW & BBW & NBW. & $\mathrm{zW}$ & BBW & NBW & 2W & BBW & NBW & $2 \mathrm{~W}$ & BBW & NBW & $2 \mathrm{~W}$ & BBW & NBW & $2 \mathrm{~W}$ & BBW & NBW \\
\hline $\begin{array}{l}1 \\
2 \\
3 \\
4 \\
5\end{array}$ & $\begin{array}{l}42856 \\
14286 \\
14286 \\
14286 \\
14286\end{array}$ & $\begin{array}{r}57144 \\
42858 \\
28572 \\
14286 \\
0\end{array}$ & \begin{tabular}{|l|}
22856 \\
-5714 \\
-5714 \\
-5714 \\
-5714
\end{tabular} & $\begin{array}{l}0 \\
0 \\
0 \\
0 \\
0\end{array}$ & $\begin{array}{l}0 \\
0 \\
0 \\
0 \\
0 \\
0\end{array}$ & $\begin{array}{l}0 \\
0 \\
0 \\
0 \\
0\end{array}$ & $\begin{array}{r}4571 \\
-1143 \\
-1143 \\
-1143 \\
-1143\end{array}$ & $\begin{array}{r}4571 \\
-1058 \\
-980 \\
-907 \\
-840\end{array}$ & $\begin{array}{r}4571 \\
-1074 \\
-1009 \\
-949 \\
-892\end{array}$ & $\begin{array}{r}9143 \\
-2286 \\
-2286 \\
-2286 \\
-2286 \\
\end{array}$ & {$\left[\begin{array}{r}9143 \\
-2116 \\
-1960 \\
-1814 \\
-1680\end{array}\right.$} & $\begin{array}{r}9143 \\
-2181 \\
-2081 \\
-1986 \\
-1895\end{array}$ & $\left|\begin{array}{l}13714 \\
-3428 \\
-3428 \\
-3428 \\
-3428\end{array}\right|$ & $\left|\begin{array}{l}13714 \\
-3175 \\
-2939 \\
-2722 \\
-2520\end{array}\right|$ & $\left|\begin{array}{l}13714 \\
-3322 \\
-3219 \\
-3119 \\
-3023\end{array}\right|$ & $\begin{array}{r}4571 \\
-1714 \\
-2286 \\
-2857 \\
-3428\end{array}$ & $\begin{array}{r}4571 \\
-1587 \\
-1960 \\
-2268 \\
-2520\end{array}$ & $\mid \begin{array}{r}4571 \\
-1623 \\
-2065 \\
-2482 \\
-2886\end{array}$ & $\left|\begin{array}{l}13714 \\
-2857 \\
-2286 \\
-1714 \\
-1143\end{array}\right|$ & $\left|\begin{array}{r}13714 \\
-2645 \\
-1960 \\
-1361 \\
-840\end{array}\right|$ & $\begin{array}{r}13714 \\
-2747 \\
-2097 \\
-1489 \\
-933 \\
\end{array}$ \\
\hline$\Sigma=$ & 100000 & 0 & 0 & 0 & 0 & 0 & 이 & 786 & 647 & 0 & 1572 & 1000 & 이 & 2358 & 1031 & -5714 & -3764 & -4486 & 5714 & 6908 & 6447 \\
\hline & 21 & & & & & & & & & & & & & & & & & & & & \\
\hline
\end{tabular}


Tabelle D.5: Vergünstigungseffekte einer geometrisch-degressiven Abschreibung mit einem Degressionssatz von 37,21\%

\begin{tabular}{|c|c|c|c|c|c|c|c|c|c|c|c|c|c|c|c|c|c|c|c|c|c|c|}
\hline \multirow[t]{4}{*}{ P. } & \multirow{4}{*}{$\begin{array}{l}\text { degr. } \\
\text { Ab- } \\
\text { schr. }- \\
\text { be- } \\
\text { träge } \\
\text { in DM } \\
(2)\end{array}$} & \multirow{4}{*}{$\begin{array}{l}\text { Rest- } \\
\text { buch- } \\
\text { wert } \\
\text { in DM } \\
\\
\text { (3) }\end{array}$} & \multirow{4}{*}{$\begin{array}{l}\text { lin. } \\
\text { Ab- } \\
\text { schr. }- \\
\text { be- } \\
\text { träge } \\
\text { in DM } \\
\quad(4)\end{array}$} & \multirow{4}{*}{$\begin{array}{c}\text { För- } \\
\text { der- } \\
\text { betrag } \\
\text { in DM } \\
\\
\text { (5) }\end{array}$} & \multicolumn{18}{|c|}{ Vergünstigungswirkungen bei alternativen Grenzsteuersätzen in DM } \\
\hline & & & & & \multicolumn{12}{|c|}{ konstante Grenzsteversätze } & \multicolumn{6}{|c|}{ varilerende Grenzsteversätze } \\
\hline & & & & & \multicolumn{3}{|c|}{0 के } & \multicolumn{3}{|c|}{208} & \multicolumn{3}{|c|}{40 \& } & \multicolumn{3}{|c|}{608} & \multicolumn{3}{|c|}{ steigend } & \multicolumn{3}{|c|}{ fallend } \\
\hline & & & & & $2 \mathrm{~W}$ & BBW & NBW & $\mathrm{ZW}$ & BBW & NBW & $2 W$ & BBW & NBW & $2 W$ & BBW & NBW & ZW & BBW & NBW & $2 W$ & $\mathrm{BBW}$ & NBW \\
\hline $\begin{array}{l}1 \\
2 \\
3 \\
4 \\
5\end{array}$ & $\begin{array}{r}37210 \\
23364 \\
14670 \\
9212 \\
15544\end{array}$ & $\left|\begin{array}{r}62790 \\
39426 \\
24755 \\
15544 \\
0\end{array}\right|$ & $\begin{array}{l}20000 \\
20000 \\
20000 \\
20000 \\
20000\end{array}$ & $\begin{array}{r}17210 \\
3364 \\
-5330 \\
-10788 \\
-4456\end{array}$ & $\begin{array}{l}0 \\
0 \\
0 \\
0 \\
0\end{array}$ & $\begin{array}{l}0 \\
0 \\
0 \\
0 \\
0\end{array}$ & $\begin{array}{l}0 \\
0 \\
0 \\
0 \\
0\end{array}$ & $\begin{array}{r}3442 \\
673 \\
-1066 \\
-2158 \\
-891\end{array}$ & $\begin{array}{r}3442 \\
623 \\
-914 \\
-1713 \\
-655\end{array}$ & $\begin{array}{r}3442 \\
632 \\
-942 \\
-1791 \\
-695\end{array}$ & $\begin{array}{r}6884 \\
1346 \\
-2132 \\
-4315 \\
-1782\end{array}$ & $\begin{array}{r}6884 \\
1246 \\
-1828 \\
-3426 \\
-1310\end{array}$ & $\begin{array}{r}6884 \\
1284 \\
-1941 \\
-3749 \\
-1478\end{array}$ & $\begin{array}{r}10326 \\
2018 \\
-3198 \\
-6473 \\
-2674\end{array}$ & $\begin{array}{r}10326 \\
1869 \\
-2742 \\
-5139 \\
-1965\end{array}$ & $\mid \begin{array}{r}10326 \\
1956 \\
-3003 \\
-5889 \\
-2357\end{array}$ & $\begin{array}{r}3442 \\
1009 \\
-2132 \\
-5394 \\
-2674 \\
\end{array}$ & \begin{tabular}{|r|}
3442 \\
934 \\
-1828 \\
-4282 \\
-1965
\end{tabular} & $\begin{array}{r}3442 \\
956 \\
-1926 \\
-4687 \\
-2251\end{array}$ & $\mid \begin{array}{r}10326 \\
1682 \\
-2132 \\
-3237 \\
-891\end{array}$ & $\begin{array}{r}10326 \\
1557 \\
-1828 \\
-2569 \\
-655\end{array}$ & $\begin{array}{r}10326 \\
1617 \\
-1956 \\
-2812 \\
-728\end{array}$ \\
\hline$\Sigma=$ & 100000 & & 100000 & 0 & 0 & 0 & 0 & 0 & 783 & 646 & 0 & 1566 & 1000 & 0 & 2350 & 1033 & -5748 & -3699 & -4466 & 5748 & 6831 & 6448 \\
\hline & $\begin{array}{l}2 W=2 \mathrm{e} \\
\mathrm{BBW}=\mathrm{Br} \\
\mathrm{NBW}=\mathrm{Ne} \\
\text { jährlich } \\
\text { jährlich }\end{array}$ & $\begin{array}{l}\text { itwert } \\
\text { ruttoba } \\
\text { ettobar } \\
\text { h steic } \\
\text { h falle }\end{array}$ & $\begin{array}{l}\text { arwert } \\
\text { rwert } \\
\text { gende } \\
\text { ende } G\end{array}$ & 2 & & ät & & $\begin{array}{l}3 \\
8\end{array}$ & 140 & , 508 & $\begin{array}{c}6081 \\
2081\end{array}$ & & & & & & & & & & & \\
\hline
\end{tabular}


In den Berechnungen zu den Tabellen D.4 und D.5 wird unterstellt, daß eine Unternehmung für eine Investition mit einer fünfjährigen Nutzungsdauer und einem Investitionsvolumen von DM 100.000,-

- durch eine Sonderabschreibung in Höhe von 22,86 Prozent der Investitionssumme

- oder durch eine degressive Abschreibung von 37,21 Prozent gefördert wird.

Die Vergünstigungswirkungen einer Verkürzung der Abschreibungsdauer werden nicht berechnet. Die Abschreibungsdauer kann immer nur um eine komplette Periode verkürzt werden. Die Herstellung der oben beschriebenen Basissituation würde aber eine Verkürzung um weniger als ein Jahr erfordern. Eine Aufrundung ${ }^{1}$ bewirkt eine nicht unerhebliche Verzerrung des Vergleichs.

Die beschleunigten Abschreibungen kürzen im Jahr ihrer Inanspruchnahme die ertragsteuerliche Bemessungsgrundlage über die lineare Abschreibung hinaus. Daraus resultiert in den Förderperioden eine vorläufige Steuerersparnis, die zugleich eine Liquiditätsentlastung ist. Der Liquiditätsvorteil wächst mit der Höhe des Grenzsteuersatzes der betreffenden Perioden. Dieser Finanzierungsbeitrag zu den Investitionskosten kann bei einer Sonderabschreibung bis zu 13,7 und bei einer degressiven Abschreibung bis zu 10,3 Prozent der Investitionssumme reichen (vgl. Tabelle D.4 und D.5).

Die Vornahme einer beschleunigten Abschreibung muß aber bei einer Abschreibungssumme, die den Anschaffungs- oder Herstellungskosten entspricht, zu einer gleich hohen Kürzung der linearen Abschreibungen in den Folgeperioden führen. Im Vergleich zu den linearen Abschreibungen kommt es in diesen Perioden zu Liquiditätsbelastungen, die mit der Höhe des Grenzsteuersatzes zunehmen. Erwirtschaftet die geförderte Unternehmung in der Nachholphase ausschließlich Verluste, unterbleibt die gesamte Nachversteuerung. Die Nachholwir-

${ }^{1}$ Die größte Annäherung würde eine Verkürzung um ein Jahr erbringen. Dies führt bei einem Grenzsteuersatz von $40 \mathrm{vH} \mathrm{zu}$ einen Vergünstigungseffekt (Nettobarwert) von DM 835,-- 
kungen einer Sonderabschreibung und einer degressiven Abschreibung unterscheiden sich. Während die Nachholwirkungen einer Sonderabschreibung über den Zeitablauf gleich verteilt sind, wachsen die einer degressiven Abschreibung mit zunehmender Zeitdauer. Besonders deutlich wird der Liquiditätsabfluß in der vierten Periode; die Nachholwirkung der degressiven Abschreibung erreicht nahezu die doppelte Höhe derjenigen einer Sonderabschreibung. ${ }^{1}$

Unterstellt man einen konstanten Grenzsteuersatz über den Abschreibungszeitraum, entsprechen sich die Liquiditätsvorteile durch die Mehrabschreibungen und die Liquiditätsbelastungen in der Nachversteuerungsphase. Folglich ist der Zeitwert einer beschleunigten Abschreibung Null. Aus diesem Grunde bezeichnet man solche Maßnahmen auch als Steuerkredit, weil der Steuervorteil wieder an den Staat zurückgewährt werden muß.

Variiert der Grenzsteuersatz infolge von Gewinn- oder Ausschüttungsschwankungen über den Abschreibungszeitraum, kann der Zeitwert von Null abweichen und hierbei sowohl positiv als auch negativ werden. Durch das Ansteigen bzw. Fallen der Grenzsteuersätze im förderungsrelevanten Zeitraum werden die Liquiditätsbe- und -entlastungen - gegenüber der Situation konstanter Grenzsteuersätze - in den einzelnen Abschreibungsperioden verstärkt bzw. reduziert. Die Differenz zwischen dem Zeitwert bei im Zeitablauf konstanten Grenzsteuersätzen und dem Zeitwert, der sich bei variierenden marginalen Steuersätzen ergibt, wird im folgenden als temporaler Progressionseffekt bezeichnet. ${ }^{2}$ Dieser Effekt wird durch die Intensität der Grenzsteuersatzschwankungen bestimmt. Wenn die Grenzsteuersätze in den Förderperioden höher als in den Nachholungsperioden sind, ist der Progressionseffekt positiv und der Zeitwert auch. Der Progressionseffekt führt zu einer endgültigen Steuerersparnis oder Steuerbelastung. Durch

${ }^{1}$ Der Restbuchwert wird in der fünften Periode abgesetzt. Dies verhindert einen weiteren Anstieg der Nachholwirkungen.

2 Der temporale Progressionseffekt tritt auf, weil die Erträge progressiv besteuert werden. Im Steuersystem besteht kein Ausgleichsverfahren, das eine vollkommene Durchschnittsbesteuerung über einen längeren Zeitraum - idealerweise der Lebensdauer der Unternehmung herstellt. 
eine Sonderabschreibung entsteht gemäß der Tabelle D.4 eine Steuerersparnis bzw. eine Steuerbelastung in Höhe von DM 5.714,- (Zeitwert). Ähnlich sind die Wirkungen einer degressiven Abschreibung; es erfolgt eine Steuerersparnis bzw. -belastung von DM 5.748,- (Zeitwert).

Diskontiert man die durch die beschleunigten Abschreibungen verursachten Einnahmen und Ausgaben ab, so erhält man den Barwert ${ }^{1}$.

$$
B_{A B}=\sum_{t=1}^{n} \frac{g_{t} * A B_{t}}{\left(1+i_{g}\right)^{t-1}}
$$

Die Abdiskontierung der Einnahmen und Ausgaben führt zu einem mit der Höhe des Kalkulationszinssatzes wachsenden Bruttozinsgewinn. Ökonomisch gesehen kann das Entstehen eines Bruttozinsgewinns damit begründet werden, daß der Investor die Liquiditätsentlastung aus der Mehrabschreibung bis zum Eintreten der Liquiditätsbelastungen durch die Nachholung in eine Sach- oder Finanzanlage investieren oder mit ihr die Aufnahme von Fremdkapital umgehen kann. Gleichgültig welche dieser Verwendungsmöglichkeiten des Liquiditätsvorteils der Investor wählt, es erwächst ihm ein Zinsgewinn. Weil der Liquiditätsvorteil mit der Höhe des Grenzsteuersatzes proportional steigt, müssen auch die Zinsgewinne mit der Grenzsteuersatzhöhe proportional zunehmen. Realisiert der Investor einen Zinsgewinn, wird aber auch die steuerliche Bemessungsgrundlage in den betreffenden Perioden erhöht; der Zinsgewinn wird besteuert, was durch den Grenzsteuersatz im Abdiskontierungsfaktor zum Ausdruck kommt. ${ }^{2}$ Je hö-

\footnotetext{
${ }^{1}$ In der Formel D.2 werden folgende Abkürzungen verwandt:
}

$\mathrm{AB}_{\mathfrak{l}}$ : Mehr- bzw. Minderabschreibung infolge einer beschleunigten Abschreibung in der Periode $t$

$\mathbf{B}_{\mathbf{A B}}$ : Barwert einer beschleunigten Abschreibung

g: $\quad$ Grenzsteuersatz in der Periode $t$

$i_{g}$ : versteuerter Kalkulationszinssatz

n: wirtschaftliche Nutzungsdauer

t: $\quad$ Periode

2 Bei der Vermeidung einer Fremdkapitalaufnahme kann der Investor die Schuldzinsen nicht mehr steuerlich geltend machen, während bei der Anlage von Eigenkapital ein steuerpflichtiger Ertrag anfällt. 
her der Grenzsteuersatz ist, desto geringer wird der Nettozinsgewinn im Vergleich zum Bruttozinsgewinn. ${ }^{1}$ Der Investor erhält durch eine beschleunigte Abschreibung einen zinslosen Steuerkredit.

Am Beispiel einer Sonderabschreibung (vgl. Tabelle D.4) wird die Besteuerungswirkung deutlich. Der Zeitwert ist bei einem konstanten Grenzsteuersatz Null, weil nur vorübergehende Steuerersparnisse erfolgen. Wenn die Erträge des begünstigten Investors mit einem Grenzsteuersatz von 60 Prozent besteuert werden, beträgt der Bruttobarwert und damit zugleich der Bruttozinsgewinn DM 2.358,-. Nach der Versteuerung dieses Zinsvorteils verbleibt dem Investor ein Nettovorteil (Nettobarwert) von DM 1.031,-. Gleiche Wirkungen ergeben sich, wenn der Investor - anstatt einer Sonderabschreibung - eine degressive Abschreibung vornimmt (vgl. Tabelle D.5).

Zusammenfassend kann festgehalten werden, daß der marginale Ertragsteuersatz eine vergünstigungsbestimmende Größe ist:

- Erstens führt eine beschleunigte Abschreibung zu Liquiditätswirkungen, die mit der Höhe des Grenzsteuersatzes steigen.

- Zweitens resultiert aus dem zeitlich differenten Anfall der Liquiditätsent- und -belastungen ein Bruttozinsgewinn.

- Drittens wird der Bruttozinsgewinn versteuert und schmilzt mit wachsendem Grenzsteuersatz.

- Viertens tritt bei einer Variation des Grenzsteuersatzes zum Zinsgewinn ein temporaler Progressionseffekt hinzu, der die Vorteile durch eine Steuerersparnis oder Steuerbelastung erhöhen bzw. reduzieren kann. Ein Verlust ist hierbei nicht ausgeschlossen.

${ }^{1}$ Zusätzlich kann der bereits im Rahmen des Zeitwertmodells beschriebene intertemporale Progressionseffekt auftreten. Entscheidend für die Frage, ob der Barwert negativ wird und damit einen Verlust anzeigt, ist das Verhältnis zwischen der Steigerungsrate des Grenzsteuersatzes im Zeitablauf auf der einen Seite und dem Abzinsungsfaktor auf der anderen Seite. Ist der Anstieg des Grenzsteuersatzes größer als der Abdiskontierungsfaktor, übertreffen die Steuermehrbelastungen den Nettozinsgewinn. Zur Berechnung der Nettobarwerte bei unterschiedlichen Grenzsteuersätzen ist der Adiskontierungsfaktor zu modifizieren (siehe Abschnitt C.II.2), was sich auch auf die Nettozinsgewinne auswirkt. 
Aus den ersten drei Effekten resultiert eine mit der Höhe des Grenzsteuersatzes unterproportional zunehmende Begünstigung.

Von besonderer Bedeutung für die Vorteile aus beschleunigten Abschreibungen ist der Umfang der steuerlichen Bemessungsgrundlage. Abschreibungen werden zu Lasten der ertragsteuerlichen Bemessungsgrundlage vorgenommen. Das heißt, daß Abschreibungen nur dann zu einer Wiedergewinnung des eingesetzten Kapitals führen, wenn sie im Umsatzprozeß erwirtschaftet werden. Übertreffen die Abschreibungen den Periodenüberschuß, führt die Vornahme einer Abschreibung zu einem Verlust. Dies gilt nicht nur für die betriebswirtschaftlich erforderlichen Abschreibungen, sondern auch für die investitionsfördernden Abschreibungen. Können lediglich die Normalabschreibungen im Umsatzprozeß erwirtschaftet werden, so ist es für den Investor unvorteilhaft, eine höhere investitionsfördernde Abschreibung vorzunehmen. Eine zusätzliche Kürzung der Steuerbemessungsgrundlage vergrößert den Verlust oder ruft ihn erst hervor; eine Steuerersparnis kommt nicht zustande. Über die gekürzten Abschreibungsbeträge der Folgeperioden kommt es nichtsdestoweniger zu Nachholwirkungen. Einzig durch einen interperiodischen Verlustausgleich können unter Umständen diese Abzüge von der ertragsteuerlichen Bemessungsgrundlage in vor- oder nachgelagerten Perioden geltend gemacht werden. ${ }^{1}$

Die grenzsteuersatzabhängigen Effekte werden in ihrem Umfang zusätzlich durch zwei weitere Faktoren - das Ausmaß der Förderung und die Länge der Nutzungsdauer - beeinflußt:

- Das Ausmaß der Vorteile wird durch die Höhe des Sonderabschreibungssatzes, die des Degressionssatzes bzw. den Umfang der Verkürzung der Abschreibungsdauer bestimmt. Entscheidend ist hierbei nicht nur der Förderumfang, sondern auch die zeitliche Verteilung der Vergünstigungen und der

${ }^{1}$ Der interperiodische Verlustausgleich wird bei der Untersuchung der Abschreibungsvergünstigungen zunächst nicht berücksichtigt. Im Abschnitt D.VI wird der interperiodische Verlustausgleich explizit betrachtet. 
Nachholwirkungen. Je näher die Förderungen am Investitionszeitpunkt in Anspruch genommen werden, desto höher werden die Zinsgewinne. ${ }^{1}$

- Ein weiterer Einflußfaktor ist die Länge der Nutzungsdauer. Mit zunehmender Länge der Nutzungsdauer werden die Nachholwirkungen und damit die Liquiditätsbelastungen auf einen längeren Zeitraum verteilt. Je weiter die Nachversteuerungen vom Zeitpunkt der Investitionsvornahme entfernt liegen, desto stärker steigen die Zinsgewinne. Die Liquiditätsvorteile können über einen längeren Zeitraum zinsbringend angelegt werden. Eine Besonderheit gilt für die degressive Abschreibungsmethode. Sie tritt, wie oben bereits dargelegt wurde, an die Stelle der linearen Abschreibung. Infolgedessen errechnet sich der effektive Fördersatz als Differenz aus dem Degressionssatz und dem linearen Abschreibungssatz. Mit der Länge der Nutzungsdauer schmilzt der lineare Abschreibungssatz. Der Degressionssatz bleibt unverändert. Aus dieser mit der Nutzungsdauer der Investitionsgüter wachsenden Differenz, was quasi einer Erhöhung des Fördersatzes gleichkommt, ergeben sich beträchtliche Nettoeinkommenswirkungen. ${ }^{2}$ Während sich die Nettozinsgewinne einer Sonderabschreibung bei einer 10-jährigen Nutzungsdauer - gegenüber einer fünfjährigen - nahezu verdoppeln, steigt der Vorteil aus einer degressiven Abschreibung um etwa das Viereinhalbfache.

1 Insofern ist Schneider, D., Sinn und Widersinn der steuerlichen Investitionsförderung für die neuen Bundesländer und des Solidaritätszuschlags, in: Der Betrieb 1991, S. 1083, beizupflichten, daß eine Verteilungsmöglichkeit bei Sonderabschreibungen für den Investor nur dann sinnvoll ist, wenn der Investor zukünftig höhere Grenzsteuersätze erwartet.

2 Zur Vermeidung dieses Effektes wurden Regelungen entwickelt. Eine Möglichkeit ist, daß die degressive Abschreibung nur dann zugelassen wird, wenn der höchste degressive Abschreibungsbetrag ein bestimmtes Verhältnis zum linearen Abschreibungsbetrag nicht überschreitet. Daneben können auch unterschiedliche Degressionssätze für Wirtschaftsgüter mit verschieden langen Nutzungszeiträumen gewährt werden. 
Tabelle D.6: Vergleich der Vergünstigungswirkungen von beschleunigten Abschreibungen unter Berücksichtigung verschiedener Nutzungszeiträume

\begin{tabular}{|c|c|c|c|c|c|c|c|c|c|c|c|c|c|}
\hline \multirow{3}{*}{$\begin{array}{l}\text { Nut- } \\
\text { zungs- } \\
\text { dauer } \\
\text { (1) }\end{array}$} & \multirow{3}{*}{$\begin{array}{c}\text { Abschrei- } \\
\text { bungsver- } \\
\text { günstigung } \\
\text { (2) }\end{array}$} & \multicolumn{12}{|c|}{$\begin{array}{c}\text { Vergünstigungswirkungen bei alternativen } \\
\text { Grenzsteuersätzen in DM }\end{array}$} \\
\hline & & \multicolumn{3}{|c|}{$0 \frac{9}{8}$} & \multicolumn{3}{|c|}{208} & \multicolumn{3}{|c|}{$40 \%$} & \multicolumn{3}{|c|}{608} \\
\hline & & ZW & BBW & NBW & ZW & BBW & NBW & $2 W$ & BBW & NBW & $\mathrm{ZW}$ & BBW & NBW \\
\hline \multirow{2}{*}{$\begin{array}{c}5 \\
\text { Jahre }\end{array}$} & Sonder-AfA & 0 & 0 & 0 & 0 & 786 & 647 & 0 & 1572 & 1000 & 0 & 2358 & 1031 \\
\hline & degr. AfA & 0 & 0 & 0 & 0 & 783 & 646 & 0 & 1566 & 1000 & 0 & 2350 & 1033 \\
\hline \multirow{2}{*}{$\begin{array}{c}10 \\
\text { Jahre }\end{array}$} & Sonder-AfA & 0 & 0 & 0 & 0 & 1398 & 1176 & 0 & 2797 & 1857 & 0 & 4195 & 1960 \\
\hline & degr. AfA & 0 & 0 & 0 & 0 & 3301 & 2803 & 0 & 6602 & 4473 & 0 & 9903 & 4767 \\
\hline \multirow{2}{*}{$\begin{array}{c}15 \\
\text { Jahre }\end{array}$} & Sonder-AfA & 0 & 0 & 0 & 0 & 1879 & 1610 & 0 & 3759 & 2595 & 0 & 5638 & 2798 \\
\hline & degr. AfA & 0 & 0 & 0 & 0 & 5453 & 4733 & 0 & 10907 & 7729 & 0 & 16360 & 8445 \\
\hline \multirow{2}{*}{$\begin{array}{c}20 \\
\text { Jahre }\end{array}$} & Sonder-AfA & 0 & 0 & 0 & 0 & 2261 & 1969 & 0 & 4521 & 3231 & 0 & 6782 & 3556 \\
\hline & degr. AfA & 0 & 0 & 0 & 0 & 7174 & 6340 & 0 & 14349 & 10561 & 0 & 21523 & 11797 \\
\hline \multicolumn{14}{|c|}{$\begin{array}{l}\text { ZW }=\text { Zeitwert } \\
\text { BBW }=\text { Bruttobarwert } \\
\text { NBW }=\text { Nettobarwert }\end{array}$} \\
\hline
\end{tabular}

\section{Abschreibung über die Anschaffungs- oder Herstellungskosten hinaus}

Die Untersuchung beschränkte sich bislang auf Abschreibungsvergünstigungen, deren kumulierte Abschreibungsbeträge der Höhe der Anschaffungs- oder Herstellungskosten entsprechen. Davon abweichend können auch Absetzungen über die Anschaffungs- bzw. Herstellungskosten hinaus gestattet werden. Hierbei wird durch die Erhöhung der Abschreibungsbasis - im Unterschied zu den beschleunigten Abschreibungen - die Verteilung der Abschreibungsbeträge über die Nutzungsdauer nicht verändert; es wird linear abgeschrieben.

Im Mittelpunkt der Diskussion um die Abschreibungen über die Anschaffungsoder Herstellungskosten hinaus stehen vor allem die Abschreibungen vom Wiederbeschaffungswert. Der Grundgedanke bei dieser Abschreibung liegt darin, $\mathrm{da} ß$ es aus betriebswirtschaftlicher Sicht notwendig sei, die Inflation und die durch den technischen Fortschritt veränderten Wiederbeschaffungspreise in den 
periodischen Absetzungen zu berücksichtigen. ${ }^{1}$ Wie sich in einem konkreten Fall der Wiederbeschaffungswert eines Investitionsobjektes bemißt, dürfte sehr umstritten sein. ${ }^{2}$ Aus investitionspolitischer Sicht ist es hingegen unerheblich, ob der über den Anschaffungs- oder Herstellungskosten liegende Wert dem Wiederbeschaffungspreis entspricht oder nicht. Eine Abschreibung über die Anschaffungs- oder Herstellungskosten hinaus wird investitionspolitisch vor allem damit begründet, daß sie zu einer nachhaltigen Stärkung der Selbstfinanzierungsmöglichkeiten führen würde. ${ }^{3}$

Die Abschreibungssumme übersteigt die Investitionssumme. Dadurch werden alle jährlichen Abschreibungsbeträge erhöht. Gestattet der Gesetzgeber eine Abschreibung über die Anschaffungs- bzw. Herstellungskosten hinaus um 2,74 Prozent, erhöhen sich die jährlichen Abschreibungen bei einem fünfjährigen $\mathrm{Ab}$ schreibungszeitraum um DM 548,-. Diese höheren Abschreibungen kürzen die steuerliche Bemessungsgrundlage in jeder Abschreibungsperiode. Abschreibungen über die Anschaffungs- oder Herstellungskosten hinaus bewirken folglich eine jährlich wiederkehrende Liquiditätsentlastung über die gesamte Nutzungsdauer, die mit der Höhe des jeweiligen Grenzsteuersatzes wächst. Der Liquiditätsvorteil ist nach der Tabelle D.7 mit einer maximalen Höhe von DM 329,relativ gering. Beispielsweise übersteigt in der Investitionsperiode der Liquiditätsvorteil einer Sonderabschreibung den einer Abschreibung über die Anschaffungs- oder Herstellungskosten hinaus um das etwa 40-fache. Voraussetzung für einen Liquiditätsgewinn ist auch hier eine ausreichend hohe Steuerbemessungsgrundlage. Verlustunternehmen werden auch durch diese Förderung - ohne einen Verlustvor- oder -rücktrag - nicht begünstigt.

${ }^{1}$ Vgl. Dietz, H., Die Normierung der Abschreibung in Handels- und Steuerbilanz, a. a. O., S. $106 \mathrm{ff}$.

2 Vgl. Haase, D., Geldentwertung und Ertragsbesteuerung, in: Mertens, P. (Hrsg.), Die Unternehmung in ihrer gesellschaftlichen Umwelt, Wiesbaden 1976, S. 289.

${ }^{3} \mathrm{Vgl}$. Fuest, W./Kroker, R., Steuerliche Förderung von Investitionen und Innovationen im internationalen Vergleich, Köln 1981, S. 20. 
Tabelle D.7: Vergünstigungswirkungen einer Abschreibung von einer Basis, die um 2,74 \% über den Anschaffungsoder Herstellungskosten liegt

\begin{tabular}{|c|c|c|c|c|c|c|c|c|c|c|c|c|c|c|c|c|c|c|c|c|c|}
\hline \multirow{4}{*}{$\begin{array}{l}\begin{array}{l}\text { Pe- } \\
\text { rio- } \\
\text { de }\end{array} \\
\text { (1) }\end{array}$} & \multirow{4}{*}{$\begin{array}{l}\text { Ab- } \\
\text { schrei- } \\
\text { bungs- } \\
\text { bet räge } \\
\text { in DM } \\
\quad(2) \\
\end{array}$} & \multirow{4}{*}{\begin{tabular}{|l} 
Rest- \\
buch- \\
wert \\
in DM \\
\\
\\
(3)
\end{tabular}} & \multirow{4}{*}{$\begin{array}{c}\text { För- } \\
\text { der- } \\
\text { be- } \\
\text { trag } \\
\text { in } D M \\
(4)\end{array}$} & \multicolumn{18}{|c|}{ Vergünstigungswirkungen bei alternativen Grenzsteuersätzen in DM } \\
\hline & & & & \multicolumn{12}{|c|}{ konstante Grenzsteuersätze } & \multicolumn{6}{|c|}{ variierende Grenzsteuersätze } \\
\hline & & & & \multicolumn{3}{|c|}{0 8 } & \multicolumn{3}{|c|}{208} & \multicolumn{3}{|c|}{$40 \frac{8}{8}$} & \multicolumn{3}{|c|}{608} & \multicolumn{3}{|c|}{ steigend } & \multicolumn{3}{|c|}{ fallend } \\
\hline & & & & $2 W$ & BBW & NBW & $\mathrm{ZW}$ & BBW & NBW & $\mathrm{ZW}$ & BBW & NBW & 2W & BBW & NBW & $\mathrm{ZW}$ & BBW & NBW & $\mathrm{ZW}$ & BBW & NBW \\
\hline $\begin{array}{l}1 \\
2 \\
3 \\
4 \\
5\end{array}$ & $\begin{array}{l}20548 \\
20548 \\
20548 \\
20548 \\
20548\end{array}$ & $\begin{array}{r}82192 \\
61644 \\
41096 \\
20548 \\
0 \\
\end{array}$ & $\begin{array}{l}548 \\
548 \\
548 \\
548 \\
548\end{array}$ & $\begin{array}{l}0 \\
0 \\
0 \\
0 \\
0\end{array}$ & $\begin{array}{l}0 \\
0 \\
0 \\
0 \\
0\end{array}$ & $\begin{array}{l}0 \\
0 \\
0 \\
0 \\
0\end{array}$ & 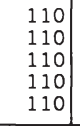 & $\begin{array}{r}110 \\
101 \\
94 \\
87 \\
81 \\
\end{array}$ & $\begin{array}{r}110 \\
103 \\
97 \\
91 \\
86\end{array}$ & $\begin{array}{l}219 \\
219 \\
219 \\
219 \\
219\end{array}$ & $\begin{array}{l}219 \\
203 \\
188 \\
174 \\
161\end{array}$ & $\begin{array}{l}219 \\
209 \\
200 \\
190 \\
182 \\
\end{array}$ & $\begin{array}{l}329 \\
329 \\
329 \\
329 \\
329\end{array}$ & $\begin{array}{l}329 \\
304 \\
282 \\
261 \\
242\end{array}$ & $\begin{array}{l}329 \\
319 \\
309 \\
299 \\
290\end{array}$ & $\begin{array}{l}110 \\
164 \\
219 \\
274 \\
329\end{array}$ & $\begin{array}{l}110 \\
152 \\
188 \\
217 \\
242\end{array}$ & $\begin{array}{l}110 \\
156 \\
198 \\
238 \\
277\end{array}$ & $\begin{array}{l}329 \\
274 \\
219 \\
164 \\
110\end{array}$ & $\begin{array}{r}329 \\
254 \\
188 \\
130 \\
81\end{array}$ & $\begin{array}{r}329 \\
263 \\
201 \\
143 \\
89\end{array}$ \\
\hline$\Sigma=$ & 102740 & & 2740 & 0 & 0 & 0 & 548 & 473 & 486 & 1096 & 945 & 1000 & 1644 & 1418 & 1545 & 1096 & 909 & 978 & 1096 & 981 & 1026 \\
\hline $\begin{array}{l}\text { ZW } \\
\text { BBI } \\
\text { NBI } \\
\text { jäl } \\
\text { jäl }\end{array}$ & $\begin{array}{l}\mathrm{W}=\text { Netto } \\
\text { hrlich st } \\
\text { hrlich fa }\end{array}$ & $\begin{array}{l}\text { barwe } \\
\text { ceiger } \\
\text { allens }\end{array}$ & $\begin{array}{l}\text { Gre } \\
\text { Grer }\end{array}$ & . & . & ätze & $\begin{array}{l}(208), \\
(60 \%,\end{array}$ & $\begin{array}{r}308, \\
508,4\end{array}$ & $\begin{array}{l}88,5 \\
8, \quad 30\end{array}$ & $\begin{array}{l}08,6 \\
8, \quad 20\end{array}$ & & & & & & & & & & & \\
\hline
\end{tabular}


Ein grundlegender Unterschied zu den Abschreibungsvergünstigungen, die im Abschnitt D.II.1 vorgestellt wurden, ist, daß es zu keinen Nachholwirkungen kommt. Bei variierenden Grenzsteuersätzen kann auch hier ein temporaler Progressionseffekt auftreten, jedoch können aufgrund fehlender Nachholwirkungen weder die Bar- noch die Zeitwerte negativ werden. Dieser Progressionseffekt ist sehr gering. Wenn man berücksichtigt, daß der durchschnittliche Grenzsteuersatz im Abschreibungszeitraum sowohl in den ab- als auch aufsteigenden Grenzsteuersatzreihen der Tabelle D.7 40 Prozent beträgt, so sind die Nettobarwerte fast mit denen in der Basissituation gleich, der ebenfalls ein Grenzsteuersatz von 40 Prozent zugrunde gelegt wurde.

Die Barwerte ${ }^{1}$ einer Abschreibung über die Anschaffungs- oder Herstellungskosten hinaus unterscheiden sich von denen beschleunigter Abschreibungen.

$$
B_{A O}=\sum_{t=1}^{n} \frac{g_{t} * A U_{t}}{\left(1+i_{g}\right)^{t-1}}
$$

Beschleunigte Abschreibungen führen zu einem Zinsgewinn. Eine Abschreibung über die Anschaffungs- oder Herstellungskosten hinaus bewirkt dagegen Steuerersparnisse, die der Investor nicht in einem Betrag zum Investitionszeitpunkt erhält, sondern über die gesamte Abschreibungsdauer verteilt. Folglich ist der Barwert der Steuerersparnis geringer als deren Zeitwert. Die Differenz zwischen dem Bar- und dem Zeitwert der Steuerersparnis sind Zinskosten bzw. entgangene Zinserträge. Diese Kosten hat ein Investor zu tragen, weil er im Investitionszeitpunkt die über die Abschreibungsdauer verteilten Steuereinsparungen quasi vorfinanzieren muß. Der Einsatz von Eigenkapital bis zum Eintreten der Steuerersparnis bedeutet einen entgangenen Zinsertrag. Wird hingegen Fremdkapital

${ }^{1}$ In der Formel D.3 werden folgende Abkürzungen verwandt:

AÜ: Überabschreibungsbetrag in der Periode $t$

$B_{A O}$ : Barwert einer Überabschreibung

g: $\quad$ Grenzsteuersatz in der Periode $t$

$i_{g}$ : versteuerter Kalkulationszinssatz

n: wirtschaftliche Nutzungsdauer

t: $\quad$ Periode 
eingesetzt, so hat der Investor die aufgenommenen Kredite bis zum Eintreten der Steuerersparnis zu verzinsen. Bei einem Grenzsteuersatz von 60 Prozent betragen diese Zinskosten bzw. entgangenen Zinserträge DM 226,-1 . Diese Opportunitätskosten kürzen allerdings die Steuerbemessungsgrundlage und verringern auf diese Weise die Steuerzahlungen, so daß beispielsweise bei einem 60-prozentigen Grenzsteuersatz eine Steuerersparnis von DM 127,- ${ }^{2}$ entsteht. Damit wird ein Teil der Zinskosten bzw. entgangenen Zinserträge kompensiert.

Eine Abschreibung über die Anschaffungs- oder Herstellungskosten hinaus führt

- erstens zu einer progressionsabhängigen Steuerersparnis

- und zweitens zu Opportunitätskosten, die steuerlich berücksichtigt werden können.

Der Gesamtvorteil wächst mit der Höhe des Grenzsteuersatzes überproportional (vgl. Tabelle D.7).

Ein weiterer Unterschied zu den beschleunigten Abschreibungen besteht in der Nutzungsdauerabhängigkeit. Wird die Abschreibungsbasis bei einer längeren Nutzungsdauer nicht zusätzlich erhöht, fallen die Vergünstigungswirkungen und dies umso mehr, je höher der zugrunde gelegte Kalkulationszinsfuß ist. Die Vorteile werden über einen längeren Zeitraum verteilt und folglich stärker abgezinst. Es entstehen zusätzliche Zinskosten bzw. entgangene Zinserträge (vgl. Tabelle D.8).

${ }^{1}$ Die Zinskosten bzw. entgangenen Zinserträge sind die Differenz zwischen dem Bruttobarwert und dem Zeitwert.

2 Die Opportunitätskosten nach Steuern ergeben sich aus der Differenz zwischen Nettobarwert und Zeitwert. 
Tabelle D.8: Vergleich der Vergünstigungswirkungen einer Abschreibung über die Anschaffungs- oder Herstellungskosten hinaus unter Berücksichtigung verschiedener Nutzungszeiträume

\begin{tabular}{|c|c|c|c|c|c|c|c|c|c|c|c|c|}
\hline \multirow{3}{*}{$\begin{array}{l}\text { Nut- } \\
\text { zungs- } \\
\text { dauer } \\
\text { (1) }\end{array}$} & \multicolumn{12}{|c|}{ Vergünstigungswirkungen bei alternativen Grenzsteuersätzen in DM } \\
\hline & & \multicolumn{3}{|c|}{$20 \%$} & \multicolumn{3}{|c|}{$40 \%$} & \multicolumn{3}{|c|}{608} \\
\hline & ZW & BBW & NBW & $\mathrm{ZW}$ & BBW & NBW & $\mathrm{ZW}$ & BBW & NBW & $\mathrm{ZW}$ & BBW & NBW \\
\hline 5 Jahre & 0 & 0 & 0 & 548 & 473 & 486 & 1096 & 945 & 1000 & 1644 & 1418 & 1545 \\
\hline 10 Jahre & 0 & 0 & 0 & 548 & 397 & 421 & 1096 & 794 & 896 & 1644 & 1191 & 1432 \\
\hline 15 Jahre & 0 & 0 & 0 & 548 & 338 & 368 & 1096 & 675 & 806 & 1644 & 1013 & 1331 \\
\hline 20 Jahre & 0 & 0 & 0 & 548 & 291 & 324 & 1096 & 581 & 728 & 1644 & 872 & 1239 \\
\hline $\begin{array}{l}\mathrm{ZW}=\mathrm{Z} \\
\mathrm{BBW}= \\
\mathrm{NBW}=\end{array}$ & $\begin{array}{l}\text { twert } \\
\text { ut tob } \\
\text { t toba }\end{array}$ & $\begin{array}{l}\text { Iwert } \\
\text { wert }\end{array}$ & & & & & & & & & & \\
\hline
\end{tabular}

\section{Zusammenfassung}

Die Vergünstigungseffekte aller Abschreibungsvergünstigungen sind grenzsteuersatzabhängig. Dies ist darauf zurückzuführen, daß alle Abschreibungsvergünstigungen eine Kürzung der ertragsteuerlichen Bemessungsgrundlage in einer oder mehreren Förderperioden des Abschreibungszeitraumes herbeiführen. Das Ausmaß der Vorteile hängt bei progressiven Steuersätzen im wesentlichen vom wirtschaftlichen Erfolg in den Förderperioden ab.

Die wichtigsten Determinanten der Vergünstigungseffekte investitionsfördernder Abschreibungen werden in der Tabelle D.9 zusammengefaßt. 
Tabelle D.9: Der Einfluß unterschiedlicher Determinanten auf die Vergünstigungswirkungen (Nettobarwerte) von Abschreibungsvergünstigungen

\begin{tabular}{|c|c|c|c|c|c|c|}
\hline \multirow[b]{3}{*}{$\begin{array}{l}\text { Abschreibungsvergün- } \\
\text { stigungen }\end{array}$} & \multicolumn{6}{|c|}{$\begin{array}{l}\text { Entwicklungsrichtung der Vergünstigungswirkun- } \\
\text { gen (Nettobarwerte) in Abhängigkeit einer zu- } \\
\text { nahme folgender Determinanten }\end{array}$} \\
\hline & \multicolumn{2}{|c|}{ Grenzsteuersatz } & \multirow{2}{*}{$\begin{array}{l}\text { wirt- } \\
\text { schaft- } \\
\text { liche } \\
\text { Nut- } \\
\text { zungs- } \\
\text { dauer }\end{array}$} & \multirow{2}{*}{$\begin{array}{l}\text { Kalku- } \\
\text { la- } \\
\text { tions- } \\
\text { zins- } \\
\text { satz }\end{array}$} & \multirow{2}{*}{$\begin{array}{l}\text { Inves- } \\
\text { ti- } \\
\text { tions- } \\
\text { summe }\end{array}$} & \multirow{2}{*}{$\begin{array}{l}\text { Förder- } \\
\text { satz } \\
\text { bzw. } \\
\text {-betrag }\end{array}$} \\
\hline & $\begin{array}{l}\text { in den } \\
\text { Zah- } \\
\text { lungs- } \\
\text { reihen }\end{array}$ & $\begin{array}{l}\text { im Dis- } \\
\text { kontie- } \\
\text { rungs- } \\
\text { faktor }\end{array}$ & & & & \\
\hline Sonderabschreibung & steigt & fallt & steigt & steigt & steigt & steigt \\
\hline degressive Abschreibung & steigt & fällt & steigt & steigt & steigt & steigt \\
\hline $\begin{array}{l}\text { Verkürzung der Ab- } \\
\text { schreibungsdauer }\end{array}$ & steigt & fällt & steigt & steigt & steigt & steigt \\
\hline $\begin{array}{l}\text { Abschreibung über die } \\
\text { AHK hinaus }\end{array}$ & steigt & steigt & fällt & fällt & steigt & steigt \\
\hline
\end{tabular}

Zwischen den beschleunigten Abschreibungen und denen über die Anschaffungs- oder Herstellungskosten hinaus bestehen zwei wesentliche Unterschiede:

- Erstens führt bei konstantem Grenzsteuersatz nur eine Abschreibung über die Anschaffungs- oder Herstellungskosten hinaus zu einer endgültigen Steuerersparnis.

- Zweitens besteht zwischen beschleunigten Abschreibungen und den Abschreibungen über die Anschaffungs- bzw. Herstellungskosten hinaus ein elementarer Unterschied in der Nutzungsdauer- und Zinsabhängigkeit. Aus den beschleunigten Abschreibungen können Zinsgewinne resultieren, dagegen stehen den Steuerersparnissen der Abschreibungen über die Anschaffungs- bzw. Herstellungskosten hinaus Zinsaufwendungen bzw. entgangene Zinserträge gegenüber. 


\section{III. Übertragung stiller Reserven}

Als investitionsfördernde Maßnahme kann auch die Übertragung stiller Reserven angesehen werden. Eine Übertragung von stillen Reserven setzt die Vornahme einer Neuinvestition voraus. Der Gesetzgeber hat die Einführung der Übertragungsregelungen in der Bundesrepublik im wesentlichen mit ihren investitionsfördernden Wirkungen begründet. In diesem Zusammenhang wurde vor allem die regionalpolitische Bedeutung betont. Man erwartete eine leichtere Verlagerung von Industriestandorten. Desweiteren wollte man durch die Übertragungsbegünstigung auch Rationalisierungsinvestitionen fördern und damit eine Verbesserung der Produktionsstruktur erreichen. ${ }^{1}$

\section{Die Entstehung stiller Rücklagen, deren Aufdeckung und Übertragung}

Stille Rücklagen sind Vermögensteile eines Unternehmens, die nicht aus der Bilanz zu ersehen sind. Sie entstehen durch Bewertungsvergünstigungen beim Anlage- und Umlaufvermögen. Im Bereich des Anlagevermögens ist das Entstehen von stillen Rücklagen in erster Linie auf Abschreibungsvergünstigungen und Wertzuwächse zurückzuführen. Zu Wertzuwächsen kommt es insbesondere bei Grundstücken. Aufgrund des Nominalwertprinzips im Steuerrecht fallen auch inflationsbedingte Wertsteigerungen an. ${ }^{2}$

Die Aufdeckung der stillen Reserven geschieht durch Verkauf des betreffenden Vermögensobjektes. Übertrifft bei der Veräußerung von betrieblichen Vermögensgegenständen der Verkaufspreis den Buchwert des Vermögensobjektes, werden in Höhe der positiven Differenz beider Werte stille Rücklagen aufgedeckt.

${ }^{1}$ Vgl. Klein, E., Die Übertragung stiller Reserven nach $§ 6 \mathrm{~b}$ EStG. Ihre volkswirtschaftliche und betriebswirtschaftliche Bedeutung, in: Zeitschrift für Betriebswirtschaftslehre 1968, S. $369 \mathrm{ff}$.

2 Vgl. Wöhe, G., Bildung, Auflösung und Übertragung stiller Rücklagen im Steuerrecht aus der Sicht der betriebswirtschaftlichen Steuerlehre, in: Zeitschrift für betriebswirtschaftliche Forschung 1966, S. $101 \mathrm{ff}$. 
Dieser Veräußerungsgewinn ${ }^{1}$ erhöht die ertragsteuerliche Bemessungsgrundlage der Unternehmung. An dieser Stelle setzt nun die Begünstigung ein. Die stillen Rücklagen dürfen auf ein Ersatzgut übertragen werden. ${ }^{2}$ Die Veräußerungsgewinne werden dann zumindest vorläufig nicht besteuert.

Die Übertragung des Veräußerungsgewinns muß nicht innerhalb einer Rechnungslegungsperiode erfolgen, sondern kann auf einen späteren Zeitpunkt verschoben werden, was durch die Zuführung des Veräußerungsgewinns in eine steuerfreie Rücklage geschieht. Diese steuerfreie Rücklage ist innerhalb einer festgelegten Frist aufzulösen und auf das Ersatzgut zu übertragen. ${ }^{3}$ Unterbleibt die Übertragung, erfolgt eine Nachversteuerung bei der Auflösung der Rücklage.

\section{Vergünstigungseffekte der Übertragung stiller Reserven}

Eine Übertragung von stillen Reserven ist grundsätzlich sowohl auf ein abnutzbares als auch auf ein nicht abnutzbares Wirtschaftsgut möglich. Hier können

\footnotetext{
${ }^{1}$ Der für die Übertragung stiller Reserven relevante Veräußerungsgewinn bezieht sich nur auf Überschüsse aus solchen Umsatzakten, "die nicht zur normalen Geschäftstätigkeit der Unternehmung gehören. Es sind dies der Verkauf von Gegenständen des Anlagevermögens, das seiner wirtschaftlichen Zwecksetzung nicht zur gewinnbringenden Veräußerung bestimmt ist, und die Veräußerung einer Unternehmung im ganzen." Rieden, W., Die betriebswirtschaftliche Bedeutung der Übertragung stiller Rücklagen gemäß $\S 6 \mathrm{~b}$ des Einkommensteuergesetzes, Diss. Köln 1972, S. 9f.

2 Die Übertragung der Veräußerungsgewinne auf ein Ersatzgut kann dadurch eingeschränkt sein, daß gesetzlich festgelegte Übertragungsregelungen bestehen, die die Übertragung nur auf bestimmte Güter zulassen. $\S 6 \mathrm{~b}$ Abschnitt $1 \mathrm{EStG}$ regelt im deutschen Steuerrecht, welche aufgedeckten stillen Reserven auf welche Ersatzgüter übertragen werden dürfen.

3 Die Vergünstigungswirkungen der Bildung einer steuerfreien Rücklage vor einer Übertragung von stillen Reserven werden hier nicht näher betrachtet. Jedoch ist darauf hinzuweisen, daß die Barwerte dieser Variante aufgrund der stärkeren Abzinsung der Nachversteuerungen - verglichen mit einer sofortigen Übertragung - ceteris paribus höher ausfallen. Außerdem sind die Vergünstigungswirkungen der Übertragung einer stillen Reserve nach vorheriger Bildung einer steuerfreien Rücklage wirkungsanalytisch mit jenen einer Investitionsrücklage vergleichbar, bei deren Auflösung eine Sonderabschreibung gewährt wird (siehe Abschnitt D.V).
} 
Tabelle D.10: Vergünstigungswirkungen einer Übertragung stiller Reserven in Höhe von DM 28.571,- auf ein abnutzbares Wirtschaftsgut

\begin{tabular}{|c|c|c|c|c|c|c|c|c|c|c|c|c|c|c|c|c|c|c|c|c|c|}
\hline \multirow{4}{*}{$\begin{array}{l}\begin{array}{l}\text { Pe- } \\
\text { rio- } \\
\text { de }\end{array} \\
\text { (1) }\end{array}$} & \multirow{4}{*}{$\begin{array}{l}\text { Ab- } \\
\text { schrei- } \\
\text { bungs- } \\
\text { beträge } \\
\text { in DM } \\
\text { (2) }\end{array}$} & \multirow{4}{*}{$\begin{array}{l}\text { Rest- } \\
\text { buch- } \\
\text { wert } \\
\text { in DM } \\
\\
\text { (3) }\end{array}$} & \multirow{4}{*}{$\begin{array}{l}\text { För- } \\
\text { der- } \\
\text { be- } \\
\text { trag } \\
\text { in DM } \\
\text { (4) }\end{array}$} & \multicolumn{18}{|c|}{ Vergünstigungswirkungen bei alternativen Grenzsteuersätzen in DM } \\
\hline & & & & \multicolumn{12}{|c|}{ konstante Grenzsteuersätze } & \multicolumn{6}{|c|}{ variierende Grenzsteuersätze } \\
\hline & & & & \multicolumn{3}{|c|}{0 \& } & \multicolumn{3}{|c|}{208} & \multicolumn{3}{|c|}{40 \% } & \multicolumn{3}{|c|}{608} & \multicolumn{3}{|c|}{ steigend } & \multicolumn{3}{|c|}{ fallend } \\
\hline & & & & $2 W$ & BBW & NBW & $\mathrm{ZW}$ & BBW & NBW & $2 \mathrm{~W}$ & BBW & NBW & $2 W$ & BBW & NBW & $\mathrm{ZW}$ & BBW & NBW & ZW & BBW & NBW \\
\hline $\begin{array}{l}1 \\
2 \\
3 \\
4 \\
5\end{array}$ & $\begin{array}{l}14286 \\
14286 \\
14286 \\
14286 \\
14286\end{array}$ & $\begin{array}{r}57144 \\
42858 \\
28572 \\
14286 \\
0\end{array}$ & 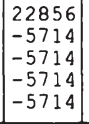 & $\begin{array}{l}0 \\
0 \\
0 \\
0 \\
0\end{array}$ & $\begin{array}{l}0 \\
0 \\
0 \\
0 \\
0\end{array}$ & $\begin{array}{l}0 \\
0 \\
0 \\
0 \\
0\end{array}$ & 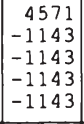 & $\begin{array}{r}4571 \\
-1058 \\
-980 \\
-907 \\
-840\end{array}$ & $\begin{array}{r}4571 \\
-1074 \\
-1009 \\
-949 \\
-892\end{array}$ & $\begin{array}{r}9143 \\
-2286 \\
-2286 \\
-2286 \\
-2286\end{array}$ & $\begin{array}{r}9143 \\
-2116 \\
-1960 \\
-1814 \\
-1680\end{array}$ & $\begin{array}{r}9143 \\
-2181 \\
-2081 \\
-1986 \\
-1895\end{array}$ & $\begin{array}{l}13714 \\
-3428 \\
-3428 \\
-3428 \\
-3428\end{array}$ & $\begin{array}{l}13714 \\
-3175 \\
-2939 \\
-2722 \\
-2520\end{array}$ & $\mid \begin{array}{l}13714 \\
-3322 \\
-3219 \\
-3119 \\
-3023\end{array}$ & $\begin{array}{r}4571 \\
-1714 \\
-2286 \\
-2857 \\
-3428\end{array}$ & $\mid \begin{array}{r}4571 \\
-1587 \\
-1960 \\
-2268 \\
-2520\end{array}$ & $\begin{array}{r}4571 \\
-1623 \\
-2065 \\
-2482 \\
-2886\end{array}$ & $\left|\begin{array}{l}13714 \\
-2857 \\
-2286 \\
-1714 \\
-1143\end{array}\right|$ & $\left|\begin{array}{r}13714 \\
-2645 \\
-1960 \\
-1361 \\
-840\end{array}\right|$ & $\begin{array}{r}13714 \\
-2747 \\
-2097 \\
-1489 \\
-933\end{array}$ \\
\hline$\Sigma=$ & 71429 & 0 & 0 & 0 & 0 & 0 & 0 & 786 & 647 & 0 & 1572 & 1000 & 0 & 2358 & 1031 & -5714 & -3764 & -4486 & 5714 & 6908 & 6447 \\
\hline
\end{tabular}


allerdings gesetzliche Übertragungsregelungen die Übertragungsmöglichkeiten als auch das Ausmaß der Übertragung stiller Reserven begrenzen. Im folgenden sollen die Vergünstigungswirkungen einer Übertragung stiller Reserven auf abnutzbare und nicht abnutzbare Wirtschaftsgüter betrachtet werden, wobei die unterschiedlichen Übertragungsregelungen außer Acht bleiben.

\section{Eine Übertragung des Veräußerungsgewinns auf ein neu angeschafftes oder} neu hergestelltes abnutzbares Investitionsobjekt verhindert in der Veräußerungsperiode eine Erhöhung der ertragsteuerlichen Bemessungsgrundlage und damit eine Besteuerung des Veräußerungsgewinns. Der Investor erlangt in der Investitionsperiode einen von der Höhe der übertragenen stillen Reserven und des Grenzsteuersatzes abhängigen Liquiditätsvorteil. Durch die Übertragung wird aber der Buchwert des Ersatzgutes in Höhe der übertragenen stillen Reserven verringert. Wenn eine stille Rücklage in Höhe von DM 28.571,- auf ein abnutzbares Investitionsobjekt mit einem Anschaffungspreis von DM 100.000,- übertragen wird, beträgt der Buchwert nur noch DM 71.429,-. Mit der Verringerung des Buchwertes geht bei abnutzbaren Wirtschaftsgütern auch eine Reduzierung der jährlichen Abschreibungsbeträge einher. Damit wird die ertragsteuerliche Bemessungsgrundlage bei einer fünfjährigen Nutzungsdauer um jährlich DM 5.714,- erhöht. Es kommt demzufolge zu einer mit der Höhe des Grenzsteuersatzes zunehmenden Nachversteuerung.

Die nachfolgende Barwertformel D. $4^{1}$ zeigt die Vergünstigungswirkungen einer Übertragung von stillen Reserven.

${ }^{1}$ In der Formel D.4 werden folgende Abkürzungen verwandt:

$\mathrm{AK}_{\mathrm{t}}$ : Kürzung des Normalabschreibungsbetrages in der Periode $\mathrm{t}$

$\mathrm{B}_{\mathrm{OA}}$ : Barwert einer Übertragung von stillen Rücklagen auf ein abnutzbares Wirtschaftsgut

gi: Grenzsteuersatz in der Periode $t$

$\mathrm{g}_{1}$ : $\quad$ Grenzsteuersatz in der Periode 1

$\mathrm{i}_{\mathrm{g}}$ : versteuerter Kalkulationszinssatz

n: wirtschaftliche Nutzungsdauer

t: $\quad$ Periode

Ü: $\quad$ Übertragungsbetrag 
(D.4) $\quad B_{0 A}=g_{1} * U-\sum_{t=1}^{n} \frac{g_{t} * A K_{t}}{\left(1+i_{g}\right)^{t-1}}$

In der Barwertformel wird unterstellt, daß in der ersten Periode eine stille Rücklage aufgedeckt und auf ein Ersatzgut übertragen wird. Am Periodenende erfolgt die erste Abschreibung. Dadurch werden diese beiden Vorgänge rechnerisch in einem Zeitpunkt - am Ende der ersten Periode - erfaßt.

Ist der marginale Ertragsteuersatz in allen relevanten Perioden gleich hoch, entsprechen sich die Steuerersparnis in der Übertragungsperiode und die Nachholeffekte, was zu einem Zeitwert von Null führt. Die Übertragung stiller Reserven ist - vergleichbar den beschleunigten Abschreibungen - ein zinsloser Steuerkredit (vgl. Tabelle D.10). Das heißt, daß der Investor bei konstanten Grenzsteuersätzen über den förderungsrelevanten Zeitraum durch einen Liquiditätsvorteil und einen Nettozinsgewinn, der auch hier unterproportional mit der Höhe der Grenzsteuersätze wächst, begünstigt wird. Darüber hinaus können sich infolge von Grenzsteuersatzschwankungen temporale Progressionseffekte und damit zusätzliche Steuervorteile bzw. -belastungen ergeben.

Der Zinsvorteil wird außerdem durch die Länge der Nutzungsdauer und das Niveau des Kalkulationszinssatzes bestimmt. Hierbei bestehen folgende $\mathrm{Zu}$ sammenhänge. Mit der Länge der Nutzungsdauer (vgl. Tabelle D.11) und der Höhe des Diskontierungssatzes wachsen die Zinsgewinne. ${ }^{1}$

1 Vgl. Hartmann, K., Staatliche Investitionshilfen an die gewerbliche Wirtschaft und deren Einfluß auf die Investitionstätigkeit mittelständischer Unternehmungen, Diss. Würzburg 1981, S. 95. 
Tabelle D.11: Vergleich der Vergünstigungswirkungen einer Übertragung von stillen Reserven in Höhe von DM 28.571,- auf ein abnutzbares Gut unter Berücksichtigung verschiedener Nutzungszeiträume

\begin{tabular}{|c|c|c|c|c|c|c|c|c|c|c|c|c|}
\hline \multirow{3}{*}{$\begin{array}{l}\text { Nut- } \\
\text { zungs- } \\
\text { dauer } \\
\text { (1) }\end{array}$} & \multicolumn{12}{|c|}{ Vergünstigungswirkungen bei alternativen Grenzsteuersätzen in DM } \\
\hline & \multicolumn{3}{|c|}{0 8े } & \multicolumn{3}{|c|}{$20 \div$} & \multicolumn{3}{|c|}{408} & \multicolumn{3}{|c|}{$60 \%$} \\
\hline & $\mathrm{ZW}$ & BBW & NBW & $\mathrm{ZW}$ & BBW & NBW & $\mathrm{ZW}$ & BBW & NBW & $\mathrm{ZW}$ & BBW & NBW \\
\hline 5 Jahre & 0 & 0 & 0 & 0 & 786 & 647 & 0 & 1572 & 1000 & 0 & 2358 & 1031 \\
\hline 10 Jahre & 0 & 0 & 0 & 0 & 1573 & 1323 & 0 & 3146 & 2090 & 0 & 4719 & 2205 \\
\hline 15 Jahre & 0 & 0 & 0 & 0 & 2193 & 1878 & 0 & 4385 & 3027 & 0 & 6578 & 3264 \\
\hline 20 Jahre & 0 & 0 & 0 & 0 & 2685 & 2338 & 0 & 5369 & 3837 & 0 & 8054 & 4223 \\
\hline $\begin{array}{l}\mathrm{ZW}=2 \\
\mathrm{BBW}= \\
\mathrm{NBW}=\end{array}$ & $\begin{array}{l}\text { twert } \\
\text { uttol } \\
\text { ttobs }\end{array}$ & $\begin{array}{l}\text { Cwert } \\
\text { wert }\end{array}$ & & & & & & & & & & \\
\hline
\end{tabular}

Ein Verlustunternehmen, das durch den Veräußerungsgewinn nicht in die Gewinnzone gerät, hat keine Vorteile durch eine Übertragung. Eine Übertragung führt für dieses Unternehmen -ohne die Berücksichtigung eines interperiodischen Verlustausgleichs - ausschließlich zu Nachholwirkungen und damit Verlusten. Im Vergleich mit den Abschreibungsvergünstigungen zeigt sich hier ein nicht unerheblicher Unterschied. Der Abzugsbetrag von der Steuerbemessungsgrundlage muß bei einer Abschreibung im Umsatzprozeß erwirtschaftet werden, während bei einer Übertragung der Veräußerungsgewinn dem Abzugsbetrag entspricht. Ein Investor, der eine Abschreibungsvergünstigung in vollem Umfang nutzen möchte, benötigt folglich vor der Inanspruchnahme der Förderung einen Gewinn in Höhe der Mehrabschreibung. Zur vollständigen Nutzung eines Übertragungsvorteils reicht es aus, wenn kein Verlust besteht.

Bei einer Übertragung auf ein nicht abnutzbares Wirtschaftsgut wird ebenfalls der Buchwert dieses Wirtschaftsgutes verringert, es darf aber - im Unterschied zu abnutzbaren Gütern - nicht abgeschrieben werden. Eine Nachholwirkung kommt also nicht in den Abschreibungsbeträgen zum Ausdruck. Die stillen Reserven werden erst bei einem erneuten Verkauf des Vermögensobjektes der Besteuerung unterzogen. Wird unterstellt, daß die Anschaffungs- oder Herstel- 
lungskosten dem Verkaufspreis entsprechen, errechnet sich der Barwert durch folgende Formel ${ }^{1}$.

$$
B_{U N}=g_{1} * U-\frac{g_{n} * U}{\left(1+i_{g}\right)^{n-1}}=\frac{\left[g_{1} *\left(1+i_{g}\right)^{n-1}-g_{n}\right] * U}{\left(1+i_{g}\right)^{n-1}}
$$

Die Vergünstigungswirkungen gleichen aufgrund der Progressionsabhängigkeit der Förderung denen der Übertragung auf abnutzbare Güter. ${ }^{2}$ Allerdings ist der Vorteil in der Regel größer als bei einem abnutzbaren Gut:

- Erstens fallen die Nachholwirkungen erst beim Verkauf des Vermögensobjektes an und nicht schon während des Nutzungszeitraums. Aus der Anlage der Liquiditätsvorteile können sich bis zur Liquiditätsbelastung in der Veräußerungsperiode höhere Zinsgewinne bilden.

- Zweitens ist bei nicht abnutzbaren Wirtschaftsgütern die Verweildauer des Vermögensobjektes im Unternehmen normalerweise länger, da zu diesen Gütern im wesentlichen Grundstücke gehören. Die Nachholwirkungen werden dadurch weit in die Zukunft verlagert, was die Zinsgewinne vergrößert.

- Drittens kann es durch eine Übertragung von stillen Reserven zu einer faktisch endgültigen Steuererspamis kommen, wenn das Vermögensobjekt nicht veräußert wird. Dies ist oft bei Grundstücken der Fall. Weil die Nachholwirkungen entfallen, entspricht der Nettoeinkommenseffekt dem Liquiditätsvorteil in der ersten Periode. Beispielsweise wird ein Investor, dessen Erträge einem 60-prozentigen Grenzsteuersatz unterliegen, durch eine Steuerersparnis in Höhe von DM 13.714,- begünstigt (vgl. Tabelle D.10).

\footnotetext{
${ }^{1}$ In der Formel D.5 werden folgende Abkürzungen verwandt:
}

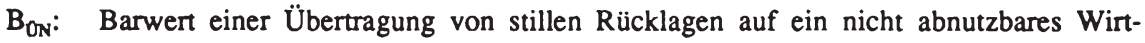
schaftsgut

$g_{\mathbf{n}}$ : Grenzsteuersatz in der Periode $n$

$g_{1}$ : $\quad$ Grenzsteuersatz in der Periode 1

$\mathrm{i}_{\mathrm{g}}$ : versteuerter Kalkulationszinssatz

n: wirtschaftliche Nutzungsdauer

Ü: $\quad$ Übertragungsbetrag

${ }^{2}$ Für die Zeitwerte einer Übertragung von stillen Reserven bedeutet das, solange $g_{1}=g_{a}$ ist, sind diese Null. Wenn $g_{1}>g_{n}$ ist, werden die Zeitwerte positiv und im umgekehrten Fall negativ. Im ersten Fall erfolgt eine Steuerersparnis und im zweiten Fall eine Steuerbelastung. 
- Viertens können bei Grundstücken Wertzuwächse entstehen. Wertzuwächse sind stille Reserven und damit vorläufige Steuerersparnisse.

\section{Zusammenfassung}

Die Übertragung stiller Reserven begünstigt den Investor durch einen Liquiditätsvorteil in der Übertragungsperiode, dem entweder in der Abschreibungsphase oder bei der Veräußerung des Vermögensobjektes Nachversteuerungen gegenüberstehen. Bei konstanten Grenzsteuersätzen beruht der Vorteil auf einem Zinsgewinn. Daneben kann sich infolge einer Veränderung der Steuersätze zusätzlich eine Steuerersparnis oder Steuerbelastung einstellen. Die Vergünstigungswirkungen ähneln demzufolge denen der beschleunigten Abschreibungen.

Die Determinanten der Vergünstigungswirkungen einer Übertragung stiller Reserven auf abnutzbare und nicht abnutzbare Wirtschaftsgüter werden in der Tabelle D.12 zusammengefaßt.

Tabelle D.12: Der Einfluß unterschiedlicher Determinanten auf die Vergünstigungseffekte (Nettobarwerte) der Übertragung von stillen Reserven

\begin{tabular}{|c|c|c|c|c|c|c|}
\hline \multirow[b]{3}{*}{$\begin{array}{l}\text { Ubertragungen stiller } \\
\text { Reserven }\end{array}$} & \multicolumn{6}{|c|}{$\begin{array}{l}\text { Entwicklungsrichtung der Vergünstigungswirkun- } \\
\text { gen (Nettobarwerte) in Abhänglgkeit einer Zu- } \\
\text { nahme folgender Determinanten }\end{array}$} \\
\hline & \multicolumn{2}{|c|}{ Grenzsteuersatz } & \multirow{2}{*}{$\begin{array}{l}\text { wirt- } \\
\text { schaft- } \\
\text { liche } \\
\text { Nut- } \\
\text { zungs- } \\
\text { dauer }\end{array}$} & \multirow{2}{*}{$\begin{array}{l}\text { Kalku- } \\
\text { la- } \\
\text { tions- } \\
\text { zins- } \\
\text { satz }\end{array}$} & \multirow{2}{*}{$\begin{array}{l}\text { Inves- } \\
\text { ti- } \\
\text { tions- } \\
\text { summe }\end{array}$} & \multirow{2}{*}{$\begin{array}{l}\text { Förder- } \\
\text { satz } \\
\text { bzw. } \\
\text {-betrag }\end{array}$} \\
\hline & $\begin{array}{l}\text { in den } \\
\text { Zah- } \\
\text { lungs- } \\
\text { reihen }\end{array}$ & $\begin{array}{l}\text { im Dis- } \\
\text { kontie- } \\
\text { rungs- } \\
\text { faktor }\end{array}$ & & & & \\
\hline $\begin{array}{l}\text { Obertragung auf ein ab- } \\
\text { nutzbares Gut }\end{array}$ & steigt & fällt & steigt & steigt & unabh. & steigt \\
\hline $\begin{array}{l}\text { Obertragung auf ein } \\
\text { nicht abnutzbares Gut }\end{array}$ & steigt & fällt & steigt & steigt & unabh. & steigt \\
\hline
\end{tabular}




\section{Investitionsfreibeträge}

1. Grundzüge und Ausgestaltungselemente von Investitionsfreibeträgen

Investitionsfreibeträge wurden bereits in einigen Staaten als Instrument zur Investitionsförderung eingesetzt. ${ }^{1}$ In der Bundesrepublik Deutschland wurden jedoch mit diesem Instrument noch nie Investitionen gefördert.

Ein Investitionsfreibetrag ${ }^{2}$ ist ein Betrag, der von der Steuerbemessungsgrundlage abgezogen werden darf, wenn eine förderungsfähige Investition vorgenommen wird. Somit setzt diese Förderung eine ausreichend hohe Steuerbemessungsgrundlage voraus. Der Abzug von der Steuerbemessungsgrundlage hat jedoch keinen Einfluß auf den Buchwert des geförderten Investitionsobjektes. Damit werden die Abschreibungsbeträge nicht verändert.

Der Investitionsfreibetrag wird häufig als Zusatz- oder Überabschreibung bezeichnet. Dies ist aus wirkungsanalytischer Sicht zutreffend. Zwischen Abschreibungen und Investitionsfreibeträgen besteht jedoch ein formaler Unterschied. Der Investitionsfreibetrag hat keinen Einfluß auf den Steuerbilanzansatz

${ }^{1}$ In Österreich wurde 1972 ein Investitionsfreibetrag in Höhe von $20 \mathrm{vH}$ der Anschaffungskosten- oder Herstellungskosten von Wirtschaftsgütern des Anlagevermögens eingeführt (§10 EStG). Frankreich gewährt Investoren seit 1979 einen Investitionsfreibetrag von $10 \mathrm{vH}$ der Anschaffungskosten. In Schweden können Unternehmen einen Freibetrag für entnommene Rücklagen in Anspruch nehmen. Dieses Instrument wird dort nur zeitweise und mit unterschiedlichen Fördersätzen eingesetzt. Einzelheiten der Förderungen finden sich bei Ederer, B./Goldmann, W., Steuerliche Investitionsförderung - ein Mittel zur Strukturpolitik? in: Wirtschaft und Gesellschaft, Nr. 2, 1981, S. 115ff; Kupsch-Werner, T., Betriebswirtschaftliche Wirkungsanalyse steuerlicher Investitionshilfen, dargestellt am Beispiel von Bewertungsfreiheit, Mehrfach-AfA und Investitionszulage, a. a. O., S. 197 und Leibfritz, W./ Meurer, C., Steuerliche Investitionsförderung im internationalen Vergleich, a. a. O., S. 59ff.

${ }^{2}$ An dieser Stelle sei noch auf eine Abgrenzung der Investitionsfreibeträge zu den Steuerfreigrenzen hingewiesen. Steuerfreigrenzen führen zu einer Steuerbefreiung, sofern die Steuerbemessungsgrundlage die Freigrenze nicht überschreitet. Wird diese Freigrenze überschritten, erfolgt die Besteuerung der gesamten Steuerbemessungsgrundlage. Das heißt, es gibt keinen Abzug von der Steuerbemessungsgrundlage. Steuerfreibetrag und Steuerfreigrenze sind von ihrer Besteuerungswirkung gleich, solange die Steuerbemessungsgrundlage unter der Freigrenze bleibt. Vgl. Knief, P., Steuerfreibeträge als Instrumente der Finanzpolitik, Köln, Opladen 1968 , S. $14 \mathrm{ff}$. 
des geförderten Investitionsobjektes, insofern ist die Bezeichnung Abschreibung eher irreführend. ${ }^{1}$

Bei der Ausgestaltung von Steuerfreibeträgen gibt es zahlreiche Möglichkeiten:2

- Steuerfreibeträge können so festgelegt werden, daß jeder anspruchsberechtigte Investor einen gleich hohen Freibetrag erhält. Der Umfang der getätigten Investitionen hat bei einem absoluten Freibetrag nur dann eine Bedeutung, wenn die Investitionssumme geringer als die Höhe des Steuerfreibetrages ist. In diesem Fall kann der Investor den Freibetrag nicht vollständig ausschöpfen.

- Desweiteren können auch relative Freibeträge gewährt werden. Relative Freibeträge sind Prozentanteile der Anschaffungs- oder Herstellungskosten einer geförderten Investition, die von der Steuerbemessungsgrundlage abgezogen werden dürfen. In den gesetzlichen Förderbestimmungen wird folglich nur der Fördersatz festgelegt. Denkbar ist auch eine Kombination zwischen einem absoluten Betrag und einem Prozentsatz. So kann ein Prozentanteil der Investitionssumme von der steuerlichen Bemessungsgrundlage abgezogen werden, jedoch darf dieser Freibetrag eine absolute Betragsgrenze nicht überschreiten. Sieht man von einer absoluten Begrenzung der Investitionsfreibeträge $a b$, steigt die Höhe des Freibetrages proportional mit der Höhe der Anschaffungsoder Herstellungskosten.

- Außerdem kann der Gesetzgeber die Investitionsfreibeträge in ihrer Höhe staffeln. Ziel dieser Staffelung ist es, bestimmten Einkommensgruppen unterschiedlich hohe Investitionsfreibeträge zuzumessen. Mit Hilfe von Freibeträgen, die mit der Gewinnhöhe absteigend gestaffelt werden, sollen vor allem kleine und mittlere Unternehmen gefördert werden. ${ }^{3}$ Die Progressionsabhängigkeit der Begünstigung wird durch diese Staffelungsform gemildert. Die

1 Vgl. Mennel. A., Internationaler Vergleich der steuerlichen Abschreibungen und Investitionsvergünstigungen, in: Recht der internationalen Wirtschaft 1976, S. 324.

2 Vgl. Peffekoven, R., Freibetrag oder Steuerkredit? in: Finanzarchiv 1971/72, S. 394f und Knief, $P$., Steuerfreibeträge als Instrumente der Finanzpolitik, a. a. O., S. $38 \mathrm{ff}$.

$3 \mathrm{Vgl}$. Uhlmann, L./Berger, M., Investitionsverhalten und Unternehmensgröße, Berlin, München 1986, S. 149. 
Staffelung der Freibeträge kann nach dem Abatement- oder Partranche-Verfahren erfolgen. Beim Abatement-Verfahren werden absolute Freibeträge vorgegeben, dagegen beim Partranche-Verfahren verschiedene Prozentsätze, die auf die Anschaffungs- oder Herstellungskosten bezogen werden. Mit dem Partranche-Verfahren ist nicht nur eine einkommensabhängige Staffelung der Freibeträge möglich, sondern auch eine, die sich an der Höhe des Investitionsvolumens orientiert. Indem man mit der Höhe der Investitionssumme abnehmende Freibeträge gewährt, kann man diese Förderung auf mittelständische Unternehmen ausrichten. Bei der Staffelung sind Sprungstellen in der Förderung unvermeidbar.

- Die bislang vorgestellten Ausgestaltungsvarianten unterschieden sich in der Art und Weise der Festlegung der Freibetragshöhe. Anstatt den Freibetrag in der Investitionsperiode zu gewähren, kann er auch über mehrere Jahre verteilt werden. Eine Verteilung des Freibetrages über mehrere Jahre macht für den Investor nur dann einen Sinn, wenn seine Steuerbemessungsgrundlage in der Investitionsperiode geringer als der Freibetrag ist. So wurde diese Ausgestaltung beispielsweise zur Förderung neu gegründeter Unternehmen vorgeschlagen. ${ }^{1}$ Im folgenden wird auf diese Ausgestaltungsmöglichkeit nicht weiter eingegangen. ${ }^{2}$

${ }^{1}$ Vgl. Reiter, G., Steuerliche Investitionsförderung zur Rezessionsüberwindung, Frankfurt a. M., Bern, New York, Paris 1988, S. 157.

2 Sofern sich die Verteilung der Investitionsfreibeträge an der Nutzungsdauer orientiert, sind die Nettoeinkommenswirkungen vergleichbar mit denen einer Abschreibung über die Anschaffungs- bzw. Herstellungskosten hinaus. Diese Förderung ist progressionsabhängig; Unternehmen mit geringeren Errrägen werden weniger begünstigt. 
Abbildung D.2: Ausgestaltungsvarianten von Investitionsfreibeträgen

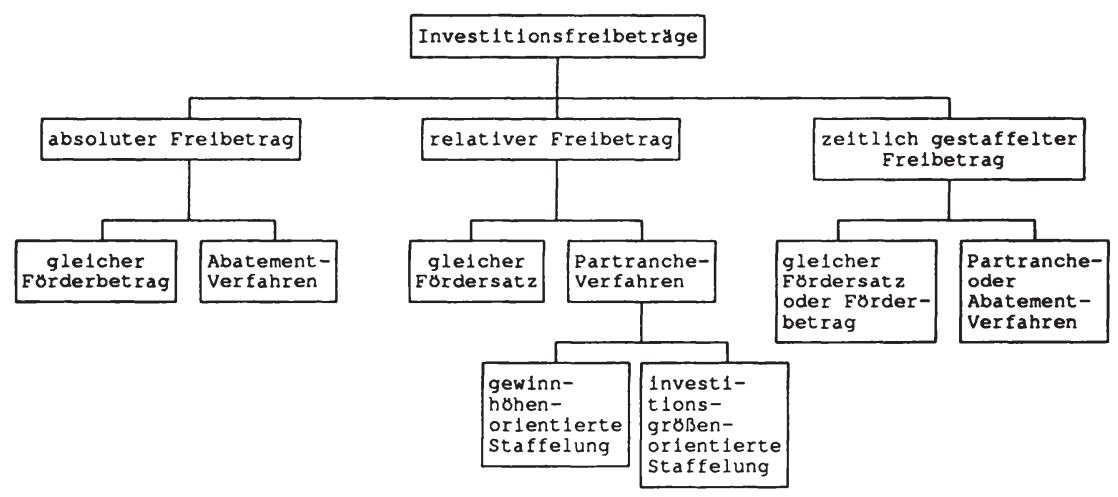

\section{Vergünstigungseffekte der Investitionsfreibeträge}

Es sollen diese unterschiedlichen Freibeträge auf ihre Vergünstigungseffekte untersucht werden. Die Möglichkeit Verluste vor- bzw. zurückzutragen wird dabei nicht berücksichtigt.

Absolute Investitionsfreibeträge reduzieren die ertragsteuerliche Bemessungsgrundlage. Infolgedessen sind die Vergünstigungswirkungen durch den marginalen Ertragsteuersatz bestimmt. Wird unterstellt, daß der Investitionsfreibetrag im Verlauf der ersten Periode beim Investor liquiditätswirksam wird, sind Bar- und Zeitwerte gleich. ${ }^{1}$

${ }^{1}$ In der Formel D.6 werden folgende Abkürzungen verwandt:

$\mathrm{B}_{\mathrm{FB}}$ : Barwert eines absoluten Investitionsfreibetrages

FB: absoluter Investitionsfreibetrag

g: Grenzsteuersatz 
Die Vergünstigungswirkungen steigen sowohl proportional mit der Höhe des absoluten Investitionsfreibetrages als auch der des marginalen Ertragsteuersatzes (vgl. Tabelle D.13). Der Vorteil des Investitionsfreibetrages besteht in einer Steuerersparnis.

Tabelle D.13: Vergünstigungseffekte eines Investitionsfreibetrages von DM 2.500,-

\begin{tabular}{|c|c|c|c|c|c|c|c|c|c|c|c|c|c|}
\hline \multirow{3}{*}{$\begin{array}{l}\text { Pe- } \\
\text { rio- } \\
\text { de } \\
\text { (1) }\end{array}$} & \multirow{3}{*}{$\begin{array}{l}\text { Frei- } \\
\text { be- } \\
\text { trag } \\
\text { in DM } \\
\quad \text { (2) }\end{array}$} & \multicolumn{12}{|c|}{ Vergünstigungswirkungen bei alternativen Grenzsteuersätzen in DM } \\
\hline & & \multicolumn{3}{|c|}{0 \& } & \multicolumn{3}{|c|}{$20 \%$} & \multicolumn{3}{|c|}{$40 \%$} & \multicolumn{3}{|c|}{$60 \%$} \\
\hline & & $2 W$ & BBW & NBW & $2 W$ & BBW & NBW & $2 \mathrm{~W}$ & BBW & NBW & $\mathrm{ZW}$ & BBW & NBW \\
\hline 1 & 2500 & 0 & 0 & 0 & 500 & 500 & 500 & 1000 & 1000 & 1000 & 1500 & 1500 & 1500 \\
\hline \multicolumn{14}{|c|}{$\begin{array}{l}2 W=\text { Zeitwert } \\
\text { BBW }=\text { Bruttobarwert } \\
\text { NBW }=\text { Nettobarwert }\end{array}$} \\
\hline
\end{tabular}

Das Ausmaß der Liquiditätsentlastung ist - gemessen an den beschleunigten $\mathrm{Ab}$ schreibungen - eher gering. Durch eine Sonderabschreibung erhält der Investor eine etwa neunmal so hohe Liquiditätsentlastung in der Förderperiode. Hier zeigt sich ein Nachteil des Investitionsfreibetrages. Weil beim Investitionsfreibetrag keine Nachholwirkungen stattfinden können, kann der Staat - bei gleicher Budgetbelastung - in der Investitionsperiode nur einen erheblich geringeren Liquiditätsvorteil gewähren.

Wenn die Investitionssumme das Ausmaß des Investitionsfreibetrages nicht erreicht, verringern sich die Steuerersparnisse. Der Vorteil bemißt sich dann nicht 
mehr nach der Höhe des absoluten Investitionsfreibetrages, sondern nach der Höhe der Investitionssumme. ${ }^{1}$

(D.7) $\quad B_{F B}=g * I V$ für $I V<F B$

Liegt eine einkommensabhängige Staffelung der absoluten Investitionsfreibeträge nach dem Abatement-Verfahren vor, sind die Vergünstigungswirkungen in zweifacher Weise einkommensabhängig. Einmal bestimmt sich ihre Höhe - wie bei den absoluten Investitionsfreibeträgen - durch die Höhe des Grenzsteuersatzes. Darüber hinaus orientiert sich die Staffelung an der Höhe des Einkommens. Im Regelfall wird eine mit der Höhe des Periodenerfolgs degressive Staffelung vorgenommen. Dies führt für unterschiedliche Ertragssituationen zu einer Nivellierung der Vergünstigungseffekte. Das heißt, dieses Verfahren bewirkt, da $ß$ Investoren mit einem Grenzsteuersatz von 20 und 60 Prozent eine Steuerersparnis von annähernd DM 1.000,- hätten. Ob der absolute Vorteil bei dieser Staffelungsform letztlich mit der Höhe des Einkommens noch zunimmt oder bereits fällt, hängt vom Progressionsanstieg und von der Degression der Freibeträge ab. Innerhalb der Freibetragsintervalle gilt jedoch die Progressionsabhängigkeit der Vorteile aus Investitionsfreibeträgen.

Während bei der Einräumung eines absoluten Investitionsfreibetrages eine Obergrenze - nämlich die der Höhe des absoluten Freibetrages - nicht überschritten werden kann, sind bei der Förderung durch relative Freibeträge grundsätzlich keine Obergrenzen vorhanden. Die Steuerersparnis wächst mit der Höhe des In-

${ }^{1}$ In der Formel D.7 werden folgende Abkürzungen verwandt:

$\mathrm{B}_{\mathrm{FB}}$ : Barwert eines absoluten Investitionsfreibetrages

FB: absoluter Investitionsfreibetrag

g: Grenzsteuersatz

IV: förderungsfähiges Investitionsvolumen 
vestitionsvolumens. In der Formel D. $8^{1}$ wird der Barwert eines relativen Investitionsfreibetrages wiedergegeben. ${ }^{2}$

(D.8)

$$
B_{F R}=g * f_{F R} * I V
$$

Eine einkommensabhängige Staffelung gemäß dem Partranche-Verfahren bewirkt bei einer mit der Einkommenshöhe fallenden Staffelung - wie beim Abatement-Verfahren - eine Nivellierung der Vergünstigungseffekte, wobei diese Wirkungen durch die Abhängigkeit von der Investitionssumme überlagert werden können. Die mit der Höhe des Investitionsvolumens wachsenden Steuerersparnisse können durch eine von der Investitionssumme abhängigen Staffelung der Freibeträge verringert werden.

\section{Zusammenfassung}

Zusammenfassend werden die wesentlichen Determinanten der Einkommenseffekte von Investitionsfreibeträgen in der Tabelle D.14 aufgeführt.

${ }^{1}$ In der Formel D.8 werden folgende Abkürzungen verwandt:

$\mathrm{B}_{\mathrm{FR}}$ : Barwert eines relativen Investitionsfreibetrages

$\mathrm{f}_{\mathrm{FR}}$ : relativer Investitionsfreibetrag

g: Grenzsteuersatz

IV: förderungsfähiges Investitionsvolumen

2 Bei einem relativen Investitionsfreibetrag von 2,5 Prozent und einem Investitionsvolumen von DM 100.000,- entsprechen die Vergünstigungseffekte denen in der Tabelle D.13. 
Tabelle D.14: Der Einfluß unterschiedlicher Determinanten auf die Vergünstigungswirkungen (Nettobarwerte) der Investitionsfreibeträge

\begin{tabular}{|c|c|c|c|c|c|c|}
\hline \multirow[b]{3}{*}{ Investitionsfreibeträge } & \multicolumn{6}{|c|}{$\begin{array}{l}\text { Entwicklungsrichtung der Vergünstigungswirkun- } \\
\text { gen (Nettobarwerte) in Abhängigkeit einer } \mathrm{Zu-} \\
\text { nahme folgender Determinanten }\end{array}$} \\
\hline & \multicolumn{2}{|c|}{ Grenzsteuersatz } & \multirow{2}{*}{$\begin{array}{l}\text { wirt- } \\
\text { schaft- } \\
\text { liche } \\
\text { Nut- } \\
\text { zungs- } \\
\text { dauer }\end{array}$} & \multirow{2}{*}{$\begin{array}{l}\text { Kalku- } \\
\text { la- } \\
\text { tions- } \\
\text { zins- } \\
\text { satz }\end{array}$} & \multirow{2}{*}{$\begin{array}{l}\text { Inves- } \\
\text { ti- } \\
\text { tions- } \\
\text { summe }\end{array}$} & \multirow{2}{*}{$\begin{array}{l}\text { Förder- } \\
\text { satz } \\
\text { bzw. } \\
\text {-betrag }\end{array}$} \\
\hline & $\begin{array}{l}\text { in den } \\
\text { Zah- } \\
\text { lungs- } \\
\text { reihen }\end{array}$ & $\begin{array}{l}\text { im Dis- } \\
\text { kontie- } \\
\text { rungs- } \\
\text { faktor }\end{array}$ & & & & \\
\hline $\begin{array}{l}\text { absoluter Investitions- } \\
\text { freibetrag }\end{array}$ & steigt & unabh. & unabh. & unabh. & unabh. & steigt \\
\hline $\begin{array}{l}\text { relativer Investitions- } \\
\text { freibetrag }\end{array}$ & steigt & unabh. & unabh. & unabh. & steigt & steigt \\
\hline $\begin{array}{l}\text { Investitionsfreibeträge } \\
\text { nach dem Abatement- } \\
\text { Verfahren }\end{array}$ & unbest. & unabh. & unabh. & unabh. & unabh. & steigt \\
\hline $\begin{array}{l}\text { Investitionsfreibeträge } \\
\text { nach dem Partranche- } \\
\text { Verfahren }\end{array}$ & unbest. & unabh. & unabh. & unabh. & unbest. & steigt \\
\hline
\end{tabular}

Die wesentliche Einflußgröße für die Vorteile aus Investitionsfreibeträgen ist wie bei allen anderen Fördermaßnahmen, die an der Steuerbemessungsgrundlage ansetzen, der marginale Ertragsteuersatz.

Die Vorteile bestehen aus keinem Zinsgewinn, sondern aus einer Steuerersparnis. Insofern haben die Investitionsfreibeträge gewisse Gemeinsamkeiten mit den Abschreibungen über die Anschaffungs- oder Herstellungskosten hinaus. 


\section{Investitionsrücklagen \\ 1. Charakterisierung der Investitionsrücklagen}

Offene ${ }^{1}$ Rücklagen, zu denen auch die Investitionsrücklagen zählen, werden im Regelfall aus bereits versteuerten Gewinnen gebildet. Sie sind Bestandteil des Eigenkapitals der Unternehmung. Die Investitionsrücklage bildet hier jedoch eine Ausnahme. Es wird ein Teil des unversteuerten Periodenerfolges in eine Rücklage eingestellt. In der Rücklage ist also ein Steuerersparnisanteil enthalten. Eine steuerfreie Rücklage kann grundsätzlich aus den unversteuerten Gewinnen mehrerer Rechnungslegungsperioden gebildet werden. ${ }^{2}$ Abweichend von anderen Investitionsfördermaßnahmen läßt sich die Investitionsrücklage im Zeitpunkt ihrer Bildung keiner konkreten Investition zurechnen. ${ }^{3}$

Unterläßt eine Unternehmung, die eine steuerfreie Rücklage gebildet hat, nach Ablauf einer bestimmten Frist bzw. Freigabe des bei der Zentralbank stillgelegten Rücklagenbetrages die Vornahme einer Investition, können unterschiedliche Sanktionen vorgesehen sein. Die Rücklage ist in der Regel gewinnerhöhend aufzulösen. Daneben kann auch der Zinsgewinn abgeschöpft werden, indem die Unternehmung den Steueranteil der Rücklage verzinst zurückerstatten muß. ${ }^{4}$ Darüber hinaus kann eine Strafsteuer verhängt werden. Weil der Investor üblicherweise erhebliche Nachteile für die Nichtvornahme einer Investition hinnehmen muß, soll dieses Instrument, obwohl es nicht direkt an einer bestimmten Investition ansetzt, Gegenstand dieser Arbeit sein. Wegen der Sanktionsmechanismen besteht ein gewisser Investitionszwang.

${ }^{1}$ Im Gegensatz zu den stillen Rücklagen, die im Abschnitt D.III behandelt wurden, sind offene Rücklagen aus der Bilanz ersichtlich.

${ }^{2} \mathrm{Vgl}$. Dickertmann, D./Pfeiffer, U., Steuerstundende Investitionsrücklage, Offene Fragen zu ihrer Ausgestaltung, in: Wirtschaftsdienst 1986, S. 412.

3 Vgl. Lehner, G., Die steuerlichen Investitionsförderungssysteme und die Unternehmensbesteuerung in der Bundesrepublik Deutschland, in Schweden, in der Schweiz und in Österreich, Wien 1979, S. 36.

4 Vgl. Wissenschaftlicher Beirat beim Bundesministerium der Finanzen, Gutachten zur Reform der Unternehmensbesteuerung, Bonn 1990, S. 16. 
Der Gesetzgeber kann mit der Gewährung von Investitionsrücklagen unterschiedliche Ziele verfolgen. Abhängig vom wirtschaftspolitischen Ziel kann man zwei Arten von Investitionsrücklagen unterscheiden, die ungebundene und die antizyklische Rücklage. Im Abschnitt V.2 werden die Vergünstigungswirkungen der ungebundenen Investitionsrücklagen und im Abschnitt V.3 die der antizyklischen Investitionsrücklagen untersucht.

\section{Ungebundene Investitionsrücklage}

Eine ungebundene Investitionsrücklage ist dadurch gekennzeichnet, daß ihr auf der Aktivseite der Bilanz kein konkreter Gegenposten entspricht. Demzufolge steht diese Rücklage ungebunden der Gesamtheit aller Aktiva gegenüber. ${ }^{1}$ Mit dieser Rücklage will man vor allem kleine und mittlere Betriebe ${ }^{2}$ und im besonderen auch Innovationen ${ }^{3}$ fördern. Mit der Gewährung einer steuerfreien Rücklage ist die Absicht verbunden, durch ein Ansparen unversteuerter Gewinne die Finanzierung von Investitionen in einer späteren Periode zu erleichtern. Diese Förderung richtet sich also an Unternehmen mit einer diskontinuierlichen Investitionstätigkeit und damit einem ungleichmäßigen Liquiditätsbedarf. ${ }^{4}$ Insgesamt erwartet man eine Verbesserung der technischen Ausstattung und somit eine erleichterte Anpassung an die wirtschaftliche Entwicklung. ${ }^{5}$

${ }^{1}$ Vgl. Dickertmann, D./Pfeiffer, U., Steuerstundende Investitionsrücklage, Offene Fragen zu ihrer Ausgestaltung, in: Wirtschaftsdienst 1986, S. 412.

2 Vgl. Institut "Finanzen und Steuern", Steuerliche Maßnahmen zur Investitionsförderung, Grüner Brief 177, Bonn 1978, S. 84f.

${ }^{3}$ Vgl. Behrens-Ramberg, W., Steuerliche Anreize bei innovativen Investitionen kleiner und mittlerer Betriebe unter vergleichender Berücksichtigung steuerlicher und nichtsteuerlicher Hilfen, Stuttgart 1985, S. 87ff; Sprenger, R. W., Indirekte steuerliche Forschungs- und Innovationsförderung: Reformvorschläge für Klein- und Mittelbetriebe wenig erfolgversprechend, in: Ifo-Schnelldienst, 1977, Heft 24, S. 6.

${ }^{4} \mathrm{Vgl}$. Drees-Behrens, Ch., Der Einfluß von Investitionsfördermaßnahmen auf betriebliche Investitionsentscheidungen, Diss. Münster 1989, S. $155 \mathrm{f}$.

${ }^{5} \mathrm{Vgl}$. Dickertmann, D./Pfeiffer, U., Steuerstundende Investitionsrücklage, Offene Fragen zu ihrer Ausgestaltung, in: Wirtschaftsdienst 1986, S. $411 \mathrm{f}$. 
Die Vergünstigungseffekte einer Investitionsrücklage lassen sich analytisch in die Wirkungen zum Zeitpunkt der Rücklagenbildung und -auflösung aufspalten.

\section{a. Vergünstigungseffekte bei der Bildung einer ungebundenen steuer- freien Rücklage}

Die Zuführung eines Teils des steuerlichen Periodenerfolgs in eine steuerfreie Rücklage bewirkt eine entsprechende Verringerung der ertragsteuerlichen $\mathrm{Be}$ messungsgrundlage. Voraussetzung für die Bildung einer steuerfreien Rücklage ist ein zu versteuernder Gewinn.

Eine steuerfreie Rücklage führt in der Periode der Rücklagenbildung zu einer Steuerersparnis, deren Umfang von der Höhe des marginalen Ertragsteuersatzes und der des Rücklagenbetrages abhängig ist. Mit der Rücklagenbildung wird quasi eine Vorausabschreibung eines in Zukunft anzuschaffenden Investitionsobjektes vorgenommen. Es kommt bereits im Zeitpunkt der Rücklagenbildung zu einer Liquiditätsverbesserung. ${ }^{1}$

$(D .9)$

$$
B_{R B}=g_{1} * R
$$

b. Vergünstigungswirkungen bei der Auflösung einer ungebundenen steuerfreien Rücklage

Die steuerfreie Rücklage ist spätestens nach Ablauf einer gesetzlich bestimmten Zeitspanne oder aus Anlaß der Durchführung einer Investition aufzulösen. Die

${ }^{1}$ In der Formel D.9 werden folgende Abkürzungen verwandt:

$\mathrm{B}_{\mathrm{RB}}$ : Barwert der Bildung einer steuerfreien Rücklage

$\mathrm{g}_{1}$ : $\quad$ Grenzsteuersatz in der Periode 1

R: Rücklagenbetrag 
Art und Weise der Auflösung beeinflußt die Vergünstigungswirkungen. Das heißt, die Vergünstigungswirkungen einer Investitionsrücklage setzen sich aus den Wirkungen bei der Rücklagenbildung und -auflösung zusammen.

Die Investitionsrücklage wird als kumulierte Fördermaßnahme ausgestaltet. Der Gesetzgeber gewährt eine steuerfreie Rücklage, die aus investitionspolitischen Gründen mit einer weiteren Fördermaßnahme - in der Regel einem Investitionsfreibetrag oder einer Sonderabschreibung - verbunden wird.

\section{aa. Steuerfreie Rücklage}

Die steuerfreie Rücklage allein ist - wie noch erläutert wird - zur Förderung von Investitionen wenig geeignet und wird deshalb als Einzelmaßnahme nicht eingesetzt. Sie wird entweder mit einer weiteren Fördermaßnahme kombiniert ${ }^{1}$ oder wird als eine mögliche Sanktion für die Nichtvornahme von Investitionen benutzt. Der Vergünstigungseffekt einer steuerfreien Rücklage kann ein Teileffekt der gesamten Nettoeinkommenswirkungen einer Investitionsrücklage sein.

Die steuerfreie Rücklage wird aufgelöst, indem der Rücklagenbetrag dem zu versteuernden Gewinn zugeschlagen wird. Dadurch steigt die ertragsteuerliche Bemessungsgrundlage in der Auflösungsperiode. Der Umfang der Nachversteuerung bemißt sich nach der Höhe der aufgelösten Rücklage und dem Grenzsteuersatz des Investors in der Auflösungsperiode. Bei konstanten Grenzsteuersätzen

${ }^{1}$ In der Bundesrepublik Deutschland wird die Investitionsrücklage auch zur Förderung der Unternehmen in den neuen Bundesländern eingesetzt. Die Investitionsrücklage wird für Investitionen gewährt, die mit einer Sonderabschreibung gefördert werden ( $\$ 6$ Fördergebietsgesetz). Die Höhe der Rücklagenbildung umfaßt den Sonderabschreibungsbetrag. Voraussetzung für die Rücklagenbildung ist, daß mit der Investition bereits begonnen wurde. Bei dieser Investitionsrücklage spielt das sonst vorherrschende Ansparmotiv keine Rolle. Der Gesetzgeber will die verwaltungsbedingten Verzögerungen bei der Durchführung der Investition auffangen, vgl. Wewers, $O$., Steuerliche Förderinstrumente für die neuen Bundesländer und Berlin - Sonderabschreibungen, Abzugsbeträge und Investitionszulagen, Heidelberg 1991, S. $20 f$. 
entsprechen sich die Steuerersparnisse in der Bildungsperiode und die Nachversteuerungen in der Auflösungsphase; der Zeitwert ist Null. Der Investor erhält einen zinslosen Steuerkredit. Die Barwertformel D. $10^{1}$ beschreibt die Vergünstigungswirkungen der steuerfreien Rücklage.

$$
B_{R}=g_{1} * R-\frac{g_{b+1} * R}{\left(1+i_{g}\right)^{b}}=\frac{\left[g_{1} *\left(1+i_{g}\right)^{b}-g_{b+1}\right] * R}{\left(1+i_{g}\right)^{b}}
$$

Die Vorteile aus dem zinslosen Steuerkredit können wie bei den beschleunigten Abschreibungen

- in einem progressionsabhängigen Liquiditätsvorteil bei der Rücklagenbildung,

- in einem Nettozinsgewinn, der mit der Höhe des Grenzsteuersatzes unterproportional zunimmt,

- und bei variierenden Grenzsteuersätzen in einer progressionsbedingten Steuerersparnis bestehen; es ist aber auch eine Steuermehrbelastung möglich. ${ }^{2}$

Wie bereits erwähnt wurde, bewirkt die steuerfreie Rücklage im Zeitpunkt der Investitionsvornahme ohne ergänzende Maßnahmen einen Liquiditätsentzug. Das heißt, die Liquidität wird in der Investitionsperiode nicht nur durch die Anschaffung oder Herstellung des Investitionsobjektes belastet, sondern zusätzlich durch die Nachversteuerung bei der Auflösung der steuerfreien Rücklage. Da-

${ }^{1}$ In der Formel D.10 werden folgende Abkürzungen verwandt:

$B_{R}$ : Barwert einer steuerfreien Rücklage

b: Rücklagenbildungsdauer

$g_{b}$ : Grenzsteuersatz in der Periode b (Auflösungsperiode)

$\mathrm{g}_{1}$ : $\quad$ Grenzsteuersatz in der Periode 1

$i_{g}$ : versteuerter Kalkulationszinssatz

R: Rücklagenbetrag

t: $\quad$ Periode

2 Ein temporaler Progressionseffekt tritt ein, wenn $g_{1}$ ungleich $g_{b}$ ist. Wenn in der Auflösungsperiode kein Gewinn ausgewiesen wird, unterbleibt eine Nachversteuerung. In diesem Fall entspricht der temporale Progressionseffekt dem Liquiditätsgewinn bei der Rücklagenbildung. Das gilt jedoch nur unter der Voraussetzung, daß kein Verlustvor- oder -rücktrag vorgenommen wird. 
durch dürfte die investitionsfördernde Wirkung der steuerfreien Rücklage gering sein. Aus diesem Grunde muß die steuerfreie Rücklage zur Investitionsförderung mit einer weiteren Fördermaßnahme kombiniert werden.

\section{bb. Auflösung einer steuerfreien Rücklage bei gleichzeitiger Gewährung eines Investitionsfreibetrages}

Der mit einer steuerfreien Rücklage verbundene, investitionspolitisch unerwünschte Liquiditätsentzug bei der Rücklagenauflösung kann durch die Gewährung eines Investitionsfreibetrages vermieden werden.

Die Verbindung der steuerfreien Rücklage mit einem Investitionsfreibetrag führt zu einer faktisch steuerfreien Auflösung der Rücklage. Es unterbleibt nicht nur eine Erhöhung des zu versteuernden Ertrages in der Auflösungsperiode, sondern auch in den Folgeperioden kann es zu keinen Nachversteuerungen kommen. Der Investor darf in vollem Umfang die im Zeitpunkt der Rücklagenbildung erzielten Steuereinsparungen behalten.

\section{cc. Auflösung einer steuerfreien Rücklage bei gleichzeitiger Gewährung einer Sonderabschreibung}

Zur Förderung von Investitionen kann die steuerfreie Rücklage auch mit einer Sonderabschreibung verbunden werden.

Mit der Gewährung einer Sonderabschreibung lassen sich zwar die auflösungsbedingten Liquiditätsbelastungen verhindern, jedoch tangiert die Sonderabschreibung die Abschreibungsbasis des betreffenden Investitionsobjektes. Dadurch verringern sich die jährlichen Abschreibungsbeträge. Es kommt über die Abschreibungsdauer zu Nachversteuerungen. Für das Ausmaß der Vergünstigungseffekte sind mehrere Grenzsteuersätze von Bedeutung. Zunächst erfährt der Investor bei 
Tabelle D.15: Vergünstigungswirkungen einer steuerfreien Rücklage in Höhe von DM 8.987,-, bei deren Auflösung eine Sonderabschreibung gewährt wird

\begin{tabular}{|c|c|c|c|c|c|c|c|c|c|c|c|c|c|c|c|c|c|c|c|}
\hline \multirow{4}{*}{$\begin{array}{l}\text { Pe- } \\
\text { rio- } \\
\text { de } \\
\text { (1) }\end{array}$} & \multirow{4}{*}{$\begin{array}{l}\text { Rück- } \\
\text { lage } \\
\text { und } \\
\text { Nach- } \\
\text { holung } \\
\text { in DM } \\
\text { (2) }\end{array}$} & \multicolumn{18}{|c|}{ Vergünstigungswirkungen bei alternativen Grenzsteuersätzen in DM } \\
\hline & & \multicolumn{12}{|c|}{ konstante Grenzsteuersätze } & \multicolumn{6}{|c|}{ variierende Grenzsteuersätze } \\
\hline & & \multicolumn{3}{|c|}{08} & \multicolumn{3}{|c|}{208} & \multicolumn{3}{|c|}{$40 \%$} & \multicolumn{3}{|c|}{608} & \multicolumn{3}{|c|}{ steigend } & \multicolumn{3}{|c|}{ fallend } \\
\hline & & $2 \mathrm{~W}$ & BBW & NBW & ZW & BBW & NBW & $2 \mathrm{~W}$ & BBW & NBW & $2 W$ & BBW & NBW & $2 \mathrm{~W}$ & BBW & NBW & $2 W$ & BBW & NBW \\
\hline $\begin{array}{r}1 \\
2 \\
3 \\
4 \\
5 \\
6 \\
7 \\
8 \\
9 \\
10\end{array}$ & $\begin{array}{r}8987 \\
0 \\
0 \\
0 \\
0 \\
-1797 \\
-1797 \\
-1797 \\
-1797 \\
-1797\end{array}$ & $\begin{array}{l}0 \\
0 \\
0 \\
0 \\
0 \\
0 \\
0 \\
0 \\
0 \\
0\end{array}$ & $\begin{array}{l}0 \\
0 \\
0 \\
0 \\
0 \\
0 \\
0 \\
0 \\
0 \\
0\end{array}$ & $\begin{array}{l}0 \\
0 \\
0 \\
0 \\
0 \\
0 \\
0 \\
0 \\
0 \\
0\end{array}$ & $\begin{array}{r}1797 \\
0 \\
0 \\
0 \\
0 \\
-359 \\
-359 \\
-359 \\
-359 \\
-359\end{array}$ & $\begin{array}{r}1797 \\
0 \\
0 \\
0 \\
0 \\
-245 \\
-227 \\
-210 \\
-194 \\
-180\end{array}$ & $\begin{array}{r}1797 \\
0 \\
0 \\
0 \\
0 \\
-264 \\
-248 \\
-233 \\
-219 \\
-206\end{array}$ & $\begin{array}{r}3595 \\
0 \\
0 \\
0 \\
0 \\
-719 \\
-719 \\
-719 \\
-719 \\
-719\end{array}$ & $\begin{array}{r}3595 \\
0 \\
0 \\
0 \\
0 \\
-489 \\
-453 \\
-419 \\
-388 \\
-360\end{array}$ & $\begin{array}{r}3595 \\
0 \\
0 \\
0 \\
0 \\
-569 \\
-543 \\
-518 \\
-494 \\
-471\end{array}$ & \begin{tabular}{|r|}
5392 \\
0 \\
0 \\
0 \\
0 \\
-1078 \\
-1078 \\
-1078 \\
-1078 \\
-1078
\end{tabular} & $\begin{array}{r}5392 \\
0 \\
0 \\
0 \\
0 \\
-734 \\
-680 \\
-629 \\
-583 \\
-539\end{array}$ & $\begin{array}{r}5392 \\
0 \\
0 \\
0 \\
0 \\
-921 \\
-893 \\
-865 \\
-838 \\
-812\end{array}$ & \begin{tabular}{|r|}
1797 \\
0 \\
0 \\
0 \\
0 \\
-1078 \\
-1078 \\
-1078 \\
-1078 \\
-1078
\end{tabular} & $\begin{array}{r}1797 \\
0 \\
0 \\
0 \\
0 \\
-734 \\
-680 \\
-629 \\
-583 \\
-539\end{array}$ & $\begin{array}{r}1797 \\
0 \\
0 \\
0 \\
0 \\
-880 \\
-852 \\
-826 \\
-800 \\
-776\end{array}$ & $\begin{array}{r}5392 \\
0 \\
0 \\
0 \\
0 \\
-359 \\
-359 \\
-359 \\
-359 \\
-359\end{array}$ & $\begin{array}{r}5392 \\
0 \\
0 \\
0 \\
0 \\
-245 \\
-227 \\
-210 \\
-194 \\
-180\end{array}$ & $\begin{array}{r}5392 \\
0 \\
0 \\
0 \\
0 \\
-276 \\
-259 \\
-244 \\
-229 \\
-215\end{array}$ \\
\hline$\Sigma=$ & 0 & 0 & 0 & 0 & 0 & 742 & 629 & 0 & 1485 & 1000 & 0 & 2227 & 1063 & -3595 & -1368 & -2337 & 3595 & 4337 & 4169 \\
\hline
\end{tabular}


der Rücklagenbildung eine mit der Höhe des Grenzsteuersatzes steigende Steuerersparnis. In der Abschreibungsphase nehmen die Steuerzahlungen und folglich die Liquiditätsbelastungen mit der Höhe der Grenzsteuersätze zu. Im Unterschied zur steuerfreien Rücklage tritt hier der Liquiditätsentzug nicht in einem Zeitpunkt auf, vielmehr wird er über die Abschreibungsdauer verteilt.

Den Barwert einer steuerfreien Rücklage, die mit einer Sonderabschreibung verbunden wird, zeigt die Formel D.11 ${ }^{1}$.

$$
B_{R S}=g_{1} * R-\sum_{t=b+1}^{b+n} \frac{g_{t} * A K_{t}}{\left(1+i_{g}\right)^{t-1}}
$$

Die Vergünstigungswirkungen gleichen ebenfalls denen der beschleunigten Abschreibungen (vgl. Tabelle D.15):

- Die Nettozinsgewinne nehmen mit der Höhe der Grenzsteuersätze unterproportional zu.

- Außerdem können sich progressionsbedingte Steuermehrbelastungen oder Steuerersparnisse ergeben.

- Der grundlegende Unterschied zur Sonderabschreibung ist, daß sich durch die Kumulation mit einer steuerfreien Rücklage der Zeitraum, in dem Zinsgewinne entstehen können, um die Rücklagenbildungsdauer verlängert.

${ }^{1}$ In der Formel D.11 werden folgende Abkürzungen verwandt:

$\mathrm{AK}_{\mathrm{t}}$ : Kürzung des Normalabschreibungsbetrages in der Periode $\mathrm{t}$

$\mathrm{B}_{\mathrm{RSA}}$ : Barwert einer steuerfreien Rücklage und Gewährung einer Sonderabschreibung bei der Rücklagenauflösung

b: Rücklagenbildungsdauer

$g_{1}$ : Grenzsteuersatz in der Periode 1

g: $\quad$ Grenzsteuersatz in der Periode $t$

$\mathrm{i}_{\mathrm{g}}: \quad$ versteuerter Kalkulationszinssatz

$\mathrm{n}$ : wirtschaftliche Nutzungsdauer

R: Rücklagenbetrag

t: $\quad$ Periode 


\section{Die antizyklisch ausgerichtete Investitionsrücklage und deren Vergün- stigungseffekte}

Investitionsrücklagen haben in einigen Ländern als antizyklisches Konjunkturstabilisierungsinstrument eine lange Tradition. ${ }^{1}$ Diese Investitionsrücklagen beruhen ebenfalls auf den oben dargelegten Ausgestaltungselementen, sie wurden aber in einigen Details der konjunkturpolitischen Zielsetzung angepaßt, wodurch sich auch die Vergünstigungswirkungen verändern.

Die konjunkturpolitische Ausrichtung basiert auf dem Gedanken, Teile des unversteuerten Gewinns in der Hochkonjunkturphase in eine Konjunkturrücklage einzustellen, um sie in der Rezession zur Finanzierung von Investitionen einzusetzen. Durch die steuerfreie Rücklagenbildung haben die Unternehmen einen Liquiditätszuwachs in Höhe der Steuerersparnis. Um auszuschließen, daß dieser Mittelzuwachs zusätzliche Investitionen in der Boomphase nach sich zieht und eine konjunkturelle Überhitzung bewirkt, wird die Rücklage im Zeitpunkt ihrer Bildung zwingend außerhalb der Unternehmung, im Regelfall auf einem Sperrkonto bei der Zentralbank ${ }^{2}$, gebunden. In der Rezession erfolgt die Freigabe der Mittel, wodurch die Finanzierungsmöglichkeiten verbessert werden sollen. ${ }^{3}$ Zur steuerfreien Rücklage werden im Investitionszeitpunkt zusätzliche Anreize in Form von Sonderabschreibungen oder Investitionsfreibeträgen gewährt.

${ }^{1}$ Beispielsweise wurden in Österreich, Schweiz, Finnland und Schweden antizyklische Investitionsrücklagen gewährt. Vgl. Ederer,B./Goldmann, W.,Steuerliche Investitionsförderung - ein Mittel zur Strukturpolitik? in: Wirtschaft und Gesellschaft, Nr. 3, 1981, S. 112ff; Lacina, $F$., Ausbau oder Umbau der steuerlichen Investitionsförderung? in: Wirtschaft und Gesellschaft, Nr. 3, 1976, S. 19ff; Leibfritz, W.IMeurer, C., Steuerliche Investitionsförderung im internationalen Vergleich, a. a. O., S. 58f; Pfaffenberger, W., Investitionssteuerung mit Hilfe steuerfreier Rücklagen - neue konjunkturpolitische Instrumente in Schweden und in der Schweiz, a. a. O., S. 14-21.

${ }^{2}$ Vgl. Cansier, D./Wilk, E., Steuerfreie Rücklagen als konjunkturpolitisches Instrument Das "Schwedische Modell", in: WSI-Mitteilungen 1977, S. 689f.

3 In Schweden wurde die Freigabe von Teilen der gesperrten Rücklage nicht nur aus konjunkturpolitischen, sondern seit den 60-er Jahren auch aus sektoral- und regionalpolitischen Erwägungen erteilt, vgl. Strömberg, D., Die schwedischen Erfahrungen, in: Wirtschaftsdienst 1975 , S. $607 f$. 
Abweichend von der ungebundenen Investitionsrücklage werden hier die Vergünstigungswirkungen in der Bildungsperiode nicht mehr ausschließlich durch die Höhe des Grenzsteuersatzes und der des Rücklagenbetrages bestimmt. Der Einfluß des Grenzsteuersatzes wird um die Höhe des Anteils (e), der bei der Zentralbank gesperrt wird, verringert. Dadurch wird der im Unternehmen verbleibende Steuererspamisanteil kleiner, oder es erfolgt sogar ein Nettoliquiditätsentzug. ${ }^{1}$

$$
B_{R B X}=\left(g_{1}-e\right) * R
$$

Ein Nettoentzug von Liquidität ${ }^{2}$ wird allerdings nur dann eintreten, wenn der sperrpflichtige Rücklagenanteil den Steuerersparnisanteil der Rücklage übersteigt. Das heißt, solange (e) größer als $\left(g_{1}\right)$ ist. Wenn die Höhe des Anteils, der bei der Zentralbank gesperrt wird, für alle Unternehmen gleich ist und der Anteil unter dem Spitzensteuersatz liegt, hat das unterschiedliche Liquiditätswirkungen. Bei den Unternehmen, deren Grenzsteuersatz den sperrpflichtigen Rücklagenanteil übertrifft, wird der Liquiditätsvorteil nicht vollständig entzogen, aber sehr wohl bei den Unternehmen, deren Grenzsteuersatz unterhalb des sperrpflichtigen Rücklagenanteils liegt. Ertragsschwache Unternehmen würden auf diese Weise Liquidität verlieren, während ertragsstärkere Unternehmen entlastet werden.

Fraglich dürfte sein, ob sich die Liquiditätsausstattung - selbst wenn der gesamte Rücklagenbetrag bei der Zentralbank stillgelegt wird - verschlechtert und eine Konjunkturdämpfung eintritt. Bei der Bildung einer steuerfreien Rücklage entsteht ein Guthaben bei der Zentralbank, das ein Eigenkapitalbestandteil ist und

${ }^{1}$ In der Formel D.12 werden folgende Abkürzungen verwandt:

$\mathrm{B}_{\mathrm{RBK}}$ : Barwert der Bildung einer Konjunkturrücklage

e: Rücklagenanteil, der bei der Zentralbank stillgelegt wird

$\mathrm{g}_{1}$ : $\quad$ Grenzsteuersatz in der Periode 1

R: Rücklagenbetrag

2 Ein Beispiel für eine Investitionsrücklage, die der Unternehmung Liquidität im Zeitpunkt der Rücklagenbildung entzieht, ist die Investitionsrücklage in der Schweiz, vgl. Helms, $V$. Investitionsfond und Lenkung privater Investitionen, Darmstadt 1976, S. 36. 
als Kreditgrundlage für Investitionen genutzt werden kann. Das Unternehmen kann sich also die notwendige Liquidität über Kredite verschaffen. Eine steuerfreie Rücklage zu bilden und zugleich einen Kredit aufzunehmen, ist für eine Unternehmung dann interessant, wenn die Fremdkapitalkosten geringer sind als die Erträge, vor allem der Steuerspareffekt der Investitionsrücklage.

Wird dem Investor bei der Rücklagenauflösung ein Investitionsfreibetrag eingeräumt, so bekommt er bei der Vornahme einer Investition den außerhalb der Unternehmung gebundenen Anteil zurück, ohne daß sich seine gegenwärtige oder zukünftige Steuerbemessungsgrundlage erhöht. Die nachfolgende Formel zeigt den Barwert der antizyklischen Rücklage, bei deren Auflösung ein Investitionsfreibetrag gewährt wird. ${ }^{1}$

$$
B_{\text {RIFK }}=\left(g_{1}-e\right) * R+\frac{e * R *\left(1+r_{g}\right)^{b}}{\left(1+i_{g}\right)^{b}}
$$

Aus einer steuerfreien Rücklage in Verbindung mit einem Investitionsfreibetrag können folgende Nettoeinkommenswirkungen entstehen:

- Die Liquiditätsaustattung wird durch den ausbezahlten Rücklagenanteil in der Investitionsperiode verbessert.

- Darüber hinaus kann das Guthaben bei der Zentralbank verzinst werden. ${ }^{2}$

${ }^{1}$ In der Formel D.13 werden folgende Abkürzungen verwandt:

$\mathrm{B}_{\mathrm{RIFK}}$ : Barwert einer Konjunkturrücklage und Gewährung eines Investitionsfreibetrages bei der Rücklagenauflösung

b: Rücklagenbildungsdauer

e: Rücklagenanteil, der bei der Zentralbank stillgelegt wird

$\mathrm{g}_{1}$ : $\quad$ Grenzsteuersatz in der Periode 1

$\mathrm{i}_{\mathrm{g}}$ : $\quad$ versteuerter Kalkulationszinssatz

$\mathrm{R}: \quad$ Rücklagenbetrag

r: $\quad$ Zinssatz für den Anteil, der bei der Zentralbank stillgelegt wird

2 In Schweden wird der gesperrte Anteil nicht verzinst, vgl. Helms, $V$. Investitionsfond und Lenkung privater Investitionen, a. a. O., S. 35. Eine Verzinsung wird beispielsweise erreicht, wenn die Unternehmen - wie bei der schweizerischen Regelung - gezwungen werden, die Rücklage in Form von verzinslichen und nicht veräußerbaren Staatsschuldtiteln zu halten. vgl. Pfaffenberger, $W$., Investitionssteuerung mit Hilfe steuerfreier Rücklagen - neue konjunkturpolitische Instrumente in Schweden und in der Schweiz, a. a. O., S. 20. 
- Die eventuellen Zinserträge für dieses Guthaben können sowohl steuerfrei als auch steuerbar gewährt werden.

- Der rückgewährte Rücklagenanteil ist bei der Berechnung des Barwertes abzudiskontieren. Der Investor kann über den stillgelegten Rücklagenbetrag zum Zeitpunkt der Rücklagenbildung nicht verfügen. Deshalb ist für den Investor die Investitionsrücklage zum Zeitpunkt der Rücklagenbildung weniger wert. Er muß seinen Liquiditätsbedarf bei der Rücklagenbildung - anstatt mit dem stillgelegten Rücklagenbetrag - durch die Aufnahme von Fremdkapital oder den Einsatz von Eigenkapital decken. Dies führt zu Zinsaufwendungen oder entgangenen Zinserträgen. Zinsaufwendungen sind von der Steuerbemessungsgrundlage abzugsfähig. Entgangene Zinserträge verhindern eine Erhöhung der Steuerbemessungsgrundlage. Beide Finanzierungsformen verringern die Steuerbemessungsgrundlage, was in der Formel D.13 durch den Grenzsteuersatz im Abdiskontierungssatz ausgedrückt wird.

Die Vergünstigungswirkungen von ungebundener und antizyklischer Investitionsrücklage können sich durch den Zinssatz für das Guthaben bei der Zentralbank und die Steuerbarkeit der Zinserträge unterscheiden.

- Ist der Abdiskontierungszinssatz (i) größer als der Zinssatz (r), der für die Anlage bei der Zentralbank gewährt wird, sinkt der Barwert - gegenüber einer ungebundenen Rücklage - und im umgekehrten Fall steigt er.

- Außerdem kommt es darauf an, ob die etwaigen Zinserträge aus der Anlage bei der Zentralbank steuerbar sind oder nicht. Steuerfreie Zinserträge führen zu einer entsprechend höheren Begünstigung, wobei der Vorteil mit der Höhe des Grenzsteuersatzes wächst.

Wenn bei der Auflösung der Investitionsrücklage eine Sonderabschreibung gewährt wird, kann es - im Unterschied zum Investitionsfreibetrag - in der Abschreibungsphase zu Nachversteuerungen kommen, so daß neben dem Liquiditätsvorteil ein Zinsgewinn entsteht. Außerdem ist hier eine zusätzliche progressionsbedingte Steuerersparnis möglich. Die Rücklage wird in der Hochkonjunktur bei zumeist hohen Steuersätzen gebildet. Bei deren Auflösung in der Rezes- 
sion können die Erträge der geförderten Unternehmung geringeren Grenzsteuersätzen unterliegen. Dies gilt vor allem auch für den Beginn der Nachversteuerungsphase, so daß es unter diesen Umständen zu progressionsbedingten Steuereinsparungen kommt. Die Formel D. $14^{1}$ zeigt die Vergünstigungswirkungen dieser Investitionsrücklage.

$$
B_{R S A X}=\left(g_{1}-e\right) * R+\frac{e * R *\left(1+r_{g}\right)^{b}}{\left(1+i_{g}\right)^{b}}-\sum_{t=b+1}^{b+n} \frac{g_{t} * A K_{t}}{\left(1+i_{g}\right)^{t-1}}
$$

Auch hier wird deutlich, daß der entscheidende Unterschied zwischen der zum Zeitpunkt der Rücklagenbildung frei verfügbaren und der gebundenen Rücklage im Anteil der gesperrten Rücklage (e), ihrer möglichen Verzinsung (r) und der eventuellen Besteuerung der Zinserträge besteht.

\section{Zusammenfassung}

Die Investitionsrücklage wird zur Förderung von Investitionen als kumuliertes Förderinstrument eingesetzt. Eine steuerfreie Rücklage als Einzelmaßnahme führt in der Investitionsperiode zu einer erfolgswirksamen Auflösung und daraus folgend zu einer Liquiditätsbelastung. Deshalb kombiniert man die steuerfreie Rücklage zur Förderung von Investitionen mit einer Sonderabschreibung oder einem Investitionsfreibetrag.

${ }^{1}$ In der Formel D.14 werden folgende Abkürzungen verwandt:

$\mathrm{AK}_{\mathrm{i}}$ : Kürzung des Normalabschreibungsbetrages in der Periode $\mathrm{t}$

$\mathrm{B}_{\text {RSAK}}$ : Barwert einer Konjunkturrücklage und Gewährung einer Sonderabschreibung bei der Rücklagenauflösung

b: Rücklagenbildungsdauer

e: Rücklagenanteil, der bei der Zentralbank stillgelegt wird

$\mathrm{g}_{1}$ : $\quad$ Grenzsteuersatz in der Periode 1

$\mathrm{i}_{\mathrm{g}}$ : versteuerter Kalkulationszinssatz

n: wirtschaftliche Nutzungsdauer

R: $\quad$ Rücklagenbetrag

r: $\quad$ Zinssatz für den Anteil, der bei der Zentralbank stillgelegt wird

t: $\quad$ Periode 
Einige bedeutende Einflußfaktoren auf die Vergünstigungseffekte werden in der Tabelle D.16 zusammengefaßt.

Tabelle D.16: Der Einfluß unterschiedlicher Determinanten auf die Vergünstigungswirkungen (Nettobarwerte) verschiedener Investitionsrücklagen

\begin{tabular}{|c|c|c|c|c|c|c|}
\hline \multirow[b]{3}{*}{ Investitionsrücklagen } & \multicolumn{6}{|c|}{$\begin{array}{l}\text { Entwicklungsrichtung der Vergünstigungswirkun- } \\
\text { gen (Nettobarwerte) in Abhängigkeit einer Zu- } \\
\text { nahme folgender Determinanten }\end{array}$} \\
\hline & \multicolumn{2}{|c|}{ Grenzsteuersatz } & \multirow{2}{*}{\begin{tabular}{|l|} 
wirt- \\
schaft- \\
liche \\
Nut- \\
zungs- \\
dauer \\
\end{tabular}} & \multirow{2}{*}{$\begin{array}{l}\text { Kalku- } \\
\text { la- } \\
\text { tions- } \\
\text { zins- } \\
\text { satz }\end{array}$} & \multirow{2}{*}{$\begin{array}{l}\text { Inves- } \\
\text { ti- } \\
\text { tions- } \\
\text { summe }\end{array}$} & \multirow{2}{*}{$\begin{array}{l}\text { Förder- } \\
\text { satz } \\
\text { bzw. } \\
\text {-betrag }\end{array}$} \\
\hline & $\begin{array}{l}\text { in den } \\
\text { Zah- } \\
\text { lungs- } \\
\text { reihen }\end{array}$ & $\begin{array}{l}\text { im Dis- } \\
\text { kontie- } \\
\text { rungs- } \\
\text { faktor }\end{array}$ & & & & \\
\hline steuerfreie Rücklage & steigt & fällt & unabh. & steigt & unabh. & steigt \\
\hline $\begin{array}{l}\text { steuerfreie Rücklage, } \\
\text { bei deren Auflösung ein } \\
\text { Investitionsfreibetrag } \\
\text { gewährt wird }\end{array}$ & steigt & unabh. & unabh. & unabh. & unabh. & steigt \\
\hline $\begin{array}{l}\text { steuerfreie Rücklage, } \\
\text { bei deren Auflösung } \\
\text { eine Sonderabschreibung } \\
\text { gewährt wird }\end{array}$ & steigt & fällt & steigt & steigt & unabh. & steigt \\
\hline $\begin{array}{l}\text { antizyklisch ausgerich- } \\
\text { tete Investitionsrück- } \\
\text { lage (bei der Auflösung } \\
\text { wird ein Investitions- } \\
\text { freibetrag gewährt) }\end{array}$ & steigt & fällt & unabh. & fällt & unabh. & steigt \\
\hline $\begin{array}{l}\text { antizyklisch ausgerich- } \\
\text { tete Investitionsrück- } \\
\text { lage (bei der Auflösung } \\
\text { wird eine Sonderab- } \\
\text { schreibung gewährt) }\end{array}$ & steigt & fällt & steigt & steigt & unabh. & steigt \\
\hline
\end{tabular}

Die Vergünstigungswirkungen aller Investitionsrücklagen werden von der Höhe des Grenzsteuersatzes bestimmt. Die Vorteile steuerfreier Rücklagen beruhen bei konstanten Grenzsteuersätzen auf einem Zinsgewinn. Wenn jedoch bei der Auflösung der Rücklage ein Investitionsfreibetrag gewährt wird kommt es zu einer Steuerersparnis.

Die antizyklische Investitionsrücklage ruft ähnliche Vergünstigungswirkungen hervor wie die ungebundene Investitionsrücklage. Unterschiedliche Nettoeinkommenswirkungen sind einmal vom gesperrten Anteil, dessen Verzinsung und einer 
möglichen Besteuerung der Verzinsung abhängig. Eine zweite wesentliche Abweichung beruht auf den verschiedenen Liquiditätswirkungen. Die frei verwendbare Investitionsrücklage führt zu einer Liquiditätsentlastung im Jahr der Rücklagenbildung, demgegenüber verbessert die antizyklische Rücklage die Liquidität im Investitionszeitpunkt.

\section{Vergünstigungswirkungen steuerlicher Investitionsfördermaßnahmen unter Berücksichtigung eines intertemporalen Verlustausgleichs}

Im Rahmen der Analyse der Vergünstigungswirkungen steuerlicher Investitionsfördermaßnahmen ${ }^{1}$ zeigte sich, daß Unternehmen, die in den Förderperioden keinen steuerpflichtigen Periodenüberschuß erwirtschaften, aus einer steuerlichen Investitionsfördermaßnahme nicht begünstigt werden. Dies ist darauf zurückzuführen, daß durch eine steuerliche Investitionsförderung die ertragsteuerliche Bemessungsgrundlage gekürzt wird. Für ein Verlustunternehmen erhöht sich hierdurch der aktuelle Verlust. Ähnliches gilt auch, wenn der Förderbetrag eine positive Steuerbemessungsgnundlage übersteigt. Die inanspruchgenommene steuerliche Investitionsfördermaßnahme verursacht dann in Höhe der Differenz zwischen dem Förderbetrag und der Steuerbemessungsgrundlage einen Verlust.

\section{Begriff und Begründung eines intertemporalen Verlustausgleichs}

Im deutschen - wie größtenteils auch im ausländischen Steuerrecht ${ }^{2}$ - existieren Verlustausgleichsregelungen. Ohne auf die detaillierte Ausgestaltung dieser

${ }^{1}$ Unter steuerlichen Fördermaßnahmen werden im folgenden nur jene Investitionsförderinstrumente subsumiert, die eine Kürzung der ertragsteuerlichen Bemessungsgrundlage herbeiführen.

${ }^{2}$ Vgl. Zierlinger, S., Die steuerliche Regelung der Belastung gewerblicher Unternehmen bei geringer Rentabilität und Verlusten. Ein Beitrag zur Unternehmensbesteuerung in der Bundesrepublik Deutschland, in den USA und in Japan, Diss. Mannheim 1985, S. 275, Tabelle 7. 
Regelungen einzugehen, wird allgemein unter einem intertemporalen Verlustausgleich die Möglichkeit verstanden, Verluste aus der aktuellen Periode mit den Überschüssen vergangener oder zukünftiger Perioden zu verrechnen. Der interperiodische Verlustausgleich setzt sich folglich aus zwei Maßnahmen, dem Verlustvortrag und dem Verlustrücktrag, zusammen. Die Länge des Verlustrückund -vortragszeitraums als auch der Umfang der zurück- oder vortragbaren Verluste ist in der Regel begrenzt. Der intertemporale Verlustausgleich kann bei den einzelnen Steuern unterschiedlich geregelt sein. ${ }^{1}$ Außerdem kann der Rückbzw. Vortrag von Verlusten aus investitionsfördernden Maßnahmen durch eine Verlustklausel $^{2}$ ausgeschlossen sein. ${ }^{3}$ Eine Verlustklausel verhindert also, daß Verlustunternehmen über einen Verlustrück- oder -vortrag in den Genuß einer steuerlichen Förderung kommen können.

Für den intertemporalen Verlustausgleich im Steuerrecht sprechen vor allem steuersystematische Gründe. In der Abschnittsbesteuerung - der Einteilung in Wirtschaftsjahre - wird ein Verstoß gegen die Steuergerechtigkeit gesehen. Diese willkürliche Zerlegung des Wirtschaftsprozesses in Abschnitte führt zu einer Diskriminierung bei schwankenden Erträgen. ${ }^{4}$ Steuerlich gerechter sei es infolgedessen, eine Durchschnittsbesteuerung über die Lebensdauer der Unternehmung vorzunehmen. Jedoch stehen der Verwirklichung einer Durchschnittsbesteuerung vor allem auch Schwierigkeiten bei der verwaltungstechnischen

${ }^{1}$ In der Bundesrepublik Deutschland besteht keine Verlustrücktragsmöglichkeit bei der Gewerbesteuer. Diese Beschränkung ist darauf zurückzuführen, daß den Gemeinden eine mit dem Verlustrücktrag verbundene finanzielle Belastung nicht aufgebürdet werden soll.

${ }^{2}$ Hinter der Verlustklausel steht das wirtschaftspolitische Bestreben, nur wirtschaftlich gesunde Unternehmen zu fördern und damit eine Fehlallokation von Kapital zu verhindern. $\mathrm{Da}$ auch ein Verlustunternehmen nicht grenzenlos Verluste ausgleichen kann, erscheint eine solche Klausel beispielsweise bei einer konjunkturpolitischen Förderung eher fragwürdig.

3 In $\S 7$ a Abs. 6 EStG von 1975 wurde die Vornahme eines Verlustrücktrages ausgeschlossen, wenn der Verlust durch die Inanspruchnahme einer erhöhten Absetzung oder Sonderabschreibung entstanden ist. $28 \mathrm{ff}$.

${ }^{4}$ Vgl. Karsten, J.-F., Die steuerliche Behandlung gewerblicher Verluste, Berlin 1958, S. 
Durchführbarkeit gegenüber. ${ }^{1}$ Demnach wird im intertemporalen Verlustausgleich ein Ersatz für eine Durchschnittsbesteuerung gesehen. ${ }^{2}$ Er ist zwar nicht in der Lage, eine echte Durchschnittsbesteuerung über die gesamte Lebensdauer der Unternehmung herbeizuführen, ${ }^{3}$ jedoch kann er die Auswirkungen der Abschnittsbesteuerung lindern.

Dem intertemporalen Verlustausgleich und im besonderen dem Verlustrücktrag schreiben einige Autoren zumindest eine geringe Wirkung auf die Investitionen zu. Vor allem wird auf die Bedeutung des Verlustrücktrags für kleine und mittlere Unternehmen in der Rezession hingewiesen. ${ }^{4}$ Ebenso wird dem Verlustausgleich eine investitionsfördernde Rolle bei Strukturkrisen beigemessen. ${ }^{5}$ Auch bei der Einführung der Verlustrücktragsregelung in das deutsche Steuerrecht im Jahre 1976 wurden wirtschaftspolitische Argumente angeführt. ${ }^{6}$ Nach der Definition von Investitionsförderungsmaßnahmen, die dieser Arbeit zugrunde gelegt wurde, ist jedoch der interperiodische Verlustausgleich keine investitionsfördernde Maßnahme, weil die direkte Verbindung zwischen dem Verlustausgleich und einem Investitionsvorhaben fehlt.

${ }^{1}$ Vgl. Schick, W., Der Verlustrücktrag, München 1976, S. $14 \mathrm{ff}$.

$2 \mathrm{Vgl}$. Hackmann, R., Interperiodische Durchschnittsbesteuerung des Einkommens, in: Finanzarchiv 1975/76, S. 10f.

${ }^{3}$ Erstens hält eine Verlustausgleichsregelung an der Abschnittsbesteuerung fest, wenn ein Ausgleichszeitraum vorgegeben wird. Der Besteuerungsabschnitt wird lediglich ausgedehnt. Zweitens würde eine Durchschnittsbesteuerung nicht nur eine Verrechnung von Verlusten und Erträgen, sondern auch von unterschiedlich hohen Erträgen verschiedener Rechnungslegungsperioden erfordern.

${ }^{4}$ Vgl. Melcher, G. H., Die Eignung von Investitionszulage, Sonderabschreibung und Verlustrücktrag für die Zwecke der Konjunkturbelebung, in: Wirtschaftswissenschaftliches Studium 1975, S. 189; Orth, M., Interperiodische Verlustkompensation im Gewerbesteuerrecht, Frankfurt a. M., Bern, Cirencester 1980, S. 108f; Reiter, G., Steuerliche Investitionsförderung zur Rezessionsüberwindung, a. a. O., S. 179ff.

5 Vgl. Stein, H.-G., Steuerlicher Verlustausgleich und Strukturwandel der Unternehmen, in: Zeitschrift für betriebswirtschaftliche Forschung 1983, S. 33ff.

6 Vgl. Barth, K., Der Verlustrücktrag vor der Tür, in: Wirtschaftsdienst 1976, S. 82f. 


\section{Der Einfluß des interperiodischen Verlustausgleichs auf die Vergün- stigungswirkungen steuerlicher Investitionsfördermaßnahmen}

Wie oben bereits begründet wurde, werden die Verlustausgleichsregelungen nicht als investitionsfördernde Maßnahme betrachtet, sondern als einen aus steuersystematischen Gründen notwendigen Bestandteil des Steuersystems. Insofern wird hier auch nicht der Frage nachgegangen, welche Vergünstigungswirkungen der intertemporale Verlustausgleich als Investitionsfördermaßnahme beim Steuerpflichtigen hervorruft. ${ }^{1}$ Es ist hier zu untersuchen, ob ein Verlustunternehmen durch einen interperiodischen Verlustausgleich in den Genuß eines Nettoeinkommensvorteils aus einer steuerlichen Investitionsfördermaßnahme kommen kann. Bei den folgenden Überlegungen wird ein allgemeiner Verlustausgleich unterstellt. Auf die detaillierten Ausgestaltungen konkreter Verlustausgleichsregelungen mit ihren spezifischen Wirkungen wird nicht eingegangen. ${ }^{2}$

\section{a. Vergünstigungseffekte investitionsfördernder Maßnahmen unter Zur- hilfenahme eines Verlustrücktrags}

Eine Unternehmung kann die Verluste aus einer steuerlichen Fördermaßnahme zurücktragen, wenn sie in einem oder in mehreren der vorangegangenen Jahre einen positiven steuerlichen Periodenerfolg erwirtschaften konnte.

Unterstellt man, daß eine Unternehmung die Verluste der gegenwärtigen Periode mit denen der vorletzten Periode aufrechnen kann, wird die positive Steuerbemessungsgrundlage der vorletzten Periode durch die Verrechnung mit dem Verlust der aktuellen Periode gekürzt. Der Vorteil, der dem Investor entsteht, muß

${ }^{1}$ Der Barwert eines Verlustrücktrags wird bei Scherrer, G., Zum Einfluß eines Verlustrücktrages auf die unternehmerische Investitionsentscheidung, in: Albach, H./Simon, H. (Hrsg.), Investitionstheorie und Investitionspolitik privater und öffentlicher Unternehmen, Wiesbaden 1976, S. 371-389, untersucht.

2 Insofern wird im folgenden unterstellt, daß für alle berücksichtigten Ertragsteuern die gleichen Verlustausgleichsregelungen bestehen. 
folglich von der Höhe des Grenzsteuersatzes vor Inanspruchnahme des Verlustrücktrages abhängen. Daraus ergibt sich für die Vergünstigungswirkungen aus der betreffenden Investitionsfördermaßnahme, daß deren Höhe durch den Grenzsteuersatz des vorletzten Jahres bestimmt werden. Neben dem Grenzsteuersatz kommt auch dem Umfang der aufrechenbaren Verluste eine wichtige Rolle zu. Je mehr Verluste mit den vorangegangenen Überschüssen verrechnet werden können, desto höher sind die Vergünstigungswirkungen.

Wurde der Verlust mit den Erträgen mehrerer Jahre aufgerechnet, so errechnet sich der Vorteil aus den Grenzsteuersätzen der Perioden, in denen aufgerechnet wurde, und dem Umfang, der in den jeweiligen Perioden ausgeglichenen Verluste. Wenn von der verfahrenstechnischen Seite abgesehen wird, fallen die Verlustentstehung und die Verlustberücksichtigung zusammen. Der Investor kommt zu einer Steuerrückerstattung und damit zu einem Liquiditätsvorteil in der Förderperiode. ${ }^{1}$

Diese Überlegungen sind in der Barwertformel D. $15^{2}$ zusammengefaßt. Ein Verlust aus einer Fördermaßnahme, die über $n$ Perioden Einfluß auf die Einkommensströme hat, soll um maximal w Perioden zurückgetragen werden können.

1 Es gibt zwei Ausgestaltungsmöglichkeiten für die Steuerrückerstattung nach einem Verlustausgleich. Der Steuererstattungsbetrag kann vom Unternehmen selbst von der Steuervorauszahlung abgezogen werden, was eine sofortige Liquiditätswirksamkeit mit sich bringt. Eine zweite Möglichkeit besteht darin, die Rückerstattung nach einem vorausgehenden Antragsverfahren durchzuführen, wodurch Verzögerungen bis zu zwei Jahren auftreten können, vgl. Reiter, G., Steuerliche Investitionsförderung zur Rezessionsüberwindung, a. a. O., S. 183.

2 In den nachfolgenden Formeln werden folgende Abkürzungen verwandt:

$\mathrm{B}_{\mathrm{VR}}$ : Barwert des Rücktrages eines förderungsbedingten Verlustes

g: $\quad$ Grenzsteuersatz in der Periode $t$

$\mathrm{i}_{\mathrm{g}}$ : versteuerter Kalkulationszinssatz

k: Verlustrücktragsperioden

$\mathrm{n}$ : wirtschaftliche Nutzungsdauer

t: $\quad$ Periode

$V_{\mathrm{t}}$ : rücktragbarer Verlust aus der Periode $t$

w: maximaler Verlustrücktragszeitraum 
Das Symbol $\left(\mathrm{VR}_{\mathrm{t}}\right)$ bezeichnet die Verluste aus der Periode $(\mathrm{t})$, die mit den Erträgen der Perioden ( $t-k)$ aufgerechnet werden.

$$
B_{V R}=\sum_{t=1}^{n} \sum_{k=1}^{w} \frac{g_{t-k} * V R_{t}}{\left(1+i_{g}\right)^{t-1}}
$$

Die Einnahmen und Ausgaben, die eine Fördermaßnahme im förderungsrelevanten Zeitraum hervorruft, werden abdiskontiert. ${ }^{1}$ Die Steuerrückerstattungen aus dem Rücktrag von Verlusten sind nicht zusätzlich abzuzinsen, weil sie ohne Verzögerung in der jeweiligen Verlustperiode liquiditätswirksam werden. ${ }^{2}$ Grundsätzlich besteht für den Investor kein Unterschied, ob er in den Genuß der Förderung über die aktuellen Erträge oder über die Erträge aus zurückliegenden Perioden kommt.

\section{b. Vergünstigungswirkungen investitionsfördernder Maßnahmen unter Berücksichtigung eines Verlustvortrags}

Wenn ein Investor seinen aktuellen Verlust mangels Periodenüberschüssen in den Vorjahren nicht ausgleichen kann, so besitzt er die Möglichkeit, den Verlust vorzutragen.

Trägt der Investor einen förderungsverursachten Verlust vor, wird der Zufluß der Förderung erst dann erfolgen, wenn es dem Investor innerhalb der folgenden Jahre möglich wird, seinen Verlust aus der steuerlichen Förderung mit entsprechenden Erträgen auszugleichen. Dabei wird sich die liquiditätsmäßige Verfügbarkeit der Förderung mindestens um ein Jahr, möglicherweise um mehrere Jahre verzögern. Das investierende Unternehmen wird demzufolge zu einem Zeitpunkt gefördert, wenn es die Investitionsausgaben getätigt und die Ver-

${ }^{1}$ Eine derartige mehrperiodige Förderung ist beispielsweise eine Abschreibung über die Anschaffungs- oder Herstellungskosten hinaus.

${ }^{2}$ Es kann bei der Steuerrückerstattung zu verwaltungsbedingten Verzögerungen kommen. In diesem Fall wären die Steuerrückerstattungen abzudiskontieren. 
lustphase überwunden hat. Die Liquiditätssituation hat sich dann möglicherweise wieder entspannt. ${ }^{1}$

Bei der Ermittlung des Barwertes sind die in die Zukunft verlagerten Steuerentlastungen abzudiskontieren. Der Investor kann in der Investitionsperiode nicht über die Förderung verfügen. Er muß die Förderung mit Eigen- oder Fremdkapital vorfinanzieren. Die Vorfinanzierung führt zu Zinsaufwendungen bzw. entgangenen Zinserträgen ${ }^{2}$. Hierdurch werden die Verluste erhöht. Diese Verluste können ebenfalls vorgetragen werden und kürzen in der Ausgleichsperiode die Steuerbemessungsgrundlage. Im Abdiskontierungsfaktor ist folglich der Grenzsteuersatz der Aufrechnungsperiode anzusetzen. Das Symbol $\left(V_{\mathrm{t}}\right)$ in der Formel D. $16^{3}$ repräsentiert die Verluste, die mit den Erträgen der Periode $(t)$ verrechnet werden. Der Verlustvortrag ist auf $m$ Perioden beschränkt.

$$
B_{V V}=\sum_{t=2}^{n+m} \frac{g_{t} * V V_{t}}{\left(1+i_{g}\right)^{t-1}}
$$

Der Barwert eines Verlustvortrages ist durch die Abdiskontierung der Steuervorteile ceteris paribus geringer als der eines Verlustrücktrages.

1 Engelmann schreibt den Liquiditätswirkungen des Verlustvortrages zumindest eine Beschleunigung des Gesundungsprozesses nach der Verlustphase zu. Vgl. Engelmann, R., Die einkommensteuerliche Verlustverrechnung und ihre betriebswirtschaftlichen Probleme, Diss. München 1966, S. 61.

2 Bei der Kreditfinanzierung sind Zinsen zu zahlen und bei der Eigenfinanzierung entgehen dem Investor Zinserträge.

3 In der Formel D.15 werden folgende Abkürzungen verwandt:

$\mathrm{B}_{\mathrm{vv}}$ : Barwert des Vortrages eines förderungsbedingten Verlustes

$\mathrm{g}_{\mathrm{i}}$ : $\quad$ Grenzsteuersatz in der Periode $t$

$i_{g}$ : versteuerter Kalkulationszinssatz

n: wirtschaftliche Nutzungsdauer

$\mathrm{m}$ : maximaler Verlustvortragszeitraum

t: $\quad$ Periode

$\mathrm{VV}_{\mathrm{t}}$ : in die Periode $\mathrm{t}$ vorgetragener Verlust 
Beispielhaft sollen die Nettoeinkommenswirkungen eines Investitionsfreibetrages berechnet werden, der über einen Verlustvortrag erst in der dritten Periode liquiditätswirksam wird. Zuvor sind einige Anmerkungen $\mathrm{zu}$ den unterstellten Modellannahmen erforderlich. Von entscheidender Bedeutung sowohl für die Möglichkeit, Verluste auszugleichen, als auch für die Vergünstigungswirkungen ist die Verlust-Gewinn-Situation im relevanten Zeitraum. In den Berechnungen werden drei konkrete Verlust-Gewinn-Situationen unterstellt. Die Erträge sollen in jenen Rechnungslegungsperioden, in denen Verluste aufgerechnet werden können, einem 20-, 40- oder 60-prozentigen Grenzsteuersatz unterliegen. Diese Annahme hilft, den Vergleich zu den oben berechneten Vergünstigungseffekten herzustellen.

Tabelle D.17: Die Wirkungen eines Verlustvortrages in die dritte Periode auf die Vergünstigungseffekte eines Investitionsfreibetrages

\begin{tabular}{|c|c|c|c|c|c|c|c|c|c|c|c|c|c|c|}
\hline \multirow{2}{*}{$\begin{array}{l}\text { Pe- } \\
\text { rio- } \\
\text { de }\end{array}$} & \multirow{2}{*}{$\begin{array}{l}\text { Frei- } \\
\text { be- } \\
\text { trag } \\
\text { in DM } \\
\quad(2)\end{array}$} & \multirow{2}{*}{$\begin{array}{l}\text { Vortrag des } \\
\text { Freibetrages } \\
\text { in DM } \\
\qquad \text { (3) }\end{array}$} & \multicolumn{12}{|c|}{$\begin{array}{c}\text { Vergünstigung bei alternativen Grenz- } \\
\text { steuersätzen in DM }\end{array}$} \\
\hline & & & g & $\mathrm{ZW}$ & BBW & NBW & $g$ & $2 W$ & BBW & NBW & g & $2 W$ & BBW & NBW \\
\hline $\begin{array}{l}1 \\
2 \\
3\end{array}$ & $\begin{array}{r}2500 \\
0 \\
0\end{array}$ & {$\left[\begin{array}{r}0 \\
0 \\
>2500\end{array}\right.$} & $\begin{array}{r}0 \\
0 \\
20\end{array}$ & $\begin{array}{r}0 \\
0 \\
500\end{array}$ & $\begin{array}{r}0 \\
0 \\
429\end{array}$ & $\begin{array}{r}0 \\
0 \\
442\end{array}$ & $\begin{array}{r}0 \\
0 \\
40\end{array}$ & $\begin{array}{r}0 \\
0 \\
1000\end{array}$ & $\begin{array}{r}0 \\
0 \\
857\end{array}$ & $\begin{array}{r}0 \\
0 \\
910\end{array}$ & $\begin{array}{r}0 \\
0 \\
60\end{array}$ & $\begin{array}{r}0 \\
0 \\
1500\end{array}$ & $\begin{array}{r}0 \\
0 \\
1286\end{array}$ & $\begin{array}{r}0 \\
0 \\
1408\end{array}$ \\
\hline$\Sigma=$ & 2500 & 2500 & & 500 & 429 & 442 & & 1000 & 857 & 910 & & 1500 & 1286 & 1408 \\
\hline \multicolumn{15}{|c|}{$\begin{array}{l}\mathrm{ZW}=\text { Zeitwert } \\
\text { BBW }=\text { Bruttobarwert } \\
\text { NBW }=\text { Nettobarwert } \\
\mathrm{g}=\text { Grenzsteuersatz }\end{array}$} \\
\hline
\end{tabular}

Aus der Tabelle D.17 wird deutlich, daß die grundlegenden Zusammenhänge zwischen der Höhe des Grenzsteuersatzes und der der Vergünstigungswirkungen von Investitionsfreibeträgen erhalten bleiben, jedoch nehmen die Nettobarwer$\mathrm{te}^{1}$ erheblich ab. Der Investor muß in der Investitionsperiode anstatt der Förde-

1 Oben wurde der Fall im Zeitablauf variierender Grenzsteuersätze behandelt, wobei in den Grenzsteuersatzreihen keine Verlustsituationen enthalten waren. Zur Berechnung der Nettobarwerte mußten die Zahlungsreihen mit unterschiedlichen Nettozinssätzen abdiskontiert 
rung andere Finanzierungsmittel einsetzen, woraus ihm Zinsaufwendungen entstehen bzw. Zinserträge entgehen. Diese Zinsaufwendungen bzw. entgangenen Zinserträge werden teilweise kompensiert, weil sie zu einer Kürzung der Steuerbemessungsgrundlage in der Aufrechnungsperiode führen. Der Nettobarwert ist bei einem Verlustvortrag stets geringer als der Zeitwert. ${ }^{1}$

\section{c. Der Einfluß des Verlustausgleichs auf die Nachversteuerungswirkun- gen von Fördermaßnahmen}

Die vorangegangenen Ausführungen zeigten, da $ß$ mit Hilfe des interperiodischen Verlustausgleichs Vergünstigungswirkungen aus einer steuerlichen Fördermaßnahme entstehen bzw. zunehmen können. Allerdings sind zusätzlich die Wirkungen des intertemporalen Verlustausgleichs auf die Nachholeffekte zu berücksichtigen.

Eine steuerliche Investitionsfördermaßnahme kann zu zukünftig geringeren $\mathrm{Ab}$ schreibungen und dadurch zu einer Erhöhung der Steuerbemessungsgrundlage in den jeweiligen Perioden führen. Erwirtschaftet das betreffende Unternehmen in diesen Perioden keinen Gewinn, verringern diese niedrigeren Abschreibungen lediglich den Verlust. Eine Nachversteuerung unterbleibt zunächst. Wenn das Verlustunternehmen einen Rück- bzw. Vortrag des gekürzten Verlustes vornimmt, kommt es über den Verlustausgleich zu Nachholwirkungen. Das heißt, daß der Vorteil aus einer steuerlichen Fördermaßnahme durch den Verlustausgleich abnehmen kann, wenn es hierdurch zu Nachversteuerungen kommt. Im Extremfall ist es möglich, daß die Nachversteuerungen die Steuervorteile der Förderung übersteigen. Der Investor hat dann - über den gesamten Zeitraum ge-

werden. Dies ist hier nicht erforderlich, weil bei einem Verlustausgleich die Möglichkeit besteht, die Zinsaufwendungen vorzutragen. Der Grenzsteuersatz im Abdiskontierungsfaktor entspricht folglich dem in der Ausgleichsperiode.

${ }^{1}$ Würden sich die Verluste bereits zu einem früheren Zeitpunkt aufrechnen lassen, wären die Zinsaufwendungen bzw. entgangenen Erträge geringer und damit die Barwerte höher. Höhere Opportunitätskosten wären bei einer späteren Verlustverrechnung die Folge. 
sehen - einen Verlust aus der Fördermaßnahme. Dieser Extremfall tritt erstens dann ein, wenn der Investor die durch Minderabschreibungen verringerten Verluste in den Perioden aufrechnet, in denen er einen höheren Grenzsteuersatz hat als in der Periode, in der er die Förderung erhielt bzw. ausgleichen konnte. Es tritt damit der an früherer Stelle beschriebene temporale Progressionseffekt auf. Zweitens kann es zu einem Verlust aus der Fördermaßnahme kommen, wenn eine zeitliche Beschränkung des Verlustvortrags besteht. ${ }^{1}$ Dies kann dazu führen, daß die Förderung nicht mehr vorgetragen werden kann, weil innerhalb des Vortragszeitraums keine Erträge vorhanden sind. Dagegen können unter Umständen die durch die Minderabschreibungen verringerten Verluste noch vorgetragen werden, weil die Minderabschreibungen zeitlich nach der Förderung folgen. Das ist vor allem bei einer Förderung in einer langanhaltenden Verlustphase möglich. ${ }^{2}$

Die Wirkungen des Verlustvortrags auf die Vorteile aus einer Fördermaßnahme, die zu Steuernachholungen führen kann, werden im folgenden anhand einer Sonderabschreibung erläutert.

1 Im Jahre 1990 wurde im deutschen Steuerrecht die zeitliche Beschränkung für den Verlustvortrag aufgehoben. Fall.

2 Je stäker der Verlustvortrag zeitlich befristet wird, desto wahrscheinlicher wird dieser 
Tabelle D.18: Die Wirkungen eines Verlustvortrages in die dritte Periode auf die Vergünstigungseffekte einer Sonderabschreibung

\begin{tabular}{|c|c|c|c|c|c|c|c|c|c|c|c|c|c|c|}
\hline \multirow{2}{*}{$\begin{array}{l}\begin{array}{l}\text { Pe- } \\
\text { rio- } \\
\text { de }\end{array} \\
\text { (1) }\end{array}$} & \multirow{2}{*}{$\begin{array}{l}\text { Ande- } \\
\text { rung } \\
\text { der } \\
\text { AfA } \\
\text { in DM } \\
\text { (2) }\end{array}$} & \multirow{2}{*}{$\begin{array}{l}\text { Vortrag der } \\
\text { Anderung } \\
\text { der Normal- } \\
\text { abschrei- } \\
\text { bung in DM } \\
\text { (3) }\end{array}$} & \multicolumn{12}{|c|}{ Vergünstigung bei alternativen Grenzsteuersätzen in DM } \\
\hline & & & g & $2 \mathrm{~W}$ & BBW & NBW & $\mathrm{g}$ & $2 \mathrm{~W}$ & BBW & NBW & $\mathrm{g}$ & $\mathrm{ZW}$ & BBW & NBW \\
\hline $\begin{array}{l}1 \\
2 \\
3 \\
4 \\
5\end{array}$ & $\begin{array}{l}22856 \\
-5714 \\
-5714 \\
-5714 \\
-5714\end{array}$ & $\begin{array}{r}I_{>}>11428 \\
0 \\
\longrightarrow>-5714 \\
\longrightarrow>-5714\end{array}$ & $\begin{array}{r}0 \\
0 \\
20 \\
20 \\
20\end{array}$ & $\begin{array}{r}0 \\
0 \\
2286 \\
-1143 \\
-1143\end{array}$ & $\begin{array}{r}0 \\
0 \\
1960 \\
-907 \\
-840\end{array}$ & $\begin{array}{r}0 \\
0 \\
2019 \\
-949 \\
-892\end{array}$ & $\begin{array}{r}0 \\
0 \\
40 \\
40 \\
40\end{array}$ & $\begin{array}{r}0 \\
0 \\
4571 \\
-2286 \\
-2286\end{array}$ & $\begin{array}{r}0 \\
0 \\
3919 \\
-1814 \\
-1680\end{array}$ & $\begin{array}{r}0 \\
0 \\
4162 \\
-1986 \\
-1895\end{array}$ & $\begin{array}{r}0 \\
0 \\
60 \\
60 \\
60\end{array}$ & $\begin{array}{r}0 \\
0 \\
6857 \\
-3428 \\
-3428\end{array}$ & $\begin{array}{r}0 \\
0 \\
5879 \\
-2722 \\
-2520\end{array}$ & $\begin{array}{r}0 \\
0 \\
6438 \\
-3119 \\
-3023\end{array}$ \\
\hline$\Sigma=$ & 0 & 0 & & 0 & 212 & 179 & & 0 & 425 & 282 & & 0 & 637 & 296 \\
\hline \multicolumn{15}{|c|}{$\begin{array}{l}2 W=\text { Zeitwert } \\
\text { BBW }=\text { Bruttobarwert } \\
\text { NBW }=\text { Nettobarwert } \\
\text { g: Grenzsteuersatz }\end{array}$} \\
\hline
\end{tabular}

Auch der Verlustvortrag aus einer Sonderabschreibung führt - verglichen mit der Verlustsituation - zu einem Vorteil, aber zu einem sehr kleinen. Die Nettoeinkommensvorteile schmelzen auf rund ein Viertel von denen eines Gewinnunternehmens. Die geringere Vergünstigungswirkung kommt durch zwei Effekte zustande. Erstens ist die Förderung abzudiskontieren, weil der Investor erst in Zukunft - in der Verlustausgleichsperiode - über sie verfügen kann. Zweitens werden beim Verlustvortrag nicht nur die Verluste aus der Förderung vorgetragen, sondern auch die Minderabschreibungen, die den Umfang der vortragbaren Verluste reduzieren. ${ }^{1}$

An dieser Stelle muß jedoch darauf hingewiesen werden, daß die Vornahme eines interperiodischen Verlustausgleichs in der Regel für ein Unternehmen auch dann Vorteile erbringt, wenn es zugleich über einen Verlustvor- oder -rücktrag zu Nachholwirkungen kommt. Die Steuerentlastung aus der Verlustverrechnung

${ }^{1}$ Wenn man den Fall, der der Tabelle D.18 zugrunde liegt, abändert und davon ausgeht, daß die Verlustverrechnung erst in der fünften Periode möglich wird, wäre die Vergünstigungswirkung Null. Bei einem weiter in die Zukunft reichenden Verlustvortrag und zugleich einer zeitlichen Begrenzung des Verlustvortrags auf fünf Jahre, werden nur noch die verminderten Abschreibungsbeträge vorgetragen und es entsteht ein Verlust aus der Förderung. 
übertrifft normalerweise die Nachversteuerungseffekte bei weitem und ist damit für den Investor vorteilhaft.

\section{d. Berechnungen zum Einfluß eines intertemporalen Verlustausgleichs auf die Nettoeinkommenswirkungen von Investitionsfördermaßnahmen}

Nachdem die Wirkungen eines Verlustvortrags auf die Vorteile aus einer Sonderabschreibung und aus einem Investitionsfreibetrag erläutert wurden, werden in der Tabelle D.19 die Vergünstigungseffekte weiterer Investitionsfördermaßnahmen unter Berücksichtigung eines intertemporalen Verlustausgleichs aufgeführt. Hierbei wird nun auch der Einfluß eines Verlustrücktrages erfaßt.

Tabelle D.19: Vergünstigungswirkungen steuerlicher Investitionsfördermaßnahmen unter Berücksichtigung eines intertemporalen Verlustausgleichs (Verlustrücktrag in die vorletzte Periode und Verlustvortrag in die dritte Periode)

\begin{tabular}{|c|c|c|c|c|c|c|c|c|c|c|}
\hline \multirow{3}{*}{$\begin{array}{l}\text { Art der } \\
\text { Kompen- } \\
\text { sation } \\
\text { (1) }\end{array}$} & \multirow{3}{*}{$\begin{array}{c}\text { Fördermaßnahme } \\
\text { (2) }\end{array}$} & \multicolumn{9}{|c|}{$\begin{array}{c}\text { Vergünstigung bei alternativen Grenz- } \\
\text { steuersätzen in DM }\end{array}$} \\
\hline & & \multicolumn{3}{|c|}{$20 \%$} & \multicolumn{3}{|c|}{40 옹 } & \multicolumn{3}{|c|}{$60 \%$} \\
\hline & & $2 \mathrm{~W}$ & BBW & NBW & $2 W$ & BBW & NBW & $2 \mathrm{~W}$ & BBW & NBW \\
\hline \multirow{6}{*}{$\begin{array}{l}\text { Verlust- } \\
\text { rücktrag }\end{array}$} & Sonderabschreibung & 0 & 786 & 647 & 0 & 1572 & 1000 & 0 & 2358 & 1031 \\
\hline & degressive Abschreibung & 0 & 783 & 646 & 0 & 1566 & 1000 & 0 & 2350 & 1033 \\
\hline & AfA. über d. AHK hinaus & 580 & 473 & 486 & 1160 & 945 & 1000 & 1739 & 1418 & 1545 \\
\hline & Ubertragung stiller Re. & 0 & 789 & 647 & 0 & 1572 & 1000 & 0 & 2358 & 1031 \\
\hline & Investitionsfreibetrag & 500 & 500 & 500 & 1000 & 1000 & 1000 & 1500 & 1500 & 1500 \\
\hline & Rücklage u. Sonder.-AfA & 0 & 742 & 629 & 0 & 1485 & 1000 & 0 & 2227 & 1063 \\
\hline \multirow{6}{*}{$\begin{array}{l}\text { Verlust- } \\
\text { vortrag }\end{array}$} & Sonderabschreibung & 0 & 212 & 179 & 0 & 425 & 282 & 0 & 637 & 296 \\
\hline & degressive Abschreibung & 0 & 246 & 206 & 0 & 492 & 325 & 0 & 738 & 342 \\
\hline & AfA. über $d$. AHK hinaus & 580 & 449 & 467 & 1160 & 899 & 971 & 1739 & 1348 & 1515 \\
\hline & Obertragung stiller Re. & 0 & 212 & 179 & 0 & 425 & 282 & 0 & 637 & 296 \\
\hline & Investitionsfreibetrag & 500 & 429 & 442 & 1000 & 857 & 910 & 1500 & 1286 & 1408 \\
\hline & Rücklage u. Sonder. -AfA & 0 & 486 & 419 & 0 & 972 & 678 & 0 & 1458 & 733 \\
\hline \multicolumn{11}{|c|}{$\begin{array}{l}Z W=\text { Zeitwert } \\
\text { BBW }=\text { Bruttobarwert } \\
\text { NBW }=\text { Nettobarwert }\end{array}$} \\
\hline
\end{tabular}


Der Investor hat bei einem Verlustrücktrag die Vorteile, die er in einer vergleichbaren Gewinnsituation erlangen würde. Gleichzeitig zeigt die Tabelle D.19, daß die Nettobarwerte bei einem Verlustvortrag in die dritte Periode gegenüber einem Verlustrücktrag - erheblich niedriger sind. Besonders stark ist der Rückgang der Vergünstigungseffekte bei den Investitionsförderinstrumenten, mit denen sich eine Nachversteuerungsmöglichkeit verbindet. Dieser Rückgang läßt sich durch den ebenfalls stattfindenden Vortrag der Nachholwirkungen erklären.

Aus den Berechnungen wird deutlich, daß sich eine Unternehmung durch den Verlustausgleich unter Umständen gegenüber einer anderen Unternehmung, die über einen längeren Zeitraum einen konstanten - aber geringen - Gewinn ausweist, besser stellen kann, wenn sie aufgrund stark schwankender Erträge Verluste in Perioden mit hohen Erträgen insbesondere zurück- aber auch vortragen kann. Dies zeigt, daß der intertemporale Verlustausgleich keine Durchschnittsbesteuerung herstellen kann. Die Nivellierung des steuerlichen Ertrags ist auf Verlustunternehmen beschränkt.

\section{Zusammenfassung}

Das Vorhandensein einer interperiodischen Verlustausgleichsregelung muß nicht unbedingt zu einem Ausgleich eines Verlustes führen, der durch eine Investitionsfördermaßnahme in der Förderperiode verursacht bzw. erhöht wurde. Insbesondere ist dies dann nicht der Fall, wenn ein Ausgleich mit den Erträgen aus vor- oder nachgelagerten Rechnungslegungsperioden nicht vollständig oder überhaupt nicht möglich ist. Außerdem können Verlustklauseln bestehen, die den Verlustausgleich ausschließen.

Durch den Verlustrücktrag können Unternehmen, die im Begünstigungszeitpunkt keinen Periodenüberschuß erwirtschaften, aus einer steuerlichen Investitionsfördermaßnahme Vorteile erhalten. Verlustentstehung und Verlustverrechnung 
fallen bei einem Verlustrücktrag zeitlich zusammen. Wenn der Verlustrücktrag nicht durchführbar ist, besteht die Möglichkeit eines Vortrags der Verluste. Auch er kann den betreffenden Investor aus einer steuerlichen Investitionsfördermaßnahme begünstigen. Jedoch tritt bei einem Verlustvortrag die Liquiditätsentlastung erst in einer zukünftigen Periode ein. Der Investor hat deshalb Zinsaufwendungen bzw. entgangene Zinserträge. Der Umfang der Vergünstigungswirkungen richtet sich bei einem Verlustrück- und -vortrag nach den Grenzsteuersätzen der betreffenden Ausgleichsperioden und dem Umfang der ausgleichbaren Verluste.

Außer den Vorteilen bleiben durch einen Verlustausgleich auch die Nachversteuerungswirkungen einer Fördermaßnahme erhalten. Im Extremfall kann per Saldo der Vorteil aus der Förderung durch den intertemporalen Verlustausgleich zu einem Nachteil werden. 


\section{Investitionsprämien}

\section{Konzeption der Investitionsprämien}

Dem Begriff der Investitionsprämie werden in der Literatur zum Teil unterschiedliche Förderinstrumente zugeordnet. Zum einen wird in einer Investitionsprämie eine steuerfreie Finanzzuwendung des Staates für eine Investition gesehen, was hier als Investitionszulage bezeichnet wird. Zum anderen steht die Bezeichnung Investitionsprämie auch für Abzüge von der Steuerschuld. Im Rahmen dieser Arbeit wird der Begriff Investitionsprämie ausschließlich für den letztgenannten Sachverhalt benutzt. ${ }^{1}$

Eine Investitionsprämie erlaubt dem Investor, einen Prozentanteil des förderungsfähigen Investitionsvolumens von seiner Steuerschuld abzuziehen. Die Steuerschuldhöhe des Investors bildet damit - ohne Ausgleichsmaßnahmen ${ }^{2}$ die absolute Obergrenze für diese Förderung. Im Unterschied zu jenen Maßnahmen, die an der Steuerbemessungsgrundlage ansetzen, wird hier die Steuerbemessungsgrundlage nicht verändert, sondern direkt die Steuerschuld. ${ }^{3}$ Damit werden die Vergünstigungswirkungen grundsätzlich nicht vom Grenzsteuersatz beeinflußt. Der Steuerschuldabzug kommt in seinen Wirkungen einer entsprechenden Tarifermäßigung gleich, wobei der Unterschied besteht, daß Tarifermäßigungen nicht an die Durchführung einer Investition geknüpft sind. ${ }^{4}$

${ }^{1}$ Neumark, F., Fiskalpolitik und Wachstumsschwankungen, Wiesbaden 1968, S. 69ff, verwandte die Bezeichnungen unechte Prämien für die Abzüge von der Steuerschuld und echte Prämien für die Investitionszulagen.

2 Auf Ausgleichsmaßnahmen wird im weiteren noch eingegangen.

3 Die Steuerschuld ergibt sich aus dem Ertragsteuersatz multipliziert mit der ertragsteuerlichen Bemessungsgrundlage.

4 Vgl. Groß, E., Staatliche Finanzierungshilfen zur Förderung von Investitionen der gewerblichen Wirtschaft im Lichte gesamtwirtschaftlicher und unternehmerischer Zielsetzungen, Diss. Münster 1977, S. 29. 
Der wirtschaftspolitische Einsatzbereich der Investitionsprämien reicht von der Konjunktur- und Wachstumspolitik ${ }^{1}$ bis hin zur Strukturpolitik. ${ }^{2}$ Zur Verwirklichung der jeweiligen wirtschaftspolitischen Ziele bieten sich einige Ansatzpunkte bei der Ausgestaltung der Investitionsprämien an. Aus wachstumsund konjunkturpolitischer Sicht erscheint eine Beschränkung auf die Förderung der Nettoinvestitionen angebracht, jedoch ist es in der Praxis nicht einfach, zwischen Brutto- und Nettoinvestitionen klar zu unterscheiden. Ferner ist aus konjunkturpolitischen Überlegungen eine Befristung der Förderung zweckmäBig. ${ }^{3}$

Eine andere Frage, die sich im Zusammenhang mit der Ausgestaltung dieser Förderung stellt, bezieht sich auf die Art der relevanten Steuerschuld. Als förderungsrelevante Steuerschuld kann der Gesetzgeber die gesamte Steuerschuld einer Unternehmung festlegen, aber auch nur die Steuerschuld, die sich aus bestimmten Steuern ergibt. Beispielsweise kann die relevante Steuerschuld nur die Steuerschuld aus der Körperschaftsteuer, Einkommensteuer oder auch

1 In der Bundesrepublik Deutschland wurde im "Gesetz zur Förderung der Stabilität und des Wachstums der Wirtschaft" vom 6. Juni 1967 die Bundesregierung ermächtigt, bei "einer Störung des gesamtwirtschaftlichen Gleichgewichts" eine Kürzung der Einkommen- bzw. der Körperschaftsteuerschuld um bis zu 7,5 vH der Anschaffungs- oder Herstellungskosten neuer Wirtschaftsgüter zu erlauben ( $\S \S 26$ und 27). Die Maßnahme ist auf ein Jahr begrenzt. Auch in Österreich wurde ergänzend zu anderen Fördermaßnahmen für das Jahr 1982 eine Investitionsprämie (zunächst $6 \mathrm{vH}$, ab Oktober $19828 \mathrm{vH}$ der Investitionssumme) zur Konjunkturbelebung eingesetzt, vgl. Leibfritz, W./Meurer, C., Steuerliche Investitionsförderung im internationalen Vergleich, a. a. O., S. 61; Swoboda, P., Antizyklische steuerliche Regelungen und betriebliche Investitionsentscheidungen, in: Finanzarchiv 1969, S. 63ff.

Der Sachverständigenrat zur Begutachtung der gesamtwirtschaftlichen Entwicklung schlug in seinem Jahresgutachten 1984/85, S. 217, Ziffer 467, vor, die Investitionsprämie nicht nur zum Zweck der Konjunkturpolitik einzusetzen, sondern damit auch wachstumspolitische Ziele zu verfolgen. Ähnlich dem "Investment Tax Credit" in den USA sollten die Investitionsprämien mit der Länge der Nutzungsdauer der geförderten Investition steigen.

${ }^{2}$ Ein Beispiel für einen sektoralen Einsatz der Investitionsprämien stellt das "Gesetz zur Anpassung und Gesundung des deutschen Steinkohlenbergbaus und der deutschen Steinkohlenbergbaugebiete" vom 15. Mai 1968 dar. Die Förderung lief zum 31. Dezember 1973 aus.

3 Vgl. Oberhauser, A., Möglichkeiten einer effizienteren Gestaltung staatlicher Investitionszuschüsse in der Rezession, in: Bohley, P./Tolkemitt, G. (Hrsg.), Wirtschaftswissenschaft als Grundlage staatlichen Handelns, Tübingen 1979, S. 90. 
der abzuführenden Umsatzsteuer umfassen. ${ }^{1}$ Mit der Wahl der relevanten Steuerschuld wird auch festgelegt, ob und in welchem Ausmaß ein Investor begünstigt wird.

Im wesentlichen werden die Investitionsprämien in zwei Varianten gewährt. Beide Varianten begünstigen den Investor in der Investitionsperiode. In den Folgeperioden unterscheiden sich die Wirkungen beider Prämien. Die eine Prämie hat keine Wirkung auf die Abschreibungsbasis, dagegen führt die andere Prämie zu einer Kürzung der Abschreibungsbasis. Die Verringerung der Abschreibungsbasis muß nicht notwendigerweise der Höhe des Steuerschuldabzuges entsprechen. ${ }^{2}$

Neben diesen beiden Investitionsprämien wurde auch eine Verteilung der Investitionsprämie über einen mehrjährigen Zeitraum diskutiert, der auch die gesamte steuerliche Nutzungsdauer umfassen kann. Hierdurch können solche kleinere und neu gegründete Unternehmen unterstützt werden, die vor dem Problem stehen, daß ihre Steuerschuld nicht ausreicht, um die Vorteile dieser Fördermaßnahme in vollem Umfange zu nutzen. Aus der einmaligen Investitionsfördermaßnahme würde sich ein laufender Beitrag zu den Kapitalaufwendungen ergeben. ${ }^{3}$ Im weiteren wird auf diese Möglichkeit nicht näher eingegangen. Bei der Investitionsförderung kommt es vor allem auf die Liquiditäts-

${ }^{1}$ Vgl. Brockhoff, K., Steuerabzüge für Investitionen, in: Finanzarchiv 1970, S. 259. Das Institut "Finanzen und Steuern", Steuerliche Maßnahmen zur Investitionsförderung, Grüner Brief Nr. 177, a. a. O., S. 65f, schlägt außerdem vor, einen Abzug von der abzuführenden Lohnsteuer vorzunehmen.

2 In den USA wurde der ursprüngliche (ab 1964) Investment Tax Credit 1982 insofern abgeändert, daß der Investor die Abschreibungsbasis um die Hälfte des Steuerabzugsbetrages kürzen muß, vgl. Leibfritz, W./ Meurer, $C$., Steuerliche Investitionsförderung im internationalen Vergleich, a. a. O., S. 63. Nach der französischen Regelung vom 15.2.1966, die bis zum 31.12.1966 in Kraft war, mußte die Abschreibungsbasis in vollem Umfang mit der geförderten Investition verrechnet werden, vgl. Fischer, L., Betriebswirtschaftliche Beurteilung der deutschen Sonderabschreibungen im internationalen Vergleich, in: Deutsche Steuer-Zeitung 1967, Ausgabe A, S. 149. Dagegen wirkt die deutsche Regelung im "Gesetz zur Förderung der Stabilität und des Wachstums der Wirtschaft" abschreibungsneutral.

${ }^{3}$ Vgl. Uhlmann, L./Berger, M., Instrumentelle Aspekte der Investitionsförderung, München 1986, S. 77. 
wirkungen in der Investitionsperiode an. Durch eine Verteilung des Steuerschuldabzugs auf mehrere Perioden können sich zwar über den gesamten Begünstigungszeitraum Steuervorteile ergeben, aber der Liquiditätseffekt bleibt durch die Höhe der Steuerschuld in der Investitionsperiode begrenzt. Geeigneter zur Förderung von Unternehmen mit geringer Steuerschuld sind Ausgleichsmaßnahmen, die im folgenden erläutert werden.

Um Unternehmen, die über keine ausreichend hohe Steuerschuld verfügen in den Genuß von Investitionsprämien kommen zu lassen, bieten sich einige ergänzende Maßnahmen an. Ein bereits im Abschnitt D.VI vorgestellter Ansatz, der interperiodische Verlustausgleich, ist auch hier einsetzbar. ${ }^{1}$ Daneben besteht die Möglichkeit, negative Beträge auszuschütten, quasi als "negative Einkommensteuer". ${ }^{2}$ Außerdem können übertragbare Gutscheine ausgestellt werden, die von Verlustunternehmen weiterveräußert werden können. ${ }^{3}$

\section{Vergünstigungswirkungen der Investitionsprämien}

Die Vergünstigungseffekte einer Investitionsprämie, die zu keinen Nachversteuerungen führen kann, sind zwar nicht vom Grenzsteuersatz des Investors abhängig, aber sehr wohl von der Höhe der Steuerschuld. Das bedeutet, daß die relevante Steuerschuld mindestens die Höhe des möglichen Abzugsbetrages erreichen muß, damit der Investor diese Maßnahme zur Gänze ausschöpfen kann. Unternehmen, die in der Förderperiode einen Verlust ausweisen müssen, haben auch keine Steuerschuld, zumindest nicht aus den Ertragsteuern. Hierin zeigt

1 Nach dem "Gesetz zur Förderung der Stabilität und des Wachstums der Wirtschaft" vom 6. Juni 1967 ist ein Verlustvortrag um ein Jahr möglich. Die amerikanische Investitionsprämie wurde mit einer 5-jährigen Vortrags- und einer 3-jährigen Rücktragsmöglichkeit ausgestattet.

${ }^{2}$ Vgl. Surrey, S. S., Steueranreize als ein Instrument der staatlichen Politik. Ein Vergleich mit direkten Ausgaben, in: Steuer und Wirtschaft 1981, S. 370.

${ }^{3} \mathrm{Vgl}$. Uhlmann, L./Berger, M., Instrumentelle Aspekte der Investitionsförderung, a. a. O., S. 77 . 
sich eine Parallelität zu den Maßnahmen, die an der Steuerbemessungsgrundlage anknüpfen. Allerdings können durch Ausgleichsmaßnahmen auch Verlustunternehmen in den Genuß von Investitionsprämien kommen. ${ }^{1}$

Sieht man von möglichen Verzögerungen ${ }^{2}$ bei der Auszahlung einer Investitionsprämie $a b$, werden die Vergünstigungswirkungen durch das förderungsfähige Investitionsvolumen und den Fördersatz bestimmt. ${ }^{3}$

$$
B_{P N}=f_{P N} * I V \quad \text { für } T 2 A Z
$$

Der Umfang der Vergünstigungswirkungen wächst proportional mit der Höhe des Fördersatzes und der des Investitionsvolumens. Bei einem Fördersatz von einem Prozent und einer Investitionssumme von DM 100.000,- hat jedes Gewinnunternehmen mit ausreichend hoher Steuerschuld einen Vorteil in Höhe von DM 1.000,-. Der mit dieser Investitionsprämie verbundene Liquiditätsgewinn in der Investitionsperiode ist - verglichen mit den Maßnahmen, die die Steuerbemessungsgrundlage verringern - äußerst bescheiden. Aufgrund der fehlenden Nachholwirkungen kann der Staat nur dann eine höhere Anfangsentlastung erreichen, wenn er bereit ist, einen erheblich höheren fiskalischen Aufwand zu tragen.

Investoren, deren Steuerschuld hinter dem maximalen Abzugsbetrag zurückbleibt, haben - was bereits angesprochen wurde - einen geringeren Vorteil.

${ }^{1}$ Auf einige Möglichkeiten, Verlustunternehmen in den Genuß von Investitionsprämien zu bringen, wurde oben bereits hingewiesen. S. 188.

${ }^{2}$ Vgl. Wöhe, G., Steuern als Mittel der Wirtschaftspolitik, in: Steuerkongreß-Report 1975,

3 In der Formel D.17 werden folgende Abkürzungen verwandt:

AZ: maximal zulässiger Abzugsbetrag von der Steuerschuld

$\mathrm{B}_{\mathrm{PN}}$ : Barwert einer Investitionsprämie, mit der keine Nachversteuerungsmöglichkeit verbunden ist

$\mathrm{f}_{\mathrm{PN}}$ : Fördersatz einer Investitionsprämie, mit der keine Nachversteuerungsmöglichkeit verbunden ist

IV: förderungsfähiges Investitionsvolumen

T: Steuerschuld 
Tabelle D.20: Vergünstigungswirkungen einer Investitionsprämie in Höhe von DM 1.575.-, die mit dem Buchwert der geförderten Investition verrechnet wird

\begin{tabular}{|c|c|c|c|c|c|c|c|c|c|c|c|c|c|c|c|c|c|c|c|c|c|}
\hline \multirow{4}{*}{$\begin{array}{l}\text { Pe- } \\
\text { rio- } \\
\text { de } \\
\text { (1) }\end{array}$} & \multirow{4}{*}{$\begin{array}{l}\text { Ab- } \\
\text { schrei- } \\
\text { bungs- } \\
\text { beträge } \\
\text { in DM } \\
\text { (2) }\end{array}$} & \multirow{4}{*}{$\begin{array}{l}\text { Rest- } \\
\text { buch- } \\
\text { wert } \\
\text { in DM } \\
\text { (3) }\end{array}$} & \multirow{4}{*}{\begin{tabular}{|c|} 
För- \\
der- \\
be- \\
trag \\
in DM \\
$(4)$
\end{tabular}} & \multicolumn{18}{|c|}{ Vergünstigungswirkungen bei alternativen Grenzsteuersätzen in DM } \\
\hline & & & & \multicolumn{12}{|c|}{ konstante Grenzsteuersätze } & \multicolumn{6}{|c|}{ variierende Grenzsteuersätze } \\
\hline & & & & \multicolumn{3}{|c|}{$0 \%$} & \multicolumn{3}{|c|}{208} & \multicolumn{3}{|c|}{40 \& } & \multicolumn{3}{|c|}{608} & \multicolumn{3}{|c|}{ steigend } & \multicolumn{3}{|c|}{ fallend } \\
\hline & & & & 2W & BBW & NBW & ZW & BBW & NBW & $\mathrm{zW}$ & BBW & NBW & 2W & BBW & NBW & zW & BBW & NBW & zW & BBW & NBW \\
\hline $\begin{array}{l}1 \\
2 \\
3 \\
4 \\
5\end{array}$ & $\begin{array}{l}19685 \\
19685 \\
19685 \\
19685 \\
19685\end{array}$ & \begin{tabular}{|r|}
78740 \\
59055 \\
39370 \\
19685 \\
0
\end{tabular} & $\begin{array}{l}1260 \\
-315 \\
-315 \\
-315 \\
-315\end{array}$ & $\begin{array}{l}0 \\
0 \\
0 \\
0 \\
0\end{array}$ & $\begin{array}{l}0 \\
0 \\
0 \\
0 \\
0\end{array}$ & $\begin{array}{l}0 \\
0 \\
0 \\
0 \\
0\end{array}$ & $\begin{array}{r}1512 \\
-63 \\
-63 \\
-63 \\
-63\end{array}$ & $\begin{array}{r}1512 \\
-58 \\
-54 \\
-50 \\
-46\end{array}$ & $\begin{array}{r}1512 \\
-59 \\
-56 \\
-52 \\
-49\end{array}$ & $\begin{array}{l}1449 \\
-126 \\
-126 \\
-126 \\
-126\end{array}$ & $\begin{array}{r}1449 \\
-117 \\
-108 \\
-100 \\
-93\end{array}$ & $\begin{array}{l}1449 \\
-120 \\
-115 \\
-109 \\
-104\end{array}$ & $\begin{array}{l}1386 \\
-189 \\
-189 \\
-189 \\
-189\end{array}$ & $\begin{array}{l}1386 \\
-175 \\
-162 \\
-150 \\
-139\end{array}$ & $\begin{array}{l}1386 \\
-183 \\
-177 \\
-172 \\
-167\end{array}$ & $\begin{array}{r}1512 \\
-95 \\
-126 \\
-158 \\
-189\end{array}$ & $\begin{array}{r}1512 \\
-87 \\
-108 \\
-125 \\
-139\end{array}$ & $\begin{array}{r}1512 \\
-89 \\
-114 \\
-137 \\
-159\end{array}$ & $\begin{array}{r}1386 \\
-158 \\
-126 \\
-95 \\
-63\end{array}$ & $\begin{array}{r}1386 \\
-146 \\
-108 \\
-75 \\
-46\end{array}$ & $\begin{array}{r}1386 \\
-151 \\
-116 \\
-82 \\
-51\end{array}$ \\
\hline$\Sigma=$ & 98425 & & 0 & 0 & 0 & 0 & 1260 & 1303 & 1296 & 945 & 1032 & 1000 & 630 & 760 & 687 & 945 & 1052 & 1013 & 945 & 1011 & 985 \\
\hline & $1 \mathrm{cn}$ & & & & & & & & & 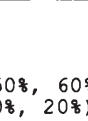 & & & & & & & & & & & \\
\hline
\end{tabular}


Sofern diese Investoren Steuern zu zahlen haben, bemißt sich die Vergünstigung ausschließlich nach der Höhe der Steuerschuld. ${ }^{1}$

$$
B_{P N}=T \quad \text { für } A Z>T
$$

Bei den Vergünstigungswirkungen einer Investitionsprämie, mit der eine Nachversteuerungsmöglichkeit verbunden ist, sind zwei Phasen zu unterscheiden. In der ersten Phase wird dem Investor eine Investitionsprämie gewährt, deren Vergünstigungseffekte vom Grenzsteuersatz unabhängig sind.

Mit der Inanspruchnahme der Investitionsprämie wird der Buchwert des Investitionsobjektes um den Steuerabzugsbetrag gekürzt. Bei einer Investitionsprämie in Höhe von 1,575 Prozent der Anschaffungs- oder Herstellungskosten, die DM 100.000,- betragen, wird der Buchwert durch den Abzug der Prämie auf DM 98.425,- verringert. Damit beginnt die zweite Phase. Die Verringerung des Buchwertes führt über die Abschreibungsdauer zu einer Erhöhung der ertragsteuerlichen Bemessungsgrundlage um jährlich DM 315,- und infolgedessen zu einer Nachversteuerung. Bei der Nachversteuerung hat - abweichend von der bereits besprochenen Variante - der individuelle Grenzsteuersatz des Investors Einfluß auf den Vergünstigungseffekt. Mit zunehmender Höhe des marginalen Ertragsteuersatzes erhöhen sich die steuerlichen Belastungen im Abschreibungszeitraum.

Der Liquiditätsvorteil nimmt in der Investitionsperiode mit der Höhe des Grenzsteuersatzes ab. Er beträgt in der Tabelle D.20 für alle Gewinnunternehmen zwischen 1,51 und 1,39 Prozent der Investitionssumme. Dieser progressionsabhängige Liquiditätseffekt ist darauf zurückzuführen, daß die erste Abschreibung

1 In der Formel D.18 werden folgende Abkürzungen verwandt:

AZ: maximal zulässiger Abzugsbetrag von der Steuerschuld

$\mathrm{B}_{\mathrm{PN}}$ : Barwert einer Investitionsprämie, mit der keine Nachversteuerungsmöglichkeit verbunden ist

T: Steuerschuld 
bereits am Ende der ersten Periode anfällt und somit zu einer grenzsteuersatzabhängigen Nachholwirkung führt. In Verbindung mit der grenzsteuersatzunabhängigen Prämie kommt es per Saldo zu einem mit der Höhe des Grenzsteuersatzes fallenden Liquiditätsvorteil.

Neben der Bedeutung des Grenzsteuersatzes ist beim Barwert dieser Fördermaßnahme der Abdiskontierungseffekt zu beachten, der wiederum von der Länge der steuerlichen Nutzungsdauer, der Höhe des Grenzsteuersatzes und dem Kalkulationszinsfuß abhängt. In der Barwertformel D.19 ${ }^{1}$ werden die Vergünstigungswirkungen einer Investitionsprämie, die zu einer Kürzung der Abschreibungsbasis führt, dargestellt. Der erste Term zeigt die Investitionsprämie und der zweite die Nachversteuerungen. Die erste Abschreibung erfolgt am Ende der ersten Periode.

$$
B_{P B W}=f_{P B W} * I V-\sum_{t \geq 1}^{n} \frac{g_{t} * A K_{t}}{\left(1+i_{g}\right)^{t-1}} \quad \text { für } T \geq A Z
$$

Der Liquiditätsvorteil des Steuerschuldabzugs und die Liquiditätsbelastungen in der Abschreibungsphase fallen zeitlich auseinander; es entsteht ein Zinsgewinn. Dieser Zinsgewinn wächst mit der Höhe des Steuerschuldabzuges. Allerdings ist der Zinsgewinn eine steuerpflichtige Einnahme. Die Zinssteuerbelastung steigt mit zunehmender Höhe der Grenzsteuersätze in der Abschreibungsphase. Der Anteil des Nettozinsgewinns am gesamten Vorteil ist jedoch gering; er beträgt bei einem 60-prozentigen Grenzsteuersatz weniger als ein Zehntel (vgl. Tabelle

1 In der Formel D.19 werden folgende Abkürzungen verwandt:

$\mathrm{AK}_{\mathrm{t}}$ : Kürzung des Normalabschreibungsbetrages in der Periode $\mathrm{t}$

AZ: maximal zulässiger Abzugsbetrag von der Steuerschuld

$\mathrm{B}_{\mathrm{PBW}}$ : Barwert einer Investitionsprämie, die mit dem Buchwert verrechnet wird

$\mathrm{f}_{\mathrm{PBW}}$ : Fördersatz einer Investitionsprämie, die mit dem Buchwert verrechnet wird

IV: förderungsfähiges Investitionsvolumen

g: $\quad$ Grenzsteuersatz der Periode $t$

$i_{g}: \quad$ versteuerter Kalkulationszinssatz

$\mathrm{n}$ : wirtschaftliche Nutzungsdauer

T: $\quad$ Steuerschuld

t: $\quad$ Periode 
D.20). ${ }^{1}$ Die Zinsgewinne erhöhen sich mit zunehmender Länge der Nutzungsdauer (vgl. Tabelle D.21).

Tabelle D.21: Vergleich der Vergünstigungswirkungen einer Investitionsprämie, mit der eine Nachversteuerungsmöglichkeit verbunden ist, unter Berücksichtigung verschieden langer Nutzungszeiträume

\begin{tabular}{|c|c|c|c|c|c|c|c|c|c|c|c|c|}
\hline \multirow{3}{*}{$\begin{array}{l}\text { Nut- } \\
\text { zungs- } \\
\text { dauer } \\
\text { (1) }\end{array}$} & \multicolumn{12}{|c|}{ Vergünstigungswirkungen bei alternativen Grenzsteuersätzen in DM } \\
\hline & \multicolumn{3}{|c|}{08} & \multicolumn{3}{|c|}{208} & \multicolumn{3}{|c|}{408} & \multicolumn{3}{|c|}{608} \\
\hline & $2 W$ & BBW & NBW & $2 W$ & BBW & NBW & $2 \mathrm{~W}$ & BBW & NBW & ZW & BBW & NBW \\
\hline 5 Jahre & 0 & 0 & 0 & 1260 & 1303 & 1296 & 945 & 1032 & 1000 & 630 & 760 & 687 \\
\hline 10 Jahre & 0 & 0 & 0 & 1260 & 1347 & 1333 & 945 & 1118 & 1060 & 630 & 890 & 751 \\
\hline 15 Jahre & 0 & 0 & 0 & 1260 & 1381 & 1363 & 945 & 1187 & 1112 & 630 & 992 & 810 \\
\hline 20 Jahre & 0 & 0 & 0 & 1260 & 1408 & 1389 & 945 & 1241 & 1156 & 630 & 1074 & 863 \\
\hline $\begin{array}{l}\mathrm{ZW}=2 \mathrm{e} \\
\mathrm{BBW}=\mathrm{B} \\
\mathrm{NBW}=\mathrm{N}\end{array}$ & $\begin{array}{l}\text { twert } \\
\text { uttol } \\
\text { ttob }\end{array}$ & $\begin{array}{l}\text { wert } \\
\text { vert }\end{array}$ & & & & & & & & & & \\
\hline
\end{tabular}

Bei variierenden Grenzsteuersätzen (vgl. Tabelle D.20) unterscheiden sich die Vergünstigungseffekte dieser Investitionsprämie deutlich von denen der Förderinstrumente, die die Steuerbemessungsgrundlage kürzen und Nachholwirkungen hervorrufen können. Einmal sind die Wirkungen variierender Grenzsteuersätze äußerst gering. Berücksichtigt man, daß der durchschnittliche Grenzsteuersatz über die gesamte Abschreibungsdauer in beiden Grenzsteuersatzreihen 40 Prozent beträgt und demzufolge mit dem in der Basissituation übereinstimmt, sind die Abweichungen der Nettobarwerte vom Basisvergünstigungseffekt sehr gering. Ein zweiter Unterschied besteht darin, daß dem Investor durch die Förderung kein Verlust entstehen kann. Dies ist darauf zurückzuführen, daß die Prämie selbst steuerfrei ist. Eine vollständige Steuernachholung wäre erst bei einem Grenzsteuersatz von 100 Prozent möglich.

\footnotetext{
${ }^{1}$ Dies wird durch den geringen Unterschied zwischen Brutto- und Nettobarwert deutlich.
} 
Eine Investitionsprämie, die zu einer Kürzung des Buchwertes führt, hat folgende Wirkungen:

- Erstens hat der Investor in der Investitionsperiode eine Steuerersparnis und damit einen Liquiditätsvorteil.

- Zweitens kommt es infolge der Kürzung der Abschreibungsbemessungsgrundlage zu einer mit der Höhe des Grenzsteuersatzes zunehmenden Nachversteuerung.

- Drittens entsteht durch die Verteilung der Nachholwirkungen über die Nutzungsdauer ein Zinsgewinn, der jedoch versteuert werden muß.

Sowohl die Nachversteuerungen als auch die Zinsgewinnbesteuerung belasten Unternehmen mit höheren Grenzsteuersätzen stärker, so daß die Vergünstigungseffekte mit der Höhe des Grenzsteuersatzes fallen.

\section{Zusammenfassung}

Eine grundlegende Gemeinsamkeit beider hier vorgestellten Prämienvarianten ist, daß die Prämie selbst unabhängig vom Grenzsteuersatz ist. Beide Prämien mindern die Steuerzahlungen. Der Vorteil der Prämie, die mit dem Buchwert des Investitionsobjektes zu verrechnen ist, fällt wegen der Nachversteuerung geringer aus. Der Nachholeffekt wird jedoch durch einen Zinsgewinn gemildert.

Die wesentlichen Einflußfaktoren auf die Vergünstigungswirkungen werden aus der Tabelle D.22 deutlich. 
Tabelle D.22: Der Einfluß unterschiedlicher Determinanten auf die Vergünstigungswirkungen (Nettobarwerte) von Investitionsprämien

\begin{tabular}{|c|c|c|c|c|c|c|}
\hline \multirow[b]{3}{*}{ Investitionsprämien } & \multicolumn{6}{|c|}{$\begin{array}{l}\text { Entwicklungsrichtung der Vergünstigungswirkun- } \\
\text { gen (Nettobarwerte) in Abhängigkeit einer Zu- } \\
\text { nahme folgender Determinanten }\end{array}$} \\
\hline & \multicolumn{2}{|c|}{ Grenzsteuersatz } & \multirow{2}{*}{$\begin{array}{l}\text { wirt- } \\
\text { schaft- } \\
\text { liche } \\
\text { Nut- } \\
\text { zungs- } \\
\text { dauer }\end{array}$} & \multirow{2}{*}{$\begin{array}{l}\text { Kalku- } \\
\text { la- } \\
\text { tions- } \\
\text { zins- } \\
\text { satz }\end{array}$} & \multirow{2}{*}{$\begin{array}{l}\text { Inves- } \\
\text { ti- } \\
\text { tions- } \\
\text { summe }\end{array}$} & \multirow{2}{*}{$\begin{array}{l}\text { Förder- } \\
\text { satz } \\
\text { bzw. } \\
\text {-betrag }\end{array}$} \\
\hline & $\begin{array}{l}\text { in den } \\
\text { Zah- } \\
\text { lungs- } \\
\text { reihen }\end{array}$ & $\begin{array}{l}\text { im Dis- } \\
\text { kontie- } \\
\text { rungs- } \\
\text { faktor }\end{array}$ & & & & \\
\hline Investitionsprämie & unabh. & unabh. & unabh. & unabh. & steigt & steigt \\
\hline $\begin{array}{l}\text { Investitionsprämie, die } \\
\text { mit der Abschreibungs- } \\
\text { basis verrechnet wird }\end{array}$ & fällt & fällt & steigt & steigt & steigt & steigt \\
\hline
\end{tabular}




\section{Investitionszuschüsse}

\section{Varianten der Investitionszuschüsse}

Die Investitionszuschüsse sind staatliche Finanzzuwendungen für Investitionen. Im Unterschied zu den in einem späteren Abschnitt noch zu untersuchenden Investitionszulagen muß der Investor die Investitionszuschüsse versteuern.

Investitionszuschüsse werden hauptsächlich in der Regionalförderung ${ }^{1}$ eingesetzt. Diesem Bereich kann man auch die Förderung durch Investitionszuschüs$\mathrm{se}^{2}$ in den neuen Bundesländern zuordnen. Zur Erreichung des Förderzieles bestehen ähnliche Ausgestaltungsmöglichkeit, wie sie bereits bei den Investitionsprämien dargelegt wurden. Vor allem kann der Gesetzgeber eine Beschränkung auf die Nettoinvestitionen oder eine Befristung der Förderung vorsehen.

Die zwei wesentlichen Varianten der Investitionszuschüsse unterscheiden sich durch die Art und Weise, wie die Versteuerung des Zuschusses erfolgt. Der Investitionszuschuß kann zum einen als zu versteuernde Betriebseinnahme gewährt werden. Das bedeutet, daß der Investitionszuschuß die steuerliche Bemessungsgrundlage und damit die Steuerzahlungen des Investors erhöht. Diesen Investitionszuschuß bezeichnet man auch als erfolgswirksame Variante. Eine zweite Variante ist erfolgsneutral. Der Investitionszuschuß erhöht hier nicht die $\mathrm{Be}$ triebseinnahmen, sondern verringert die Abschreibungsbasis des geförderten Investitionsobjektes. Es erfolgt eine Nachversteuerung über die Abschreibungsdauer.

1 In der Bundesrepublik Deutschland, in Frankreich, in Großbritannien, in Schweden und in den USA werden die Investitionszuschüsse im Rahmen der regionalen Wirtschaftsförderung eingesetzt. Vgl. Leibfritz, W./Meurer, C., Steuerliche Investitionsförderung im internationalen Vergleich, a. a. O., S. 95ff; vgl. Lüder, K., Zum Einfluß staatlicher Investitionsfördermaßnahmen auf die unternehmerische Investitionsentscheidung, in: Zeitschrift für Betriebswirtschaft 1984 , S. 543f.

${ }^{2} \mathrm{Vgl}$. Lohse, D./Lornsen-Veit, B./Sonnemann, E., Fördermaßnahmen, in: KPMG Deutsche Treuhandgruppe (Hrsg.), Investitionen in den neuen Bundesländern. Fördermaßnahmen, Restrukturierung, Unternehmenskauf, Düsseldorf 1992, S. $18 \mathrm{ff}$. 
Dem Investor kann ein Wahlrecht zwischen beiden Varianten eingeräumt werden. ${ }^{1}$ Ein solches Wahlrecht führt bei einem identischen Fördersatz zu einer stärkeren Begünstigung des Investors, der einen erfolgsneutralen Investitionszuschuß nutzt.

\section{Vergünstigungseffekte von Investitionszuschüssen}

Der erfolgswirksame Investitionszuschuß erhöht die steuerliche Bemessungsgrundlage in der Investitionsperiode. Der Zuschuß wird dadurch besteuert. In der Formel D. $20^{2}$ wird dieser Zusammenhang formal beschrieben.

$$
B_{z u s}=(1-g) * f_{z U s} * I V
$$

Der Umfang der Besteuerung des Investitionszuschusses steigt mit der Höhe des Grenzsteuersatzes, wodurch gleichzeitig der Nettoeinkommensvorteil sinkt. Verlustunternehmen werden ohne die Berücksichtigung eines intertemporalen Verlustausgleichs am höchsten begünstigt. Der Nettoeinkommenseffekt und damit zugleich der Liquiditätsvorteil in der Förderperiode beträgt bei einem Investitionsvolumen von DM 100.000,- und einem erfolgswirksamen Investitionszuschuß von 1,667 Prozent der Anschaffungs- oder Herstellungskosten zwischen 1,67 und 0,67 Prozent der Investitionskosten (vgl. Tabelle D.23).

${ }^{1}$ Für die Investitionszuschüsse im Rahmen der "Verbesserung der regionalen Wirtschaftsstruktur" besteht ein Wahlrecht. Diese Förderung gilt auch für die neuen Bundesländer.

2 In der Formel D.20 werden folgende Abkürzungen verwandt:

$B_{\text {zus: }}$ Barwert eines erfolgswirksamen Investitionszuschusses

$f_{\text {zus: }} \quad$ Fördersatz eines erfolgswirksamen Investitionszuschusses

g: Grenzsteuersatz

IV: förderungsfähiges Investitionsvolumen 
Tabelle D.23: Vergünstigungswirkungen eines Investitionszuschusses von DM $1.667,-$ bei erfolgswirksamer Behandlung

\begin{tabular}{|c|c|c|c|c|c|c|c|c|c|c|c|c|c|}
\hline \multirow{3}{*}{$\begin{array}{l}\text { Pe- } \\
\text { rio- } \\
\text { de } \\
\\
\text { (1) }\end{array}$} & \multirow{3}{*}{$\begin{array}{c}\mathrm{Zu}- \\
\text { schuß } \\
\text { in } \mathrm{DM} \\
\\
\\
\text { (2) }\end{array}$} & \multicolumn{12}{|c|}{$\begin{array}{c}\text { Vergünstigungswirkungen bei alternativen Grenzsteuer- } \\
\text { steuersätzen in DM }\end{array}$} \\
\hline & & \multicolumn{3}{|c|}{$0 \%$} & \multicolumn{3}{|c|}{$20 \%$} & \multicolumn{3}{|c|}{$40 \frac{8}{8}$} & \multicolumn{3}{|c|}{$60 \%$} \\
\hline & & $2 \mathrm{~W}$ & BBW & NBW & $2 \mathrm{~W}$ & BBW & NBW & ZW & BBW & NBW & $2 \mathrm{~W}$ & BBW & NBW \\
\hline 1 & 1667 & 1667 & 1667 & 1667 & 1333 & 1333 & 1333 & 1000 & 1000 & 1000 & 667 & 667 & 667 \\
\hline $\begin{array}{l}\text { ZW } \\
\text { BBW } \\
\text { NBW }\end{array}$ & $\begin{array}{l}=\text { Zeit } \\
N=\text { Bru } \\
N=\text { Net }\end{array}$ & $\begin{array}{l}\text { wert } \\
\text { ttobar } \\
\text { tobarn }\end{array}$ & $\begin{array}{l}\text { wert } \\
\text { ert }\end{array}$ & & & & & & & & & & \\
\hline
\end{tabular}

Ein Verlustunternehmen wird durch einen Zuschuß am stärksten begünstigt. Dies gilt nicht uneingeschränkt, wenn man die Wechselwirkungen, die sich in Verbindung mit einem intertemporalen Verlustausgleich ergeben, in die Betrachtung einbezieht. Der Zuschuß erhöht die Steuerbemessungsgrundlage und verringert somit den Verlust. Zu einer Versteuerung des Zuschusses kann es wegen des Verlustes nicht kommen. Beim Vor- oder Rücktrag wird der um den Zuschuß verringerte Verlust mit den Erträgen der vor- bzw. nachgelagerten Perioden verrechnet. Weil der Verlust um den Zuschuß gekürzt wird, ist der Umfang der Steuererstattung aus dem Verlustausgleich geringer, als er ohne die Förderung wäre. Ein intertemporaler Verlustausgleich führt auch für ein Verlustunternehmen zu einer Versteuerung des Zuschusses.

Unterschiedliche Wirkungen haben der Rück- und der Vortrag der Verluste. Bei einem Verlustrücktrag wird der aktuelle Verlust mit den vorangegangenen Erträgen verrechnet. Der Verlustrücktrag bewirkt eine Steuererstattung in der Förderperiode, die jedoch wegen des Zuschusses geringer ist. ${ }^{1}$ Der Zuschuß wird über den Verlustrücktrag noch in der Förderperiode versteuert. Demgegenüber bewirkt ein Verlustvortrag eine Versteuerung des Zuschusses und damit eine Liquiditätsbelastung in einer zukünftigen Periode. Der Liquiditätsvorteil in

${ }^{1}$ Bei einem Verlustrücktrag schrumpft der Vorteil eines erfolgswirksamen Investitionszuschusses von DM 1.667,- mit zunehmendem Grenzsteuersatz bis auf DM 667,- zusammen. 
der Förderperiode umfaßt den gesamten Zuschußbetrag. ${ }^{1}$ Zusammenfassend kann festgehalten werden, daß durch den Zuschuß nur für die Verlustunternehmen eine hohe Begünstigung zustande kommt, die jedoch ihre Verluste nicht ausgleichen können. Einen höheren Liquiditätsvorteil in der Förderperiode haben die Verlustunternehmen, die ihre Verluste nur vortragen, aber nicht zurücktragen können.

Bei einer erfolgsneutralen Behandlung des Investitionszuschusses muß der Investor den mit der Durchführung der geförderten Investition erhaltenen Geldbetrag zunächst nicht versteuern. Stattdessen wird die Abschreibungsbasis des Investitionsobjektes gekürzt. Infolge der verminderten Abschreibungen erhöht sich über die Abschreibungsdauer die ertragsteuerliche Bemessungsgrundlage. Der Umfang der Nachholwirkungen ist folglich durch die Höhe der Grenzsteuersätze in der Nachversteuerungsphase bestimmt. Je höher die Grenzsteuersätze in der Nachversteuerungsphase sind, desto höher sind die Liquiditätsbelastungen.

Der Barwert eines erfolgsneutralen Investitionszuschusses wird in der Formel D. $21^{2}$ dargestellt. Der erste Term zeigt den steuerfreien Zuschuß und der zweite die jährlichen Nachversteuerungen.

$$
B_{\text {ZUBW }}=f_{\text {ZUBW }} * I V-\sum_{i=1}^{n} \frac{g_{t} * A K_{t}}{\left(I+i_{g}\right)^{t-1}}
$$

Der Investor hat durch einen erfolgsneutralen Investitionszuschuß weitgehend gleiche Vorteile wie bei einer Förderung durch eine Investitionsprämie, die mit

${ }^{1}$ In der Tabelle D.23 beträgt der Liquiditätsvorteil in der Förderperiode DM 1.667,-

${ }^{2}$ In der Formel D.21 werden folgende Abkürzungen verwandt:

AK $K_{\imath}$ Kürzung des Normalabschreibungsbetrages in Periode t

$\mathrm{B}_{\text {ZuBw: }}$ Barwert eines erfolgsneutralen Investitionszuschusses

$f_{\text {zuBw: }}$ Fördersatz eines erfolgsneutralen Investitionszuschusses

gi: $\quad$ Grenzsteuersatz der Periode $t$

IV: förderungsfähiges Investitionsvolumen

$i_{g}: \quad$ versteuerter Kalkulationszinssatz

t: $\quad$ Periode 
Tabelle D.24: Vergünstigungswirkungen eines erfolgsneutralen Investitionszuschusses in Höhe von DM 1.575.-

\begin{tabular}{|c|c|c|c|c|c|c|c|c|c|c|c|c|c|c|c|c|c|c|c|c|c|}
\hline \multirow{4}{*}{ 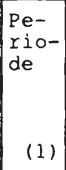 } & \multirow{4}{*}{$\begin{array}{l}\text { Ab- } \\
\text { schrei- } \\
\text { bungs- } \\
\text { beträge } \\
\text { in DM } \\
\text { (2) }\end{array}$} & \multirow{4}{*}{$\begin{array}{l}\text { Rest- } \\
\text { buch- } \\
\text { wert } \\
\text { in DM } \\
\text { (3) }\end{array}$} & \multirow{4}{*}{$\begin{array}{l}\text { För- } \\
\text { der- } \\
\text { betrag } \\
\text { in DM } \\
\\
\text { (4) }\end{array}$} & \multicolumn{18}{|c|}{ Vergünstigungswirkungen bei alternativen Grenzsteuersätzen in DM } \\
\hline & & & & \multicolumn{12}{|c|}{ konstante Grenzsteuersätze } & \multicolumn{6}{|c|}{ variierende Grenzsteuersatze } \\
\hline & & & & \multicolumn{3}{|c|}{08} & \multicolumn{3}{|c|}{$20 \%$} & \multicolumn{3}{|c|}{$40 \%$} & \multicolumn{3}{|c|}{$60 \%$} & \multicolumn{3}{|c|}{ steigend } & \multicolumn{3}{|c|}{ fallend } \\
\hline & & & & $2 \mathrm{~W}$ & BBW & NBW & $2 \mathrm{~W}$ & BBW & NBW & $\mathrm{zW}$ & BBW & NBW & zW & BBW & NBW & ZW & BBW & NBW & $2 \mathrm{~W}$ & BBW & NBW \\
\hline $\begin{array}{l}1 \\
2 \\
3 \\
4 \\
5\end{array}$ & $\begin{array}{l}19685 \\
19685 \\
19685 \\
19685 \\
19685\end{array}$ & \begin{tabular}{|r|}
78740 \\
59055 \\
39370 \\
19685 \\
0
\end{tabular} & $\begin{array}{l}1260 \\
-315 \\
-315 \\
-315 \\
-315\end{array}$ & \begin{tabular}{|r|}
1575 \\
0 \\
0 \\
0 \\
0
\end{tabular} & $\begin{array}{r}1575 \\
0 \\
0 \\
0 \\
0\end{array}$ & \begin{tabular}{|r|}
1575 \\
0 \\
0 \\
0 \\
0
\end{tabular} & $\mid \begin{array}{r}1512 \\
-63 \\
-63 \\
-63 \\
-63\end{array}$ & $\begin{array}{r}1512 \\
-58 \\
-54 \\
-50 \\
-46\end{array}$ & \begin{tabular}{|r|}
1512 \\
-59 \\
-56 \\
-52 \\
-49
\end{tabular} & $\begin{array}{l}1449 \\
-126 \\
-126 \\
-126 \\
-126\end{array}$ & $\left|\begin{array}{r}1449 \\
-117 \\
-108 \\
-100 \\
-93\end{array}\right|$ & $\begin{array}{r}1449 \\
-120 \\
-109 \\
-109 \\
-104\end{array}$ & $\begin{array}{r}1386 \\
-189 \\
-189 \\
-189 \\
-189\end{array}$ & $\begin{array}{l}1386 \\
-175 \\
-150 \\
-150 \\
-139\end{array}$ & $\left|\begin{array}{l}1386 \\
-183 \\
-172 \\
-172 \\
-167\end{array}\right|$ & $\mid \begin{array}{r}1512 \\
-95 \\
-158 \\
-158 \\
-189\end{array}$ & $\begin{array}{r}1512 \\
-87 \\
-125 \\
-125 \\
-139\end{array}$ & $\left|\begin{array}{r}1512 \\
-89 \\
-137 \\
-137 \\
-159\end{array}\right|$ & $\begin{array}{r}1386 \\
-158 \\
-95 \\
-95 \\
-63\end{array}$ & $\begin{array}{r}1386 \\
-146 \\
-75 \\
-75 \\
-46\end{array}$ & $\begin{array}{r}1386 \\
-151 \\
-82 \\
-82 \\
-51\end{array}$ \\
\hline$\Sigma=$ & 98425 & & 0 & 1575 & 1575 & 1575 & 1260 & 1303 & 1296 & 945 & 1032 & 1000 & 630 & 760 & 687 & 945 & 1052 & 1013 & 945 & 1011 & 985 \\
\hline $\begin{array}{l}Z \\
B \\
N \\
j\end{array}$ & $\mathrm{cn}$ & & & & & & & & & 20 & & & & & & & & & & & \\
\hline
\end{tabular}


dem Buchwert der geförderten Investition verrechnen wird (vgl. Tabelle D.24 und D.25):

- Der Investor kommt in der Investitionsperiode in den Genuß eines Liquiditätsvorteils. Im Unterschied zur Investitionsprämie gilt das auch für Verlustunternehmen.

- Die staatliche Zuwendung wird quasi in der Abschreibungsphase versteuert. Der Nettovorteil aus der Zuwendung sinkt mit der Höhe der Grenzsteuersätze in der Nachversteuerungsphase.

- Darüber hinaus hat der Investor über den Abschreibungszeitraum einen steuerpflichtigen Zinsgewinn.

- Außerdem werden mit zunehmender Länge der Nutzungsdauer die Nachholwirkungen auf einen längeren Zeitraum verteilt. Infolgedessen erhöhen sich mit der Länge der Nutzungsdauer die zu versteuernden Zinsgewinne und damit auch die Nettovorteile.

- Diese Zinsgewinne wachsen mit der Höhe des Kalkulationszinssatzes.

Die Nachholwirkungen und die Zinsgewinnbesteuerung verringern mit zunehmender Höhe des Grenzsteuersatzes den Vorteil aus dieser Fördermaßnahme.

Tabelle D.25: Vergleich der Vergünstigungswirkungen eines erfolgsneutralen Investitionszuschusses unter Berücksichtigung verschieden langer Nutzungszeiträume

\begin{tabular}{|c|c|c|c|c|c|c|c|c|c|c|c|c|}
\hline \multirow{3}{*}{$\begin{array}{l}\text { Nut- } \\
\text { zungs- } \\
\text { dauer } \\
\text { (1) }\end{array}$} & \multicolumn{12}{|c|}{ Vergünstigungswirkungen bei alternativen Grenzsteuersätzen in DM } \\
\hline & \multicolumn{3}{|c|}{$0 \%$} & \multicolumn{3}{|c|}{$20 \%$} & \multicolumn{3}{|c|}{40 \% } & \multicolumn{3}{|c|}{60 iे } \\
\hline & $2 W$ & BBW & NBW & $2 W$ & BBW & NBW & $\mathrm{ZW}$ & BBW & NBW & $2 W$ & BBW & NBW \\
\hline 5 Jahre & 1575 & 1575 & 1575 & 1260 & 1303 & 1296 & 945 & 1032 & 1000 & 630 & 760 & 687 \\
\hline 10 Jahre & 1575 & 1575 & 1575 & 1260 & 1347 & 1333 & 945 & 1118 & 1060 & 630 & 890 & 751 \\
\hline 15 Jahre & 1575 & 1575 & 1575 & 1260 & 1381 & 1363 & 945 & 1187 & 1112 & 630 & 992 & 810 \\
\hline 20 Jahre & 1575 & 1575 & 1575 & 1260 & 1408 & 1389 & 945 & 1241 & 1156 & 630 & 1074 & 863 \\
\hline $\begin{array}{l}2 \mathrm{~W}=\mathrm{Ze} \\
\mathrm{BBW}=\mathrm{B} \\
\mathrm{NBW}=\mathrm{N}\end{array}$ & $\begin{array}{l}\text { itwer } \\
\text { ruttol } \\
\text { ettob }\end{array}$ & $\begin{array}{l}\text { arwert } \\
\text { rwert }\end{array}$ & & & & & & & & & & \\
\hline
\end{tabular}


Im Gegensatz zu den Investitionsprämien werden Verlustunternehmen durch den erfolgsneutralen Zuschuß grundsätzlich am höchsten gefördert. Dieses Ergebnis ist - analog zur erfolgswirksamen Variante - bei der Einbeziehung eines interperiodischen Verlustausgleichs zu modifizieren. Der Verlustfall ist hier allerdings nicht für den Zuschuß in der Investitionsperiode erheblich, sondern für die Nachversteuerungswirkungen. Wenn ein Investor in der Abschreibungsphase Verluste hat, bleiben die Nachversteuerungswirkungen aus. Jedoch kann es über den Verlustausgleich zu Nachversteuerungen kommen.

\section{Zusammenfassung}

Im Vergleich zu den oben vorgestellten Investitionsförderinstrumenten setzen die Investitionszuschüsse keinen Gewinn in der Begünstigungsperiode voraus. Verlustunternehmen erhalten den Förderbetrag ohne einen Abzug und sind gegenüber Gewinnunternehmen bevorteilt, sofern kein interperiodischer Verlustausgleich vorgenommen wird.

Die Einflußfaktoren auf die Vergünstigungswirkungen sind in der Tabelle D.26 zusammengefaßt.

Tabelle D.26: Der Einfluß unterschiedlicher Determinanten auf die Vergünstigungswirkungen (Nettobarwerte) von Investitionszuschüssen

\begin{tabular}{|c|c|c|c|c|c|c|}
\hline \multirow[b]{3}{*}{ Investitionszuschüsse } & \multicolumn{6}{|c|}{$\begin{array}{l}\text { Entwicklungsrichtung der Vergünstigungswirkun- } \\
\text { gen (Nettobarwerte) in Abhängigkeit einer Zu- } \\
\text { nahme folgender Determinanten }\end{array}$} \\
\hline & \multicolumn{2}{|c|}{ Grenzsteuersatz } & \multirow{2}{*}{$\begin{array}{l}\text { wirt- } \\
\text { schaft- } \\
\text { liche } \\
\text { Nut- } \\
\text { zungs- } \\
\text { dauer }\end{array}$} & \multirow{2}{*}{$\begin{array}{l}\text { Kalku- } \\
\text { la- } \\
\text { tions- } \\
\text { zins- } \\
\text { satz }\end{array}$} & \multirow{2}{*}{$\begin{array}{l}\text { Inves- } \\
\text { ti- } \\
\text { tions- } \\
\text { summe }\end{array}$} & \multirow{2}{*}{$\begin{array}{l}\text { Förder- } \\
\text { satz } \\
\text { bzw. } \\
\text {-betrag }\end{array}$} \\
\hline & $\begin{array}{l}\text { in den } \\
\text { Zah- } \\
\text { lungs- } \\
\text { reihen }\end{array}$ & $\begin{array}{l}\text { im Dis- } \\
\text { kontie- } \\
\text { rungs- } \\
\text { faktor }\end{array}$ & & & & \\
\hline $\begin{array}{l}\text { erfolgswirksamer } \\
\text { Investitionszuschuß }\end{array}$ & fällt & unabh. & unabh. & unabh. & steigt & steigt \\
\hline $\begin{array}{l}\text { erfolgsneutraler } \\
\text { Investitionszuschuß }\end{array}$ & fällt & fällt & steigt & steigt & steigt & steigt \\
\hline
\end{tabular}


Beide Investitionszuschüsse führen zu Vergünstigungswirkungen, die mit der Höhe des Grenzsteuersatzes zunehmen. Die unterschiedliche steuerliche Behandlung der Zuschüsse wirkt sich dahingehend aus, daß bei der erfolgsneutralen Variante auch die Wirkungen der Länge der Nutzungsdauer und der Höhe des Kalkulationszinsfußes auf das Nettoeinkommen zu beachten sind.

\section{Zinszuschüsse}

\section{Abgrenzung von Finanzierungshilfen}

Die Zinszuschüsse sind ein Instrument, das man zu den sogenannten staatlichen Finanzierungshilfen zählt. Diese Instrumente werden in der Praxis häufig kombiniert eingesetzt. Aus diesem Grund soll eine kurze Abgrenzung vorgenommen werden.

Die staatlichen Fördermaßnahmen im Bereich der Finanzierungshilfen setzen die Aufnahme eines Kredites voraus. Insofern unterscheiden sie sich von anderen Förderinstrumenten. Der Gesetzgeber will mit diesen Maßnahmen die Fremdfinanzierung eines Investitionsvorhabens erleichtern und verbilligen. Mit den Finanzierungshilfen werden Unternehmen unterstützt, deren Zugang zu den Kreditmärkten aufgrund minderer oder mangelnder Sicherheiten beschränkt ist. Diese Kreditnehmer müssen deshalb für ihre privatwirtschaftlichen Kredite in den Zinsen hohe Risikoprämien bezahlen. Finanzierungshilfen sind aus diesen Gründen besonders für neu gegründete ${ }^{1}$ und einen Teil der mittelständischen

${ }^{1}$ Die Geschäftsbanken treffen ihre Kreditentscheidungen häufig auf der Grundlage der Qualität der angebotenen Sicherheiten und der Geschäftszahlen früherer Jahre, vgl. May, E., Erfolgreiche Existenzgründungen und öffentliche Förderung. Eine vergleichende empirische Analyse geförderter und nichtgeförderter Gründungsunternehmen, Göttingen 1981, S. 81. Dazu kommt in der Regel eine geringe Eigenkapitalquote, die die Fremdfinanzierungsmöglichkeiten beschränkt, vgl. Hunsdiek, D., Ausgestaltung und Beurteilung der Existenzgründungsförderung, in: Nathusius, K./Klandt, H./Kirschbaum, G. (Hrsg.), Unternehmensgründung. Konfrontation von Forschung und Praxis, Bergisch-Gladbach 1984, S. 122. 
Unternehmen $^{1}$ von Bedeutung. Außerdem erleichtern diese Instrumente die Finanzierung von risikoreichen Investitionen. ${ }^{2}$ Es lassen sich drei Maßnahmen bei den staatlichen Finanzierungshilfen unterscheiden (vgl. Abbildung D.3).

Abbildung D.3: Übersicht über die staatlichen Finanzierungshilfen

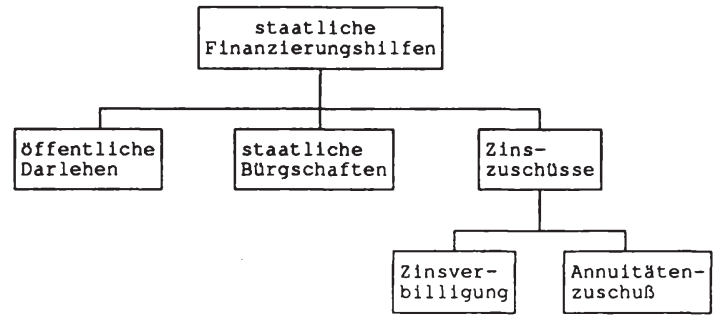

Bei den öffentlichen Darlehen tritt der Staat als Gläubiger auf, indem er der zu fördernden Unternehmung einen Kredit gewährt. ${ }^{3}$ Im Vergleich mit einer privatwirtschaftlichen Kreditnahme sind für den Schuldner mit dem staatlichen Kredit Vorteile verbunden. Er erhält Sonderkonditionen, deren Art und Umfang im Einzelfall verschieden sind. ${ }^{4}$ Mit Hilfe einer staatlichen Bürgschaft wird

${ }^{1}$ Vgl. Mischon, C., Zum Problem der Diskriminierung mittelständischer Betriebe. Eine empirische Analyse, Göttingen 1980, S. 83ff.

2 Finanzierungsengpässe können besonders bei riskanten Innovationen auftreten, vgl. Cassier, S. C., Investitionen und Finanzierung, in: Besters, H. (Hrsg.), Wandlungen im Investitionsverhalten, Baden-Baden 1983, S. 53 und 59f.

${ }^{3}$ Der Kredit muß hierbei nicht von Bund, Ländern oder Kommunen bereitgestellt werden, sondern kann auch von Sonderfonds, Sondervermögen (z. B. ERP-Sondervermögen) und öffentlich rechtlichen Kreditinstituten (z. B. Kreditanstalt für Wiederaufbau) gewährt werden.

${ }^{4}$ Sonderkonditionen können beispielsweise für den Zinssatz, die Kreditnebenkosten, die Höhe des Auszahlungsbetrages, die Kreditsicherung, die Tilgungsbedingungen und die Laufzeit gewährt werden. Vgl. Zeitel, G., Staatliche Darlehensgewährung als Mittel der Finanzund Wirtschaftspolitik, in: Finanzarchiv 1967, S. 202ff; Dickertmann, D., Öffentliche Finanzierungshilfen. Darlehen, Schuldendiensthilfen und Bürgschaften als Instrument des finanzwirtschaftlichen Interventionismus, Baden-Baden 1980, S. 51. 
ein privater Kredit gesichert. Die Reduzierung des Kreditausfallrisikos verschafft dem Kreditnehmer die Möglichkeit, beim privaten Kreditgeber ebenfalls Sonderkonditionen auszuhandeln. ${ }^{1}$ Über Art und Ausmaß der Sonderkonditionen entscheidet praktisch der Markt.

Außerdem gewährt der Staat Zinszuschüsse. Bei diesem Instrument übernimmt der Staat einen Teil der Zinsbelastung und verringert auf diese Weise die effektiven vom Unternehmen zu zahlenden Fremdkapitalkosten. Diese Entlastung kann über eine Zinsverbilligung oder einen Annuitätenzuschuß herbeigeführt werden.

Die Vorteile für den Investor aus dem öffentlichen Darlehen und der staatlichen Bürgschaft sind zum Teil schwer quantifizierbar, weil diese Vorteile nicht explizit in Geld ausgedrückt werden können. Dennoch handelt es sich hierbei um geldwerte Leistungen. Darüber hinaus beinhalten diese Instrumente häufig mehrere Leistungen. Aus diesem Grund werden in dieser Arbeit die öffentlichen Darlehen und die staatlichen Bürgschaften nicht weiter untersucht. Die folgende Analyse wird sich ausschließlich den Vergünstigungswirkungen der Zinszuschüsse widmen. Da aus der Gewährung von öffentlichen Darlehen und staatlichen Bürgschaften direkt bzw. indirekt auch eine Zinsverbilligung folgen kann, wird auch ein möglicher Vorteil dieser Maßnahmen mitbehandelt.

\section{Erscheinungsformen und Ausgestaltungselemente der Zinszuschüsse}

Der Gesetzgeber kann Zinszuschüsse als Zinsverbilligung und Annuitätenzuschuß gewähren. Beide sollen im folgenden näher erläutert werden.

${ }^{1}$ In der Tendenz wird sich auch hier eine Zinsverbilligung einstellen. Vgl. Siedenberg, A., Investitionsorientierte Fiskalpolitik, Berlin 1976, S. 58; Dickertmann, D., Öffentliche Finanzierungshilfen. Darlehen, Schuldendiensthilfen und Bürgschaften als Instrument des finanzwirtschaftlichen Interventionismus, a. a. O., S. 59. 
Bei einer Zinsverbilligung leistet der Staat in der Regel einen Zuschuß direkt an das kreditgewährende Institut, das quasi als Subventionsmittler auftritt. Dadurch kann der Kreditgeber dem Kreditnehmer einen staatlich verbilligten Kreditzins gewähren. ${ }^{1}$ Der Umfang der Finanzzuwendung bemißt sich nicht nur nach dem Ausmaß der Zinssatzreduzierung, sondern auch nach dem gewählten Verfahren der Zinsverbilligung, den Tilgungsmodalitäten, der Kredithöhe und nicht zuletzt nach der Länge des Zinsbegünstigungszeitraums.

Bei der Verbilligung des Kreditzinses durch eine staatliche Förderung können zwei Verfahren verwandt werden, die die Vergünstigungseffekte beeinflussen können. Im ersten Verfahren wird der Kreditzinssatz auf ein bestimmtes Zinsniveau herabsubventioniert. Wurde zwischen dem Kreditgeber und dem Investor ein variabler Zinssatz über die Kreditlaufzeit vereinbart, kann das Ausmaß der Zinsverbilligung im Begünstigungszeitraum schwanken. Das Zinsänderungsrisiko wird bei diesem Verfahren auf den Staat übertragen. ${ }^{2}$

Eine zweite Möglichkeit besteht darin, den marktüblichen Kreditzinssatz für den Investor um eine bestimmte Zahl von Prozentpunkten zu verringern. Damit trägt der Investor bei einem Kredit mit einem variablen Zinssatz das Zinsänderungsrisiko. Infolgedessen kann beim ersten Verfahren bei gleichzeitiger Vereinbarung eines variablen Kreditzinses - im Gegensatz zum zweiten Verfahren - das Aus$\mathrm{ma} ß$ der jährlichen Zinsverbilligung schwanken. Neben den verfahrensimmanenten Schwankungen, die vor allem auf Marktzinsschwankungen zurückzuführen sind, kann bei beiden Verfahren durch eine degressive Staffelung eine jährlich abnehmende Zinssatzreduzierung herbeigeführt werden. Eine im Zeitablauf fallende Staffelung der Zinsverbilligung ist dann angebracht, wenn der Investor besonders in der Anfangsphase der Investition von den Fremdkapitalkosten entlastet werden soll. Somit kann das jährliche Ausmaß der Kreditzinssatzreduzie-

${ }^{1}$ Vgl. Richter, J., Die Zinssubventionen in der Bundesrepublik Deutschland, Frankfurt a. M. 1970 , S. $16 \mathrm{f}$.

${ }^{2}$ Dickertmann, D., Öffentliche Finanzierungshilfen. Darlehen, Schuldendiensthilfen und Bürgschaften als Instrument des finanzwirtschaftlichen Interventionismus, a. a. O., S. 76ff. 
rung wirtschaftspolitisch gewollt bzw. verfahrensbedingt schwanken oder eine jährlich gleichbleibende Höhe aufweisen.

Die jährlichen Zinszahlungen bemessen sich nach der Höhe der Kreditzinsen und der der Restschuld, die die Zinszahlungsbemessungsgrundlage darstellt. Je höher die Restschuld, desto höher sind die Zinszahlungen. Bei einer Zinsverbilligung steigt der Vorteil des Investors mit der Höhe der Restschuld.

Die Restschuldhöhe hängt ihrerseits von der Kredithöhe und dem Tilgungsmodus ab, der die Verteilung der Tilgungsraten im Zeitablauf festlegt. Die Kredithöhe richtet sich nach dem Fremdfinanzierungsbedarf des Investors, und die Tilgungsmodalitäten sind durch die Konditionen auf dem Kreditmarkt gegeben. Beide Determinanten bewegen sich weitgehend außerhalb der staatlichen Einflußsphäre, sind jedoch von Bedeutung für die Höhe des Zinszuschusses. ${ }^{1}$ Wenn man konstante Tilgungsraten unterstellt, verringert sich die Restschuld und damit die Zinszahlungen. Das bedeutet aber auch, daß die Einsparungen bei den Zinszahlungen im Zeitablauf sinken. Der größte Vorteil wird dem Investor zuteil, wenn der Kredit im Zinsbegünstigungszeitraum tilgungsfrei ist, dann bleibt die Förderung über diesen Zeitraum konstant.

Neben der Höhe des jährlichen Zinszuschusses ist die Länge des Förderzeitraums für die Vergünstigungswirkungen von Bedeutung. Der Förderungszeitraum muß nicht zwingend mit der Nutzungsdauer der geförderten Investition übereinstimmen. Die wirtschaftspolitische Absicht, die mit der Maßnahme verbunden wird, liegt meist darin, die hohen Anfangsbelastungen zu reduzieren. Eine sich über den gesamten Nutzungszeitraum spannende Förderung ist infolgedessen nicht erforderlich.

${ }^{1}$ Es besteht zwar die Möglichkeit, daß der Staat die Gewährung einer Zinsverbilligung an einen Tilgungsmodus bindet und die begünstigte Kredithöhe beschränkt, jedoch sind das keine notwendigen Ausgestaltungskriterien. 
Mit dem Annuitätenzuschuß wird ein anderer Weg beschritten, um die vom Markt beschafften Finanzierungsmittel zu verbilligen. Der Annuitätenzuschuß richtet sich direkt an den Kreditnehmer. Er erhält einen Zuschuß durch den er von einem Teil der Fremdkapitalkosten entlastet wird. Der Zuschuß muß nicht auf die Reduzierung der Zinslast beschränkt sein, sondern kann auch auf die Tilgungszahlungen ausgedehnt werden. ${ }^{1}$

Die entscheidenden Ausgestaltungselemente sind die Höhe des jährlichen Annuitätenzuschusses und - wie bei der Zinsverbilligung - die Länge des Begünstigungszeitraumes. Auch hier kann der Annuitätenzuschuß vergleichbar der Zinsverbilligung zeitlich degressiv gestaltet werden.

\section{Vergünstigungswirkungen der Zinszuschüsse}

Bei einer Zinsverbilligung handelt es sich nicht um einen direkten Zuschuß an den Investor, sondern an den Kreditgeber. Der Kreditgeber verbilligt jedoch den Kreditzins, so daß sich die pagatorische Zinslast für den Kreditnehmer reduziert. Aus bilanzieller Sicht stellen Zinszahlungen Betriebsaufwendungen dar, die die steuerliche Bemessungsgrundlage für die Einkommen- bzw. Körperschaftsteuer mindern. Weil die Zinsverbilligung eine Verringerung der Zinszahlungen zur Folge hat, erhöht sich ceteris paribus die steuerliche Bemessungsgrundlage in der Begünstigungsperiode; es erfolgt eine Versteuerung des Zinszuschusses. Diese faktische Besteuerung des Zinszuschusses bewirkt, daß Investoren mit einem niedrigen Grenzsteuersatz stärker begünstigt werden als solche mit einem höheren. Verlustunternehmen haben die höchsten Nettoeinkommensvorteile, wobei es - wie bei den erfolgswirksamen Zuschüssen - über den interperiodischen Verlustausgleich zu Nachversteuerungen kommen kann.

1 Hier besteht die Möglichkeit, den Anteil der Tilgungsbeihilfe als zurückzuzahlendes Darlehen zu gewähren, vgl. Richter, J., Die Zinssubventionen in der Bundesrepublik Deutschland, a. a. O., S. 21. 
Tabelle D.27: Vergünstigungswirkungen einer Zinsverbilligung um 0,59 Prozentpunkte für einen Kredit mit konstanten Tilgungsraten

\begin{tabular}{|c|c|c|c|c|c|c|c|c|c|c|c|c|c|c|c|c|c|c|c|c|c|}
\hline \multirow{4}{*}{$\begin{array}{l}\text { Pe- } \\
\text { rio- } \\
\text { de } \\
\\
\text { (1) }\end{array}$} & \multirow{4}{*}{$\begin{array}{l}\text { Rest- } \\
\text { schuld } \\
\text { in DM } \\
\text { (2) }\end{array}$} & \multirow{4}{*}{$\begin{array}{l}\text { Til- } \\
\text { gung } \\
\text { in DM } \\
\\
\\
\text { (3) }\end{array}$} & \multirow{4}{*}{$\begin{array}{l}2 \text { ins- } \\
\text { be- } \\
\text { gün- } \\
\text { sti- } \\
\text { gung } \\
\text { in DM } \\
(4)\end{array}$} & \multicolumn{18}{|c|}{ Vergünstigungswirkungen bei alternativen Grenzsteuersätzen in DM } \\
\hline & & & & \multicolumn{12}{|c|}{ konstante Grenzsteuersätze } & \multicolumn{6}{|c|}{ variierende Grenzsteuersätze } \\
\hline & & & & \multicolumn{3}{|c|}{08} & \multicolumn{3}{|c|}{208} & \multicolumn{3}{|c|}{40 \& } & \multicolumn{3}{|c|}{608} & \multicolumn{3}{|c|}{ steigend } & \multicolumn{3}{|c|}{ fallend } \\
\hline & & & & $\mathrm{ZW}$ & BBW & NBW & ZW & BBW & NBW & $2 W$ & BBW & NBW & $2 \mathrm{~W}$ & BBW & NBW & $2 W$ & BBW & NBW & $\mathrm{ZW}$ & BBW & NBW \\
\hline $\begin{array}{l}1 \\
2 \\
3 \\
4 \\
5\end{array}$ & $\begin{array}{r}80000 \\
60000 \\
40000 \\
20000 \\
0\end{array}$ & $\begin{array}{l}20000 \\
20000 \\
20000 \\
20000 \\
20000\end{array}$ & $\begin{array}{l}590 \\
472 \\
354 \\
236 \\
118\end{array}$ & $\begin{array}{l}590 \\
472 \\
354 \\
236 \\
118\end{array}$ & $\begin{array}{r}590 \\
437 \\
304 \\
187 \\
87\end{array}$ & $\begin{array}{r}590 \\
437 \\
304 \\
187 \\
87\end{array}$ & $\begin{array}{r}472 \\
378 \\
283 \\
189 \\
94\end{array}$ & $\begin{array}{r}472 \\
350 \\
243 \\
150 \\
69\end{array}$ & $\begin{array}{r}472 \\
355 \\
250 \\
157 \\
74\end{array}$ & $\begin{array}{r}354 \\
283 \\
213 \\
142 \\
71\end{array}$ & $\begin{array}{r}354 \\
262 \\
182 \\
112 \\
52\end{array}$ & $\begin{array}{r}354 \\
270 \\
194 \\
123 \\
59\end{array}$ & $\begin{array}{r}236 \\
189 \\
142 \\
94 \\
47\end{array}$ & $\begin{array}{r}236 \\
175 \\
121 \\
75 \\
35\end{array}$ & $\begin{array}{r}236 \\
183 \\
133 \\
86 \\
42\end{array}$ & $\begin{array}{r}472 \\
331 \\
213 \\
118 \\
47\end{array}$ & $\begin{array}{r}472 \\
3 C 6 \\
182 \\
94 \\
35\end{array}$ & $\begin{array}{r}472 \\
313 \\
192 \\
103 \\
40\end{array}$ & $\begin{array}{r}236 \\
236 \\
213 \\
165 \\
94\end{array}$ & $\begin{array}{r}236 \\
219 \\
182 \\
131 \\
69\end{array}$ & $\begin{array}{r}236 \\
227 \\
195 \\
144 \\
77\end{array}$ \\
\hline$\Sigma=$ & & 100000 & 1771 & 1771 & 1606 & 1606 & 1417 & 1285 & 1308 & 1063 & 963 & 1000 & 708 & 642 & 680 & 1181 & 1089 & 1120 & 945 & 838 & 879 \\
\hline $\begin{array}{l}2 h \\
\mathrm{BE} \\
\mathrm{NB} \\
j a \\
j a\end{array}$ & $\begin{array}{l}=2 \mathrm{eit} \\
\mathrm{w}=\mathrm{Bru} \\
\mathrm{W}=\mathrm{Net} \\
\text { hrlich } \\
\text { hrlich }\end{array}$ & $\begin{array}{l}\text { steigeno } \\
\text { fallende }\end{array}$ & $\begin{array}{l}\text { de Gr } \\
\text { e Gre }\end{array}$ & 80 & ers & $\begin{array}{l}t z e \\
z e\end{array}$ & $\begin{array}{l}08, \\
8,\end{array}$ & 8), & $\begin{array}{l}08, \\
\text { of, } 3\end{array}$ & 0\%, & 6081 & & & & & & & & & & \\
\hline
\end{tabular}


Ein Liquiditätsvorteil fällt nicht nur in der Investitionsperiode an, sondern über den Begünstigungszeitraum. Der Liquiditätsgewinn in der ersten Periode ist allerdings - bei gleicher fiskalischer Belastung - deutlich geringer als bei anderen Fördermaßnahmen. Er erreicht nur etwas mehr als ein Drittel des ohnehin nicht besonders hohen Liquiditätsvorteils der erfolgswirksamen Investitionszuschüsse (vgl. Tabelle D.23 und D.27).

Der Barwert ${ }^{1}$ eines Zinszuschusses läßt sich formal wie folgt darstellen: ${ }^{2}$

$$
B_{z Z}=\sum_{t=1}^{u} \frac{\left(I-g_{t}\right) * z_{t} * K_{t}}{\left(I+i_{g}\right)^{t-1}}
$$

Der Umfang der Zinszahlungsverringerung in der Periode $(t)$ wird durch die Zinsverbilligung $\left(\mathrm{z}_{\mathrm{l}}\right)$ und die Restschuld $\left(\mathrm{K}_{\mathrm{t}}\right)$ bestimmt.

Für die Barwerte ist vor allem die Verteilung der Liquiditätsvorteile von Bedeutung. Umso höhere Zinszuschüsse in der Anfangsphase der Investition gewährt werden, desto höher ist der Vergünstigungseffekt. Das bedeutet, daß die später gewährten Zinszuschüsse stärker abdiskontiert werden. Ökonomisch läßt sich der Abdiskontierungseffekt auf folgende Weise erklären. Würde der Investor den Zuschuß in einem Betrag im Investitionszeitpunkt erhalten, könnte er sich in geringerem Umfang verschulden und müßte auf diese Weise weniger Zinsen bezahlen. Höhere Zinszahlungen können jedoch steuerlich geltend gemacht wer-

${ }^{1}$ In den Barwerten wird von der Hinzurechnung der Dauerschuldzinsen bei den Gewerbeertragsteuern abstrahiert.

2 In der Formel D.22 werden folgende Abkürzungen verwandt:

$\mathrm{B}_{\mathrm{zz}}$ : Barwert eines Zinszuschusses

g: $\quad$ Grenzsteuersatz in der Periode $t$

$\mathrm{i}_{\mathrm{g}}$ : versteuerter Kalkulationszinssatz

$\mathrm{K}_{\mathbf{\imath}}$ : Kredithöhe in der Periode $\mathrm{t}$ (Restschuld)

u: Begünstigungszeitraum

t: $\quad$ Periode

z: $\quad$ Kreditzinssatzverbilligung in Prozentpunkte 
den. Die Opportunitätskosten umfassen die Zinszahlungen abzüglich der Steuereinsparungen durch die steuerliche Geltendmachung der Zinszahlungen. ${ }^{1}$ Über den Begünstigungszeitraum hat der Investor aus einer Zinsverbilligung um 0,59 Prozentpunkte bei einer Tilgung in fünf gleichen Raten einen Nettovorteil, der mit der Höhe seines marginalen Ertragsteuersatzes von DM 1.606,- bis auf DM 680,- fällt (vgl. Tabelle D.27).

Bei einem über den Begünstigungszeitraum ansteigenden Ertragsteuersatz fallen die Vergünstigungswirkungen in der Tabelle D.27 höher aus als bei einem gegenläufigen Grenzsteuersatzverlauf. Die Erklärung für diesen Unterschied ist, $\mathrm{da} ß$ die Zinszuschüsse aufgrund der Tilgung im Zeitablauf abnehmen. Steigen die Grenzsteuersätze im Zeitablauf an, werden die hohen Zinszuschüsse in den ersten Jahren weniger durch die Besteuerung gekürzt. Diese Wirkung kommt allerdings nur zustande, wenn der Kredit vollständig oder zum großen Teil getilgt wird. Wäre der Kredit im Zinsbegünstigungszeitraum tilgungsfrei, käme einer Änderung der Grenzsteuersätze keine Bedeutung zu.

Der wesentliche Unterschied zwischen der Zinsverbilligung und dem Annuitätenzuschuß besteht darin, daß der Annuitätenzuschuß dem Investor direkt zufließt. Damit wird die ertragsteuerliche Bemessungsgrundlage nicht durch die verringerten Zinszahlungen - wie bei der Zinsverbilligung - erhöht, sondern unmittelbar durch den Annuitätenzuschuß. Die Zinsverbilligung und der Annuitätenzuschuß haben bei gleicher Dosierung und Verteilung über den Förderzeitraum im Ergebnis gleiche Vergünstigungswirkungen. ${ }^{2}$ Formal wird der Ausdruck $\left(\mathrm{z}_{\mathfrak{\imath}} * \mathrm{~K}_{\mathrm{t}}\right)$ in der Formel D.22 durch den Annuitätenzuschuß ersetzt.

${ }^{1}$ In der Barwertformel kommt dies durch den Grenzsteuersatz im Abzinsungsfaktor zum Ausdruck. In der Tabelle D.27 wird dies durch die Differenz zwischen Brutto- und Nettobarwert deutlich.

2 Berücksichtigt man jedoch die Hinzurechnung der Dauerschuldzinsen in der Steuerbemessungsgrundlage bei der Gewerbeertragsteuer, ergibt sich ein Unterschied. Bei einer Förderung mit Hilfe einer Zinsverbilligung fällt die Hinzurechnung der Dauerschuldzinsen geringer aus als bei der Gewährung eines Annuitätenzuschusses. 
Eine Verlängerung des Begünstigungszeitraums verursacht ceteris paribus zusätzliche Vergünstigungseffekte, wenn zugleich das Fördervolumen bei einer Zinsverbilligung oder einem Annuitätenzuschuß insgesamt erhöht wird. Wird allerdings das Fördervolumen nicht erhöht, sondern lediglich über einen längeren Zeitraum verteilt, verringern sich sowohl die jährlichen Liquiditätszuflüsse als auch die Nettobarwerte. Die jährlichen Nettovorteile sind stärker abzudiskontieren, d.h., die Kreditaufnahme und damit die Zinsaufwendungen steigen.

\section{Zusammenfassung}

Beide Zinszuschußvarianten weisen - von den Ausgestaltungsbesonderheiten abgesehen - weitgehende Gemeinsamkeiten auf und führen im Grunde genommen zu gleichen Vergünstigungswirkungen.

Der Grenzsteuersatz hat den gleichen Einfluß auf den Nettoeinkommensvorteil eines Zinszuschusses wie bei einem Investitionszuschuß, obwohl die Vergabe dieser Förderung an andere Voraussetzungen geknüpft ist. ${ }^{1}$ Das gilt auch für die Wechselwirkungen mit einem intertemporalen Verlustausgleich. Insofern könnte man die Zinszuschüsse wirkungsanalytisch als eine spezielle Variante der Investitionszuschüsse auffassen. Die wesentlichen Unterschiede sind jedoch, daß die Zinszuschüsse vor allem einen laufenden Liquiditätszufluß verursachen und sich ihre Förderwirkungen nicht ausschließlich auf eine Periode konzentrieren. Außerdem setzen sie die Aufnahme eines Kredites voraus. Die Förderung orientiert sich nicht direkt am Investitionsvolumen, sondern an der Fremdkapitalbelastung.

1 Hier ist einschränkend festzuhalten, daß sich bei der Gewerbeertragsteuer in der Behandlung von Fremdkapitalzinsen und Investitionszuschüssen Unterschiede ergeben. 
Tabelle D.28: Der Einfluß unterschiedlicher Determinanten auf die Vergünstigungswirkungen (Nettobarwerte) von Zinszuschüssen

\begin{tabular}{|c|c|c|c|c|c|c|}
\hline \multirow[b]{3}{*}{ Zinszuschüsse } & \multicolumn{6}{|c|}{$\begin{array}{l}\text { Entwicklungsrichtung der Vergünstigungswirkun- } \\
\text { gen (Nettobarwerte) in Abhängigkeit einer Zu- } \\
\text { nahme folgender Determinanten }\end{array}$} \\
\hline & \multicolumn{2}{|c|}{ Grenzsteuersatz } & \multirow{2}{*}{$\begin{array}{l}\text { wirt- } \\
\text { schaft- } \\
\text { liche } \\
\text { Nut- } \\
\text { zungs- } \\
\text { dauer }\end{array}$} & \multirow{2}{*}{$\begin{array}{l}\text { Kalku- } \\
\text { la- } \\
\text { tions- } \\
\text { zins- } \\
\text { satz }\end{array}$} & \multirow{2}{*}{$\begin{array}{l}\text { Inves- } \\
\text { ti- } \\
\text { tions- } \\
\text { summe }\end{array}$} & \multirow{2}{*}{$\begin{array}{l}\text { Förder- } \\
\text { satz } \\
\text { bzw. } \\
\text {-betrag }\end{array}$} \\
\hline & $\begin{array}{l}\text { in den } \\
\text { Zah- } \\
\text { lungs- } \\
\text { reihen }\end{array}$ & $\begin{array}{l}\text { im Dis- } \\
\text { kontie- } \\
\text { rungs- } \\
\text { faktor }\end{array}$ & & & & \\
\hline Zinsverbilligung & fällt & steigt & unabh. & fällt & unabh. & steigt \\
\hline Annuitätenzuschuß & fällt & steigt & unabh. & fällt & unabh. & steigt \\
\hline
\end{tabular}

\section{Investitionszulagen}

1. Einsatzbereich, Ausgestaltung und Vergünstigungswirkungen der Investitionszulagen

Eine Investitionszulage ist eine Geldleistung des Staates, die ein Investor zur Durchführung einer förderungswürdigen Investition erhält. In Anlehnung an Neumark $^{1}$ wird die Investitionszulage auch - im Gegensatz zu den Abzügen von der Steuerschuld - als echte Prämie bezeichnet.

Investitionszulagen erfreuen sich in der Wirtschaftspolitik einer zunehmenden Beliebtheit. Gerade auch in der Bundesrepublik werden und wurden Investitionszulagen zur Verfolgung unterschiedlicher wirtschaftspolitischer Ziele gewährt. Investitionszulagen wurden zur konjunkturellen Stabilisierung der Beschäftigung in den 70-er und 80 -er Jahren eingesetzt. ${ }^{2}$ Daneben werden mit Hilfe der In-

${ }^{1}$ Vgl. Neumark, F., Fiskalpolitische Maßnahmen als Mittel der Konjunkturpolitik, in: Zeitschrift für betriebswirtschaftliche Forschung 1968, S. 499.

${ }^{2}$ Hier ist $\S 4$ b des Investitionszulagengesetzes vom 23. Dezember 1974 und 3. Juni 1982 zu erwähnen, vgl. Felix, G., Grundsätzliches und Kritisches zur Beschäftigungsförderungszulage 1982 ( $\S 4$ b des Investitionszulagengesetzes neue Fassung), in: Betriebs-Berater 1982, S. 1600ff; Söffing, G., Die Änderung des Investitionszulagengesetzes im Rahmen der Kon- 
vestitionszulage regionalpolitische und strukturpolitische Anliegen gefördert. ${ }^{1}$ Aber auch im Ausland hat man sich zur Durchsetzung wirtschaftspolitischer Ziele der Investitionszulagen bedient. ${ }^{2}$

Bei der Ausgestaltung der Investitionszulagen wurden ähnliche Überlegungen angestellt wie bei der der Investitionsprämien. So wird auch hier aus konjunkturund wachstums- als auch haushaltspolitischen Gründen zwischen einer Bruttound Nettovariante unterschieden. ${ }^{3}$ Ein weiteres Ausgestaltungselement ist die Befristung der Investitionszulage. Eine befristete Gewährung kann die konjunkturstabilisierende Wirksamkeit von Investitionszulagen verbessern. ${ }^{4}$

Die Höhe der Investitionszulage bemißt sich nach dem Fördersatz und dem förderungsfähigen Investitionsvolumen. Die Investitionszulage ist vom Investor nicht zurückzuzahlen und auch nicht zu versteuern. ${ }^{5}$ Ferner wirkt sich die Inan-

junkturmaßnahmen, in: Finanz-Rundschau 1975, S. $129 \mathrm{ff}$.

${ }^{1}$ Die Regionalförderung wurde auf der Grundlage der $\S 1$ bis 3 des Investitionszulagengesetzes und dem $\S 19$ des Berlinförderungsgesetzes betrieben, vgl. Zitzmann, G., Gewährung von Investitionszulagen nach dem Investitionszulagengesetz und nach $\S 19$ des BerlinFG, in: Der Betrieb 1987, Beilage Nr. 2; derselbe, Die Neuordnung der Regionalzulage nach dem $\S \S$ 1 bis 3 Investitionszulagengesetz, in: Der Betrieb 1986, Beilage Nr. 9. Das Investitionszulagengesetz wurde im Jahre 1991 geändert und hat heute seinen Förderschwerpunkt im Bereich der neuen Bundesländer, vgl. Hoffmann, B., Das Investitionszulagengesetz 1991 (Teil I und II), in: Der Betrieb 1991, S. 1694ff und S. 1745ff. Stärker strukturpolitisch ausgerichtet ist die Förderung von Forschung und Entwicklung ( $\$ 4$ Investitionszulagengesetz) und die der Investitionen im Bereich der Energieerzeugung und -verteilung ( $\$ 4 \mathrm{a}$ Investitionszulagengesetz), vgl. Röthlingsdörfer, K. Ch./Sprenger, R.-U., Effizienz der indirekten steuerlichen Forschungsförderung, a. a. O., S. $41 \mathrm{f}$ und 45.

2 Vgl. Leibfritz, W./Meurer, C., Steuerliche Investitionsförderung im internationalen Vergleich, a. a. O., S. $93 \mathrm{ff}$

3 Auf die damit verbundenen Problematiken soll nicht näher eingegangen werden, vgl. Wittmann, F., Zum Wirkungspotential der Investitionszulage, in: Die Betriebswirtschaft 1982, 2, S. 183ff; Städler, A., Investitionszulage dämpfte den Beschäftigungsrückgang, in: IfoSchnelldienst, Nr. 3, 1985, S. 10f.

${ }^{4}$ Vgl. Oberhauser, A., Möglichkeiten einer effizienteren Gestaltung staatlicher Investitionszuschüsse in der Rezession, in: Bohley, P./Tolkemitt, G. (Hrsg.), Wirtschaftswissenschaft als Grundlage staatlichen Handelns, a. a. O., S. $96 \mathrm{f}$.

5 Vgl. Vogel, H., Steuergeschenke - Steuervergünstigungen zu rechtfertigen oder abzubauen?, in: Steuerberaterjahrbuch 1980/81, S. 59. 
spruchnahme einer Investitionszulage neutral auf den Buchwert der geförderten Investition aus, was Steuernachholwirkungen verhindert. ${ }^{1}$ Sie verbleibt damit endgültig im geförderten Unternehmen. Steuerliche Determinanten - wie der Grenzsteuersatz, die Steuerbemessungsgrundlage oder die Steuerschuld - haben keinen Einfluß auf die Vergünstigungswirkungen.

Erhält eine investierende Unternehmung eine Investitionszulage in dem Jahr, in dem die Investition vorgenommen wird, ${ }^{2}$ sind Bar- und Zeitwert gleich. Der Vergünstigungseffekt wird ausschließlich durch die Höhe des Fördersatzes und die des Investitionsvolumens bestimmt. ${ }^{3}$

$$
B_{\mathrm{zL}}=f_{\mathrm{zL}} * I V
$$

Bei einem Fördersatz von einem Prozent und einer Investitionssumme von DM 100.000,- ergibt sich für alle Investoren - auch Verlustunternehmen - ein Subventionsbetrag und gleichzeitig eine Erhöhung des verfügbaren Einkommens um DM 1.000,-.

Betrachtet man die Investitionszulage unter dem Liquiditätsaspekt, zeigt sich der Nachteil dieses Förderinstruments. Der Liquiditätseffekt ist nicht hoch. Wenn der Staat durch die Gewährung einer Investitionszulage hohe Liquiditätsvorteile

1 Eine Kürzung des Buchwertes um den Zulagenbetrag würde zu einer Versteuerung dieser Zuwendung führen. Damit wären die Vergünstigungswirkungen von Investitionszulage und erfolgsneutralem Investitionszuschuß identisch.

2 Der Mittelzufluß kann sich aus verwaltungstechnischen Gründen erheblich verzögern. Vgl. Haberstock, L., Vergleichende Analyse steuerlicher Maßnahmen zur Beeinflussung der konjunkturellen Entwicklung, in: Reber, G. (Hrsg.), Personal- und Sozialorientierung der BWL, Bd. 2, a. a. O., S. 73, der davon ausgeht, daß die Investitionszulage in der Regel ein Jahr nach der Anschaffung oder Herstellung der Unternehmung zufließt. Ollenburg, $G$., Investitionszulagen, -abgaben und derlei mehr, in: Pahlke, J./Seuferle, W. (Hrsg.), Waldemar Koch zum 80. Geburtstag, Bochum 1982, S. 17, hält gar eine Wartezeit bis zur Liquiditätswirksamkeit der Investitionszulage von mehr als zwei Jahren für möglich.

${ }^{3}$ In der Formel D.23 werden folgende Abkürzungen verwandt:

$\mathrm{B}_{\mathrm{ZL}}: \quad$ Barwert einer Investitionszulage

$\mathrm{f}_{\mathrm{ZL}}$ : Fördersatz einer Investitionszulage

IV: förderungsfähiges Investitionsvolumen 
in der Investitionsperiode schaffen möchte, muß er sein Förderbudget entsprechend erhöhen. Eine hohe Zulage ist ein vergleichsweise teueres Instrument.

\section{Zusammenfassung}

Das Ausmaß der Vergünstigungswirkungen der Investitionszulagen bleibt mit Ausnahme des Investitionsvolumens durch die individuelle Situation des Investors weitgehend unbeeinflußt.

Tabelle D.29: Der Einfluß unterschiedlicher Determinanten auf die Vergünstigungswirkungen (Nettobarwerte) einer Investitionszulage

\begin{tabular}{|c|c|c|c|c|c|c|}
\hline & \multicolumn{6}{|c|}{$\begin{array}{l}\text { Entwicklungsrichtung der Vergüstlgungswirkun- } \\
\text { gen (Nettobarwerte) in Abhängigkeit einer Zu- } \\
\text { nahme folgender Determinanten }\end{array}$} \\
\hline & \multicolumn{2}{|c|}{ Grenzsteuersatz } & \multirow{2}{*}{$\begin{array}{l}\text { wirt- } \\
\text { schaft- } \\
\text { liche } \\
\text { Nut- } \\
\text { zungs- } \\
\text { dauer }\end{array}$} & \multirow{2}{*}{$\begin{array}{l}\text { Kalku- } \\
\text { la- } \\
\text { tions- } \\
\text { zins- } \\
\text { satz }\end{array}$} & \multirow{2}{*}{$\begin{array}{l}\text { Inves- } \\
\text { ti- } \\
\text { tions- } \\
\text { summe }\end{array}$} & \multirow{2}{*}{$\begin{array}{l}\text { Forder- } \\
\text { satz } \\
\text { bzw. } \\
\text {-betrag }\end{array}$} \\
\hline & $\begin{array}{l}\text { in den } \\
\text { Zah- } \\
\text { lungs- } \\
\text { reihen }\end{array}$ & $\begin{array}{l}\text { im Dis- } \\
\text { kontie- } \\
\text { rungs- } \\
\text { faktor }\end{array}$ & & & & \\
\hline Investitionszulage & unabh. & unabh. & unabh. & unabh. & steigt & steigt \\
\hline
\end{tabular}

\section{Zusammenfassender Überblick}

Das Ziel dieses Kapitels war es, eine Auswahl bedeutender Investitionsförderinstrumente vorzustellen und deren Vergünstigungswirkungen allgemein und mit Hilfe von Modellrechnungen zu erläutern. Dabei zeigte sich, daß Gemeinsamkeiten und Unterschiede in den Vergünstigungswirkungen vor allem davon abhängen, in welcher Form die Förderung gewährt wird. Aus der Abbildung D.4 gehen die wesentlichen Förderinstrumente, deren Gewährungsformen und die wichtigsten Determinanten der Vergünstigungseffekte hervor. 
Abbildung D.4: Systematisierung investitionsfördernder Maßnahmen und ihre Determinanten

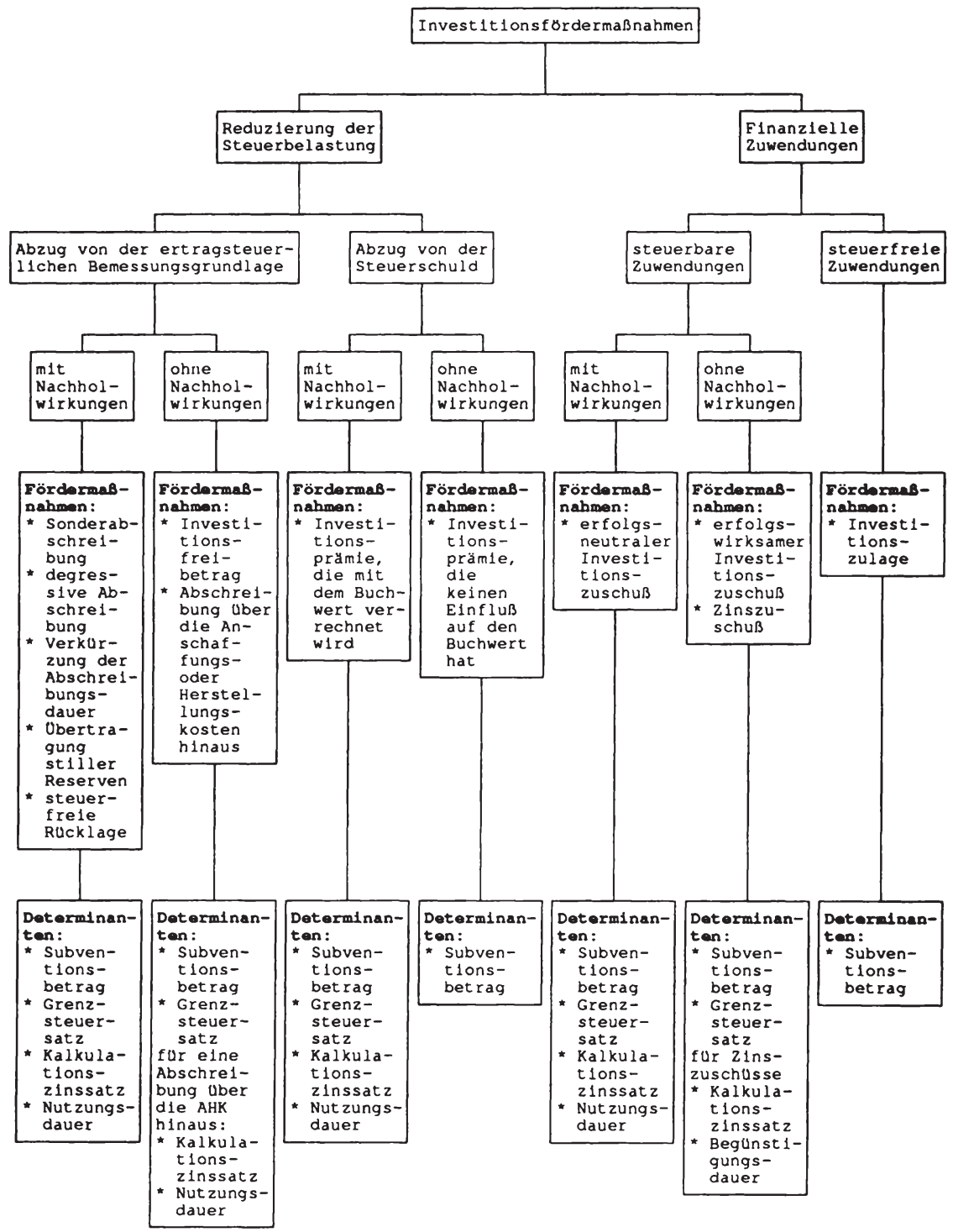




\section{E. VERGLEICH DER VERGÜNSTIGUNGSEFFEKTE INVESTITIONS- FÖRDERNDER MASSNAHMEN}

Im Kapitel D wurden die Vergünstigungseffekte investitionsfördernder Maßnahmen anhand von Modellrechnungen ausführlich erläutert. Aufbauend auf diesen Ergebnissen sollen nun die Vergünstigungswirkungen miteinander verglichen werden.

Die vergleichende Gegenüberstellung wird unter zwei Aspekten vorgenommen. Im ersten Abschnitt werden die Vergünstigungseffekte, die sich im förderungsrelevanten Zeitraum einstellen, miteinander verglichen. Im Mittelpunkt des zweiten Abschnitts stehen die zeitpunktbezogenen Liquiditätswirkungen.

\section{Systematischer Vergleich der Vergünstigungswirkungen über den gesamten Nutzungszeitraum eines geförderten Investitionsobjektes}

Die Investitionsfördermaßnahmen verändern das verfügbare Einkommen der geförderten Investoren. Hierbei ist zwischen dem Einkommenseffekt über die gesamte Begünstigungsdauer und dem in einer Periode dieses Zeitraumes zu unterscheiden. Die zeitraumbezogenen Vergünstigungen einer Fördermaßnahme wurden im Kapitel D durch die Zeit- und Barwerte zum Ausdruck gebracht. Der Vergleich stützt sich ausschließlich auf die Nettobarwerte. Die Zeitwerte sind für einen Vergleich von Fördermaßnahmen, deren Wirkungen sich über verschieden lange Zeiträume erstrecken, weniger geeignet.

Die Vergünstigungswirkungen werden unter drei Gesichtspunkten verglichen. Im Mittelpunkt des Abschnittes b steht die Betrachtung der Vergünstigungswirkungen von Fördermaßnahmen bei unterschiedlich hohen Grenzsteuersätzen. Im Abschnitt $c$ werden die Vergünstigungswirkungen bei verschieden langen Nutzungszeiträumen untersucht. Abschließend werden im Abschnitt d die Vergünstigungseffekte bei variierenden Grenzsteuersätzen analysiert. Zur Erleichterung 
der Übersicht werden zuvor im Abschnitt a die oben ermittelten Vergünstigungswirkungen einander gegenübergestellt.

\section{Gegenüberstellung der Nettobarwerte investitionsfördernder Maßnah- men}

In den Tabellen E.1 und E.2 werden die ermittelten Vergünstigungseffekte dargestellt durch die Nettobarwerte - unter der Berücksichtigung unterschiedlicher Besteuerungssituationen und Nutzungszeiträumen zusammengefaßt. 
Tabelle E.1: Vergünstigungswirkungen (Nettobarwerte) investitionsfördernder Maßnahmen bei einem Investitionsvorhaben mit einer 5-jährigen Nutzungsdauer in unterschiedlichen Besteuerungssituationen

\begin{tabular}{|c|c|c|c|c|c|c|}
\hline & \multicolumn{6}{|c|}{ Grenzertragsteuersatzverlauf } \\
\hline & \multicolumn{4}{|c|}{ konstant } & \multicolumn{2}{|c|}{ variierend } \\
\hline & 08 & $20 \%$ & 40 \% & $60 \%$ & stei. & fall. \\
\hline & (1) & $(2)$ & (3) & (4) & (5) & $(6)$ \\
\hline \multicolumn{7}{|l|}{ Kürzung der steuerbemeeungegrundlage } \\
\hline Sonderabschreibung & 0 & 647 & 1000 & 1031 & -4486 & 6447 \\
\hline degressive Abschreibung & 0 & 646 & 1000 & 1033 & -4466 & 6448 \\
\hline $\begin{array}{l}\text { Ubertragung auf ein abnutzbares } \\
\text { Wirtschaftsgut }\end{array}$ & 0 & 647 & 1000 & 1031 & -4486 & 6447 \\
\hline $\begin{array}{l}\text { steuerfreie Rücklage und Gewährung } \\
\text { einer Sonderabschreibung }\end{array}$ & 0 & 629 & 1000 & 1063 & -2337 & 4169 \\
\hline Abschreibung über die AHK hinaus & 0 & 486 & 1000 & 1545 & 978 & 1026 \\
\hline Investitionsfreibetrag & 0 & 500 & 1000 & 1500 & *) & *) \\
\hline \multicolumn{7}{|l|}{ Rurzung dar stouerschuld } \\
\hline Investitionsprämie & 0 & 1000 & 1000 & 1000 & *) & *) \\
\hline $\begin{array}{l}\text { Investitionsprämie, die mit der } \\
\text { Abschreibungsbasis verrechnet wird }\end{array}$ & 0 & 1296 & 1000 & 687 & 1013 & 985 \\
\hline \multicolumn{7}{|l|}{ Steuerbare zuwendung } \\
\hline $\begin{array}{l}\text { erfolgswirksame Variante der } \\
\text { Investitionszuschüsse }\end{array}$ & 1667 & 1333 & 1000 & 667 & *) & *) \\
\hline $\begin{array}{l}\text { erfolgsneutrale Variante der } \\
\text { Investitionszuschüsse }\end{array}$ & 1575 & 1296 & 1000 & 687 & 1013 & 985 \\
\hline $\begin{array}{l}\text { Zinsverbilligung über einen } \\
\text { fünfjährigen Zeitraum }\end{array}$ & 1606 & 1308 & 1000 & 680 & 1120 & 879 \\
\hline \multicolumn{7}{|l|}{ Steuerfreie Zuwendung } \\
\hline Investitionszulage & 1000 & 1000 & 1000 & 1000 & *) & *) \\
\hline $\begin{array}{l}\text { *) : eine Variation der Grenzsteu } \\
\text { Förderung ohne Bedeutung }\end{array}$ & $z e$ & $\mathrm{~m} 2$ & & ist & für $d$ & \\
\hline
\end{tabular}


Tabelle E.2: Vergünstigungswirkungen (Nettobarwerte) investitionsfördernder Maßnahmen bei einem Investitionsvorhaben mit einer 10-, 15- und 20-jährigen Nutzungsdauer in unterschiedlichen Besteuerungssituationen

\begin{tabular}{|c|c|c|c|c|c|c|c|c|c|c|c|c|}
\hline & \multicolumn{4}{|c|}{10 Jahre } & \multicolumn{4}{|c|}{15 Jahre } & \multicolumn{4}{|c|}{20 Jahre } \\
\hline & 0 多 & $20 \%$ & $40 \%$ & $60 \%$ & 0 各 & $20 \%$ & 408 & 608 & 0 요 & $20 \%$ & $40 \div$ & 608 \\
\hline \multicolumn{13}{|l|}{ Ribrz. der steuerbem. } \\
\hline Sonderabschreibung & 0 & 1176 & 1857 & 1960 & 0 & 1610 & 2595 & 2798 & 0 & 1969 & 3231 & 3556 \\
\hline $\begin{array}{l}\text { degressive } \\
\text { Abschreibung }\end{array}$ & 0 & 2803 & 4473 & 4767 & 0 & 4733 & 7729 & 8445 & 0 & 6340 & 10561 & 11797 \\
\hline $\begin{array}{l}\text { Ubertragung auf ein } \\
\text { abnutzbares Wirt- } \\
\text { schaftsgut }\end{array}$ & 0 & 1323 & 2090 & 2205 & 0 & 1878 & 3027 & 3264 & 0 & 2338 & 3837 & 4223 \\
\hline $\begin{array}{l}\text { steuerfreie Rücklage } \\
\text { U. Gewährung einer } \\
\text { Sonderabschreibung }\end{array}$ & 0 & 748 & 1271 & 1378 & 0 & 913 & 1504 & 1663 & 0 & 1019 & 1706 & 1920 \\
\hline $\begin{array}{l}\text { Abschreibung über } \\
\text { die AHK hinaus }\end{array}$ & 0 & 421 & 896 & 1432 & 0 & 368 & 806 & 1331 & 0 & 324 & 728 & 1239 \\
\hline $\begin{array}{l}\text { Investitions- } \\
\text { freibetrag }\end{array}$ & 0 & 500 & 1000 & 1500 & 0 & 500 & 1000 & 1500 & 0 & 500 & 1000 & 1500 \\
\hline \multicolumn{13}{|l|}{ Kurz. der st.-Schuld } \\
\hline Investitionsprämie & 0 & 1000 & 1000 & 1000 & 0 & 1000 & 1000 & 1000 & 0 & 1000 & 1000 & 1000 \\
\hline $\begin{array}{l}\text { Investitionsprämie, } \\
\text { die mit der Ab- } \\
\text { schreibungsbasis } \\
\text { verrechnet wird }\end{array}$ & 0 & 1333 & 1060 & 751 & 0 & 1363 & 1112 & 810 & 0 & 1389 & 1156 & 863 \\
\hline \multicolumn{13}{|l|}{ Steuerbare zuwendung } \\
\hline $\begin{array}{l}\text { erfolgswirksamer } \\
\text { Investitionszuschuß }\end{array}$ & 1667 & 1333 & 1000 & 667 & 1667 & 1333 & 1000 & 667 & 1667 & 1333 & 1000 & 667 \\
\hline $\begin{array}{l}\text { erfolgsneutraler } \\
\text { Investitionszuschuß }\end{array}$ & 1575 & 1333 & 1060 & 751 & 1575 & 1363 & 1112 & 810 & 1575 & 1389 & 1156 & 863 \\
\hline $\begin{array}{l}\text { Zinsverbilligung für } \\
\text { fünf Jahre }\end{array}$ & 1606 & 1308 & 1000 & 680 & 1606 & 1308 & 1000 & 680 & 1606 & 1308 & 1000 & 680 \\
\hline \multicolumn{13}{|l|}{ Steuerfre1e zuwondung } \\
\hline Investitionszulage & 1000 & 1000 & 1000 & 1000 & 1000 & 1000 & 1000 & 1000 & 1000 & 1000 & 1000 & 1000 \\
\hline
\end{tabular}




\section{Vergleichende Betrachtung der Vergünstigungswirkungen von In- vestitionsfördermaßnahmen für Unternehmen mit verschieden hohen Grenzsteuersätzen}

Im folgenden sollen die Vergünstigungseffekte investitionsfördernder Maßnahmen unter dem Aspekt einer über den förderungsrelevanten Zeitraum konstanten Ertragsbesteuerung verglichen werden. Die Betrachtung stützt sich auf die Ergebnisse der Tabelle E.1. Den Berechnungen wurde ein gefördertes Investitionsobjekt mit einer fünfjährigen Nutzungsdauer und einer Investitionssumme von DM 100.000,- zugrunde gelegt.

Das Ziel des Vergleichs ist es, die Vergünstigungseffekte der verschiedenen Fördermaßnahmen bei alternativen Besteuerungssituationen miteinander zu vergleichen. Das heißt, zu prüfen ob die einzelnen Investitionsförderinstrumente eher Unternehmen mit hohen oder niedrigen Grenzsteuersätzen begünstigen.

Zwischen der Größe des geförderten Unternehmens und den Vorteilen aus der Fördermaßnahme kann eine Beziehung bestehen. Große Unternehmen haben in der Regel absolut höhere Gewinne gegenüber kleineren Unternehmen. Die Gewinnhöhe bestimmt im wesentlichen die Höhe des individuellen Grenzsteuersatzes. Ein zwingender Zusammenhang zwischen Unternehmensgröße und Grenzsteuersatzhöhe besteht jedoch nicht. Erstens werden die Gewinne in der Bundesrepublik ab einem zu versteuernden Einkommen von DM 120.000,- bzw. 240.000,- mit dem Spitzensteuersatz besteuert. Diese Einkommenshöhe wird auch von vielen kleinen Unternehmen übertroffen. Zweitens ist die Gewinnhöhe kein hinreichendes Merkmal für die Einteilung in Unternehmensgrößen. ${ }^{1}$ Insbesondere ergeben sich Probleme beim Zusammenhang von Unternehmensgröße und Steuerbelastung. Der Unternehmensgewinn wird umso geringer besteuert, je

1 Eine Abgrenzung von Unternehmensgrößen ist nicht unproblematisch. Eine Unternehmung ist durch zahlreiche Ausprägungen gekennzeichnet, welche sich nur sehr schwer mit Hilfe eines einzigen Kriteriums ausdrücken lassen. In der Literatur finden verschiedene Abgrenzungen Verwendung. Vgl. Marwede, E., Die Abgrenzungsproblematik mittelständischer Unternehmen. Eine Literaturanalyse, Augsburg 1983, S. $17 \mathrm{ff}$. 
größer die Zahl der Kapitaleigner ist, deren Einkünfte sich in der Progressionszone des Einkommensteuertarifs bewegen. Außerdem spielt die Höhe der anderen Einkünfte eines Kapitaleigners eine wichtige Rolle. Letztlich sind auch die persönlichen Verhältnisse des Kapitaleigners steuerlich relevant und wirken damit auf die steuerliche Belastung der Unternehmensgewinne. ${ }^{1}$

Vergleicht man die Nettobarwerte der einzelnen Maßnahmen in der Tabelle E.1, in den Spalten (1) bis (4), so werden zwci Ergebnisse deutlich:

- Erstens läßt sich keine generelle Rangfolge nach dem Umfang der Vergünstigungseffekte der einzelnen Maßnahmen aufstellen. Die Nettobarwerte entwickeln sich - wie bereits im Kapitel D festgestellt wurde - bei einer Veränderung der Grenzsteuersätze in unterschiedliche Richtungen. Das heißt, sie steigen, fallen oder bleiben unverändert, wenn sich die Grenzsteuersätze erhöhen. Konkrete Rangfolgen in Abhängigkeit der Vergünstigungsniveaus lassen sich folglich nur für konkrete Besteuerungssituationen, zum Beispiel für eine 0 -, 20- oder 60-prozentige Grenzbesteuerung, ableiten.

- Zweitens bewirken ähnlich konzipierte Investitionsförderinstrumente auch weitgehend identische oder zumindest gleichgerichtete Vergünstigungswirkungen. Die Einzelmaßnahmen lassen sich zu Maßnahmengruppen zusammenfassen.

Eine Förderung von Investitionen durch eine Kürzung der Steuerbemessungsgrundlage, z.B. durch einen Investitionsfreibetrag oder eine Abschreibungsvergünstigung, führt zu progressionsabhängigen Vorteilen. Damit werden allgemein die Unternehmen am stärksten begünstigt, deren Erträge mit einem hohen Grenzsteuersatz besteuert werden. Verlustunternehmen kommen - ohne Verlustausgleichsmaßnahmen - nicht in den Genuß einer Förderung.

1 Vgl. Kern, G., Die gruppenspezifische Be- und Entlastung von Klein-, Mittel- und Großunternehmen durch staatliche Abgaben und Transferzahlungen, Diss. Mainz 1984, S. $244 f$. 
Das führt beispielsweise dazu, daß neu gegründete Unternehmen durch die fehlenden oder geringen Gewinne gar nicht bzw. kaum gefördert werden. Überdies bleibt diesen Unternehmen der Verlustrücktrag versagt, so daß sie lediglich die Verluste in zukünftige Perioden vortragen können. Die betreffenden Unternehmen erhalten die Förderung erst in der Zukunft; sie müssen die Förderung durch Kredite oder Eigenkapital vorfinanzieren. Dies führt zu Zinsaufwendungen bzw. zu einer entgangenen Eigenkapitalverzinsung und damit zu einer Verringerung der Vergünstigungseffekte. Hiervon sind besonders die Vergünstigungswirkungen aus den Maßnahmen betroffen, mit denen eine Nachversteuerungsmöglichkeit verbunden ist, so z.B. beschleunigte Abschreibungen, Übertragungen stiller Rücklagen und Investitionsrücklagen.

Die Steuerkredite, d.h. die steuerlichen Instrumente, mit denen Nachversteuerungen verbunden sein können, führen zu einer Vergünstigungswirkung von höchstens DM 1.063.-. Bei einem Investitionsfreibetrag oder einer Abschreibung über die Anschaffungs- oder Herstellungskosten hinaus ist eine Steuernachholung ausgeschlossen; sie haben einen Nettoeinkommenseffekt von bis zu DM 1.500.bzw. DM 1.545,-. Dagegen sind die Steuerkredite für Investoren mit geringen Grenzsteuersätzen vorteilhafter als Investitionsfreibeträge oder Abschreibungen über die Anschaffungs- oder Herstellungskosten hinaus.

In der Tabelle E.1 werden die Vergünstigungseffekte von zwei verschiedenen Arten von Investitionsprämien, d.h. Abzügen von der Steuerschuld, dargestellt. Die Investitionsprämien führen zwar zu keinen einheitlichen Vergünstigungswirkungen; es bestehen aber gewisse Gemeinsamkeiten. Der Investor hat bei fehlender Steuerschuld keinen Vorteil. Deshalb werden neu gegründete Unternehmen in der Regel nicht begünstigt. ${ }^{1}$

Die Investitionsprämie, der keine Nachholeffekte folgen können, hat für alle Unternehmen mit einer ausreichend hohen Steuerschuld einen einheitlichen Vor-

${ }^{1}$ Wie im Kapitel D bereits erläutert wurde, lassen sich auch für die Investitionsprämien eine Reihe von Verlustausgleichsmaßnahmen konstruieren. 
teil in Höhe von DM 1.000,-, was dem Vergünstigungseffekt in der Basissituation ${ }^{1}$ entspricht. Im Unterschied zu den Förderinstrumenten, die an der Steuerbemessungsgrundlage ansetzen, werden auch Unternehmen mit geringen Grenzsteuersätzen, die jedoch eine ausreichend hohe Steuerschuld haben, durch diese Maßnahme in gleicher Weise wie Unternehmen mit hohen Grenzsteuersätzen begünstigt.

Bei einer Investitionsprämie, die über eire Kürzung der Abschreibungsbasis zu Nachholungen führt, sind die Vergünstigungseffekte grenzsteuersatzabhängig. Die Vergünstigungswirkungen sinken mit der Höhe des Grenzsteuersatzes von DM 1.296,- bei einem 20-prozentigen bis auf DM 687,- bei einem 60-prozentigen Grenzsteuersatz. Im Unterschied zur Investitionsprämie, der keine Nachholwirkungen folgen, werden Unternehmen mit unterschiedlichen Grenzsteuersätzen nicht mehr gleich begünstigt. Gerade die Investoren mit einem geringeren Grenzsteuersatz erhalten durch diese Investitionsprämie die höheren Vorteile.

Steuerbare Zuwendungen gewährt der Staat insbesondere in Form von Zinszuschüssen, erfolgsneutralen und erfolgswirksamen Investitionszuschüssen. Zwischen diesen Maßnahmen bestehen nur kleine Vergünstigungsunterschiede. Gemeinsam ist allen drei Instrumenten, daß die Nettoeinkommensvorteile mit zunehmender Höhe des Grenzsteuersatzes abnehmen. Aufgrund dieser Beziehung von Grenzsteuersatz und Vergünstigungseffekt werden durch Zuschüsse die Unternehmen, die unter Ertragsschwierigkeiten leiden oder sogar Verluste erwirtschaften, im Vergleich zu allen anderen Maßnahmen am höchsten unterstuitzt. Wird im Verlustfall ein intertemporaler Verlustausgleich vorgenommen, kann das die Vergünstigungswirkungen erheblich reduzieren. ${ }^{2}$ Diese Förder-

${ }^{1}$ Die Basissituation ist durch einen Investor mit einem Grenzsteuersatz von 40 Prozent gekennzeichnet, der eine Investition mit einer fünfjährigen Nutzungsdauer und einem Investitionsvolumen von DM 100.000,- tätigt.

2 Die Vergünstigungswirkungen, die bei einem Verlustunternehmen den kompletten Zuwendungsbetrag umfassen, sind bei der Vornahme eines interperiodischen Verlustausgleichs geringer. Bei der Verrechnung der aktuellen Verluste mit den Erträgen der vor- oder nachgelagerten Perioden erfolgt quasi über den intertemporalen Verlustausgleich eine Versteuerung der Zuwendung. 
maßnahmen dürften besonders für neu gegründete Unternehmen vorteilhaft sein. ${ }^{1}$

Eine steuerfreie Zuwendung, d.h. eine Investitionszulage, erhöht das verfügbare Einkommen unabhängig von der Besteuerungssituation. Der Vergünstigungseffekt entspricht dem in der Basissituation. Alle Unternehmen erhalten einen gleichen, allerdings - verglichen mit anderen Maßnahmen - nicht besonders hohen Vorteil. Folglich werden durch diese Förderung auch neu gegründete Unternehmen in gleicher Weise begünstigt. Wenn man die Verlustsituation außer Acht läßt, stimmen die Vergünstigungseffekte einer Investitionszulage und einer Prämie, die keine Nachholwirkungen hat, überein.

Die Ausführungen zeigten, daß die Vergünstigungswirkungen in unterschiedlicher Weise vom Grenzsteuersatz beeinflußt werden.

- Unternehmen mit niedrigen Grenzsteuersätzen werden durch Prämien, die Nachholeffekte haben können, Investitions- und Zinszuschüsse am stärksten begünstigt. Verlustunternehmen werden jedoch nur durch die Zuschüsse gefördert.

- Investitionsprämien, mit denen keine Nachversteuerungsmöglichkeit verbunden ist, und Investitionszulagen bewirken weitgehend gleiche Vorteile für alle Unternehmen, solange bei der Gewährung einer Prämie eine ausreichend hohe Steuerschuld vorhanden ist.

- Kürzungen der Steuerbemessungsgrundlage bevorteilen Unternehmen mit hohen Grenzsteuersätzen, insbesondere wenn die Steuerentlastungen nicht zu Nachholungen führen.

${ }^{1}$ Die Investitionsprämie, die keine Nachholeffekte hat, und der erfolgsneutrale Zuschuß verursachen - von der Verlustsituation abgesehen - identische Vergünstigungseffekte. 


\section{Vergleich der Vergünstigungswirkungen von Investitionsfördermaß- nahmen für kurz- und langlebige Wirtschaftsgüter}

Der bisherige Vergleich der Vergünstigungseffekte wurde unter der Annahme einer fünfjährigen Nutzungsdauer der geförderten Investition durchgeführt. Eine fünfjährige Nutzungsdauer ist relativ kurz für die meisten Investitionsobjekte. Insofern ist es angebracht, die Vorteile von Fördermaßnahmen unter der Berücksichtigung verschieden langer Nutzungszeiträume zu vergleichen. Es ist folglich der Frage nachzugehen, inwiefern die Investitionsfördermaßnahmen eher langoder kurzlebige Investitionsobjekte begünstigen. Nicht nur innerhalb einer Unternehmung werden Wirtschaftsgüter mit unterschiedlicher Nutzungsdauer eingesetzt, sondern darüber hinaus zeigen sich auch erhebliche Unterschiede in den durchschnittlichen Nutzungszeiträumen von Anlagegütern zwischen den einzelnen Branchen. So sind die durchschnittlichen Nutzungszeiträume von Investitionsgütern in der Grundstoffindustrie oder bei öffentlichen Versorgungsunternehmen wesentlich länger als beispielsweise im Handwerk oder im Dienstleistungsbereich.

Aus der Tabelle E.2 wird folgendes deutlich:

- Erstens gelten auch für einen längeren Nutzungszeitraum die grundlegenden Zusammenhänge zwischen dem Grenzsteuersatz und dem Vergünstigungseffekt.

- Zweitens werden Verlustunternehmen bei einer Verlängerung der Nutzungsdauer nicht bzw. nicht zusätzlich begünstigt.

- Drittens führt eine längere Nutzungsdauer bei jenen Investitionsfördermaßnahmen zu einem höheren Vergünstigungseffekt, mit denen sich eine Nachversteuerungsmöglichkeit verbindet.

Die Förderinstrumente, die eine Kürzung der ertragsteuerlichen Bemessungsgrundlage herbeiführen und denen zugleich Steuernachholungen folgen können (z.B. beschleunigte Abschreibungen, Übertragungen stiller Reserven und Investitionsrücklagen), bewirken bei einer längeren Nutzungsdauer beträchtliche 
Nettoeinkommensvorteile. Die Vorteile übersteigen diejenigen aller anderen Fördermaßnahmen der Tabelle E.2 um ein Vielfaches. Vor allem ragt hier die degressive Abschreibung heraus. Darüber hinaus ist beachtenswert, daß das Ausmaß der Vergünstigungseffekte bei diesen Fördermaßnahmen schon bei geringen Grenzsteuersätzen sehr hoch ist. Langlebige Wirtschaftsgüter und damit auch Unternehmen und Branchen, deren Investitionen durch eine überdurchschnittliche Nutzungsdauer gekennzeichnet sind, werden demzufolge besonders begünstigt. Dieser hohe Nettoeinkommenseffekt ist darauf zurückzuführen, daß sich die Nachholwirkungen über einen längeren Zeitraum verteilen, wodurch sich der Zinsgewinn erhöht. Dieser Effekt wird verstärkt, wenn die Subventionsbeträge relativ hoch sind und somit hohe Liquiditätsvorteile in der Begünstigungsperiode entstehen, die die Grundlage für die Zinsgewinne sind.

Der Investitionsfreibetrag und die Abschreibung über die Anschaffungs- oder Herstellungskosten hinaus kürzen ebenfalls die steuerliche Bemessungsgrundlage, führen jedoch nicht zu Nachversteuerungen. Die Steuerersparnisse durch den Investitionsfreibetrag sind von der Nutzungsdauer unabhängig. Demgegenüber fallen die Vergünstigungswirkungen bei einer Abschreibung über die Anschaffungs- oder Herstellungskosten hinaus mit zunehmender Länge der Nutzungsdauer. Die Verteilung der Förderung auf einen längeren Zeitraum führt zu steigenden Opportunitätskosten ${ }^{1}$.

Der Vorteil aus einem Steuerschuldabzug verändert sich bei einer längeren Nutzungsdauer wenig bzw. gar nicht. Einzig die Investitionsprämie, bei der es über die Verrechnung mit dem Buchwert der geförderten Investition zu einer Nachversteuerung kommen kann, führt zu höheren Vergünstigungswirkungen. Der zusätzliche Vergünstigungseffekt fällt allerdings deutlich geringer aus als bei den Steuerkrediten ${ }^{2}$. Das ist im wesentlichen auf den geringeren Subven-

${ }^{1}$ Die Opportunitätskosten bestehen aus entgangenen Zinserträgen für das Eigenkapital oder zu zahlenden Fremdkapitalzinsen, die aufgrund der Vorfinanzierung der über den Nutzungszeitraum verteilten Förderungen anfallen.

2 Steuerkredite sind Abzüge von der ertragsteuerlichen Bemessungsgrundlage, denen Nachholwirkungen folgen können. 
tionsbetrag zurückzuführen, der in der Nachversteuerungsphase auch eine geringere Ausgangsbasis für die Zinsgewinne darstellt.

Die Nettoeinkommenswirkungen von steuerbaren Zuwendungen werden überhaupt nicht bzw. kaum durch eine längere Nutzungsdauer beeinflußt. Nur die Vergünstigungswirkungen des erfolgsneutralen Zuschusses wachsen mit einem längeren Nutzungszeitraum. Diese Vorteile gleichen denen der Investitionsprämie, die über eine verringerte Abschreibungsbasis zu Steuernachholungen führt.

Eine längere Nutzungsdauer verändert die Vergünstigungswirkungen einer steuerfreien Zuwendung nicht. Der Investor erfährt weiterhin eine Begünstigung, die der in der Basissituation entspricht.

Aus diesen Ausführungen wird deutlich, daß die Förderung langlebiger Wirtschaftsgüter mit Hilfe von Maßnahmen, mit denen eine Nachversteuerungsmöglichkeit verbunden ist, für den Investor am vorteilhaftesten ist. Insbesondere gilt dies für Maßnahmen, die eine Kürzung der Steuerbemessungsgrundlage herbeiführen und hier vor allem für die degressive Abschreibung. Wenn man zusätzlich berücksichtigt, daß in den einzelnen Branchen der durchschnittliche Nutzungszeitraum für die Anlagegüter zum Teil sehr unterschiedlich ist, führen diese Maßnahmen zu branchenabhängigen und damit strukturabhängigen Vergünstigungsunterschieden.

\section{Vergleichende Analyse der Vergünstigungswirkungen bei Grenzsteuer- satzänderungen im Zeitablauf}

Investitionsfördermaßnahmen können ihre Wirkungen über einen Zeitraum von mehreren Jahren entfalten. Innerhalb dieser Zeitspanne kann sich die Ertragssituation verändern, was sich wiederum in einer Veränderung der Besteuerungssätze niederschlagen kann. Die sich im Zeitablauf ändernden Grenzsteuersätze 
können einen erheblichen Einfluß auf das Ausmaß der Vergünstigungseffekte haben.

Eine Änderung der Ertragssituation einer Unternehmung kann verschiedene Ursachen haben wie beispielsweise Struktur- oder Konjunkturkrisen. Beim Eintritt solcher Krisen verzeichnen die meisten Unternehmen sinkende Gewinne, während die Gewinne in der Aufschwung- bzw. Gesundungsphase im Regelfall wieder ansteigen. Die krisenverursachten Ertragsschwankungen können sich bei einkommen- und körperschaftsteuerpflichtigen Unternehmen unterschiedlich auswirken. Personenunternehmen unterliegen unabhängig vom Ausschüttungsverhalten einer progressiven Besteuerung. Sinken die Erträge in die Progressionszone, hat das eine direkte Wirkung auf die Höhe des Grenzsteuersatzes. Dagegen müssen Kapitalgesellschaften selbst geringe Erträge, die thesauriert werden, mit einem Ertragsteuersatz von ca. 60 Prozent versteuern. Zu einer Steuersatzänderung kann es bei Kapitalgesellschaften - abgesehen von der Verlustsituation vor allem durch eine Änderung des Gewinnausschüttungsverhaltens kommen.

Bei Konjunkturkrisen ist ein besonderer Aspekt von Bedeutung. Im Rahmen der Konjunkturpolitik können auch die Steuertarife variiert werden, wobei in einer Rezession die Steuersätze gesenkt und in der Boomphase erhöht werden. Bei einer konjunkturbedingten Veränderung der Tarife kann der Grenzsteuersatz dann nicht nur durch die rezessive Gewinnentwicklung sinken, sondern zusätzlich durch die Tarifsenkung. $\mathrm{Zu}$ entsprechenden Erhöhungen kommt es in der Hochkonjunktur. Grundsätzlich werden durch eine solche Tarifpolitik die konjunkturbedingten Besteuerungsschwankungen verstärkt.

Neben den gesamtwirtschaftlichen oder den strukturellen Krisen können Ertragsschwierigkeiten auch unternehmensindividuell sein. Erhebliche Ertragsschwankungen können beispielsweise von Produktzyklen ausgehen. Durch die Produktentwicklung, den Produktionsbeginn und die Produkteinführung in den Markt entstehen Kosten, die die Gewinne senken. Nach dieser Anlaufphase entstehen in der Regel Projektgewinne, die nach einer Reifephase wieder zurückgehen 
können. ${ }^{1}$ Der Produktzyklus hat vor allem dann einen erheblichen Einfluß auf das Gesamtergebnis der Unternehmung, wenn die Produktpalette des Unternehmens sehr klein ist.

Für viele neu gegründete Unternehmen ist kennzeichnend, daß sie im Zeitraum nach der Gründungsphase steigende Erträge erwirtschaften. Neue Unternehmen werden häufig als Einzelunternehmen oder Personengesellschaft gegründet, so daß deren Erträge uneingeschränkt progressionsabhängig sind. Folglich steigt nach der Gründung der individuelle Grenzsteuersatz des Investors.

Bei der Betrachtung der Vergünstigungseffekte in der Tabelle E.1 (Spalte (5) und (6)) wird wiederum deutlich, daß die Vergünstigungswirkungen innerhalb der jeweiligen Maßnahmengruppe weitgehende Gemeinsamkeiten aufweisen. Bei den nachfolgenden Analysen werden die Vergünstigungswirkungen gruppenweise diskutiert.

Maßnahmen, die an der Steuerbemessungsgrundlage ansetzen, haben bei schwankenden Erträgen unterschiedliche Steuerentlastungswirkungen. Hierbei kommt es darauf an, ob mit diesen Maßnahmen eine Nachversteuerungsmöglichkeit verbunden ist oder nicht.

Investoren, die eine steuerliche Förderung erhalten, der Steuernachholungen folgen können, müssen bei steigenden Grenzsteuersätzen über den förderungsrelevanten Zeitraum höhere Steuerzahlungen entrichten, als sie an Vorteilen aus der Förderung bekommen. Beschleunigte Abschreibungen, Übertragungen stiller Reserven und Investitionsrücklagen können so zu einem Verlust führen. Der Verlust ist - verglichen mit den positiven Nettoeinkommenswirkungen bei konstanten Grenzsteuersätzen - relativ groß. Diese steuerprogressionsbedingten Verluste können nicht vor- oder zurückgetragen werden. Die Möglichkeit eines

${ }^{1}$ Vgl. Stein, H.-G., Steuerlicher Verlustausgleich und Strukturwandel der Unternehmen, in: Zeitschrift für betriebswirtschaftliche Forschung 1983, S. 34. 
Verlustes aus einer Fördermaßnahme besteht folglich auch bei den Unternehmen, die über den gesamten förderungsrelevanten Zeitraum Gewinne erzielen.

Eine ansteigende Ertragsentwicklung dürfte typisch sein für viele Unternehmen in einer Aufschwungphase nach einer Strukturkrise oder Rezession. Das bedeutet, daß eine Rezessionsbekämpfung, die beispielsweise mit Hilfe von Sonderabschreibungen durchgeführt wird, bei den geförderten Unternehmen insgesamt eine Steuermehrbelastung verursachen kann. Der Verlust kann sogar noch verstärkt werden, wenn zusätzlich der Steuertarif aus konjunkturpolitischen Gründen in der Rezession gesenkt und in der Aufschwungphase erhöht wird. Die Kombination von beschleunigten Abschreibungen und Steuertarifänderungen zur Beeinflussung der Konjunktur kann das Verlustproblem verschärfen.

Eine aufsteigende Gewinnentwicklung ist auch für zahlreiche neu gegründete Unternehmen kennzeichnend. Unternehmen, die nach der Gründung eine positive Ertragsentwicklung aufweisen, müssen infolge der Förderung mehr Steuern entrichten. Diese förderungsbedingten Steuerzahlungen können die noch im Aufbau befindlichen Unternehmen in ihrem Entwicklungsprozeß behindern. Ein ähnliches Ergebnis kann sich einstellen, wenn diese Förderinstrumente zur Innovationsförderung eingesetzt werden. Führt der Einsatz dieser Instrumente zu einer Ertragsentwicklung, die sich an den normalen Produktzyklus anlehnt, kommt es infolge der Förderung zu erheblichen Steuermehrbelastungen.

Im relevanten Zeitraum fallende Grenzsteuersätze führen zu erheblichen Steuerersparnissen. Die Vergünstigungswirkungen können sogar diejenigen bei einem konstanten Grenzsteuersatz von 60 Prozent um mehr als das Sechsfache übersteigen. Im Gegensatz zur oben beschriebenen Entwicklung werden die Unternehmen besonders begünstigt, deren Gewinnsituation sich im Zeitablauf verschlechtert. Beispielsweise können die Erträge bei sich anbahnenden Strukturkrisen oder in Konjunkturabschwungphasen zurückgehen. Wurde die Förderung in der Hochkonjunkturphase gewährt, zum Beispiel mit dem Ziel der Regional- oder Innovationsförderung, kommt es in der Abschwungphase zu keinen 
oder geringen Nachholwirkungen. Die als Steuerkredit konzipierte Maßnahme führt in dieser Situation zu einer endgültigen Steuerersparnis.

Mit Investitionsfreibeträgen und Abschreibungen über die Anschaffungs- oder Herstellungskosten hinaus sind keine Nachversteuerungsmöglichkeiten verbunden. Die Nettoeinkommensvorteile werden durch im Zeitablauf variierende Grenzsteuersätze nicht bzw. nur in geringem Ausmaß berührt.

Auch die Vergünstigungswirkungen eines Steuerschuldabzuges werden durch schwankende Erträge wenig bzw. gar nicht beeinflußt. Nur die Vorteile einer Investitionsprämie, die mit der Abschreibungsbasis verrechnet werden muß, werden durch variierende Steuersätze leicht verändert. Der geringe Einfluß beruht darauf, daß der Steuerschuldabzug selbst die Steuerbemessungsgrundlage nicht tangiert und somit quasi steuerfrei ist. Lediglich die Kürzung des Buchwertes entfaltet im Abschreibungszeitraum Wirkungen auf die Steuerbemessungsgrundlage. Ein Verlust aus der Fördermaßnahme ist nicht möglich.

Die Investitionszuschüsse und die Zinskostenzuschüsse sind steuerbare Finanzzuwendungen. Von diesen Förderungen gehen - mit Ausnahme der Zinszuschüsse - infolge sich im Zeitablauf ändernder Grenzsteuersätze keine nennenswerten Nettoeinkommenseffekte aus. Durch die Förderung können auch keine Verluste entstehen.

Durch einen Zinszuschuß wird ein Investor, dessen Erträge im Zeitablauf steigenden Grenzsteuersätzen unterliegen, erkennbar stärker begünstigt, als dies bei einer entgegengerichteten Entwicklung der Grenzsteuersätze der Fall ist. $\mathrm{Zu}$ diesem Effekt kommt es jedoch nur, wenn der Kredit im Zinsbegünstigungszeitraum - wie in den Modellrechnungen unterstellt wurde - vollständig oder zumindest weitgehend getilgt wird. Unter diesen Bedingungen werden die Unternehmen, deren Erträge sich im förderungsrelevanten Zeitraum verbessern und deren Grenzsteuersatz sich infolgedessen erhöht, begünstigt. Dies betrifft beispielsweise Unternehmen, die eine konjunkturell oder strukturell bedingte 
Ertragsschwäche überwinden. Bei einer aufsteigenden Ertragsentwicklung können auch neu gegründete und sich am Anfang eines Produktzyklus stehende Unternehmen Vorteile haben. Vergleicht man die Nettoeinkommensschwankungen der Zinszuschüsse, die aus einer Veränderung der Grenzbesteuerung im Zeitablauf resultieren können, mit denen der sogenannten Steuerkredite ${ }^{1}$, so sind diese relativ gering.

Eine steuerfreie Zuwendung, d.h. eine Investitionszulage, begünstigt den Investor in der Investitionsperiode. Variierende Grenzsteuersätze sind ohne Einfluß auf die Vergünstigungseffekte.

Zusammenfassend kann man festhalten, daß durch eine Änderung der Grenzsteuersätze im förderungsrelevanten Zeitraum vor allem die Vergünstigungseffekte der Fördermaßnahmen stark beeinflußt werden, die eine Kürzung der Steuerbemessungsgrundlage herbeiführen und denen später Nachholeffekte folgen können. Weitaus geringere Schwankungen der Nettoeinkommensvorteile weisen die Zinszuschüsse bei variierenden Grenzsteuersätzen auf. Solche Grenzsteuersatzvariationen sind für die Vergünstigungseffekte aus anderen Fördermaßnahmen von geringer Bedeutung oder sogar bedeutungslos.

\section{Vergleich der Liquiditätsvorteile im Jahr der Investitionsvornahme}

Die aus der Inanspruchnahme von Investitionsfördermaßnahmen über den gesamten Begünstigungszeitraum resultierenden Vergünstigungswirkungen wurden im vorhergehenden Abschnitt betrachtet. Im folgenden sollen die Liquiditätswirkungen der Fördermaßnahmen in der Investitionsperiode verglichen werden. Diese Liquiditätswirkungen sind deshalb von Bedeutung, weil die Investitionsausgaben in der Investitionsperiode zu einem Abfluß liquider Mittel führen. Der

1 Als Steuerkredite werden solche Instrumente bezeichnet, die in der Förderperiode zu einer Kürzung der Steuerbemessungsgrundlage, jedoch in späteren zu einer entsprechenden Erhöhung führen. 
Investor hat im Investitionszeitpunkt ein Finanzbedarf, den die verschiedenen Fördermaßnahmen in unterschiedlicher Höhe decken.

Die Liquiditätswirkungen, die die einzelnen Förderinstrumente in der ersten Periode nach den Modellrechnungen haben, sind in der Tabelle E.3 zusammengefaßt. In den Berechnungen wird von einem Investitionsvolumen in Höhe von DM 100.000,- ausgegangen.

Tabelle E.3: Liquiditätswirkungen investitionsfördernder Maßnahmen bei unterschiedlichen Besteuerungssituationen in der ersten Begünstigungsperiode

\begin{tabular}{|c|c|c|c|c|}
\hline & \multicolumn{4}{|c|}{ Grenzertragsteuersatz } \\
\hline & 0 \& & 20 8 & 40 \% & 60 \&े \\
\hline & (1) & (2) & (3) & $(4)$ \\
\hline \multicolumn{5}{|l|}{ Kurzung dar steuerbemeseungsgrundlage } \\
\hline Sonderabschreibung & 0 & 4571 & 9143 & 13714 \\
\hline degressive Abschreibung & 0 & 3442 & 6884 & 10326 \\
\hline $\begin{array}{l}\text { Ubertragung auf ein abnutzbares } \\
\text { Wirtschaftsgut }\end{array}$ & 0 & 4571 & 9143 & 13714 \\
\hline Investitionsrücklage & 0 & 1197 & 3595 & 5392 \\
\hline Abschreibung uber die AHK hinaus & 0 & 110 & 219 & 329 \\
\hline Investitionsfreibetrag & 0 & 500 & 1000 & 1500 \\
\hline \multicolumn{5}{|l|}{ Kurzung der steuerachuld } \\
\hline Investitionsprämie & 0 & 1000 & 1000 & 1000 \\
\hline $\begin{array}{l}\text { Investitionsprämie, die mit der Ab- } \\
\text { schreibungsbasis verrechnet wird }\end{array}$ & 0 & 1512 & 1449 & 1386 \\
\hline \multicolumn{5}{|l|}{ steuerbare zuwenching } \\
\hline $\begin{array}{l}\text { erfolgswirksame Variante der Investi- } \\
\text { tionszuschüsse }\end{array}$ & 1667 & 1333 & 1000 & 667 \\
\hline $\begin{array}{l}\text { erfolgsneutrale variante der Investi- } \\
\text { tionszuschüsse }\end{array}$ & 1575 & 1512 & 1449 & 1386 \\
\hline $\begin{array}{l}\text { Zinsverbilligung über einen fünf jähri- } \\
\text { gen Zeitraum }\end{array}$ & 590 & 472 & 354 & 236 \\
\hline \multicolumn{5}{|l|}{ Steuerfre1e zuwendung } \\
\hline Investitionszulage & 1000 & 1000 & 1000 & 1000 \\
\hline
\end{tabular}


Aus der vorstehenden Tabelle wird deutlich, daß die Investitionsfördermaßnahmen der einzelnen Maßnahmengruppen ähnliche Vorteile hervorrufen. Die Liquiditätseffekte werden im folgenden gruppenweise verglichen.

Eine Förderung von Investitionen durch Abzüge von der Steuerbemessungsgrundlage entlastet in unterschiedlichem Ausmaß die Liquidität des Investors. Es kommt entscheidend darauf an, ob mit der Maßnahme eine Nachversteuerungsmöglichkeit verbunden ist. Die Steuerkredite, z.B. beschleunigte Abschreibungen und Übertragungen stiller Reserven, verursachen die höchsten Liquiditätswirkungen in der Investitionsperiode. ${ }^{1}$ Jedoch wird nicht jeder Investor gleich begünstigt. Je höher der Grenzsteuersatz ist, desto höher sind die Liquiditätsvorteile. Beachtenswert ist jedoch, daß im Vergleich zu anderen Maßnahmen selbst bei geringen Grenzsteuersätzen hohe Liquiditätseffekte zustande kommen können. So umfaßt der Liquiditätsvorteil eines Investors, dessen Erträge einer 20-prozentigen Grenzbesteuerung unterliegen, immer noch das bis zu Viereinhalbfache gegenüber dem Liquiditätseffekt in der Basissituation ${ }^{2}$.

Verlustunternehmen werden grundsätzlich nicht begünstigt. Hier kann nur ein Verlustrücktrag eine Liquiditätsentlastung herbeiführen. Ein Verlustvortrag entlastet dagegen die Liquidität erst in den kommenden Jahren. Kann ein Investor seine Verluste zurücktragen, hat er relativ hohe Liquiditätseffekte. Die Liquidität von Existenzgründern, die in der Anfangsperiode Verluste erwirtschaften, wird nicht entlastet, weil sie ihre Verluste nicht zurücktragen können. In einer Rezession oder einer Strukturkrise kann mit diesen Maßnahmen ein Liqui-

${ }^{1}$ Ein wichtiger Hinweis ist zu den Investitionsrücklagen erforderlich. Eine ungebundene Investitionsrücklage verbessert die Liquiditätsausstattung in der Rücklagenbildungsperiode. Der Liquiditätszufluß erfolgt bei dieser Investitionsrücklage vor der Investitionsvornahme. Bei einer antizyklischen Investitionsrücklage fällt - im Gegensatz zur ungebundenen Rücklage der Liquiditätszufluß und die Investitionsvornahme in einem Zeitpunkt an. Demzufolge müssen die Liquiditätsvorteile der Investitionsrücklage in der Tabelle E.3 differenziert gesehen werden. Bei der ungebundenen Investitionsrücklage entspricht der Liquiditätsvorteil dem im Rücklagenbildungszeitpunkt, während es sich bei der antizyklischen Variante um den Liquiditätseffekt im Investitionszeitpunkt handelt.

2 Der Liquiditätseffekt in der Basissituation beträgt DM 1.000,-. 
ditätsvorteil verbunden sein, weil sie bereits bei niedrigen Grenzsteuersätzen zu relativ hohen Liquiditätseffekten führen. Diese Liquiditätsvorteile dürften jedoch nur in einem frühen Stadium der Rezession oder Strukturkrise zustande kommen, in dem die Unternehmen noch Gewinne erzielen oder noch Rücktragsmöglichkeiten vorhanden sind. Hingegen werden in einer langanhaltenden Rezession bzw. Strukturkrise aufgrund fehlender Erträge und erschöpfter Verlustrücktragsmöglichkeiten immer weniger Unternehmen Liquiditätsvorteile haben.

Investitionsfreibeträge und Abschreibungen über die Anschaffungs- oder Herstellungskosten hinaus, bewirken ebenfalls progressionsabhängige Liquiditätseffekte. Allerdings sind die Liquiditätsentlastungen im Begünstigungszeitpunkt weitaus geringer als bei den Steuerkrediten. Den höchsten Liquiditätseffekt hat ein Investitionsfreibetrag, den ein Investor mit einem 60-prozentigen Grenzsteuersatz in Anspruch nimmt. Vergleicht man diesen Liquiditätseffekt mit dem Vorteil eines Investors, dessen Gewinn mit einem Grenzsteuersatz von 20 Prozent besteuert wird und der eine Sonderabschreibung nutzt, beträgt der Liquiditätseffekt nur etwa ein Drittel. Die äußerst geringen Liquiditätsvorteile einer Abschreibung über die Anschaffungs- oder Herstellungskosten hinaus erklären sich dadurch, daß sich die Liquiditätsentlastungseffekte über die Nutzungsdauer verteilen. Im Verlustfall kann es bei der Inanspruchnahme eines Investitionsfreibetrages oder einer Abschreibung über die Anschaffungs- oder Herstellungskosten hinaus nur über einen Verlustrücktrag zu einer Verbesserung der Liquiditätsausstattung kommen.

Die Investitionsprämien - also die Maßnahmen, die einen Abzug von der Steuerschuld erlauben - führen mit einer Ausnahme, Verlustunternehmen werden durch die Investitionsprämien nicht begünstigt, zu unterschiedlichen Liquiditätswirkungen. Eine Investitionsprämie, die keine Nachholeffekte hat, bewirkt eine für alle Unternehmen einheitliche Liquiditätsverbesserung in der ersten Periode in Höhe von DM 1.000,-. Demgegenüber begünstigt eine Investitionsprämie, mit der eine Nachversteuerungsmöglichkeit verbunden ist, Unternehmen mit höheren Grenzsteuersätzen weniger. Dieser Effekt ist darauf zurück- 
zuführen, daß in den Berechnungen sowohl die Prämienzahlung als auch die erste Abschreibung in der ersten Periode erfolgt, wodurch der Liquiditätseffekt in dieser Periode grenzsteuersatzabhängig wird.

Die Liquiditätswirkungen der Investitionsprämien unterscheiden sich deutlich von den Maßnahmen, die an der Steuerbemessungsgrundlage ansetzen. Abhängig von der Art der Prämie fallen die Liquiditätsvorteile mit der Höhe des Grenzsteuersatzes oder bleiben konstant. Außerdem sind die Liquiditätsvorteile bei den Steuerkrediten wesentlich höher. In Bezug auf die Förderung von Verlustunternehmen bestehen weitgehende Übereinstimmungen. Für Existenzgründer und in langanhaltenden Konjunktur- und Strukturkrisen kommt es in der Regel zu keiner Liquiditätsentlastung. ${ }^{1}$

Steuerbare Zuwendungen entlasten mit zunehmender Höhe des marginalen Ertragsteuersatzes die Liquidität weniger. Abgesehen von diesem grundsätzlichen Zusammenhang bestehen bei den verschiedenen Zuschußvarianten einige Besonderheiten. Die Investitionszuschüsse bewirken Liquiditätsvorteile, die für Gewinnunternehmen im großen und ganzen in der Größenordnung derjenigen der Investitionsprämien, die von der Abschreibungsbasis abzuziehen sind, liegen. Verlustunternehmen erhalten nur dann hohe Liquiditätsvorteile, wenn ein Verlustrücktrag nicht möglich ist. Durch den Rücktrag der Verluste aus der ersten Periode und deren Verrechnung mit den Erträgen der vorangegangenen Perioden kommt es zu einer Versteuerung der Zuschüsse. Während die Liquiditätseffekte des erfolgswirksamen Zuschusses und des Zinszuschusses durch einen Verlustrücktrag in eine Periode mit hohen Erträgen erheblich verringert werden, sind die Nachholwirkungen über den Verlustrücktrag bei einem erfolgsneutralen $\mathrm{Zu}$ schuß relativ gering. ${ }^{2}$ Durch die Begünstigung von Unternehmen, die nur

${ }^{1}$ Unterschiede können sich nur durch eine verschieden ausgestaltete Verlustausgleichsregelung ergeben.

2 Beispielsweise beträgt der Liquiditätseffekt eines erfolgswirksamen Zuschusses bei einem Verlustrücktrag in eine Periode, in der die Erträge des Investors einer 60-prozentigen Grenzbesteuerung unterlagen, nur noch DM 667,-. Dagegen wird der Investor bei einem erfolgsneutralen Zuschuß in dieser Situation immer noch mit DM 1.386,- begünstigt. 
geringe Gewinne oder sogar Verluste erwirtschaften, dürften die Finanzierungsvorteile der Investitionszuschüsse sowohl in Struktur- und Konjunkturkrisen als auch für neu gegründete Unternehmen von Bedeutung sein.

Demgegenüber sind die Liquiditätsgewinne der Zinszuschüsse sehr viel geringer, was sich darauf zurückführen läßt, daß die Zinszuschüsse über einen Begünstigungszeitraum verteilt werden. Diese Zuschüsse, haben unter dem Liquiditätsaspekt den Nachteil, daß sie in relativ geringem Umfang die Finanzierungskosten in der Investitionsperiode auffangen. Jedoch erstreckt sich die Förderung über einen längeren Zeitraum und verbessert während der Anlaufphase einer Investition die Finanzierungssituation.

Der Mittelzufluß den eine steuerfreie Zuwendung, d.h. eine Investitionszulage, bewirkt, ist unabhängig von der Höhe des Grenzsteuersatzes. Im großen und ganzen ist der Umfang des Liquiditätsvorteils der Investitionszulage mit jenem der Investitionsprämie, die keine Nachholeffekte hat, vergleichbar, wenn von einer Verlustsituation abgesehen wird.

Die Liquiditätswirkungen der verschiedenen Fördermaßnahmen lassen sich wie folgt zusammenfassen:

- Maßnahmen, die zu einer Kürzung der Steuerbemessungsgrundlage führen, entlasten die Liquidität von Unternehmen mit höheren Grenzsteuersätzen relativ stärker. Hierbei zeigte sich, daß vor allem beschleunigte Abschreibungen, Übertragungen stiller Reserven und Investitionsrücklagen ${ }^{1}$ die höchsten Liquiditätsvorteile aller Maßnahmen hervorrufen können.

- Investitionszuschüsse und Investitionsprämien, die über eine verringerte Abschreibungsbasis zu Nachholungen führen können, verbessern hingegen die Liquiditätsausstattung von Unternehmen mit geringeren Grenzsteuersätzen stärker.

${ }^{1} \mathrm{Zu}$ einer Liquiditätsentlastung in der Investitionsperiode führt nur eine antizyklische Investitionsrücklage. Eine ungebundene Rücklage entlastet bereits im Zeitpunkt der Rücklagenbildung die Liquidität. 
- Einen für alle Unternehmen gleich hohen Liquiditätseffekt bewirken Investitionszulagen und Investitionsprämien, denen keine Nachversteuerungen folgen.

- Sehr geringe Liquiditätsvorteile in der Investitionsperiode haben die Zinszuschüsse und die Abschreibungen über die Anschaffungs- oder Herstellungskosten hinaus.

- Die Liquidität von Verlustunternehmen wird durch Abzüge von der Steuerschuld oder der Steuerbemessungsgrundlage - ohne Verlustausgleichsregelungen - nicht verbessert. 


\section{F. SCHLUSSBETRACHTUNG}

Die Aufgabe dieser Arbeit bestand darin, die Vergünstigungswirkungen verschiedener investitionsfördernder Maßnahmen, die in der praktischen Politik angewandt und in der Literatur diskutiert werden, aufzuzeigen und miteinander zu vergleichen.

Die Vergünstigungswirkungen wurden mittels Modellrechnungen quantifiziert. Die Fördersätze und -beträge, die den Berechnungen zugrunde liegen, wurden auf eine einheitliche Vergleichsgrundlage abgestellt, die Basissituation. In der Basissituation wird ein Investor über den förderungsrelevanten Zeitraum - unabhängig von der Fördermaßnahme, die er nutzt - in Höhe von DM 1.000,- begünstigt. Der Vorteil des Investors über den förderungsrelevanten Zeitraum entspricht der unmittelbaren Haushaltsbelastung des Staates aus dieser Maßnahme. In der Basissituation sind folglich alle Fördermaßnahmen für den Staat gleich teuer. Es wurde angenommen, daß der Investor in der Basissituation einen Grenzsteuersatz in Höhe von 40 Prozent hat, eine Investition in Höhe von DM 100.000,- tätigt und das Investitionsobjekt über fünf Jahre nutzt.

In der Untersuchung wurde gezeigt, daß einige Maßnahmen - trotz unterschiedlicher Bezeichnungen - gleich aufgebaut sind und infolgedessen auch ähnliche Vergünstigungseffekte hervorrufen. Die Ergebnisse, die sich im Rahmen des Vergünstigungsvergleichs - gestützt auf die Modellrechnungen - ergaben, werden noch einmal kurz zusammengefaßt:

1. Die diversen Fördermaßnahmen führen - abhängig von der Steuerbelastung des Investors - zu unterschiedlich hohen Nettoeinkommensvorteilen:

- Wenn man über den förderungsrelevanten Zeitraum einen konstanten Grenzsteuersatz des Investors annimmt, werden Unternehmen mit niedrigen Grenzsteuersätzen durch steuerbare Zuwendungen (Investitions- und Zinszuschüsse) und Steuerschuldabzüge, mit denen eine Nachversteuerungsmöglichkeit 
verbunden ist, am höchsten begünstigt. In der Verlustsituation hat der Investor - ohne Verlustausgleichsmaßnahmen - aus den Steuerschuldabzügen keine Nettoeinkommensvorteile. Dagegen kommt es bei den steuerbaren $\mathrm{Zu}$ wendungen entscheidend darauf an, ob ein intertemporaler Verlustausgleich vorgenommen wird oder nicht. Durch einen Verlustvor- oder -rücktrag kommt es zu einer Versteuerung der Zuwendung; die Vorteile verringern sich.

- Keine Rolle spielt die Höhe des Grenzsteuersatzes bei einer Förderung durch eine steuerfreie Zuwendung (Investitionszulage) und einen Steuerschuldabzug, der zu keinen Steuernachholungen führt, wobei beim Steuerschuldabzug eine ausreichend hohe Steuerschuld Voraussetzung ist.

Kürzungen der Steuerbemessungsgrundlage (z.B. Abschreibungsvergünstigungen, Investitionsfreibeträge und -rücklagen) wirken sich aufgrund der Progressionsabhängigkeit der Fördervorteile zugunsten von Unternehmen mit hohen Grenzsteuersätzen aus. Dabei sind die Maßnahmen, denen keine Steuernachholungen folgen (Investitionsfreibeträge und Abschreibungen über die Anschaffungs- oder Herstellungskosten hinaus), besonders progressionsabhängig. Unternehmen mit Verlusten werden durch Maßnahmen, die die Steuerbemessungsgrundlage tangieren, grundsätzlich nicht begünstigt. Hier kann allenfalls ein intertemporaler Verlustausgleich zu Vorteilen aus der Förderung verhelfen, sofern aufrechenbare Erträge in der Vergangenheit oder Zukunft bestehen.

2. Alle Steuernachholregelungen, die mit einer Fördermaßnahme verbunden sind, bevorteilen grundsätzlich jene Investoren, die Investitionsobjekte mit langen Nutzungszeiträumen anschaffen. Sehr hohe Vergünstigungseffekte haben die Maßnahmen, die an der Steuerbemessungsgrundlage ansetzen und hier vor allem die degressive Abschreibung. Dagegen sind die nutzungsdauerabhängigen Vergünstigungseffekte der Investitionsprämien, die zu Nachholungen führen, und die der erfolgsneutralen Investitionszuschüsse weniger ausgeprägt. Nachteilig wirkt sich für den Investor bei einer langen Nutzungsdauer aus, wenn die 
Förderung - wie es bei der Abschreibung über die Anschaffungs- oder Herstellungskosten hinaus der Fall ist - an die Nutzungsdauer gekoppelt ist. Für alle anderen Maßnahmen ist die Nutzungsdauer unbedeutend.

3. Die Förderung kann sich über mehrere Jahre auf das verfügbare Einkommen des Investors auswirken. In diesem Zeitraum können Ertragsschwankungen die Höhe der Grenzbesteuerung verändern. Derartige Grenzsteuersatzänderungen können einen erheblichen Einfluß auf die Vorteile von Fördermaßnahmen haben:

- Sinken die Grenzsteuersätze in der Nachversteuerungsphase, haben Fördermaßnahmen, die die Steuerbemessungsgrundlage kürzen und zu Nachversteuerungen führen, - beispielsweise beschleunigte Abschreibungen, Übertragungen stiller Reserven - hohe Nettoeinkommensvorteile, die diejenigen bei konstanten Grenzsteuersätzen um ein Vielfaches übersteigen können. Bei im Zeitablauf ansteigenden Grenzsteuersätzen bewirken diese Fördermaßnahmen eine erhebliche Steuermehrbelastung. Steuerprogressionsbedingte Verluste können durch Verlustausgleichsregelungen nicht aufgefangen werden.

- Im Zeitablauf variierende Grenzsteuersätze haben - abgesehen von den Zinszuschüssen, deren Vergünstigungswirkungen unter bestimmten Voraussetzungen ebenfalls nennenswerten Schwankungen unterworfen sein können -, bei allen anderen Fördermaßnahmen nur einen geringen oder keinen Einfluß auf das verfügbare Einkommen.

4. Von Bedeutung für den Investor sind nicht nur die zeitraumbezogenen Vergünstigungseffekte, sondern auch die zeitpunktbezogenen Liquiditätseffekte. Bei der Vornahme einer Investition wird die Liquidität des Investors in der Investitionsperiode durch die Investitionsausgaben belastet. Der Finanzierungseffekt einer Fördermaßnahme darf deshalb nicht unterschätzt werden.

- Die Instrumente, die an der Steuerbemessungsgrundlage ansetzen und Nachversteuerungen hervorrufen (z.B. beschleunigte Abschreibungen und 
Übertragungen von stillen Reserven), haben bereits in niedrigen Progressionsstufen hohe Liquiditätseffekte. Jedoch sind die Liquiditätsvorteile progressionsabhängig. Verlustunternehmen werden nicht begünstigt. Bei letzteren kann ein Verlustrücktrag die Liquiditätsaustattung verbessern. Die Förderinstrumente, die ebenfalls die Steuerbemessungsgrundlage verringern, aber zu keinen Nachholwirkungen führen (Investitionsfreibeträge und Abschreibungen über die Anschaffungs- oder Herstellungskosten hinaus), bewirken einen erheblich geringeren Liquiditätsvorteil. Die Progressionsabhängigkeit der Förderung besteht auch hier.

- Sowohl die Steuerschuldabzüge, die mit einer Nachversteuerungsmöglichkeit verbunden sind als auch die steuerbaren Finanzzuwendungen (Investitions- und Zinszuschüsse) erhöhen die Liquidität bei Unternehmen mit niedrigen Grenzsteuersätzen stärker als bei solchen mit hohen. Die Vorteile bleiben deutlich hinter denen der Instrumente zurück, die die Steuerbemessungsgrundlage verringern und Nachholeffekte haben. Außerdem ist zu berücksichtigen, daß Steuerschuldabzüge Verlustunternehmen ohne Verlustausgleichsmaßnahmen nicht begünstigen. Dagegen kann der Liquiditätsvorteil bei den steuerbaren Finanzzuwendungen durch die Vornahme eines Verlustrücktrages abnehmen.

Steuerfreie Finanzzuwendungen, also Investitionszulagen, und Abzüge von der Steuerschuld, mit denen keine Nachholungen verbunden sind, haben für alle Investoren einen gleichen Liquiditätsvorteil. Verlustunternehmen werden jedoch bei Steuerschuldabzügen nicht gefördert.

- Wenig wird die Liquidität in der Investitionsperiode entlastet, wenn sich die Förderung - wie es bei einer Abschreibung über die Anschaffungs- oder Herstellungskosten hinaus oder bei einem Zinszuschuß der Fall ist - über einen längeren Zeitraum erstreckt. Der Vorteil dieser Maßnahmen besteht jedoch in einem laufenden Liquiditätsvorteil über einen längeren Zeitraum. 


\section{ABBILDUNGSVERZEICHNIS}

Seite

Abbildung B.1: Die möglichen Begünstigten einer Weitergabe der Investitionsförderung $\ldots \ldots \ldots \ldots \ldots$

Abbildung B.2: $\quad$ Systematisierung investitionsfördernder Maßnahmen ...................

Abbildung D.1: Übersicht über die abschreibungsvergünstigenden Maßnahmen ................

Abbildung D.2: Ausgestaltungsvarianten von Investitionsfreibeträgen ................

Abbildung D.3: Übersicht über die staatlichen Finanzierungshilfen ................... 130

Abbildung D.4: Systematisierung investitionsfördernder Maßnahmen und ihre Determinanten .......... 


\section{TABELLENVERZEICHNIS}

Seite

Tabelle D.1: Zusammenstellung der Ausgestaltungselemente der Modellrechnungen . . . . . . . . . . . .

Tabelle D.2: $\quad$ Förderbeträge und -sätze ausgewählter Förderinstrumente für die Modellrechnungen ........

Tabelle D.3: Systematik der degressiven Abschreibungsmethoden ...................

Tabelle D.4: Vergünstigungseffekte einer Sonderabschreibung in Höhe von DM $22.856,-\ldots \ldots \ldots \ldots$. . . . .

Tabelle D.5: Vergünstigungseffekte einer geometrisch-degressiven Abschreibung mit einem Degressionssatz von $37,21 \% \ldots \ldots \ldots \ldots \ldots \ldots$

Tabelle D.6: Vergleich der Vergünstigungswirkungen von beschleunigten Abschreibungen unter Berücksichtigung verschiedener Nutzungszeiträume . . . . .

Tabelle D.7: Vergünstigungswirkungen einer Abschreibung von einer Basis, die um 2,74\% über den Anschaffungs- oder Herstellungskosten liegt ....

Tabelle D.8: Vergleich der Vergünstigungswirkungen einer Abschreibung über die Anschaffungs- oder Herstellungskosten hinaus unter Berücksichtigung verschiedener Nutzungszeiträume . . . . . . .

Tabelle D.9: $\quad$ Der Einfluß unterschiedlicher Determinanten auf die Vergünstigungswirkungen (Nettobarwerte) investitionsfördernder Abschreibungsvarianten . 
Tabelle D.10: Vergünstigungswirkungen einer Übertragung stiller Reserven in Höhe von DM 28.571,- auf ein abnutzbares Wirtschaftsgut .........

Tabelle D.11: Vergleich der Vergünstigungswirkungen einer Übertragung von stillen Reserven in Höhe von DM 28.571,- auf ein abnutzbares Gut unter Berücksichtigung verschiedener Nutzungszeiträume

Tabelle D.12: $\quad$ Der Einfluß unterschiedlicher Determinanten auf die Vergünstigungseffekte (Nettobarwerte) der Übertragung von stillen Reserven ..........

Tabelle D.13: Vergünstigungseffekte eines Investitionsfreibetrages von DM $2.500,-\ldots \ldots \ldots \ldots \ldots \ldots$

Tabelle D.14: $\quad$ Der Einfluß unterschiedlicher Determinanten auf die Vergünstigungswirkungen (Nettobarwerte) der Investitionsfreibeträge $\ldots . . \ldots \ldots \ldots$

Tabelle D.15: Vergünstigungswirkungen einer steuerfreien Rücklage in Höhe von DM 8.987,-, bei deren Auflösung eine Sonderabschreibung gewährt wird $\ldots \ldots \ldots \ldots \ldots \ldots \ldots \ldots \ldots \ldots \ldots$

Tabelle D.16: Der Einfluß unterschiedlicher Determinanten auf die Vergünstigungswirkungen (Nettobarwerte) verschiedener Varianten von Investitionsrücklagen $\ldots \ldots \ldots \ldots \ldots \ldots \ldots \ldots \ldots$

Tabelle D.17: Die Wirkungen eines Verlustvortrages in die dritte Periode auf die Vergünstigungseffekte eines Investitionsfreibetrages . . . . . . . . . 104

Tabelle D.18: Die Wirkungen eines Verlustvortrages in die dritte Periode auf die Vergünstigungseffekte einer Sonderabschreibung $\ldots \ldots \ldots \ldots \ldots$ 
Tabelle D.19: Vergünstigungswirkungen steuerlicher Investitionsfördermaßnahmen unter Berücksichtigung eines intertemporalen Verlustausgleichs (Verlustrücktrag in die vorletzte Periode und Verlustvortrag in die dritte Periode) $\ldots \ldots \ldots \ldots \ldots$

Tabelle D.20: Vergünstigungswirkungen einer Investitionsprämie in Höhe von DM 1.575,-, die mit dem Buchwert der geförderten Investition verrechnet wird $\ldots \ldots \ldots \ldots \ldots \ldots \ldots$

Tabelle D.21: Vergleich der Vergünstigungswirkungen einer Investitionsprämie mit der eine Nachversteuerungsmöglichkeit verbunden ist, unter Berücksichtigung verschiedener Nutzungszeiträume . .

Tabelle D.22: Der Einfluß unterschiedlicher Determinanten auf die Vergünstigungswirkungen (Nettobarwerte) von Investitionsprämien $\ldots \ldots \ldots \ldots \ldots$

Tabelle D.23: Vergünstigungswirkungen eines Investitionszuschusses von DM 1.667,- bei erfolgswirksamer Behandlung ...............

Tabelle D.24: Vergünstigungswirkungen eines erfolgsneutralen Investitionszuschusses in Höhe von DM 1.575,-

Tabelle D.25: Vergleich der Vergünstigungswirkungen eines erfolgsneutralen Investitionszuschusses unter Berücksichtigung verschiedener Nutzungszeiträume

Tabelle D.26: Der Einfluß unterschiedlicher Determinanten auf die Vergünstigungswirkungen (Nettobarwerte) von Investitionszuschüssen $\ldots \ldots \ldots \ldots \ldots$

Tabelle D.27: Vergünstigungswirkungen einer Zinsverbilligung um 0,59 Prozentpunkte für einen Kredit mit konstanten Tilgungsraten $\ldots \ldots \ldots \ldots \ldots$

Tabelle D.28: $\quad$ Der Einfluß unterschiedlicher Determinanten auf die Vergünstigungswirkungen (Nettobarwerte) von Zinszuschüssen $\ldots \ldots \ldots \ldots \ldots$ 
Tabelle D.29: Der Einfluß unterschiedlicher Determinanten auf die Vergünstigungswirkungen (Nettobarwerte) einer Investitionszulage . . . . . . . . . .

Tabelle E.1: Vergünstigungswirkungen (Nettobarwerte) investitionsfördernder Maßnahmen bei einem Investitionsvorhaben mit einer 5-jährigen Nutzungsdauer in unterschiedlichen Besteuerungssituationen ..................

Tabelle E.2: Vergünstigungswirkungen (Nettobarwerte) investitionsfördernder Maßnahmen bei einem Investitionsvorhaben mit einer 10-, 15- und 20-jährigen Nutzungsdauer in unterschiedlichen Besteuerungssituationen ..............

Tabelle E.3: Liquiditätswirkungen investitionsfördernder Maßnahmen bei unterschiedlichen Besteuerungssituationen in der ersten Begünstigungsperiode 


\section{SYMBOLVERZEICHNIS}

$A_{\mathrm{t}}: \quad$ Ausgaben in Periode $t$

$\mathrm{AB}_{\mathfrak{t}}$ : $\quad$ Mehr- bzw. Minderabschreibung infolge einer beschleunigten Abschreibung in der Periode $t$

AD: degressiver Abschreibungsbetrag

$\mathrm{AK}_{\mathrm{t}}$ : Kürzung des Normalabschreibungsbetrages in der Periode $\mathrm{t}$

$A U_{1}:$ Überabschreibungsbetrag in der Periode $t$

AZ: maximal zulässiger Abzugsbetrag von der Steuerschuld

$\mathrm{B}_{\mathrm{AB}}$ : Barwert einer beschleunigten Abschreibung

$\mathrm{B}_{\mathrm{AU}}$ : Barwert einer Überabschreibung

$\mathrm{B}_{\mathrm{FB}}$ : Barwert eines absoluten Investitionsfreibetrages

$\mathrm{B}_{\mathrm{FR}}$ : Barwert eines relativen Investitionsfreibetrages

$\mathrm{B}_{\mathrm{PBW}}$ : Barwert einer Investitionsprämie, die mit dem Buchwert verrechnet wird

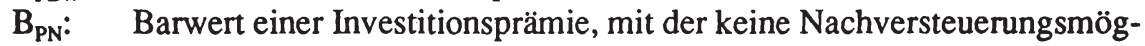
lichkeit verbunden ist

$B_{R}$ : Barwert der Bildung einer steuerfreien Rücklage

$\mathrm{B}_{\mathrm{RBK}}$ : Barwert der Bildung einer Konjunkturrücklage

$B_{R G}: \quad$ Barwert einer steuerfreien Rücklage

$\mathrm{B}_{\mathrm{RIFK}}$ : Barwert einer Konjunkturrücklage und Gewährung eines Investitionsfreibetrages bei der Rücklagenauflösung

$\mathrm{B}_{\mathrm{RSA}}$ : Barwert einer steuerfreien Rücklage und Gewährung einer Sonderabschreibung bei der Rücklagenauflösung

$\mathrm{B}_{\mathrm{RSAK}}$ : Barwert einer Konjunkturrücklage und Gewährung einer Sonderabschreibung bei der Rücklagenauflösung

$\mathrm{B}_{U \mathrm{U}}: \quad$ Barwert einer Übertragung von stillen Rücklagen auf ein abnutzbares Wirtschaftsgut

$\mathrm{B}_{\text {UN: }}$ : Barwert einer Übertragung von stillen Rücklagen auf ein nicht abnutzbares Wirtschaftsgut

$\mathrm{B}_{\mathrm{VR}}$ : Barwert des Rücktrages eines förderungsbedingten Verlustes

$\mathrm{B}_{\mathrm{vv}}$ : Barwert des Vortrages eines förderungsbedingten Verlustes

$\mathrm{B}_{\mathrm{ZL}}$ : Barwert einer Investitionszulage

$B_{\text {zus }}$ : Barwert eines erfolgswirksamen Investitionszuschusses

$\mathrm{B}_{\text {ZuBw: }}$ Barwert eines erfolgsneutralen Investitionszuschusses

$\mathrm{B}_{\mathrm{zz}}$ : Barwert eines Zinszuschusses

BW: Buchwert

b: $\quad$ Rücklagenbildungsdauer

$D_{t}$ : Normalabschreibungen in Periode $t$

d: Degressionssatz

$\mathrm{E}_{\mathrm{t}}$ : $\quad$ Einnahmen in Periode $\mathrm{t}$

e: Rücklagenanteil, der bei der Zentralbank stillgelegt wird 
FB: absoluter Investitionsfreibetrag

$\mathrm{FK}_{\mathbf{t}}$ : Fremdkapitalzinszahlungen

$\mathrm{f}_{\mathrm{FR}}: \quad$ relativer Investitionsfreibetrag

$\mathrm{f}_{\mathrm{PBW}}$ : Fördersatz einer Investitionsprämie, die mit dem Buchwert verrechnet wird

$\mathrm{f}_{\mathrm{PN}}$ : Fördersatz einer Investitionsprämie, mit der keine Nachversteuerungsmöglichkeit verbunden ist

$\mathrm{f}_{\mathrm{zL}}$ : Fördersatz einer Investitionszulage

$\mathbf{f}_{\text {zus: }}$ : Fördersatz eines erfolgswirksamen Investitionszuschusses

$f_{\text {zuBw: }}$ Fördersatz eines erfolgsneutraler. Investitionszuschusses

g: Grenzsteuersatz

$g_{b}: \quad$ Grenzsteuersatz in der Periode b (Auflösungsperiode)

$\mathrm{g}_{\mathrm{e}}$ : marginaler Einkommen- bzw. Körperschaftsteuersatz

$\mathrm{g}_{\text {gew: }}$ marginaler Gewerbeertragsteuersatz

$\mathrm{g}_{\mathrm{n}}$ : $\quad$ Grenzsteuersatz in der Periode $\mathrm{n}$

$g_{\mathrm{r}}$ : Grenzsteuersatz in der Periode $\mathrm{t}$

$\mathrm{g}_{1}$ : $\quad$ Grenzsteuersatz in der Periode 1

IV: förderungsfähiges Investitionsvolumen

i: $\quad$ unversteuerter Kalkulationszinssatz

$\mathrm{i}_{\mathrm{g}}$ : versteuerter Kalkulationszinssatz

$i_{\mathrm{g}}$ : $\quad$ versteuerter Kalkulationszinssatz der Periode $j$

$\mathrm{K}_{\mathrm{t}}$ : $\quad$ Kredithöhe in der Periode $\mathrm{t}$ (Restschuld)

k: $\quad$ Verlustrücktragsperioden

$\mathrm{m}$ : maximaler Verlustvortragszeitraum

$\mathrm{n}$ : wirtschaftliche Nutzungsdauer

R: $\quad$ Rücklagenbetrag

r: $\quad$ Zinssatz für den Anteil, der bei der Zentralbank stillgelegt wird

SB: ertragsteuerliche Bemessungsgrundlage

$\mathrm{SB}_{\mathrm{t}}$ : $\quad$ Ertragsteuerbemessungsgrundlage in Periode $\mathrm{t}$

$s_{\mathrm{h}}: \quad$ Gewerbesteuerhebesatz

$\mathrm{s}_{\mathrm{m}}$ : $\quad$ Gewerbesteuermeßzahl

T: $\quad$ Steuerschuld

t: $\quad$ Periode

u: $\quad$ Begünstigungszeitraum

Ü: Übertragungsbetrag

$V_{R_{1}}$ : rücktragbarer Verlust aus der Periode $t$

$\mathrm{VV}_{\mathrm{t}}: \quad$ in die Periode $\mathrm{t}$ vorgetragener Verlust

w: maximaler Verlustrücktragszeitraum

z: $\quad$ Kreditzinssatzverbilligung in Prozentpunkten 


\section{LITERATURVERZEICHNIS}

Albach, $H$.

Die degressive Abschreibung, Wiesbaden 1967

Albach, $H$.

Steuersystem und unternehmerische Investitionspolitik, Wiesbaden 1970

Albrecht, D./Thormählen, $T$.

Subventionen. Politik und Problematik, Frankfurt a. M., Bern, New York 1985

Alewell, $K$.

Subventionen als betriebswirtschaftliche Frage, Köln, Opladen 1965

Andel, $N$.

Subventionen als Instrument des finanzwirtschaftlichen Interventionismus, Tübingen 1970

Baan, $W$.

Substanz- und Ertragsteuern in der Kapitalwertmethode, Der Betrieb 1980,

S. $700-703$ und $746-750$

Bargen, R.-D. von

Subventionen und Subventionspolitik - Eine theoretische und empirische Analyse, Diss. Bremen 1987

Barth, $K$.

Mißverständnisse um den Verlustrücktrag, in: Wirtschaftsdienst 1975, S. 205-207

Barth, $K$.

Der Verlustrücktrag vor der Tür, in: Wirtschaftsdienst 1976, S. 82-82

Bauer, $F$.

Die Investitionsförderung im österreichischen Steuersystem, in: Wirtschaftspolitische Blätter, Nr. 5, 1979, S. 93-101 
Becker, $W$.

Die Eigenkapitalbasis nicht emissionsfähiger Unternehmen als Ansatzpunkt einer unternehmensgrößenbezogenen Strukturpolitik unter besonderer Berücksichtigung neuerer Entwicklungen in der Bundesrepublik Deutschland, Diss. Mainz 1979

Behrens-Ramberg, $W$.

Steuerliche Anreize bei innovativen Investitionen kleiner und mittlerer Industrieunternehmen unter vergleichender Berücksichtigung nichtsteuerlicher Hilfen, Stuttgart 1985

Berthold, $U$.

Zur Theorie der Subvention. Ein Beitrag zur mikroökonomischen Analyse der Subventionswirkungen und ihrer wirtschaftspolitischen Beurteilung, Bern, Stuttgart 1967

Blümle, $G$.

Theorie der Einkommensverteilung, Berlin, Heidelberg, New York 1975

Böckenkamp, E.

Besteuerung der Subventionen. Wirtschaftliche Wirkungen von öffentlichen Finanzhilfen ausgehenden Einflüsse auf die steuerlichen Bemessungsgrundlagen, Diss. Köln 1966

Bös, $D$.

Gedanken zum Subventionsbegriff in den Wirtschaftswissenschaften, in:

Wenger, K., Förderungsverwaltung, Wien, New York 1973, S. 43-55

Bohling, W.

Wirtschaftspolitische und wirtschaftsverfassungsrechtliche Probleme staatlicher und kommunaler Subventionen. Zum Verhältnis von Staat und Wirtschaft, Frankfurt am Main, Bern, New York, Paris 1989

Breuker, $P$.

Besitzsteuerliche Korrekturen im Rahmen des investitionsrechnerischen

Kapitalwert-Modelles, in: Steuer und Wirtschaft 1972, S. 239-248

Brockhoff, $K$.

Steuerabzüge für Investitionen, in: Finanzarchiv 1970, S. 256-272 
Brown, E. C.

Investitionsanreize durch Steuern, in: Recktenwald, H. C. (Hrsg.), Finanztheorie, Köln, Berlin 1970, S. 366-375

Bundesministerium für Finanzen

Bericht der Bundesregierung über die Entwicklung der Finanzhilfen des Bundes und der Steuervergünstigungen für die Jahre 1987 bis 1990 (12. Subventionsbericht), Bonn 1989

Busch, $R$.

Steuerentlastung oder Transferzahlungen, Eine Untersuchung anhand geltender Steuerentlastungsnormen, Diss. Köln 1974

Cansier, D./Wilk, E.

Steuerfreie Rücklagen als konjunkturpolitisches Instrument - Das "Schwedische Modell", in: WSI-Mitteilungen 1977, S. 688-697

Cassier, S. C.

Investitionen und Finanzierung, in: Besters, H. (Hrsg.), Wandlungen im Investitionsverhalten, Baden-Baden 1983, S. 52-68

Dickertmann, $D$.

Öffentliche Finanzierungshilfen. Darlehen, Schuldendiensthilfen und Bürgschaften als Instrument des finanzwirtschaftlichen Interventionismus, Baden-Baden 1980

Dickertmann, D./Pfeiffer, $U$.

Steuerstundende Investitionsrücklage. Offene Fragen zu ihrer Ausgestaltung, in: Wirtschaftsdienst 1986, S. 411-417

Dietz, $H$.

Die Normierung der Abschreibung in Handels- und Steuerbilanz, Opladen 1971

Drees-Behrens, Ch.

Der Einfluß von Investitionsfördermaßnahmen auf betriebliche Investitionsentscheidungen, Diss. Münster 1989

Ederer, B./Goldmann, W.

Steuerliche Investitionsförderung - ein Mittel zur Strukturpolitik? in: Wirtschaft und Gesellschaft, Nr. 2, 1981, S. 109-126 
Engelmann, $R$.

Die einkommensteuerliche Verlustverrechnung und ihre betriebswirtschaftlichen Probleme, Diss. München 1966

Felix, G.

Grundsätzliches und Kritisches zur Beschäftigungszulage 1982 ( 4 des Investitionszulagengesetzes neue Fassung), in: Betriebs-Berater 1982, S. $1600-1604$

Fischer, $L$.

Betriebswirtschaftliche Beurteilung der deutschen Sonderabschreibungen im internationalen Vergleich, in: Deutsche Steuer-Zeitung 1967, Ausgabe A, S. 149-151

Folkers, $C$

Wer wird durch Steuervergünstigungen eigentlich begünstigt? $\mathrm{Zu}$ einem Problem der materiellen Inzidenz, in: Finanzarchiv 1988, S. 214-235

Fricke, $D$.

Inzidenzbegriffe und Inzidenzkonzepte, in: Das Wirtschaftsstudium 1979, S. 507-512

Fuest, W.

Steuerliche Investitionsförderung in fünf Länder, Köln 1979

Fuest, W./Kroker, F.

Steuerliche Förderung von Investitionen und Innovationen im internationalen Vergleich, Köln 1981

Fuest, W./Kroker, $R$.

Unternehmens und Investitionsbesteuerung im internationalen Vergleich, in: iw-trends 1/1987, Köln 1987, S. Al-A17.

Gaugler, E.

Sonderabschreibungen als Konjunkturmaßnahme, in: Zeitschrift für betriebswirtschaftliche Forschung 1968, S. 518-524

Geiger, $K$.

Probleme der steuerlichen Wirtschaftsförderung, in: Deutsches Steuerrecht 1977, S. 299-304 
Gröbner, B. F.

Subventionen - Eine kritische Analyse, Göttingen 1983

Groß, E.

Staatliche Finanzierungshilfen zur Förderung von Investitionen der gewerblichen Wirtschaft im Lichte gesamtwirtschaftlicher und unternehmerischer Zielsetzungen, Diss. Münster 1977

Haase, $D$.

Geldentwertung und Ertragsbesteuerung, in: Mertens, P. (Hrsg.), Die Unternehmung in ihrer gesellschaftlichen Umwelt, Wiesbaden 1976, S. 283-297

Haberstock, $L$.

Vergleichende Analyse steuerlicher Maßnahmen zur Beeinflussung der konjunkturellen Entwicklung, in: Reber, G. (Hrsg.), Personal- und Sozialorientierung der BWL, Bd. 2, Stuttgart 1977, S. 69-81

Hackmann, $R$.

Interperiodische Durchschnittsbesteuerung des Einkommens, in: Finanzarchiv 1975/76, S. 1ff

Hagemann, $R$.

Die Problematik einen Verlustrücktrages, in: Wirtschaftsdienst 1975, S. 122-124

Hamm, W.

Sektorale Strukturpolitik, in: Albers, W., u. a. (Hrsg.), Handwörterbuch der Wirtschaftswissenschaft (HdWW), Bd. 7, Stuttgart, New York, Tübingen, Göttingen, Zürich 1988, S. 479-491

Hansmeyer, K.-H.

Transferzahlungen an Unternehmen (Subventionen), in: Handbuch der Finanzwissenschaft, Bd. 1, Tübingen 1977, S. 959-996

Hartmann, $K$.

Staatliche Investitionshilfen an die gewerbliche Wirtschaft und deren Einfluß auf die Investitionstätigkeit mittelständischer Unternehmungen, Diss. Würzburg 1981 
Hauser, H.-J.

Verteilungswirkungen der Staatsverschuldung, Eine kreislauftheoretische Inzidenzbetrachtung, Frankfurt am Main 1979

$\operatorname{Hax}, K$.

Was ist betriebswirtschaftlich notwendige Abschreibung? in: Angehm, O./Künzi H. P. (Hrsg.), Beiträge zur Lehre von der Unternehmung, Stuttgart 1968, S. 147-168

Hax, H./Marschdorf, H.-J.

Investitionsförderung in der Bundesrepublik Deutschland - eine betriebswirtschaftliche Analyse, in: Österreichische Länderbank (Hrsg.), Wirtschaftsdienst, Sonderdruck zum Symposium "Investitionsneigung und Investitionsförderung", Wien 1981, S. 12-22

Helms, $V$.

Investitionsfond und Lenkung privater Investitionen, Darmstadt 1976

Hoffmann, $B$.

Das Investitionszulagengesetz 1991, Teil I/II, in: Der Betrieb 1991, S. 1694-1699 und S. 1745-1750

Huiskamp, J.C.L/Wisselink, M. A./Siedenberg, A.

Steuerpolitik und private Investitionstätigkeit in der EG, in: Steuer und Wirtschaft 1977, S. 86-94

Hunsdiek, $D$.

Ausgestaltung und Beurteilung der Existenzgründungsförderung, in: Nathusius, K./Klandt, H./Kirschbaum, G. (Hrsg.), Unternehmensgründung. Konfrontation von Forschung und Praxis, Bergisch-Gladbach 1984, S. 111-136

Hunsdiek, D./May-Strobl, E.

Gründungsfinanzierung durch den Staat. Fakten, Erfolg und Wirkung, Stuttgart 1987

Institut "Finanzen und Steuern"

Steuerliche Maßnahmen zur Investitionsförderung, Grüner Brief Nr. 177, Bonn 1978 
Jatzek, H.-G./Leibfritz, W.

Der Einfluß der Steuern auf die Investitionstätigkeit der Unternehmen, Berlin, München 1982

Kann, $G$.

Staatliche Maßnahmen zur Verringerung der Finanzierungsprobleme kleiner und mittlerer Unternehmen - unter besonderer Berücksichtigung konjunktureller Gesichtspunkte -, in: Kamp, M. E. (Hrsg.), Informationen zur Mittelstandsforschung, Nr. 40, Bonn 1978

Karsten, J.-F.

Die steuerliche Behandlung gewerblicher Verluste, Berlin 1958

Keifer, $R$.

Der Kalkulationszinsfuß und investitionstheoretische Entscheidungsmodelle, Diss. Mannheim 1970

Kern, G.

Die gruppenspezifische Be- und Entlastung von Klein-, Mittel- und Großunternehmen durch staatliche Abgaben und Transferzahlungen, Diss. Mainz 1984

Klein, $E$.

Die Übertragung stiller Reserven nach $\S 6 \mathrm{~b}$ EStG. Thre volkswirtschaftliche und betriebswirtschaftliche Bedeutung, in: Zeitschrift für Betriebswirtschaftslehre 1968, S. 353-378

Klemp, A. H.

Öffentliche Finanzhilfen (Subventionen) - Instrumente staatlicher Finanzinterventionen. Eine Untersuchung zum investiven Wirkungspotential und zur Effizienz staatlicher Finanzhilfen, Frankfurt am Main, Bern, New York, Paris 1990

Knief, $P$.

Steuerfreibeträge als Instrumente der Finanzpolitik, Köln, Opladen 1968

Kops, $M$.

Der Inzidenzbegriff in der Finanzwissenschaft, in: Wirtschaftswissenschaftliches Studium 1987, S. 59-65 
Krauskopf, $K$.

Steuerliche Aspekte der Investitionspolitik, Diss. Bern 1972

Kroker, R./Fuest, W.

Investitionsförderung in den neuen Bundesländern - Eine betriebswirtschaftliche Effizienzanalyse, in: iw-Trends 1/1991, S. A1-A17

Külp, $B$.

Verteilungstheorie, 2. Auflage, Stuttgart, New York 1981

Kupsch-Werner, $T$.

Betriebswirtschaftliche Wirkungsanalyse steuerlicher Investitionshilfen, dargestellt am Beispiel von Bewertungsfreiheit, Mehrfach-AfA und Investitionszulage, Diss. Regensburg 1977

Lacina, $F$.

Ausbau oder Umbau der steuerlichen Investitionsförderung? in: Wirtschaft und Gesellschaft, Nr. 3, 1976, S. 9-25

Langen, $W$.

Grundlagen, Ansatzstellen und Maßnahmen der unternehmsgrößenbezogenen Wirtschaftspolitik in der Bundesrepublik Deutschland, Diss. Bonn 1977

Lehner, $G$.

Die degressive Abschreibung, Wirkungen und Probleme, in: Wirtschaft und Gesellschaft, Nr. 2, 1981, S. 127-142

Lehner, $G$.

Die steuerlichen Investitionsförderungssysteme und die Unternehmensbesteuerung in der Bundesrepublik Deutschland, in Schweden, in der Schweiz und in Österreich, Wien 1979

Leibfritz, $W$.

Staatliche Investitionsförderung - Ansatzpunkte der verschiedenen Instrumente und Möglichkeiten der Beurteilung, in: Bombach, G./Gahlen, B./Ott, A. E., Neuere Entwicklungen in der Investitionstheorie und -politik, Tübingen 1980, S. 477-510 
Leibfritz, $W$.

Staatliche Investitionsförderung in der Bundesrepublik - Ein Vergleich mit dem österreichischen Modell -, in: Ifo-Schnelldienst, Nr. 16, 1979, S. 3037

Leibfritz, W.IMeurer, C.

Steuerliche Investitionsförderung im internationalen Vergleich, Berlin, München 1985

\section{Littmann, $K$.}

Problemstellung und Methode der heutigen Finanzwissenschaft, in: Neumark, F./Andel, N./Haller, H. (Hrsg.), Handbuch der Finanzwissenschaft, 3. Auflage, Bd. 1, Tübingen 1977, S. 100-120

Lohse, D./Lornsen-Veit, B./Sonnemann, E.

Fördermaßnahmen, in: KPMG Deutsche Treuhand Gruppe (Hrsg.), Investitionen in den neuen Bundesländern. Fördermaßnahmen, Restrukturierung, Unternehmenskauf, Düsseldorf 1992

Lüder, $K$.

Zum Einfluß staatlicher Investitionsfördermaßnahmen auf unternehmerische Investitionsentscheidungen, in: Zeitschrift für Betriebswirtschaft 1984, S. 531-547

Marwede, $E$.

Die Abgrenzungsproblematik mittelständischer Unternehmen. Eine Literaturanalyse, Augsburg 1983

May, E.

Erfolgreiche Existenzgründungen und öffentliche Förderung. Eine vergleichende empirische Analyse geförderter und nichtgeförderter Gründungsunternehmen, Göttingen 1981

Meinhold, W.

Subventionen, in: Handwörterbuch der Sozialwissenschaften, Bd. X, Stuttgart, Tübingen, Göttingen 1959, S. 236-247

Meißner, W.IFassing, W.

Wirtschaftsstruktur und Strukturpolitik, München 1989 
Melcher, G.-H.

Die Eignung von Investitionszulage, Sonderabschreibung und Verlustrücktrag für die Zwecke der Konjunkturbelebung, in: Wirtschaftswissenschaftliches Studium 1975, S. 187-190

Mellwig, $W$.

Sensitivitätsanalyse des Steuereinflusses in der Investitionsplanung - Überlegungen zur praktischen Relevanz einer Berücksichtigung der Steuern bei der Investitionsentscheidung -, in: Zeitschrift für betriebswirtschaftliche Forschung 1980, S. 16-39

Mennel, A.

Internationaler Vergleich der steuerlichen Abschreibungen und Investitionsvergünstigungen, in: Recht der internationalen Wirtschaft 1976, S. 321-327

Mischon, $C$.

Zum Problem der Diskriminierung mittelständischer Betriebe. Eine empirische Analyse, Göttingen 1980

Neumark, $F$.

Fiskalpolitik und Wachstumsschwankungen, Wiesbaden 1968

Neumark, $F$.

Fiskalpolitische Maßnahmen als Mittel der Konjunkturpolitik, in: Zeitschrift für betriebswirtschaftliche Forschung 1968, S. 490-503

Niemann, $J$.

Die Beurteilung der Vorteilhaftigkeit einer Investition anhand ihres Kapitalwertes unter Berücksichtigung von Preis- und Geldwertschwankungen, Diss. Mainz 1970

Oberhauser, A.

Möglichkeiten einer effizienteren Gestaltung staatlicher Investitionszuschüsse in der Rezession, in: Bohley, P./Tolkemitt, G. (Hrsg.), Wirtschaftswissenschaft als Grundlage staatlichen Handelns, Tübingen 1979, S. $85-103$

Oberhauser, A.

Das Schuldenparadox, in: Jahrbuch für Nationalökonomie und Statistik, Stuttgart 1985, S.333-348 
Ollenburg, $G$.

Investitionszulagen, -abgaben und derlei mehr, in: Pahlke, J./Seuferle, W. (Hrsg.), Waldemar Koch zum 80.Geburtstag, Bochum 1982, S. 13-36

Orth, $M$.

Interperiodische Verlustkompensation im Gewerbesteuerrecht, Frankfurt a. M., Bern, Cirencester 1980

Peffekoven, $R$.

Freibetrag oder Steuerkredit? Zu einem Problem der Einkommensteuerreform, in: Finanzarchiv 1971/72, S. 392-417

Pfaffenberger, $W$.

Investitionssteuerung mit Hilfe steuerfreier Rücklagen - neue konjunkturpolitische Instrumente in Schweden und in der Schweiz, Berlin 1969

Pieper, G.

Liquiditäts- und Rentabilitätswirkungen steuerlicher Investitionshilfen und ihr Einfluß auf die unternehmerische Investitionsentscheidung, Diss. Hamburg 1970

Priewasser, $E$.

Betriebliche Investitionsentscheidungen, Berlin, New York 1972

Reiter, $G$.

Steuerliche Investitionsförderung zur Rezessionsüberwindung, Frankfurt

a. M., Bern, New York, Paris 1988

Richter, $J$.

Die Zinssubventionen in der Bundesrepublik Deutschland, Frankfurt a. M. 1970

Rieden, $W$.

Die betriebswirtschaftliche Bedeutung der Übertragung stiller Rücklagen gemäß § 6b des Einkommensteuergesetzes, Diss. Köln 1972

Röthlingshöfer, K. Ch./Sprenger, R.-U.

Effizienz der indirekten steuerlichen Forschungsförderung, Berlin, München 1977 
Rudolph, $B$.

Klassische Kapitalkostenkonzepte zur Bestimmung des Kalkulationszinsfußes für die Investitionsrechnung, in: Zeitschrift für betriebswirtschaftliche Forschung 1986, S. 608-617

Sachverständigenrat zur Begutachtung der gesamtwirtschaftlichen Entwicklung Jahresgutachten 1984/85

Schaub, G.

Die Bestimmung des Kalkulationszinsfußes bei Investitionsentscheidungen auf Grund der Kapitalbeschaffungsmöglichkeiten der Unternehmer, Diss. Köln 1968

Scheffler, $W$.

Betriebswirtschaftliche Analyse der Steuervergünstigungen für Investitionen in den neuen Bundesländern, in: Deutsches Steuerrecht 1991, S. 524-531

Scherrer, $G$.

Zum Einfluß eines Verlustrücktrages auf die unternehmerische Investitionsentscheidung, in: Albach, H./Simon, H. (Hrsg.), Investitionstheorie und Investitionspolitik privater und öffentlicher Unternehmen, Wiesbaden 1976, S. 371-389

Schick, $W$.

Der Verlustrücktrag, München 1976

Schlecht, $O$.

Strukturpolitik in der Marktwirtschaft, Köln, Berlin, Bonn, München 1968

Schmölders, G./Hansmeyer, $K .-H$.

Allgemeine Steuerlehre, 5. Auflage, Berlin 1980

Schneider, $D$.

Investition, Finanzierung und Besteuerung, 6. Auflage, Wiesbaden 1989

Schneider, $D$.

Sinn und Widersinn der steuerlichen Investitionsförderung für die neuen Bundesländer und des Solidaritätszuschlags, in: Der Betrieb 1991, S. 1081-1087 
Schneider, $D$.

Steuerbelastung und Steuerüberwälzung der Unternehmung in der Inflation, in: Mertens, P. (Hrsg.), Die Unternehmung in ihrer gesellschaftlichen Umwelt, Wiesbaden 1976, S. 321-341

Schreiber, $U$.

Rechtsformabhängige Unternehmensbesteuerung? Eine Kritik des Verhältnisses von Einkommen- und Körperschaftsteuer auf der Grundlage eines Modells für mehrperiodige Steuerbelastungsvergleiche, Köln 1987

Schuler, D. W.

Der Einfluß von Sonderabschreibungen auf Zahlungsströme, Diss. Berlin 1975

Siedenberg, A.

Investitionsorientierte Fiskalpolitik, Berlin 1976

Söffing, $G$.

Die Änderung des Investitionszulagengesetzes im Rahmen der Konjunkturmaßnahmen, in: Finanz-Rundschau 1975, S. 129-136

Sommer, $R$.

Fiskalische Investitionsanreize. Ein Beitrag zu einer Theorie der Investitionsförderung, Spardorf 1988

Sprenger, $R$. W.

Indirekte steuerliche Forschungs- und Innovationsförderung: Reformvorschläge für Klein- und Mittelbetriebe wenig erfolgversprechend, in: IfoSchnelldienst, Heft 24, 1977, S. 5-16

Städler, A.

Investitionszulage dämpfte den Beschäftigungsrückgang, in: Ifo-Schnelldienst, Heft 3, 1985, S. 7-12

Steger, $U$.

Alternative Konzepte der Investitionsplanung - Ansatzpunkte, Probleme, Effizienzausgleich, in: Sarrazin, Th. (Hrsg.), Investitionslenkung, BonnBad Godesberg 1976, S. 43ff

Stein, H.-G.

Steuerlicher Verlustausgleich und Strukturwandel der Unternehmen, in: Zeitschrift für betriebswirtschaftliche Forschung 1983, S. 29-40 
Strömberg, $D$.

Die schwedischen Erfahrungen, in: Wirtschaftsdienst 1975, S. 602-608

Supper, $M$.

Wirtschaftsförderung in marktwirtschaftlicher Sicht, in: Gantner, M./ Rinderer, C. (Hrsg.), Staatliche Wirtschaftsförderung, Frankfurt a. M., Bern, New York, Paris 1988, S. 35-44

Surrey, S. S.

Steueranreize als ein Instrument der staatlichen Politik. Ein Vergleich mit direkten Ausgaben, in: Steuer und Wirtschaft 1981, S. 359-377

Swoboda, $P$.

Antizyklische steuerliche Regelungen und betriebliche Investitionsentscheidungen, in: Finanzarchiv 1969, S. 55-95

Timm, $H$.

Steuervergünstigungen und Transferzahlungen als Instrumente der staatlichen Allokations- und Stabilitätspolitik. Ein kritischer Vergleich, in: Duwendag, D./Siebert, H. (Hrsg.), Politik und Markt. Wirtschaftliche Probleme der 80-er Jahre, Stuttgart, New York, S. 237-250

Uhlmann, L./Berger, $M$.

Instrumentelle Aspekte der Investitionsförderung, München 1986

Uhlmann, L./Berger, $M$.

Investitionsverhalten und Unternehmensgröße, Berlin, München 1986

Vogel, $H$.

Steuergeschenke, in: Steuerberaterjahrbuch 1980/81, S. 49-86

Weichsel, $L$.

Beschleunigte Abschreibungen, Wachstum und Konjunktur, Köln, Opladen 1964

Weigel, W.

Steuern bei Investitionsentscheidungen. Ein kapitalmarkttheoretischer Ansatz, Wiesbaden 1989 
Wewers, $O$.

Steuerliche Förderinstrumente für die neuen Bundesländer und Berlin Sonderabschreibungen, Abzugsbeträge und Investitionszulagen, Heidelberg 1991

Wissenschaftlicher Beirat beim Bundesministerium der Finanzen

Gutachten zur Reform der Unternehmensbesteuerung, Bonn 1990

Wittmann, $F$.

Die Erhöhung der degressiven AfA-Sätze - Ein geeignetes Mittel zur Investitionsbelebung? in: Die Betriebswirtschaft 1978, S. 395-403

Wittmann, $F$.

Zum Wirkungspotential der Investitionszulage, in: Die Betriebswirtschaft 1983, S. 183-191

Wöhe, $G$.

Bildung, Auflösung und Übertragung stiller Rücklagen im Steuerrecht aus der Sicht der betriebswirtschaftlichen Steuerlehre, in: Zeitschrift für betriebswirtschaftliche Forschung 1966, S. 98-117

Wöhe, G.

Steuern als Mittel der Wirtschaftspolitik, in: Steuerkongressreport 1975, S. $169-195$

Zeitel, G.

Staatliche Darlehensgewährung als Mittel der Finanz- und Wirtschaftspolitik, in: Finanzarchiv 1967, S. 193-214

Zierlinger, $S$.

Die steuerliche Regelung der Belastung gewerblicher Unternehmen bei geringer Rentabilität und Verlusten. Ein Beitrag zur Unternehmensbesteuerung in der Bundesrepublik Deutschland, in den USA und in Japan, Diss. Mannheim 1985

Zimmermann, $H$.

Subventionen und Verteilung, Zur empirischen Erfaßbarkeit von Subventionen, in: Dreißig, W.,(Hrsg.) Öffentliche Finanzwirtschaft und Verteilung IV, Berlin 1976, S. 9-57 
Zimmermann, H./Henke, K.-D.

Finanzwissenschaft. Eine Einführung in die Lehre von der öffentlichen Finanzwissenschaft, 5. Auflage, München 1987

Zitzmann, $G$.

Gewährung von Investitionszulagen nach dem InvZulG und nach $\$ 19$ des Berlin FG, in: Der Betrieb 1987, Beilage Nr. 2

Zitzmann, $G$.

Die Neuordnung der Regionalzulage nach den $\S \S 1$ bis 3 Investitionszulagengesetz, in: Der Betrieb 1986, Beilage Nr. 9 


\section{FINANZWISSENSCHAFTLICHE SCHRIFTEN}

Band 1 Werner Steden: Finanzpolitik und Einkommensverteilung. Ein Wachstums- und Konjunkturmodell der Bundesrepublik Deutschland. 1979.

Band 2 Rainer Hagemann: Kommunale Finanzplanung im föderativen Staat. 1976.

Band 3 Klaus Scherer: Maßstäbe zur Beurteilung von konjunkturellen Wirkungen des öffentlichen Haushalts. 1977.

Band 4 Brita Steinbach: "Formula Flexibility" - Kritische Analyse und Vergleich mit diskretionärer Konjunkturpolitik. 1977.

Band 5 Hans-Georg Petersen: Personelle Einkommensbesteuerung und Inflation. Eine theoretisch-empirische Analyse der Lohn- und veranlagten Einkommensteuer in der Bundesrepublik Deutschland. 1977.

Band 6 Friedemann Tetsch: Raumwirkungen des Finanzsystems der Bundesrepublik Deutschland. Eine Untersuchung der Auswirkungen der Finanzreform von 1969 auf die Einnahmenposition der untergeordneten Gebietskörperschaften und ihrer regionalpolitischen Zieladäquanz. 1978.

Band 7 Wilhelm Pfähler: Normative Theorie der fiskalischen Besteuerung. Ein methodologischer und theoretischer Beitrag zur Integration der normativen Besteuerungstheorie in der Wohlfahrtstheorie. 1978.

Band 8 Wolfgang Wiegard: Optimale Schattenpreise und Produktionsprogramme für öffentliche Unternehmen. Second-Best Modelle im finanzwirtschaftlichen Staatsbereich. 1978.

Band 9 Hans P. Fischer: Die Finanzierung des Umweltschutzes im Rahmen einer rationalen Umweltpolitik. 1978.

Band 10 Rainer Paulenz: Der Einsatz finanzpolitischer Instrumente in der Forschungs- und Entwicklungspolitik. 1978.

Band 11 Hans-Joachim Hauser: Verteilungswirkungen der Staatsverschuldung. Eine kreislauftheoretische Inzidenzbetrachtung. 1979.

Band 12 Gunnar Schwarting: Kommunale Investitionen. Theoretische und empirische Untersuchungen der Bestimmungsgründe kommunaler Investitionstätigkeit in NordrheinWestfalen 1965-1972. 1979.

Band 13 Hans-Joachim Conrad: Stadt-Umland-Wanderung und Finanzwirtschaft der Kernstädte. Amerikanische Erfahrungen, grundsätzliche Zusammenhänge und eine Fallstudie für das Ballungsgebiet Frankfurt am Main. 1980.

Band 14 Cay Folkers: Vermögensverteilung und staatliche Aktivität. Zur Theorie distributiver Prozesse im Interventionsstaat. 1981.

Band 15 Helmut Fischer: US-amerikanische Exportförderung durch die DISC-Gesetzgebung. 1981.

Band 16 Günter Ott: Einkommensumverteilungen in der gesetzlichen Krankenversicherung. Eine quantitative Analyse. 1981.

Band 17 Johann Hermann von Oehsen: Optimale Besteuerung. (Optimal Taxation). 1982.

Band 18 Richard Kössler: Sozialversicherungsprinzip und Staatszuschüsse in der gesetzlichen Rentenversicherung. 1982.

Band 19 Hinrich Steffen: Zum Handlungs- und Entscheidungsspielraum der kommunalen Investitionspolitik in der Bundesrepublik Deutschland. 1983.

Band 20 Manfred Scheuer: Wirkungen einer Auslandsverschuldung des Staates bei flexiblen Wechselkursen. 1983. 
Band 21 Christian Schiller: Staatsausgaben und crowding-out-Effekte. Zur Effizienz einer Finanzpolitik keynesianischer Provenienz. 1983.

Band 22 Hannelore Weck: Schattenwirtschaft: Eine Möglichkeit zur Einschränkung der öffentlichen Verwaltung? Eine ökonomische Analyse. 1983.

Band 23 Wolfgang Schmitt: Steuern als Mittel der Einkommenspolitik. Eine Ergänzung der Stabilitätspolitik? 1984.

Band 24 Wolfgang Laux: Erhöhung staatswirtschaftlicher Effizienz durch budgetäre Selbstbeschränkung? Zur Idee einer verfassungsmäßig verankerten Ausgabengrenze. 1984.

Band 25 Brita Steinbach-van der Veen: Steuerinzidenz. Methodologische Grundlagen und empirisch-statistische Probleme von Länderstudien. 1985.

Band 26 Albert Peters: Ökonomische Kriterien für eine Aufgabenverteilung in der Marktwirtschaft. Eine deskriptive und normative Betrachtung für den Allokationsbereich. 1985.

Band 27 Achim Zeidler: Möglichkeiten zur Fortsetzung der Gemeindefinanzreform. Eine theoretische und empirische Analyse. 1985.

Band 28 Peter Bartsch: Zur Theorie der längerfristigen Wirkungen 'expansiver' Fiskalpolitik. Eine dynamische Analyse unter besonderer Berücksichtigung der staatlichen Budgetbeschränkung und ausgewählter Möglichkeiten der öffentlichen Defizitfinanzierung. 1986.

Band 29 Konrad Beiwinkel: Wehrgerechtigkeit als finanzpolitisches Verteilungsproblem. Möglichkeiten einer Kompensation von Wehrungerechtigkeit durch monetäre Transfers. 1986.

Band 30 Wolfgang Kitterer: Effizienz- und Verteilungswirkungen des Steuersystems. 1986.

Band 31 Heinz Dieter Hessler: Theorie und Politik der Personalsteuern. Eine Kritik ihrer Einkommens- und Vermögensbegriffe. 1993.

Band 32 Wolfgang Scherf: Die beschäftigungspolitische und fiskalische Problematik der Arbeitgeberbeiträge zur Rentenversicherung. Eine Auseinandersetzung mit der Kritik an der lohnbezogenen Beitragsbemessung. 1987.

Band 33 Andreas Mästle: Die Steuerunion. Probleme der Harmonisierung spezifischer Gütersteuern. 1987.

Band 34 Günter Ott: Internationale Verteilungswirkungen im Finanzausgleich der Europäischen Gemeinschaften. 1987.

Band 35 Heinz Haller: Zur Frage der zweckmäßigen Gestalt gemeindlicher Steuern. Ein Diskussionsbeitrag zur Gemeindesteuerreform. 1987.

Band 36 Thomas Kuhn: Schlüsselzuweisungen und fiskalische Ungleichheit. Eine theoretische Analyse der Verteilung von Schlüsselzuweisungen an Kommunen. 1988.

Band 37 Walter Hahn: Steuerpolitische Willensbildungsprozesse in der Europäischen Gemeinschaft. Das Beispiel der Umsatzssteuer-Harmonisierung. 1988.

Band 38 Ulrike Hardt: Kommunale Finanzkraft. Die Problematik einer objektiven Bestimmung kommunaler Einnahmemöglichkeiten in der gemeindlichen Haushaltsplanung und im kommunalen Finanzausgleich. 1988.

Band 39 Jochen Michaelis: Optimale Finanzpolitik im Modell überlappender Generationen. 1989.

Band 40 Bernd Raffelhüschen: Anreizwirkungen der sozialen Alterssicherung. Eine dynamische Simulationsanalyse. 1989.

Band 41 Berend Diekmann: Die Anleihe- und Darlehenstransaktionen der Europäischen Gemeinschaften. 1990.

Band 42 Helmut Kaiser: Konsumnachfrage, Arbeitsangebot und optimale Haushaltsbesteuerung. Theoretische Ergebnisse und mikroökonometrische Simulation für die Bundesrepublik Deutschland. 1990. 
Band 43 Rüdiger von Kleist: Das Gramm-Rudman-Hollings-Gesetz. Ein gescheiterter Versuch der Haushaltskonsolidierung. 1991.

Band 44 Rolf Hagedorn: Steuerhinterziehung und Finanzpolitik. Ein theoretischer Beitrag unter besonderer Berücksichtigung der Hinterziehung von Zinsertrăgen. 1991.

Band 45 Cornelia S. Behrens: Intertemporale Verteilungswirkungen in der gesetzlichen Krankenversicherung der Bundesrepublik Deutschland. 1991.

Band 46 Peter Saile: Ein ökonomischer Ansatz der Theorie der intermediären Finanzgewalten Die Kirchen als Parafisci. 1992.

Band 47 Peter Gottfried: Die verdeckten Effizienzwirkungen der Umsatzsteuer. Eine empirische allgemeine Gleichgewichtsanalyse. 1992.

Band 48 Andreas Burger: Umweltorientierte Beschäftigungsprogramme. Eine Effizienzanalyse am Beispiel des "Sondervermőgens Arbeit und Umwelt". 1992.

Band 49 Jeanette Malchow: Die Zuordnung verteilungspolitischer Kompetenzen in der Europäischen Gemeinschaft. Eine Untersuchung aufgrund einer Fortentwicklung der ökonomischen Theorie des Föderalismus. 1992.

Band 50 Barbara Seidel: Die Einbindung der Bundesrepublik Deutschland in die Europäischen Gemeinschaften als Problem des Finanzausgleichs. 1992.

Band 51 Ralph Wiechers: Markt und Macht im Rundfunk. Zur Stellung der öffentlich-rechtlichen Rundfunkanstalten im dualen Rundfunksystem der Bundesrepublik Deutschland. 1992.

Band 52 Klaus Eckhardt: Probleme einer Umweltpolitik mit Abgaben. 1993.

Band 53 Oliver Schwarzkopf: Die Problematik unterschiedlicher Körperschaftsteuersysteme innerhalb der EG. 1993.

Band 54 Thorsten Giersch: Bergson-Wohlfahrtsfunktion und normative Ökonomie. 1993.

Band 55 Li-Fang Chou: Selbstbeteiligung bei Arzneimitteln aus ordnungspolitischer Sicht. Das Beispiel der Bundesrepublik Deutschland. 1993.

Band 56 Harald Schlee: Einkommensteuerliche Behandlung von Transferzahlungen. Zur Neuordnung der Familienbesteuerung sowie der Besteuerung von Versicherungsleistungen und Sozialtransfers. 1994.

Band 57 Alexander Spermann: Kommunales Krisenmanagement. Reaktionen baden-württembergischer Stadtkreise auf steigende Sozialhilfekosten und Einnahmenausfälle (198092). 1993.

Band 58 Otto Roloff / Sibylle Brander / Ingo Barens / Claudia Wesselbaum: Direktinvestitionen und internationale Steuerkonkurrenz. 1994.

Band 59 Claudia Wesselbaum-Neugebauer: Intemationale Steuerbelastungsvergleiche. 1994.

Band 60 Stephanie Miera: Kommunales Finanzsystem und Bevölkerungsentwicklung. Eine Analyse des kommunalen Finanzsystems vor dem Hintergrund der sich abzeichnenden Bevölkerungsentwicklung am Beispiel Niedersachsens unter besonderer Berücksichtigung des Landkreises Wolfenbüttel und seiner Gemeinden. 1994.

Band 61 Wolfgang Schert: Die Bedeutung des kaldorianischen Verteilungsmechanismus für die gesamtwirtschaftlichen Wirkungen der staatlichen Neuverschuldung. 1994.

Band 62 Rainer Volk: Vergleich der Vergünstigungseffekte der verschiedenen investitionsfördernden Maßnahmen. 1994. 